\title{
Zweiter Beratungsgegenstand:
}

\section{Die Offentliche Sache}

\section{Bericht von Professor Dr. Werner W e b e r, Göttingen}

I.

Die öffentliche Sache hat im Begriffssystem des modernen deutschen Verwaltungsrechts - ähnlich wie der Verwaltungsakt oder die juristische Person des öffentlichen Rechts - ihren festen Platz; ihre Handlichkeit ist vielfältig erprobt. Diese Handlichkeit ist das Ergebnis eines langen Prozesses theoretischer Bemühungen, deren Weg die Monographie von The odor $M a u n z^{1}$ ) und die gerafften Darstellungen der Verwaltungsrechtslehrbücher unserer Tage ${ }^{2}$ ) nachzeichnen. Es kann nicht der Sinn einer Gegenwartsbesinnung auf das Problem der öffentlichen Sache sein, rückwärtsgewendet noch einmal durch alle älteren Schichten von Zweifeln und variierenden Deutungsversuchen durchzustoßen, die wir glücklich hinter uns gelassen haben und unter die $\mathrm{M}$ a u $\mathrm{nz}$ mit seiner Arbeit eine Art Schlußstrich gezogen hat. Das wäre vielmehr Aufgabe eines besonderen Kapitels der neueren Verwaltungsrechtsgeschichte und hätte insofern nur einen historischen Aufhellungseffekt. Bei allem Respekt vor der historischen Forschung oder gerade wegen dieses Respekts enthalte ich mich auch des Versuchs, den teils römischrechtlich-pandektistischen, teils kanonistischen und schließlich deutschrechtlichen Ursprüngen nachzugehen, in denen eine Art Vorgängerschaft der modernen Lehre von der öffentlichen Sache zu entdecken wäre. Die Lage ist hier ähnlich wie bei der Lehre von den juristischen Personen des öffentlichen Rechts, also den öffentlich-rechtlichen Körperschaften, Anstalten und Stiftungen. Dieser Lehre ist es im Zusammenwirken von Wissenschaft, Gesetzgebung und Rechtsprechung im Verlauf der letzten ein

1) Theodor Ma unz, Hauptprobleme des öffentlichen Sachenrechts (1933).

2) Besonders Ernst Forsth off, Lehrbuch des Verwaltungsrechts I (8. Aufl. 1961) S. 325 ff.; Hans J. W o l ff, Verwaltungsrecht I (4. Aufl. 1961) S. 305 ff.; v. Tu re g g - K r a u s, Lehrbuch des Verwaltungsrechts (4. Aufl. 1962) S. 176 ff.; Hans Peters, Lehrbuch der Verwaltung (1949) S. $207 \mathrm{ff}$. 
bis zwei Menschenalter gelungen, eine große Vielfalt historischer Korporationen und Institutionen, teils sehr individueller Herkunft und Gestalt, der Gegenwartslage zu adaptieren und sozusagen in das moderne Verwaltungsrechtssystem zu inkorporieren. Bei der öffentlichen Sache hat sich eine vergleichbare konstruktive Inkorporation vollzogen. Was heute als öffentliche Sache begriffen wird, gehört, obwohl es rechtlich vielerlei historische Ursprünge haben kann, ganz dem gegenwärtigen Verwaltungsrechtssystem an; auch an der geistigen Beherrschungskraft, die der Abstraktion moderner juristischer Begriffsbildung eigen ist, nimmt der Begriff der öffentlichen Sache in vollem Maße teil. Deshalb werden die Bedingungen für die Entfaltung dieser Kraft dem Begriff der öffentlichen Sache vom System und der Praktikabilität des zeitgenössischen Verwaltungsrechts, nicht von den fernen historischen Ursprüngen her gesetzt. In diesem Sinne werden meine Darlegungen die öffentliche Sache ganz als Gegenwartserscheinung verstehen.

Sie werden freilich diese Betonung der Modernität nicht übertreiben. Denn so sehr jedem die großen Wandlungen gegenwärtig sind, denen Verwaltung und Verwaltungsrecht in unserer Zeit ausgesetzt sind, glaube ich nicht, da $\beta$ die notwendigen Bemühungen, diese Wandlungen zu erfassen und ihnen gerecht zu werden, gerade am Begriff der öffentlichen Sache mit Umdeutungen und Umbildungen anzusetzen haben. Dies schon deshalb nicht, weil die einmal zur communis opinio erhobenen begrifflichen Fixpunkte der Rechtsdogmatik nicht aufgegeben werden können, ohne daß man den Boden für die geistige Meisterung der rechtlichen Ordnungs- und Gestaltungsprobleme ins Schwanken bringt. Sodann ist die rechtsstaatliche Rechtssicherheit bei den öffentlichen Sachen in hohem Maße mit im Spiele. Vor allem aber bietet die öffentliche Sache ihrer abstrakten Begrifflichkeit nach nur bescheidene Ansätze, Perspektiven für eine neue Sicht der Gegenwartsprobleme der Verwaltungsordnung zu öffnen. Diese Ausblicke müssen anderswo gesucht werden.

II.

Wer von der öffentlichen Sache handelt, gerät leicht in die Versuchung, von der begrifflichen Konstruktion der öffentlichen Sache und ihren begrifflichen Elementen alsbald zu den verwaltungsrechtlichen Sachmaterien überzugehen, in denen vornehmlich mit der öffentlichen Sache operiert wird. Man ist dann bald beim Wasserrecht und dem Wegerecht und bei der 
anstaltlichen Nutzung öffentlicher Sachen, also beim Anstaltsrecht. Unbestreitbar müssen alle diese Materien zur Exemplifikation des Rechts der öffentlichen Sache herangezogen werden, und zwar gerade auch dort, wo, wie im Wasser- und Wegerecht, der Gemeingebrauch in Frage steht, in dem sich die Probleme der öffentlichen Sache in besonders charakteristischer Weise verdichten. Aber wenn man bedenkt, daB auch das ganze Verwaltungsvermögen des zivilen Verwaltungsdienstes, des Militärwesens und der kirchlichen Aufgabenerfüllung unter den Begriff der öffentlichen Sache fällt $t^{3}$ ), dann erweist sich schon deshalb eine ausschließliche Betrachtung unseres Gegenstandes unter den Aspekten etwa des Wegerechts oder Wasserrechts als zu eng. Utberdies haben Wegerecht, Wasserrecht, Anstaltsrecht usf. jeweils eine eigene, in sich geschlossene Ordnung, die sich nicht in einer Paraphrasierung des Rechts der öffentlichen Sache erschöpft. Wer also, wie ich heute, nach dem Auftrag des Vorstandes unserer Vereinigung die Aufgabe hat, das Problem der öffentlichen Sache zu behandeln, der hat sich eben mit diesem Gegenstand zu beschäftigen und nicht die Probleme des Wasserrechts, Wegerechts und Anstaltsrechts als solche zu traktieren. Diese Materien stehen ihm nur als Feld der Belege und Anwendungsfälle offen, und er findet sein Demonstrationsmaterial keineswegs allein dort.

\section{III.}

Den gegenwärtigen Stand der Lehre von der öffentlichen Sache findet man nächst der großen Monographie von Theodor M a u z vor allem in den neuesten Auflagen der Lehrbücher von Ernst For s th of $f$, Hans J. W o l f f und v. Turegg$\mathrm{Kr}$ a u s$\left.{ }^{4}\right)$, auch in dem jüngst erschienenen Beitrag von Hans J. W olf f im Handwörterbuch der Sozialwissenschaften ${ }^{5}$ ) zu-

3) Etwas mißverständlich ist die Bemerkung von Ulrich S c h e u n e r, Die Gemeinverträglichkeit im Rahmen des Gemeingebrauchs und der Nutzung öffentlicher Sachen, in: Festschr. f. Paul Gieseke (1958) S. 73 ff. (75), daß man die Kategorie der res sacrae, weil aus anderer Wurzel stammend, bei einem Katalog der öffentlichen Sachen beiseitezulassen habe. Gewil hat hier die Staatsgarantie des Kirchengutes ihre eigene Bedeutung (darüber auch unten S. 151). Unabhängig davon ist aber den res sacrae der Charakter als öffentliche Sachen weder nach weltlichem noch nach kirchlichem Recht abzusprechen. Hierzu vor allem Ernst Forsthoff, Res sacrae, AöR NF 31 (1940) S. 209 ff.

4) Siehe Anm. 2.

5) Hans J. W olff, Art. „Offentliche Sachen“, HdSW Bd. 8 (38. Lief. 1961). Zu nennen ist ferner der Beitrag von Theodor $\mathrm{M}$ a u $\mathbf{n z}$, Das Recht der öffentlichen Sachen und Anstalten, Heft 11 des Sam- 
sammenfassend dargestellt. Daß dabei noch manche Einzelfragen problematisch sind, wird von diesen Autoren nicht verschwiegen. Vor allem beim Gemeingebrauch und beim Sondergebrauch und den Sondernutzungsrechten an Gemeingebrauchssachen ist einiges in Bewegung. Theoretisch umstritten ist nach wie vor auch die zivilrechtliche Konstruktion der Verkehrssicherungspflicht hinsichtlich der öffentlichen Sachen durch die Rechtsprechung der Zivilgerichte. Das alles trifft jedoch nicht den Kern der Lehre.

Indessen scheint auch in den Grundlagen der Lehre von der öffentlichen Sache noch eine gewisse Unsicherheit zu bestehen, jedenfalls kein volles Einverständnis zu herrschen. Das erkennt man beispielsweise daran, daB Forsth of $f$, W o l $f$ und v. Turegg-Kraus, übrigens jeweils in einer blo $B$ beiläufigen Bemerkung, auch die Elektrizität zu den öffentlichen Sachen rechnen ${ }^{6}$ ), daß ferner die Neigung besteht, auch den Luftverkehr, also die Benutzung des Luftraums außerhalb der vom Bodeneigentümer beherrschten Sphäre ${ }^{7}$ ), ferner den Besuch der Kirchengebäude ${ }^{8}$ ) als Gemeingebrauch aufzufassen und daß man die Belegung eines Friedhofes mit Gräbern gleichfalls als Gemeingebrauch am Friedhof und den Erwerb eines Erbbegräbnisses etwa als Begründung des Sondernutzungsrechts an einer Gemeingebrauchssache konstruiert findet ${ }^{9}$ ). Bei den Beispielen des Friedhofs und des Kirchenbesuchs ist natürlich nicht streitig, daß Kirche und Friedhof öffentliche Sachen sind. Aber es macht auch für den Begriff der öffentlichen Sache selbst einen Unterschied, ob man die Friedhofsbenutzung als Gemeingebrauch oder, was ich mit der wohl herrschenden Ansicht (vgl. BGHZ 25, 200) für eindeutig halte, als Anstaltsbenutzung auffaßt und ob man den

melwerks „Die Verwaltung“ (4. Aufl. 1957) und Strickrock, Das öffentliche Sachenrecht, Der Betrieb 1958, $1119 \mathrm{ff}$. Die neue Arbeit von Jürgen $\mathrm{S}$ a l z w e d e l, Gedanken zur Fortentwicklung des Rechts der öffentlichen Sachen, DOV 1963, $241 \mathrm{ff}$. setzt sich schon mit den in Münster gehaltenen Referaten auseinander; sie bleibt deshalb hier außer Betracht.

6) For s th of $f$, Lehrb. S. 328; Hans J. W o If $f$, Verwaltungsrecht I S. 307; v. Turegg-Kraus, Lehrb. S. 178; so auch Zippelius, DOV 1958, 840 und die Begründung zum Entwurf einer Verwaltungşrechtsordnung für Württemberg (1931) S. 532, wo wahrscheinlich der Ursprung dieser Meinung liegt.

7) Forsth off, Lehrb. S. 328; Hans J. W o if $f$, Verwaltungsrecht I S. 307, 324; Dersel be, HdSW Bd. 8 S. 37. Ebenso die Begründung zum EWVRO S. 532.

8) Forsthoff, Lehrb. S. 339; anders in seiner Abhandlung Res sacrae, AöR NF 31 (1940) S. $220 \mathrm{f}$.

9) Forsth of $f$, Lehrb. S. 339; Hans $J$. W o If $f$, Verwaltungsrecht I S. 329. 
Kirchenbesuch als Gemeingebrauch qualifiziert oder nicht ${ }^{10}$ ). Eine Auflösung aller handlichen Vorstellungen von öffentlicher Sache anderseits bedeutet es, diesen Begriff auch auf die Elektrizität und den Luftraum oberhalb der durch $\S 905$ BGB abgesteckten Einflußsphäre des Eigentümers zu erstrekken. $\mathrm{Da} \beta$ sich heute im Luftraum ein Verkehr abspielt, wie er cum grano salis vergleichbar auch auf den Straßen und Strömen stattfindet, macht den Luftverkehrsraum ebensowenig zur öffentlichen Sache, wie der Schiffsverkehr das hohe Meer zur öffentlichen Sache stempelt, und die Tatsache, daß die Elektrizität unter den verschiedensten Gesichtspunkten der Ordnung und daseinsnotwendigen Versorgung Gegenstand öffentlichen Interesses und verwaltungsrechtlicher Regelungen ist, reiht sie gleichfalls noch nicht unter die öffentlichen Sachen $\left.\operatorname{ein}^{11}\right)$.

Hier liegen Fehlschlüsse vor, denen schon an dieser Stelle die später noch zu begründende These entgegenzuhalten ist, $\mathrm{da} B$ die öffentliche Sache begrifflich in einem Zusammenhang, einer Spannung, einem Komplementärverhältnis - oder wie man es zunächst andeutend nennen will - zum privatrechtlichen Sachbegriff und dessen körperlichen Beherrschungsmöglichkeiten steht. Anders ausgedrückt: Offentliche Sachen sind nur körperliche Gegenstände im Sinne der Sachdefinition des $\S 90$ BGB oder doch im Sinne einer vom Gesetz angenommenen Eigentumsfähigkeit wie bei den Gewässern; sie wären bewegliche Sachen und Grundstücke unter der Privatrechtsordnung, wenn sie nicht den Status öffentlicher Sachen hätten. Die Zuerkennung des Status als öffentliche Sache dient gerade dazu, sie, jedenfalls soweit es für ihre öffentliche Indienststellung erforderlich ist, von den sonst für sie eintretenden Konsequenzen der sachenrechtlichen Privatrechtsordnung zugunsten eines stattdessen für sie maßgebenden öffentlich-rechtlichen Regimes zu eximieren. Wo deshalb die Fähigkeit, Sache im Sinne der Privatrechtsordnung zu sein, versagt, wie beim offenen Meer, dem hohen Luftraum oder gar der Stratosphäre und etwa der elektrischen Energie, hat auch das Reden von der öf fentlichen Sache keinen Sinn, weil das ihr immanente kontrastierende und abgrenzende Moment entfällt. Mit Recht hat Ulrich Scheuner seine Erwägungen über das Prinzip der Gemeinverträglichkeit zwar auf den Luftverkehr und den Schiffsverkehr auf dem Meere ausgedehnt, dabei aber

10) Zum Kirchenbesuch unten S. 176 Anm. 62.

11) Noch weiter geht die Unsicherheit in der Abgrenzung bei Diether H a s, Die öffentlichen Sachen, DVBl. 1962, $653 \mathrm{ff}$. 
für den hohen Luftraum, die Stratosphäre und das Meer nicht den Charakter als offentliche Sache in Anspruch genommen ${ }^{12}$ ).

IV.

Eine wirklichkeitsbezogene Erörterung unseres Problems wird sich im übrigen zunächst darüber Rechenschaft abzulegen haben, welche Fortentwicklung das Recht der öffentlichen Sache in der neueren, d. h. seit Gründung der Bundesrepublik ergangenen Gesetzgebung und Rechtsprechung erfahren hat.

1. Im Bereich der Gesetzgebung sind Bund und Länder daran in gleicher Weise beteiligt. Es ist unverkennbar, daß die neueren Gesetze eine viel bewußtere Haltung gegenüber dem Problem der öffentlichen Sache einnehmen, als es früher der Fall war.

a) In den jetzt einheitlichen Bestimmungen über die Zwangsvollstreckung gegen die öffentliche Hand (§ 882 a Abs. 2 ZPO, § 170 Abs. 3 VwGO) ist erklärt, daß die Vollstreckung unzulässig ist „, in Sachen, die für die Erfüllung öffentlicher Aufgaben unentbehrlich sind oder deren Veräußerung ein öffentliches Interesse entgegensteht". Das deckt das Verwaltungsvermögen ganz $^{13}$ ) und von den Sachen im Gemeingebrauch jedenfalls einen wesentlichen Teil, wenn auch nicht beispielsweise die Grundstücke der Privatgewässer, in die eine Zwangsvollstreckung den Gemeingebrauch am Wasser ohnehin nicht berührt. Ähnliches bestimmt $\S 39$ Abs. 3 des Bundesbahngesetzes für alle Sachen, die für die Erfüllung der gesetzlichen Aufgaben der Bundesbahn unentbehrlich sind. Weniger eindeutig ist der Schutz gegenüber dem Enteignungszugriff positivrechtlich normiert. Ein Enteignungseingriff in Teile des Sondervermögens „Deutsche Bundesbahn" setzt nach $\S 39$ Abs. 1 BundesbahnG die Zustimmung der Bundesregierung voraus, die, wenn sie die Zustimmung erteilt, darin eingeschlossen die etwa erforderliche Entwidmung ausspricht. $\S 24$ des Straßengesetzes von Nordrhein-Westfalen vom 28. November 1961 (NW GVBl. S. 305) - ähnlich $\S 22$ des Hessischen Straßengesetzes vom 9. Oktober 1962 (HessGVBl. S. 437) - läßt die Enteignung einer Straße nur insoweit zu, „als die mit der Enteignung angestrebte Benutzung weder im Widerspruch zur Widmung steht noch den Bestand der Sache beeinträchtigt". Das Landbeschaffungsgesetz ( $\$ 16 \mathrm{Nr}$. 1 Buchst. a und d), das Bundesleistungsgesetz ( $\$ 4$ Abs. 2), das Flur-

12) Ulrich Sch e u ner, Festschr. f. Paul Gieseke (1958) S. 90 ff.

13) Dazu die Göttinger Dissertation von Werner $M$ i edta $\mathrm{nk}$, Die Zwangsvollstreckung gegen die öffentliche Hand (1963). 
bereinigungsgesetz ( $\$ 45$ Abs. 1 u. 2) und das Bundesbaugesetz (§90 Abs. 2 Nr. 2) lassen erkennen, daß die dort vorgesehenen Enteignungen, Anforderungen und Veränderungen keineswegs immer und grundsätzlich vor öffentlichen Sachen Halt machen. In den Kirchenverträgen Niedersachsens (Art. 18 Abs. 2), Schleswig-Holsteins (Art. 23 Abs. 1), Hessens (Art. 8 Abs. 2) und von Rheinland-Pfalz (Art. 9 Abs. 2) hat der staatliche Partner zugesichert: „Die Landesbehörden werden bei der Anwendung enteignungsrechtlicher Vorschriften auf die kirchlichen Belange Rücksicht nehmen" (im Wortlaut etwas anders Art. 23 Abs. 2 des Kieler Vertrages). Offensichtlich ist damit aber nur die etwaige Enteignung kirchlichen Finanzvermögens gemeint, während dem Enteignungsakt kaum die Kraft zuerkannt werden soll, auch die kirchenamtliche Widmung kirchlichen Verwaltungsvermögens (einschließlich der res sacrae) beiseitezuschieben, also Kirchengut zu säkularisieren. Denn dem steht die in das Grundgesetz und durchweg auch in die Konkordate und Kirchenverträge rezipierte Garantieklausel des Art. 138 Abs. 2 WRV entgegen, in der mit Johannes $\mathrm{Heckel}$ gerade der Schutz der öffentlichen Funktion des Kirchengutes als zugesichert $\mathrm{zu}$ erblicken ist $\left.{ }^{14}\right)$. Im übrigen könnte auffallen, daß die neueren evangelischen Kirchenverträge (seit Loccum 1955) im Gegensatz zu den deutschen Konkordaten und älteren evangelischen Kirchenverträgen ${ }^{15}$ ) keine Widmungsgarantie im Sinne einer Zusicherung dahin mehr enthalten, daß kirchlichen Zwecken gewidmete staatliche Grundstücke und Gebäude diesen Zwecken auch weiterhin erhalten bleiben. Indessen liegt die Erklärung hierfür darin, da $ß$ nach den Auseinandersetzungsbestimmungen der neuen Kirchenverträge in deren Geltungsbereich nunmehr alles kirchlichen $Z$ wecken dienende Landeseigentum auf die Kirchen selbst überführt ist.

b) Handfestere Beiträge zum Recht der öffentlichen Sache liefern die neuen $\mathrm{StraBe}$ g e s e t ze, voran das Bundesfernstraßengesetz von 1953 in der Fassung vom 6. August 1961 (BGBl. I S. 1742). Lehrbuchgerecht bestimmt § 2 dieses Gesetzes, daß eine Straße die Eigenschaft einer Bundesfernstraße durch Widmung erhält, der die Aufstufung einer öffentlichen Straße zur Bundesfernstraße im Ergebnis gleichsteht. Die Eigenschaft kann durch Abstufung oder Einziehung wieder verloren gehen. Widmung, Umstufung und Einziehung liegen

14) Johannes $\mathrm{Heckel}$, Kirchengut und Staatsgewalt, in: Festschr. f. Rudolf Smend (1952) S. $103 \mathrm{ff}$.

15) RK Schlußprot. zu Art. 17, Art. $10 \S 3$ bayer. K, Art. 4 Abs. 2, 5 preuß. K, Art. $V$ Abs. 2 bad. $K$, Art. 18 bayer. KV, Art. 6 Abs. 2 preuß. KV, Art. III Abs. 2 bad. KV. 
in der Zuständigkeit der obersten Landesstraßenbaubehörde (§ 2 Abs. 6). Die Widmung wird, sofern der Träger der StraBenbaulast nicht selbst zur Verfügung über das Straßengrundstück berechtigt ist, als Akt vorgestellt, der die Zustimmung des Eigentümers oder eines sonst zur Nutzung dinglich Berechtigten voraussetzt ( $\S 2$ Abs. 2). Weiter heißt es, daß durch privatrechtliche Verfügungen oder durch Verfügungen im Wege der Zwangsvollstreckung über die der Straße dienenden Grundstücke oder Rechte an ihnen die Widmung nicht berührt wird (§ 2 Abs. 3). Das alles sind klassische Grundsätze des Rechts der öffentlichen Sache. In dessen traditionellen Bahnen bleibt ferner die Vorschrift des $\S 8$ Abs. 10, wonach die Einräumung von Sondernutzungsrechten am Straßenkörper der Bundesfernstraßen sich nach bürgerlichem Recht richtet, wenn sie den Gemeingebrauch nicht beeinträchtigt, wobei eine Beeinträchtigung von nur kurzer Dauer für Zwecke der öffentlichen Versorgung außer Betracht bleibt. Hier wird also an der Konstruktion festgehalten, daß der Status der Straße als öffentlicher Sache die privatrechtliche Eigentümerposition nur soweit verdrängt, als die Widmung reicht ${ }^{10}$ ).

Anderseits enthält das Bundesfernstraßengesetz zwei Neuerungen: Die eine ist in $\$ 7$ Abs. 1 Satz 4 enthalten, wonach die Erhebung von Gebühren für den Gemeingebrauch einer besonderen gesetzlichen Regelung bedarf. Daraus wird gelegentlich eine Bestätigung dafür entnommen, daß es - mindestens grundsätzlich - auch 'einen entgeltlichen Gemeingebrauch gebe ${ }^{17}$ ); damit geraten allerdings die Grenzen zwischen Ge-

16) Herbert $\mathrm{K}$ r ü g e r, Grundfragen einer rechtsstaatlichen Wassergesetzgebung (1957) S. $134 \mathrm{f}$. polemisiert heftig gegen diese Regelung, ohne indessen, wie ich meine, die theoretische und praktische Folgerichtigkeit auf seiner Seite zu haben. Friedrich $S \mathrm{ch}$ ack sucht in seiner materialreichen Abhandlung „Das rechtliche Wesen der wegerechtlichen Sondernutzung nach altem und neuem Recht" (VerwArch 54/1963, $43 \mathrm{ff}$., $57 \mathrm{ff}$.) die Tragweite des $\$ 8$ Abs. 10 BFStrG wieder einzuschränken, worin ihm allerdings der BGH (Urteil vom 11. Juli 1962 - V ZR 175/60 -, Energiewirtsch. Tagesfragen 1962, 280) offensichtlich nicht zu folgen bereit ist. Arnold Kö t t g e n s tief ansetzende Kritik (Gemeindliche Daseinsvorsorge und gewerbliche Unternehmerinitiative, 1961 S. $24 \mathrm{ff}$.) wird der neuen Straßengesetzgebung insofern nicht ganz gerecht, als diese durchaus den „Mehrzweckcharakter" des Weges anerkennt und die Widmung des Weges erheblich über den Gemeingebrauch hinaus auf die Fälle des Sondergebrauchs ausdehnt, wenn auch nicht auf die Benutzungsarten, die jenseits der Verkehrsfunktion des Weges liegen.

17) So Forsth off, Lehrb. S. 339. E. R. Huber, Zur Problematik des Gemeingebrauchs an öffentlichen Straßen, DOV 1955, 129 ff., 135 ff.; D e r s e 1 b e, Wegekosten und Kraftverkehr (1954) S. $31 \mathrm{f}$. Die Folgerung ist nicht zwingend, wie Herbert $\mathrm{Kr}$ ü ger, 
meingebrauch und Anstaltsordnung ins Fließen, wie übrigens

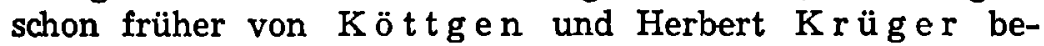
merkt worden ist $\left.{ }^{18}\right)$. Zum andern konstruiert $\S 8$ des Bundesfernstraßengesetzes den Sondergebrauch an Bundesfernstraßen als ein öffentlich-rechtliches Rechtsverhältnis, das einer befristeten oder widerruflichen Gebrauchserlaubnis der StraBenbaubehörde (in Ortsdurchfahrten der Gemeinde), aber daneben nicht mehr der privatrechtlichen Zustimmung des Eigentümers als solchen bedarf ${ }^{19}$ ) und für das Sondernutzungsgebühren, also öffentlich-rechtliche Abgaben erhoben werden dürfen, bei deren Bemessung auch der wirtschaftliche Vorteil der Sondernutzung berücksichtigt werden kann. Hier ist also, um mit Arnold $\mathrm{K}$ ö $\mathrm{t} \mathrm{tg}$ e ${ }^{20}$ ) zu reden, der Charakter der Wege als öffentlich-rechtlicher Mehrzweckinstitute klar anerkannt und ist innerhalb des Kondominiums von öffentlichem Recht und Privatrecht, das bisher für die Rechtsverhältnisse an öffentlichen Straßen kennzeichnend war, mithin eine Grenzkorrektur zugunsten der öffentlichen Sachherrschaft vorgenommen. In diesem Rahmen hält sich übrigens auch $\S 32$ des Personenbeförderungsgesetzes vom 21. März 1961 (BGBl. I S. 241) für die Benutzung von öffentlichen Straßen durch Straßenbahnen. Das Verständnis für das Anliegen Otto Mayers bei seiner Lehre vom öffentlichen Eigentum, das zu überdenken jüngst wiederholt nahegelegt worden ist ${ }^{21}$ ), befindet sich danach offensichtlich im Vordringen.

Von den neuen Landesstraßengesetzen hält sich das zeitlich erste, das Berliner Straßengesetz vom 11. Juli 1957 (GVBI. S. 743), noch stark in den Bahnen des Konventionellen. Widmung und Entwidmung sind in der üblichen Weise geordnet (§§ 3,4$)$. Unter der UUberschrift „Eigentum und Gemeingebrauch" bestimmt $\S 8$ (Abs. 1): „Das Eigentum an öffentlichen Straßen ist Privateigentum, das durch die Bestimmung der

Gegen eine Entstaatlichung der öffentlichen Wege (1954) S. 21 f. mit Recht angemerkt hat. Dazu auch unten S. 179.

18) Arnold $K$ öt tg e $n$, Offentliches Sachenrecht, in: Deutsches Verwaltungsrecht, herausg. von Hans Frank (1937) S. $441 \mathrm{f}$.; Herbert $\mathrm{K} r$ üg e $r$, Gegen eine Entstaatlichung der öffentlichen Wege S. $23 \mathrm{ff}$.

19) Insoweit scheinen mir die Ausführungen von Klaus S t e r n, Zur Problematik des energiewirtschaftlichen Konzessionsvertrags, AöR 84 (1959) S. 137 ff., 273 ff. (hier S. 167 ff.), der bei a 11 e n über den Gemeingebrauch hinausgehenden "Sondernutzungen" den Eigentümer auch weiterhin für beteiligt hält, als der Uberprüfung bedürftig.

20) Arnold Köttgen, Gemeindliche Daseinsvorsorge S. 28, 34.

21) Ernst Forsth of $f$, Lehrb. S. 329 ff. in dem Exkurs der Anm. 3; Peter L e r c h e, Zum Rechtsschutz im Recht der öffentlichen Sachen, DVBl. 1955, $283 \mathrm{ff}$. (286 f.). 
Straße für den Gemeingebrauch beschränkt ist." Für jede Sondernutzung, d.h. den Gebrauch der öffentlichen Straßen über den Gemeingebrauch hinaus, ist die Zustimmung des Straßeneigentümers und eine straßenaufsichtliche Erlaubnis erforderlich ( $\S 10$ Abs. 1), die im allgemeinen nur precario erteilt wird ( $\$ 10$ Abs. 4). Nutzungen für Zwecke der öffentlichen Versorgung, der öffentlichen Verkehrsunternehmungen, der Entwässerung usf. ist, wie sich versteht, eine größere Stabilität eingeräumt (§ 11). „Für Sondernutzungen“, so heißt es in $\S 10$ Abs. 5 allgemein, "kann der Straßeneigentümer Entgelte erheben." Die Straßenordnung für die Stadt Bremen vom 10. Mai 1960 (GBl. S. 51), schon durch ihren Namen mehr als polizeiliche Regelung denn als Straßengesetz ausgewiesen, bringt nur die traditionelle Gegenüberstellung von Gemeingebrauch, Sondernutzung kraft Gebrauchserlaubnis und Verleihung von Sondernutzungsrechten, ohne sonst für das Problem der öffentlichen Sache neue Aufschlüsse zu liefern.

Eine weitere Gruppe von Landesstraßengesetzen, umfassend das Bayerische Straßen- und Wegegesetz vom 11. Juli 1958 (GVBI. S. 147) ${ }^{22}$ ) in der Fassung des Gesetzes vom 22. Dezember 1960 (GVBl. S. 298), das Straßengesetz des Landes Nordrhein-Westfalen vom 28. November 1961 (GVBl. S. 305), das Straßen- und Wegegesetz des Landes Schleswig-Holstein vom 22. Juni 1962 (GVBl. S. 237), das Hessische Straßengesetz vom 9. Oktober 1962 (GVBl. S. 437), das Niedersächsische Straßengesetz vom 14. Dezember 1962 (GVBl. S. 251) und das Landesstraßengesetz für Rheinland-Pfalz vom 15. Februar 1963 (GVBl. S. 57), ist das Ergebnis von Koordinierungsberatungen zwischen den beteiligten Ländern. Diese Gesetze stimmen infolgedessen in den uns hier interessierenden Fragen im wesentlichen überein. Sie suchen zugleich möglichst den Anschluß an das Modell des Bundesfernstraßengesetzes. Wie dieses gehen sie davon aus, daß in den öffentlichen Straßen und Wegen privatrechtlich verstandenes Eigentum und der Status als öffentliche Sache zusammentreffen. Widmung und Entwidmung sind nach dem Vorbild des Bundesfernstraßengesetzes normiert. Ebenso ist (außer in Schleswig-Holstein) die Vorschrift kopiert, daß für den Gemeingebrauch, der an sich unentgeltlich ist, Gebühren nur auf Grund ausdrücklicher gesetzlicher Vorschrift erhoben werden können. Vor allem aber konstruieren sie den Sondergebrauch, jedenfalls im Normalfalle, wie das Bundesfernstraßengesetz als ein öffentlich-rechtliches Rechts-

22) $\mathrm{Zu}$ diesem näher Reinhold $\mathrm{Z}$ i p peli u s, Grundfragen des öffentlichen Sachenrechts und das Bayerische Straßen- und Wegegesetz, DOV 1958, $838 \mathrm{ff}$. 
verhältnis, das durch befristete oder widerrufliche Gebrauchserlaubnis des Trägers der Straßenbaulast ohne Mitwirkung des Eigentümers als solchen begründet wird und für das öffentlichrechtliche Sondernutzungsgebühren erhoben werden können ${ }^{23}$ ).

Freilich ergeben sich hier einige Besonderheiten, die ihren Grund darin haben, daß die Verhältnisse bei den Straßen und Wegen des Landesrechts etwas komplizierter liegen als bei den uniformen Bundesfernstraßen. Ich beschränke mich auch insoweit auf das Wichtigste: Das bayerische Gesetz spricht in diesem Zusammenhang von Sondernutzung nach öffentlichem Recht und Sondernutzung nach bürgerlichem Recht. Es legt die Sondernutzung nach öffentlichem Recht, im wesentlichen mit dem Bundesfernstraßengesetz übereinstimmend, auf die Fälle fest, in denen durch die Benutzung der Gemeingebrauch beeinträchtigt werden kann, während eine Sondernutzung immer dann nach bürgerlichem Recht eingeräumt wird, wenn durch die Benutzung der Gemeingebrauch - außer für nur kurze Dauer - nicht beeinträchtigt werden kann (Art. 22). Die Benutzung der Straßen für Zwecke der öffentlichen Versorgung, so fügt die Vorschrift hinzu, regelt sich stets nach bürgerlichem Recht. Entsprechendes bestimmen das LandesstraBengesetz von Nordrhein-Westfalen ( $\$ 23$ Abs. 1), SchleswigHolstein ( $(28)$, Hessen $(\S 20)$, Niedersachsen ( $(23$ Abs. 1) und Rheinland-Pfalz ( $\$ 45$ Abs. 1). Alle sechs Gesetze schreiben übereinstimmend vor, daß bei „sonstigen öffentlichen Straßen“, d. h. solchen, die weder Landstraßen I. oder II. Ordnung noch Gemeindestraßen sind, sich jedwede Form der Sondernutzung nach bürgerlichem Recht regelt. Bemerkenswert ist, daß ebendiese Gesetze es den Gemeinden gestatten, die Sondernutzung von Gemeindestraßen und "sonstigen öffentlichen Straßen" durch genehmigungsbedürftige Satzung abweichend zu regeln. Charakteristisch ist schließlich eine in ihnen enthaltene Abgrenzungsnorm, die in der Fassung Schleswig-Holsteins (§18 Abs. 1) wie folgt lautet:

„Ist der Träger der Straßenbaulast nicht Eigentümer der Grundstücke, die für die öffentliche Straße in Anspruch ge-

23) Die gelegentlich vertretene Auffassung (F or st h of $f$, Lehrb. S. 345; Wilhelm S t ri ckrock, Zum "begünstigenden" Verwaltungsakt, in: Festschr. f. Willibalt Apelt [1958] S. $231 \mathrm{ff}$., 235 ff.), die Einräumung des Sondergebrauchs könne nur dann versagt werden, wenn überwiegende öffentliche Interessen es geböten, die bisher schon anfechtbar war, läßt sich angesichts der neuen Regelung im Bundesfernstraßengesetz und in den Landesstraßengesetzen (befristete oder widerrufliche Gestattung) sicher nicht mehr rechtfertigen. Insofern ist Martin $\mathrm{Bullinger,} \mathrm{Die} \mathrm{Mineralölfernleitun-}$ gen (1962) S. 40 ff. zuzustimmen. 
nommen worden sind, so steht ihm die Ausübung der Rechte des Eigentümers insoweit zu, als dies die Aufrechterhaltung des Gemeingebrauchs und die Verwaltung und Unterhaltung erfordern. Im gleichen Umfang obliegt es ihm, die Pflichten des Eigentümers zu erfüllen."

Im ganzen behandeln so das Bundesfernstraßengesetz und die ihm folgenden sechs Landesstraßengesetze das Problem der öffentlichen Sache im Sinne einer behutsamen Fortentwicklung. Sie sehen die öffentlichen Wege als der allgemeinen (privatrechtlichen) Eigentumsordnung zugehörig an mit der Maßgabe, daß der durch die Widmung zum Gemeingebrauch konstituierte Status als öffentliche Sache die Eigentümerrechte und -pflichten verdrängt, soweit die Widmungswirkung reicht, und daß die Ausübung dieser Rechte und Pflichten dem StraBenbaulastträger zugeordnet wird, soweit er nicht ohnehin Eigentümer ist und er jener Rechte und Pflichten zur Aufrechterhaltung des Gemeingebrauchs und zur Verwaltung und Unterhaltung der öffentlichen Sache bedarf. Neu ist die Entscheidung, die Oberflächensondernutzungen wegen ihres engen, möglicherweise beeinträchtigenden Zusammenhanges mit dem Gemeingebrauch ganz in den öffentlichen Status der öffentlichen Sache hineinzunehmen. Die das Privateigentum als solches verdrängende Widmung wird also nunmehr über den reinen Gemeingebrauch hinaus auch auf die Oberflächensondernutzungen ausgedehnt, die damit gleichfalls ganz den Dispositionen des öffentlichen Herrn der öffentlichen Sache unterliegen und allein kraft öffentlicher Sachherrschaft - gegebenenfalls gegen öffentliche Benutzungsgebühren - vergeben werden ${ }^{24}$ ). Die Regelung bedeutet eine vernünftige Korrektur bisher vorhandener Halbheiten und Widersprüchlichkeiten; eine entscheidende Änderung des herkömmlichen Instituts der öffentlichen Sache stellt sie indessen nicht dar. - Utbrigens verzichtet auch das Niedersächsische Deichgesetz vom 1. März 1963 (Nds. GVBl. S. 81) darauf, das Privateigentum an den Deichen mehr als im Rahmen der Widmung erforderlich zurückzudrängen.

Das Hamburgische Wegegesetz vom 4. April 1961 (GVBl. S. 117) dagegen, nach Auskunft von Friedrich Sch a ck und $\mathrm{D}$ iether $\mathrm{H}$ a as nach eingehender Beratung mit Professoren der Universität Hamburg geschaffen ${ }^{25}$ ), zeigt, jeden-

24) Also ohne Beteiligung des Wegeeigentümers als solchen; vgl. oben Anm. 19.

25) Friedrich Schack, Bemerkenswertes aus dem Hamburgischen Wegegesetz vom 4. April 1961, DVB1. 1961, 898; Diether H a a s, DVBl. 1962, 656. 
falls im Vordergrund, ein anderes Bild, obwohl auch dieses Gesetz an manchen Passagen erkennen läßt, da $\beta$ Hamburg an den Bemühungen um die Koordinierung der Landesstraßengesetze beteiligt war. Hier wird in Anknüpfung an eine ältere, ihrer Tragweite nach allerdings umstrittene hamburgische Tradition ${ }^{26}$ ) die Rechtsfigur eines "öffentlichen Eigentums“ vorgestell ${ }^{27}$ ). Was damit gemeint ist, kann nur recht begriffen werden, wenn man sich den Wortlaut des mit "Wegeeigentum" überschriebenen $\S 4$ des Gesetzes vor Augen hält:

„(1) Grundflächen, die als öffentliche Wege gewidmet sind und der Freien und Hansestadt Hamburg gehören, stehen einschließlich der in $\S 2$ Absatz 2 genannten Gegenstände in öffentlichem Eigentum der Freien und Hansestadt Hamburg. Das öffentliche Eigentum begründet eine hoheitliche Sachherrschaft. Die in öffentlichem Eigentum stehenden Gegenstände sind dem Rechtsverkehr entzogen. Die Vorschriften des bürgerlichen Rechts, insbesondere über den Besitz und das Eigentum, finden keine Anwendung.

(2) Das öffentliche Eigentum an einer Grundfläche oder an einem sonstigen Gegenstand besteht, solange diese zum öffentlichen Weg gehören. Offentliches Eigentum entsteht frühestens mit dem Zeitpunkt, in dem die Freie und Hansestadt Hamburg nach bürgerlichem Recht unbelastetes Eigentum erwirbt. Endet die Zugehörigkeit zum öffentlichen Weg, so ist die Freie und Hansestadt Hamburg wieder Eigentümerin im Sinne des bürgerlichen Rechts.

(3) Werden Gegenstände im Sinne des § 2 Absatz 2 getrennt, so verwandelt sich das öffentliche Eigentum an ihnen in bürgerlich-rechtliches Eigentum der Freien und Hansestadt Hamburg oder desjenigen, dem die Freie und Hansestadt Hamburg die Aneignung gestattet hat.

26) Dazu Edith $\mathbf{S a t z}$, Das öffentliche Eigentum in Hamburg, Fischers Zeitschr. 70 (1934), 161 ff.; B e h r, Offentlicher Grund und Staatsgrund im Hamburgischen Verwaltungsrecht, HansRGZ 1930, $135 \mathrm{ff}$. Uber die Bedenken hiergegen Fr. Sch a ck, DVBl. 1961, $897 \mathrm{ff}$.

27) Zur Problematik ihrer rechtlichen Zulässigkeit $\mathrm{Fr}$. S c h a ck, aaO. S. 898. Herrn Kollegen Friedrich Schack verdanke ich die Kenntnis des (gedruckten) Stenographischen Berichts über die Verhandlungen des Wegegesetz-Ausschusses der Hamburger Bürgerschaft vom 22. Februar 1960, der die Diskussion mit den Hamburger Professoren (Schultze-v. Lasaulx, Ipsen, Schack, Privatdozent Dr. Stoll) wiedergibt. Die Problematik des Unternehmens wird daran in hohem Grade deutlich. Von einer klaren Billigung der das "öffentliche Eigentum" verfolgenden Senatsvorlage durch die Gesamtheit der beteiligten Professoren und von bedenkenfreier Meinungsbildung im Ausschuß läßt sich jedenfalls nicht sprechen. 
(4) Bauliche Anlagen, die auf oder unter einer in öffentlichem Eigentum stehenden Grundfläche in Ausübung einer Befugnis nach dem Fünften Teil dieses Gesetzes hergestellt worden sind, werden nicht Bestandteile dieser Grundfläche. Bestehen solche baulichen Anlagen bei der Entstehung des öffentlichen Eigentums, so verlieren sie gleichzeitig die etwaige Eigenschaft als Bestandteil des Wegegrundes.

(5) Grundflächen, an denen öffentliches Eigentum entstanden ist, sind aus dem Grundbuch auszuscheiden und zum öffentlichen Grund zu tilgen."

Darüber, wie es mit öffentlichen Wegen zu halten ist, an denen die Freie und Hansestadt Hamburg nicht oder noch nicht nach bürgerlichem Recht unbelastetes Eigentum erworben hat, die also nicht öffentliches Eigentum der Freien und Hansestadt sein können, sagt das Gesetz nichts. Im übrigen aber bleibt das Gesetz in der Konsequenz seiner öffentlichrechtlichen Konstruktion. Als Sondernutzungen faßt es $(\S 19)$ alle Benutzungen der öffentlichen Wege zusammen, die ihren Gebrauch durch andere dauernd ausschließen oder in den Wegekörper eingreifen oder über die Teilnahme am allgemeinen öffentlichen Verkehr (Gemeingebrauch) oder den Anliegergebrauch hinausgehen. Es wird also nicht zwischen Oberflächenbenutzungen, die möglicherweise den Gemeingebrauch beeinträchtigen, und Benutzung des Straßenkörpers in dessen Tiefe unterschieden, so daß diese Unterscheidung auch nicht für eine Differenzierung in den rechtlichen Benutzungsgestattungen verwendet werden kann. Die Befugnis zur Sondernutzung jedweder Art wird vielmehr durch die stets nur befristete und gegebenenfalls unter Widerrufsvorbehalt erteilte Erlaubnis der Wegeaufsichtsbehörde begründet; sie ist mit einer Gebührenpflicht verbunden. Ergänzend bestimmt $\S 19$ Abs. 6, daß der Senat oder mit seiner Zustimmung die Wegeaufsichtsbehörde Sondernutzungen auch durch öffentlich-rechtliche Verträge einräumen können.

Sieht man näher zu, so bedeutet diese Regelung gegenüber den vorher erörterten nur insofern einen Unterschied, als in Hamburg vertragliche Sondernutzungsrechte an öffentlichen Sachen nur durch öffentlich-rechtliche Verträge, nicht durch Verträge bürgerlichen Rechts begründet werden können. Soweit davon auszugehen ist, daß die öffentlichen Wege in Hamburg permanent im Eigentum der Freien und Hansestadt stehen, begründet das praktisch keinen wesentlichen Unterschied gegenüber den anderen Ländern und den Bundesstraßen. Nur bietet das Hamburger Recht keine Sicherung dafür, daß, wenn man etwa einen Straßenkörper in der Tiefe durch dauernde 
Kabel- oder Rohrleitungen benutzen will, dafür wirklich ein Vertrag geschlossen werden muß und die Wegeaufsichtsbehörde einen nicht nur mit einer befristeten Gebrauchserlaubnis abspeist. Das öffentliche Eigentum selbst, das in $\S 4$ des Gesetzes proklamiert und definiert wird, erweist sich in Wahrheit nur als eine andere Art der Benennung für den öffentlichrechtlichen Status, den eine öffentliche Straße auch nach gemeindeutschem Recht durch die Widmung empfängt ${ }^{28}$ ). Die gedankliche Konstruktion hat auch nicht den Vorzug besserer Praktikabilität und größerer theoretischer Folgerichtigkeit gegenüber den Lösungen, bei denen das deutsche Binnenland verblieben ist, und jedenfalls trägt sie neue Erkenntnisse über das Recht der öffentlichen Sache nicht ein ${ }^{29}$ ). In dem Hamburgischen Gesetz über Grün- und Erholungsanlagen vom 18. Oktober 1957 (GVBl. S. 466) und in dem Wassergesetz Hamburgs vom 20. Juni 1960 (GVBl. S. 335) ist sie übrigens nicht verwendet, während sie anscheinend in einem neuen Deichgesetz Hamburgs ein weiteres Experimentierfeld finden soll $\left.{ }^{30}\right)$.

Das Hamburgische Wegegesetz enthält aber noch eine weitere Besonderheit, nämlich in seinem $\S 5$ eine schon in $\S 6$ des Gesetzes über Grün- und Erholungsanlagen von 1957 vorgebildete dezidierte Stellungnahme zur Frage der Verkehrssicherungspflicht in Ansehung öffentlicher Sachen. Offensichtlich in Gegenwirkung zur zivilrechtlichen, nämlich an die $\S \S 823,836$ BGB angelehnten Begründung der Verkehrssicherungspflicht durch die Zivilgerichte und heute den Bundesgerichtshof ${ }^{31}$ ) bestimmt $\S 5$ des Hamburgischen Gesetzes unter der Überschrift „Haftung“:

„Die Rechte und Pflichten, die der Freien und Hansestadt Hamburg und ihren Bediensteten in Zusammenhang mit der Durchführung dieses Gesetzes, insbesondere mit der Anlage, Unterhaltung und Benutzung der öffentlichen Wege

28) Wenn die von Fr. S ch a ck, DVBI. 1961 S. 898 mitgeteilte amtliche Begründung zu $\S 4$ des Gesetzes betont, daß es sich hier um "Rechtsgedanken von großer praktischer Auswirkung und $\mathrm{Be}-$ deutung " handele, so ist das eine Selbsttäuschung des Verfassers dieser Begründung.

29) Diese sind auch nicht den kommentierenden Bemerkungen von Diether Ha a s, DVBl. 1962, $656 \mathrm{zu}$ entnehmen.

s0) So Diether $\mathrm{H}$ a a s, DVBl. 1962, 656. Anscheinend sind diese Unterschiedlichkeiten in der Dezernatsverteilung der Hamburger Senatsverwaltung begründet.

31) $\mathrm{BGH}$ NJW 1952, 1089; 1953, 1865; BGHZ 6, 195; 9, $373=$ VwRspr. 5, 825; BGHZ 12, 94; 14, 83; 16, 95 = VwRspr. 8, 145; BGHZ 20,57; 21,48; 31, 73; 34, 206; 37, 69; 37, 165; VwRspr. 14, $830=$ DOV 1962, 615, VwRspr. 14, 929 . 
zustehen oder obliegen, bestimmen sich ausschließlich nach den Vorschriften des öffentlichen Rechts. Die Pflichten werden als Amtspflicht im Sinne des Artikels 34 des Grundgesetzes von den Bediensteten der Freien und Hansestadt Hamburg erfüllt.“

Es ist indessen leicht zu erkennen, daß der Gesetzgeber Hamburgs mit dieser Vorschrift, obwohl ihn der Bundesgerichtshof in BGHZ 9, 373 mit einer etwas undurchsichtigen Wendung ${ }^{32}$ ) hierzu zu ermuntern scheint, seine Kompetenz überschritten hat. Denn hier handelt es sich nicht um Wegerecht, sondern um Schadensersatzpflichten, sei es aus Amtshaftung, sei es aus allgemeinem Deliktsrecht. Diese Materie ist bundesgesetzlich geregelt, und zwar erschöpfend; in sie kann ein Landesgesetzgeber nicht modifizierend eingreifen ${ }^{\mathbf{3}}$ ). Wenn es Hamburg nicht paßt, daß der Bundesgerichtshof die Verkehrssicherungspflicht bei öffentlichen Sachen zivilrechtlich konstruiert, so kann man mit ihm darin sympathisieren; aber der hamburgische Landesgesetzgeber ist dagegen machtlos.

In der Sache selbst haben gewiß die Autoren, die die erwähnte Rechtsprechung des Bundesgerichtshofs unter logischen und rechtssystematischen Gesichtspunkten kritisiert haben $^{34}$ ), gute Gründe auf ihrer Seite. Jedenfalls hätten sie recht, wenn das geltende Schadensersatzrecht in sich nicht Ungereimtheiten enthielte. Es ist unschwer zu deduzieren, daß die Straßenbaulast eine öffentlich-rechtliche Aufgabe ist, deren Vernachlässigung eine Amtspflichtverletzung darstellt und Amtshaftungsansprüche gemäß $\S 839$ BGB in Verb. mit Art. 34 GG auslösen muß. Aber man muß sich fragen, wozu das führen würde. $\mathrm{Da}$ die Verkehrssicherungspflicht kaum jemals

32) Sie ist mit Recht kritisiert bei Hans J. W olf $f$, Verwaltungsrecht I S. 320.

33) Die Gründe, die Fr. Sch a ck (DVBl. 1961 S. 899) für die Zulässigkeit der Regelung anführt, halte ich nicht für überzeugend.

34) Ernst For st h of f, Lehrb. S. $347 \mathrm{ff}$; D e r sel be, DVBl. 1952, $164 \mathrm{ff}$.; Hans J. W o I f f, Verwaltungsrecht I S. $319 \mathrm{ff}$;; H a u e is en, NJW 1953, 1614; K r a t t, DOV 1954, 521; N ed de n, NJW 1956, 1015; S p a n n e r, Grenzen zwischen öffentlichem Recht und bürgerlichem Recht im Wegerecht (1958) S. $16 \mathrm{ff}$., der auch über die Gegenmeinungen referiert; $\mathrm{Cl}$ a s e $\mathrm{n}$, DOV 1959, 284; Hans Thierfelder, DOV 1960, 898; 1962, 256; Hans Freund, DOV 1961, 695; Fr. S c h a c k, DVBl. 1961, 899; Klaus S te r n, AöR 84 (1959) S. $164 \mathrm{f}$. (etwas vermittelnd); Herbert $\mathrm{Kr}$ ü g e r, Grundfragen $S .136 \mathrm{f}$, , dieser freilich unter Verkennung der Tatsache, daß der BGH (BGHZ 9, 373; 14, 83) die zivilrechtliche Haftungskonstruktion ausdrücklich nicht auf das Eigentum an der öffentlichen Sache, sondern auf die Tatsache der vom Gegenstand ausgehenden Gefährdung Dritter zurückführt. 
anders als fahrlässig verletzt wird, bei fahrlässiger Amtspflichtverletzung jedoch die Amtshaftung nur subsidiär Platz greift, würde die Anwendung der Amtshaftungsgrundsätze auf die Verkehrssicherungspflicht angesichts der Reichweite des heute bestehenden Sozial- und Privatversicherungsschutzes bewirken, daß in der erdrückenden Mehrzahl aller Schadensfälle die Träger der sozialen oder privaten Kranken-, Unfall-, Renten- und Kraftfahrzeughaftpflichtversicherung den Schaden zu tragen hätten und der eigentlich Schuldige, nämlich der für den verkehrssicheren Zustand der Straßen, Wege und Wasserwege Verantwortliche, verschont würde ${ }^{35}$ ). Demgegenüber waltet in der Rechtsprechung des Bundesgerichtshofs doch wohl die höhere Weisheit, wenn sie durch Heranziehung der allgemeinen Deliktsvorschriften statt der Amtshaftung den zur Verkehrssicherung Verpflichteten nicht aus dem realen Einstehen für seine Verfehlungen entläßt, und die zitierten hamburgischen Haftungsvorschriften verlieren einiges von ihrem zensurierenden Pathos, wenn man in ihnen das mitbestimmende Motiv erkennt, peinliche Haftungsfolgen aus eigenem Verschulden von der Freien und Hansestadt auf andere Lastenträger abzubürden ${ }^{36}$ ).

Für das Problem der öffentlichen Sache ergibt sich hieraus, $\mathrm{da} \beta$ in der Berührung mit dem Schadensersatzrecht die logische Konsequenz nicht um ihrer selbst willen überspannt werden darf.

c) Wendet man sich von hier aus dem neuen $W$ a s se r$\mathrm{rech} \mathrm{t} z u$, das sich im Wasserhaushaltsgesetz des Bundes vom 27. Juli 1957 (BGBl. I S. 1110)/19. Februar 1959 (BGBl. I S. 37) und in den auf seiner Grundlage ergangenen Landeswassergesetzen $^{37}$ ) präsentiert, so ist leicht erkennbar, daß auch in

35) Forsth off, Lehrb. S. 351, Spanner, aaO. S. 20 und S ch a ck, DVBl. 1961, 899 dürften dieses Moment zu stark bagatellisieren. Zu der Frage auch Hansjörg Jell i nek, Grenzen der Verkehrssicherungspflicht auf öffentlichen Straßen, in: Gedächtnisschrift $f$. Walter Jellinek (1955) S. 565 ff., 572, und $\mathrm{H}$ e y e $n$, Die höchstrichterliche Rechtsprechung zur Verkehrssicherungspflicht, NJW 1955, 326 ff.

36) Die Erwägungen, die ausweislich des stenographischen Berichts (vgl. oben Anm. 27) in der Sitzung des Wegerechts-Ausschusses der Hamburg. Bürgerschaft zu diesem Punkte angestellt wurden, erschöpften die Problematik nicht.

37) Es handelt sich um folgende Landeswassergesetze: BadenWürttemberg 25. Februar 1960 (GBl. S. 17); Bayern 26. Juli 1962 (GVBl. S. 143); Berlin 23. Februar 1960 (GVBl. S. 133); Bremen 13. März 1962 (GBl. S. 59); Hamburg 20. Juni 1960 (GVBl. S. 335); Hessen 6. Juli 1960 (GVBI. S. 69); Niedersachsen 7. Juli 1960 (GVBl. S. 105); Nordrhein-Westfalen 22. Mai 1962 (GVBl. S. 235); RheinlandPfalz 9. August 1960 (GVBl. S. 153); Saarland 28. Juni 1960 (ABl. S. 511); Schleswig-Holstein 25. Februar 1960 (GVBl. S. 39). 
diesem Bereich bald mehr, bald weniger an der Vorstellung festgehalten ist, es gebe an den Gewässern und ihrem Bett Eigentum im Sinne der Privatrechtsordnung, das durch die hier generell und gesetzlich ausgesprochene Widmung zu einem näher gekennzeichneten Gemeingebrauch, mehr noch aber durch eine streng öffentlich-rechtliche Regulierung individueller Benutzungsmöglichkeiten modifiziert ist ${ }^{38}$ ). Daß der Wasserrechtsgesetzgeber einige Mühe hat, die fließenden Gewässer mit ihrem Bett und die an ihnen gelegentlich wechselnden Bodenverhältnisse eigentumsrechtlich reibungslos zu placieren, und daB dem Eigentümer selbst an oberirdischen Gewässern nur begrenzte Nutzungsmöglichkeiten zugestanden sind $(\$ 24$ WHG) ${ }^{39}$ ), würde das Problem der öffentlichen Sache als solches nicht berühren. Gleichwohl ist hier durch die neue Wassergesetzgebung eine ganz andere Lage entstanden als im Wegerecht, worauf bald zurückzukommen ist.

Eine Parallele zum „öffentlichen Eigentum" des Hamburgischen Wegegesetzes findet sich im Wassergesetz für BadenWürttemberg vom 25 . Februar 1960 (GBl. S. 17). Nach § 4 Abs. 1 dieses Gesetzes steht das Bett eines Gewässers erster Ordnung im „öffentlichen Eigentum" des Landes, das eines Gewässers zweiter Ordnung im "öffentlichen Eigentum" der Gemeinde. Das gilt allerdings nur, soweit das Bett des Gewässers sich nicht im Eigentum eines anderen befindet oder mit Rechten Dritter belastet ist ( $\S 4$ Abs. 1 Satz 2, $\S 4$ Abs. 5). An sogen. privaten Gewässern gibt es überhaupt nur Privateigentum $(\S 6)$, und künstlich überflutete Flächen sowie Seen, Teiche und Weiher mit ständig fließendem oberirdischem $\mathrm{Zu}-$ und Ablauf stehen, auch wenn sie dem Lande oder einer Gemeinde gehören, nur in deren Privateigentum ( $\$ 4$ Abs. 1 Satz 2). Uber das öffentliche Eigentum am Bett öffentlicher Gewässer sagt $\S 5$ aus, für dieses öffentliche Eigentum gälten die Vorschriften des bürgerlichen Rechts über das Grundeigentum nur, soweit

38) Hierzu Paul Gi e seke, Rechtseinheit im Wasserrecht? Veröff. des Instituts für das Recht der Wasserwirtschaft Heft 9 (1961) S. $7 \mathrm{ff}$., $13 \mathrm{ff}$.; auch BGHZ 28, 34 (37 f.).

39) $\mathrm{Zu}$ dieser Problematik Rudolf Si e vers, Nutzung und Eigentum an oberirdisch fließenden Gewässern, DVBl. 1962, 77 ff.; Derselbe, Der Rechtsweg im Wasserrecht, DVB1. 1962, 193; Derselbe, Die Problematik der Landesgesetzgebung zum Wasserrecht, DVBl. 1962, 313 ff.; D e r s e l b e, Der natürliche Wasserlauf im Recht, VerwArch 51 (1960), 187 ff.; Paul G i e s e k e, Veröff. des Instituts für das Recht der Wasserwirtschaft Heft 9 (1961) S. 7 ff., $13 \mathrm{ff}$.; Helmut R. K ül z, Eigentum und Verwaltungskompetenzen an den Bundeswasserstraßen, ebenda S. $27 \mathrm{ff}$.; Karl Kübler, Rechtseinheit im Wasserrecht, DƠV 1961, $935 \mathrm{ff} . ;$ Jürgen S a l z wede1, Gemeingebrauch im Wegerecht und Wasserrecht, Zeitschr. f. Wasserrecht 1 (1963) S. $73 \mathrm{ff}$. 
nicht die aus der Zweckbestimmung der öffentlichen Gewässer und die aus dem Wasserrecht folgenden Beschränkungen entgegenständen. Das ist nun wirklich nichts weiter als die allgemeine Definition der öffentlichen Sache, und wenn $\S 5$ Satz 2 hinzufügt, über öffentliches Eigentum könne durch Privatrechtsgeschäft nicht verfügt werden, so bedeutet das der Sache nach lediglich das Verbot, einmal begründetes von Rechten Dritter unbelastetes Landes- und Gemeindeeigentum an Gewässern erster und zweiter Ordnung zu reprivatisieren. Ähnlich wie im hamburgischen Wegerecht ist mithin das „öffentliche Eigentum" des Wasserrechts von Baden-Württemberg nur ein Etikett für den Status bestimmter öffentlicher Sachen, hier zweier Kategorien von Gewässern, bei denen öffentliche Sachherrschaft und Eigentümerrecht permanent in der Hand des öffentlichen Aufgabenträgers vereinigt sind, die sich aber im Charakter als öffentliche Sache sonst in nichts von den übrigen Gewässern unterscheiden.

Im übrigen könnte man geneigt sein, das verwaltungsrechtliche Regime der öffentlichen Wege zu dem der Gewässer in Parallele zu setzen. Man stößt dann alsbald auf die Abweichung, daß Sondernutzungsrechte an Gewässern nach der verbindlichen Rahmenvorschrift in $\S 8$ des Wasserhaushaltsgesetzes heute nur durch öffentlich-rechtlichen Akt, die „Bewilligung", begründet werden können, und könnte sich bewogen fühlen, hierin eine besonders fortschrittliche Art des Umgehens mit der öffentlichen Sache zu sehen, nach deren Beispiel man den bei Wegen für die Begründung von Sondernutzungsrechten noch dominierenden bürgerlich-rechtlichen Vertrag zu ersetzen hätte. In Wahrheit lassen sich öffentliche Wege und Gewässer nur beschränkt parallelisieren ${ }^{40}$ ).

Offentliche Wege sind als solche nur zum Gemeingebrauch und nach heutigem Verständnis auch zu bestimmten, jeweils durch Gebrauchserlaubnis zu erschließenden öffentlich-rechtlichen Oberflächensondernutzungen gewidmet, nichts weiter. Wenn daneben der Wegekörper in seiner Tiefe so, da $B$ der Widmungszweck dadurch nicht berührt wird, für die Verlegung von Rohren, Kabeln usf. Verwendung findet, so steht nichts dagegen, diese Verwendungsart nach Privatrecht abzuwickeln. Das ist sogar das Natürliche und Praktische. Denn für den Fall, daß Wegeherr und Eigentümer nicht identisch sind, besteht weder Anlaß noch Recht, den privaten Eigentümer aus einer Verwertungsmöglichkeit $z u$ verdrängen, die für den Status der öffentlichen Sache irrelevant ist. Praktisch

40) Das gelangt auch in der soeben (Anm. 39) zitierten Abhandlung von Jürgen $S$ a $l \mathrm{z}$ w e d e $l$ zum Ausdruck. 
ist $\mathrm{zu}$ bedenken, daß öffentliche Wege, besonders in einer Zeit der Stadtsanierung und der Straßennetzmodernisierung häufig aufgelassen werden und ihr Areal wieder privater Verwendung zugeführt wird. Rohre, Kabel usf. bleiben dann in ihrem Grunde vielfach liegen, und es würde zu erheblichen Mißlichkeiten führen, wenn in einem solchen Falle das öffentlich-rechtliche Benutzungsrecht eine Novation durch einen bürgerlich-rechtlichen Vertrag erfahren müßte. Ähnliche Schwierigkeiten würden entstehen, wenn ein öffentlicher Weg über bisher privat genutztes Gelände geführt wird, in dem bereits Rohre und Kabel auf Grund privatrechtlicher Vertragsgestattung liegen oder wenn Wege verlegt werden, die sich mit Rohren und Kabeln kreuzen ${ }^{41}$ ).

Wesentlich anders bei den Gewässern. Das neue Wasserrecht wendet sich dem ganzen nationalen Wasserhaushalt zu und behandelt ihn zwar nicht als öffentliche Sache, aber als eine Art Gemeingut. Dessen Nutzung baut grundsätzlich nicht auf der Eigentumsordnung auf - wie schon daraus zu erkennen ist, daß das Wasserhaushaltsgesetz des Bundes den Eigentümer nur am Rande erwähnt -, sondern vollzieht sich nach einem universellen verwaltungsrechtlichen Regime, das die wesentlichsten Normalbenutzungen der Gewässer durch die Hoheitsakte der Erlaubnis und Bewilligung erschließt. Daneben gibt es einige erlaubnisfreie Benutzungen, die die Wassergesetze ziemlich genau, und zwar einengend, definieren und die sie in Gemeingebrauch und Eigentümer- sowie Anliegergebrauch aufgliedern.

Angesichts dieser Ordnung der Dinge haben die Gewässer einen greifbaren Status als öffentliche Sache nur noch erstens dann, wenn sie als Kanäle und ausgebaute Stromschiffahrtswege, also im System der Bundeswasserstraßen anstaltsähnlich organisiertes Verwaltungsvermögen darstellen, und zweitens, soweit an ihnen Gemeingebrauch besteht. Dieser Gemeingebrauch aber ist bei den Gewässern, die nicht Bundeswasserstraßen sind, nicht wie bei den Wegen die wesensbestimmende öffentliche Hauptfunktion, und ebensowenig stellt er sich wie dort als Ubberlagerung und Verdrängung des privaten Eigentums dar. Er begründet als solcher, von den Verkehrswegen der Bundeswasserstraßen abgesehen, auch keine besondere Verwaltungsträgerschaft mit öffentlicher Verantwortung für die Gewässer und keine Unterhaltungs- und Verkehrssiche-

41) Dies kann auch gegenüber der von Arnold $\mathrm{K}$ öttge $\mathrm{n}, \mathrm{Ge}-$ meindliche Daseinsvorsorge und gewerbliche Unternehmerinitiative $\mathrm{S}$. $24 \mathrm{ff}$. an $\S 8 \mathrm{Abs}$. 10 BFStrG geübten Kritik eingewendet werden. 
rungspflicht. Vielmehr handelt es sich bei ihm nur um eine von mehreren Normalbenutzungsmöglichkeiten, die, wiederum von den Schiffahrtswegen abgesehen, überdies nur noch nebengeordnete Bedeutung hat ${ }^{42}$ ) und die als partielle Teilhabe der Allgemeinheit an den Gewässernutzungen im Rahmen eines durch Gesetz und Einzelhoheitsakte festgelegten öffentlichrechtlichen Gesamtsystems dieser Benutzungen zu kennzeichnen ist. Das schließt nicht aus, diesen Gemeingebrauch, so weit er reicht, auch weiterhin nach Analogie des Gemeingebrauchs an Wegen zu behandeln und die Gewässer in diesem Umfange, also partiell, als öffentliche Sache zu definieren. Aber die Parallele paßt im Grunde nur für den Gemeingebrauch durch Schiffs- und Bootsverkehr. Im übrigen jedoch sind der Begriff der öffentlichen Sache und das Wasserbenutzungssystem des neuen Wasserrechts inkommensurabel geworden. Jedenfalls aber sind die durch Erlaubnis und Bewilligung begründeten Wassernormalbenutzungen mit den als Trabanten oder Gegenpositionen des Gemeingebrauchs auftretenden Fällen des Sondergebrauchs und der Sondernutzungen an Wegen nicht vergleichbar. Infolgedessen bietet das neue Regime der wasserrechtlichen Erlaubnisse und Bewilligungen auch kein Modell für Nachbildungen im Wegerecht.

2. Die Rech tsp rechung des letzten Jahrzehnts hat die Lehre von der öffentlichen Sache als solche nicht wesentlich weiterentwickelt, so weit sie sich auch in die Fragen der Widmung und Entwidmung, des Rechtsschutzes und des Umfangs des Gemeingebrauchs überhaupt und in Abgrenzung zum Sondergebrauch auffächern mußte. In seinem Urteil vom 30. April 1953 (BGHZ 9, $373=$ VwRspr. 5, 825) hat der Bundesgerichtshof allerdings Anlaß gefunden, einige grundsätzliche Betrachtungen zu dem Problem anzustellen. Das Urteil referiert zunächst knapp über die älteren, zivilistisch ausgerichteten Deutungsversuche, charakterisiert dann die Lehre vom öffentlichen Eigentum (domaine public) im Sinne von Otto Mayer und legt anschließend, hierbei immerhin grundsätzlich auch eine ausschließliche öffentlich-rechtliche Herrschaft über eine Sache als theoretisch möglich andeutend, dar, daß nach der bestehenden Rechtsordnung die bürgerlich-rechtliche und die öffentlich-rechtliche Sachherrschaft an ein und derselben Sache zusammenträfen. Das Wesen der öffentlichen Sache bestehe bei dieser Betrachtungsweise in einem durch die Widmung begrenzten öffentlich-rechtlichen Nutzungsverhält-

42) So auch betont von Ulrich $\mathrm{S} c \mathrm{~h}$ e u n er, Festschr. f. Gieseke S. 78; ähnlich Jürgen $\mathrm{S}$ a l:z w e d e I, Zeitschr. f. Wasserrecht 1 (1963), $73 \mathrm{ff}$. 
nis. Das Privateigentum (in der Hand des Staates oder eines Dritten) trete bei Konkurrenz mit der inhaltlich begrenzten öffentlich-rechtlichen Herrschaft mit seinen Einzelrechten und Einzelpflichten nach dem Grundsatz vom Vorrang des öffentlichen Rechts vor dem bürgerlichen Recht und dem allgemeinen Rechtsgrundsatz von der Schwäche des umfassenderen Rechts gegenüber dem begrenzteren Recht insoweit zurück, als es unvereinbar mit jenem öffentlich-rechtlichen Nutzungsverhältnis sei. Das ist nun freilich nichts Neues, sondern nur eine Umschreibung der Auffassung, die seit Jahrzehnten der kontinuiérlichen Rechtsprechung des Reichsgerichts und des Bundesgerichtshofs zugrunde liegt.

Erwähnt wurde schon die Rechtsprechung des Bundesgerichtshofs zur Verkehrssicherungspflicht hinsichtlich der öffentlichen Wege und Wasserstraßen. Mit dieser Frage setzt sich besonders die letzterwähnte Entscheidung (BGHZ 9, 373, ferner das Urteil BGHZ 14, 83) auseinander. Der Bundesgerichtshof räumt hier, was von der Kritik vielfach übersehen wird, ein, daß die Herstellung und Unterhaltung der öffentlichen Wege und Wasserstraßen eine Aufgabe des Staates und anderer öffentlicher Körperschaften bilde, unter öffentlichem Recht stehe und hoheitlich bewältigt werde, also Teil der öffentlichen Verwaltung sei. Seine Entscheidung vom 5. Februar 1962 (VwRspr. 14, 929 [931 f.]) hat das noch einmal stark unterstrichen. Gleichwohl gelangt er unter Ablehnung der Amtshaftung zur Annahme der allgemeinen (privatrechtlichen) Deliktshaftung. Denn die Haftungsgrundlage sei hier nicht das privatrechtliche oder öffentlich-rechtliche Sachherrschaftsverhältnis, sondern die Tatsache der vom Gegenstand ausgehenden Gefährdung Dritter, und es sei mit dem Reichsgericht nicht einzusehen, inwiefern es denn einen Unterschied machen solle, ob eine Privatperson oder ein Verwaltungsträger aus der Vernachlässigung der Verkehrssicherungspflicht einzustehen habe. Uber die theoretische Uberzeugungskraft dieser Argumentation kann man geteilter Meinung sein. Aber sie setzt sich jedenfalls mit dieser Begründung in den eben erwähnten Entscheidungen nicht mit der Lehre von der öffentlichen Sache in Widerspruch, und überdies ist, wie schon dargelegt wurde, die Schwäche der Deduktion durch die höhere Gerechtigkeit des Ergebnisses gemildert und sogar geheilt.

Die meisten der sonstigen Entscheidungen sind durch die neue Straßengesetzgebung überholt ${ }^{43}$ ). So in der Frage, wie-

43) Eine Zusammenfassung bietet noch einmal Friedrich $\mathrm{Sch}$ a ck , Das rechtliche Wesen der wegerechtlichen Sondernutzung nach altem und neuem Recht, VerwArch. 54/1963, $43 \mathrm{ff}$. 
weit auch für Oberflächennutzungen an Straßen kraft Gebrauchserlaubnis die Zustimmung des Eigentümers erforderlich sei und dieser ein privatrechtliches Entgelt verlangen könne. Außer für Berlin hat diese Rechtsprechung seit dem Bundesfernstraßengesetz und den ihm folgenden neuen Landesstraßengesetzen (auch dem Personenbeförderungsgesetz hinsichtlich der Straßenbahnen) keine Bedeutung mehr, weil diese Gesetze alle Oberflächensondernutzungen in die öffentliche Sachherrschaft hineinnehmen und sie als erlaubnis- und gebührenpflichtige Auswirkungen eines öffentlich-rechtlichen Rechtsverhältnisses an der öffentlichen Sache verstehen. Dagegen bleibt das Problem bestehen, den unentgeltlichen Gemeingebrauch (einschließlich des Anliegergebrauchs) auf der einen Seite von den über den Gemeingebrauch hinausgehenden öffentlich-rechtlichen Sondernutzungen und privatrechtlich eingeräumten Benutzungen auf der anderen Seite abzugrenzen. Indessen hat auch die hierzu entwickelte höchstrichterliche Rechtsprechung nur noch historisches Interesse, da die neuen Straßengesetze z. T. ganz bewußt neue Abgrenzungskriterien aufgestellt haben und die vorbehaltenen gemeindlichen Regelungen es für die Ortsstraßen noch tun werden.

Von unvermindertem theoretischem und praktischem Interesse ist hingegen die Frage, ob das Hausverbot gegen unerwünschte Besucher öffentlicher Verwaltungsgebäude aus der öffentlichen Sachherrschaft (so die Berliner und Hamburger Verwaltungsgerich te) ${ }^{44}$ ) oder aus dem privatrechtlich verstandenen Hausrecht herzuleiten ist, wie der Bundesgerichtshof angenommen hat ${ }^{45}$ ). Dabei ist allerdings zu bemerken, daB die Verwaltungsgerichte es mit Hausverboten gegen querulatorische Petenten, der Bundesgerichtshof es mit einem seinem Gewerbe als Photograph nachgehenden Eindringling in das Standesamt zu tun hatte. Man kann die beiden Fälle mit dem Oberverwaltungsgericht Hamburg (MDR 1957, 188) in der Tat verschieden beurteilen, sollte aber besser bei beiden Tatbeständen allein auf die öffentliche Sachherrschaft abstellen ${ }^{46}$ ).

V.

Die Gesetzgebung der Nachkriegsjahre trägt danach immerhin einige bemerkenswerte, die Rechtsprechung weniger neue

44) BezVG Berlin DVBl. 1950, 245; OVG Berlin DVBl. 1952, 763; OVG Hamburg MDR 1957, 188; ihnen folgend OVG Münster JZ $1963,566$.

45) BGH vom 26. Oktober 1960 (VwRspr. 13, $483=$ DVBl. 1961, $46=$ BGHZ 33, 230).

46) Näher zu dem Problem Walter Fr ühling, Das Hausrecht öffentlicher Einrichtungen (Göttingen Diss. 1962). In dem hier empfohlenen Sinne schon Köttgen, Offentliches Sachenrecht S. $443 \mathrm{f}$. 
Züge zum Recht der öffentlichen Sache bei. Des eigenen Nachdenkens über das Problem wird man jedenfalls nicht enthoben.

Das gilt zunächst für die Utberprüfung der Konstruktion der öffentlichen Sache in grundsätzlicher Hinsicht. In den literarischen Beiträgen zu unserem Problem werden, was verständlich ist, die Einzelfragen des Rechts der öffentlichen Sachen meist an den Gemeingebrauchssachen erläutert; einschlägige Gerichtsentscheidungen sind aus naheliegenden Gründen fast nur aus dem Gebiete des Gemeingebrauchs und Sondergebrauchs zu ermitteln ${ }^{47}$ ), und es ist in gleichem Sinne bezeichnend, daß der Entwurf einer Verwaltungsrechtsordnung für Württemberg, neben dem Finanzvermögen auch das Verwaltungsvermögen ausdrücklich ausschließend, als öffentliche Sachen im Sinne des Entwurfs nur die Gemeingebrauchssachen anerkannt wissen will ${ }^{48}$ ). Demgegenüber muß mit einigem Nachdruck betont werden, was natürlich auch die herrschende Lehre keineswegs verkennt und die Begründung zum Entwurf einer Verwaltungsrechtsordnung gleichfalls ausdrücklich einräumt ${ }^{49}$ ), daß auch die Gegenstände des Verwaltungsvermögens (einschließlich desjenigen der Kirchen und der res sacrae) zu den öffentlichen Sachen gehören. Das bedeutet gleichzeitig, daß eine praktikable Lehre der öffentlichen Sache sich entsprechend orientieren muß. Sie muß nämlich in ihren theoretischen Grundlagen so beschaffen sein, daß sie das Verwaltungsvermögen - dieses wieder aufgegliedert in solches eines verwaltungsinternen und solches eines externen, d. h. dem Publikum zugewendeten Gebrauchs - und die Sachen im Gemeingebrauch in gleicher Weise erfaßt und deckt. Das vor Augen zu haben, ist u. a. deshalb wichtig, weil von einzelnen Sachen im Gemeingebrauch, etwa im Stile des Hamburgischen Wegegesetzes und des Wassergesetzes von BadenWürttemberg offenbar immer wieder die Verlockung ausgeht, die öffentliche Sache nach den Vorstellungen eines besonderen "öffentlichen Eigentums" zu konstruieren ${ }^{50}$ ), was neben an-

47) Eine Ausnahme bilden die in den Anm. 44 und 45 zitierten Entscheidungen hinsichtlich des „Hausrechts“ an Verwaltungsgebäuden und OVG Koblenz DVBl. 1956, 624 wegen der Verfügung über das Läuten von Kirchenglocken.

48) Art. 177 bis 190 des Entwurfs in der revidierten Fassung von 1936, Ergänzungsband zur Verwaltungsrechtsordnung für Württemberg (1936).

49) Ergänzungsband 1936 S.96; ähnlich schon der Hauptband (1931) S. 535.

60) Das zeigt sich besonders deutlich an den oben Anm. 39 aufgeführten Veröffentlichungen von $S$ i e vers, $K \ddot{u} l z$ und $K \ddot{u} b-$ le $\mathrm{r}$, ferner bei Diether $\mathrm{H}$ a a s, DVBl. 1962, $657 \mathrm{f}$. 
deren Unstimmigkeiten jedenfalls dazu führen würde, die Einbeziehung des Verwaltungsvermögens in die öffentlichen Sachen $\mathrm{zu}$ vereiteln ${ }^{51}$ ).

Die in Gesetzgebung, Rechtsprechung und Schrifttum herrschende Grundkonstruktion der öffentlichen Sache halte ich für richtig und keiner wesentlichen Korrektur für bedürftig52). Sie geht davon aus, daß die öffentlichen Sachen, soweit sie überhaupt eigentumsfähig sind, in dem einen und einheitlichen Eigentum stehen, das für das deutsche Rechtssystem im Bürgerlichen Gesetzbuch ausgeformt ist. Diese Sachen erhalten aber durch die Widmung ${ }^{53}$ ) für einen in ihnen verkörperten öffentlichen Zweck einen besonderen öffentlich-rechtlichen Status ${ }^{54}$ ) mit einem positiven und negativen Effekt. Der positive Effekt beruht darin, daß eine besondere öffentlichrechtliche Sachherrschaft über die öffentliche Sache begründet wird, die öffentlich-rechtliche Dispositionsmacht über sie und Verantwortung für sie zugleich $u \mathrm{mfa}^{\mathrm{B}} \mathrm{t}^{55}$ ); der negative äußert sich so, daß diese öffentliche Sachherrschaft die Nutzungs- und Verfügungsmöglichkeiten des Eigentümers, auch die ihm etwa

51) Die Bedeutung der Lehre von der öffentlichen Sache für das Verwaltungsvermögen wird weithin unterschätzt. Wie wesentlich sie beispielsweise für das Verwaltungsvermögen der Eisenbahnen und dort insonderheit für die Schienenwege ist - hier auch im Zusammenhang mit dem Institut der Planfeststellung -, haben in den letzten Jahren berufene Juristen der Deutschen Bundesbahn überzeugend herausgearbeitet. Es sei vor allem verwiesen auf: Martin $\mathrm{Koch}$, Uber Grundlagen und Bedeutung des öffentlichen Eisenbahn-Sachenrechts, Folge 3 der Schriftenreihe „Die Bundesbahn" (1953); D e r s e l b e in dem von Werner Haustein herausgegebenen Sammelwerk „Die Eisenbahnen im deutschen öffentlichen Recht" (1960) S. 134 ff., 145 ff., 156 ff.; Karl W i n k l e r, Bedeutung des Privateigentums bei öffentlichen Sachen, insbesondere beim Zusammentreffen öffentlicher Verkehrswege, in: Beiträge zum Eisenbahnrecht, herausg. von Werner Haustein (1955) S. 39 ff.

52) Dies richtet sich besonders gegen Vorstöße wie den von Heinrich $\mathrm{Cl}$ a s e $\mathrm{n}$, Das mit Zivil- und Verwaltungsrecht gemischte Rechtsverhältnis, DOV 1959, 281 ff., aber auch etwa gegen die Tendenzen von Diether $\mathrm{H}$ a a S, DVBl. 1962, $653 \mathrm{ff}$. und gegen das "öffentliche Eigentum“ im Wegerecht Hamburgs und im Wasserrecht Baden-Württembergs.

53) Nähere Erörterungen über die Widmung können in diesem Zusammenhang unterbleiben. Die hier sich anbietenden Probleme sind bei Hermann Schellenberg, Die Widmung (1955) angerührt.

54) In gleichem Sinne spricht Arnold $K$ öttgen, Offentliches Sachenrecht, in Deutsches Verwaltungsrecht, herausg. von Hans Frank (1937) S. 437 von der Eigenschaft der öffentlichen Sache als „Stand“.

55) Auf diese Doppelseitigkeit der öffentlich-rechtlichen Sachherrschaft hat schon Arnold $K o ̈ t t g$ e $n$ aaO. S. 436 f., 442 f., 445 hingewiesen. 
durch Zwangsvollstreckung, Enteignungs- und polizeiliche Eingriffe abringbaren, verdrängt. Der Umfang der öffentlichen Sachherrschaft und dementsprechend das MaB der Verdrängung der privatrechtlichen Eigentümerbefugnisse wird durch den Widmungszweck bestimmt. Für Umfang und Dichte des öffentlichen Status auf der einen und die entsprechende Einengung der privatrechtlichen Eigentümerposition auf der anderen Seite gibt es bei den verschiedenen öffentlichen Sachen eine erhebliche Variationsbreite. Vom Eigentümer der Sache aus gesehen, sofern dieser nicht etwa mit dem öffentlichen Herrn der öffentlichen Sache identisch ist, kann sich die Widmung zur öffentlichen Sache sowohl als Eigentumsbindung darstellen, wie beim Gemeingebrauch an Gewässern, als auch - und das ist meist der Fall - als Eigentumsbeschränkung, deren Auferlegung gegen den Willen des Eigentümers eine Enteignung bedeutet.

In dem so beschriebenen Kern deckt der Begriff der öffentlichen Sache Verwaltungsvermögen und Sachen im Gemeingebrauch gleichermaßen. Gewiß ist diese Begriffsbestimmung abstrakt; aber gerade deshalb ist sie handlich und präzis zugleich. Mit ihr kann allen Anforderungen, denen das Regime der öffentlichen Sachen genügen muß, entsprochen werden. Es läßt sich gegen sie nicht etwa einwenden, daß bei ihr die öffentliche Sachherrschaft gegenüber der zivilistischen Betrachtungsweise zu kurz komme. Denn dieses Zu-kurz-Kommen liegt nicht im dargelegten Begriff der öffentlichen Sache; es könnte sich nur bei einer Fehlanwendung einstellen, so darin, daß der Bundesgerichtshof auch bei der Einräumung eines einfachen Oberflächensondergebrauchs an öffentlichen Wegen noch den Privateigentümer beteiligt sein ließ und da $\beta$ er das Verbot zum Betreten eines Rathauses primär auf die zivilrechtlichen Eigentümerbefugnisse stützen zu sollen glaubte. $\mathrm{Da} \beta$ solche Fehlanwendungen unschwer zurechtgerückt werden können, zeigt die geschilderte Entwicklung der neuen Straßengesetzgebung in der Behandlung des Sondergebrauchs.

Die hier verteidigte herrschende Lehre von der öffentlichen Sache verdient auch Anerkennung wegen ihres hohen Grades an Rechtsstaatlichkeit. Es wäre der Rechtssicherheit und dem fundamentalen Charakter der Eigentumsordnung nicht bekömmlich, wollte man diese nach unserer Rechtstradition ihrer Grundregelung nach zwar im Privatrecht beheimatete, aber doch für unsere ganze Lebenswelt verbindliche Eigentumsordnung ${ }^{58}$ ) relativieren, sei es indem man sie als "bloß zivilistisch"

56) Gegen eine „Zerreißung“ des einheitlichen, ganzheitlichen Eigentumsbegriffs in ein "öffentliches“ und ein „privates“ Eigen- 
abstempelt und sie gegenüber der Ausstrahlungsgewalt der öffentlichen Verwaltung prinzipiell abwertet, sei es indem man neben ihr in unklarem gegenseitigem Verhältnis eine konkurrierende Ordnung „öffentlichen Eigentums" errichtet. Uberdies gebietet die rechtsstaatliche Rücksichtnahme auf die in concreto betroffenen Eigentümer, bei öffentlichen Sachen nicht um irgendeines mißverstandenen Prinzips willen die totale öffentliche Sachherrschaft unter gänzlicher Verdrängung des Eigentümers zu fordern, wo eine beschränkte öffentliche Sachherrschaft unter Belassung der überschießenden Rechte des Eigentümers für die Erfüllung der öffentlichen Zwecke vollauf genügt.

Hinzu treten eine Reihe praktischer Erwägungen. Es kommt häufiger vor, als man gemeinhin denkt, daß öffentliche Sachherrschaft und Eigentum an einer öffentlichen Sache sich nicht. decken und beide sich sinnvoll und notwendig ergänzen. Ebenso ereignet es sich nicht selten, daß eine Sache privaten Eigentums öffentliche Sache wird und später durch Entwidmung wieder in unbeschränktes privates Eigentum zurückfällt. Dafür einige Beispiele: Verwaltungsdienststellen und Anstalten befinden sich oft auf gemieteten Grundstücken. Die Befugnis zur Widmung als öffentliche Sache verschafft sich die Verwaltung gegenüber dem Eigentümer vielfach nicht durch Eigentumserwerb, sondern durch einfachen Gestattungsvertrag oder Begründung von Dienstbarkeiten auf fremdem Grunde. Schiffe, Fahrzeuge und Geräte, die etwa auf Grund des Bundesleistungsgesetzes „zum Gebrauch“ in Anspruch genommen und dem Verwaltungsvermögen oder Militärgerät einverleibt sind, verbleiben im Eigentum des bisherigen Eigentümers. Offentliche Sammlungen und Bibliotheken bestehen häufig aus sogen. "Leihgaben" anderer Eigentümer als des Bibliotheksträgers. Die Deutsche Forschungsgemeinschaft e. V. stellt Bibliotheksbestände, Forschungseinrichtungen und ganze Institute als öffentliche Sache anderen Sachherren, etwa den Universitäten, zur Verfügung, ohne mit gutem Grund ihre Eigentümerstellung aufzugeben. Uberaus zahlreich sind die Fälle, in denen Kirchen und sakrale Gegenstände bestimmten Privatleuten oder juristischen Personen alten und neuen Rechts, auch dem Staat und politischen Gemeinden gehören und den öffentlichen $Z$ wecken anderer kirchlicher Destinatäre, etwa dem Gemeindekirchendienst einer Orts- oder Anstaltskirchengemeinde gewidmet sind. Das fortbestehende Privat-

tum auch Klaus Stern, Zur Problematik des energiewirtschaftlichen Konzessionsvertrags, AöR 84 (1959) 137 ff., 273 ff. (163 f.). 
eigentum ist in allen diesen Beispielen nicht ein überflüssiges Relikt, das man besser abstieße, sondern ist neben der Widmung zur öffentlichen Sache ein wesentliches Element der konkreten Ordnungszusammenhänge. Grundstücke des Verwaltungsvermögens können ferner mit Dienstbarkeiten und sogar mit Grundpfandrechten ${ }^{57}$ ) belastet sein und müssen sich insofern der Behandlung nach Zivilrechtsgrundsätzen anbequemen. Selbst öffentliche Wege sind oftmals legitim in privater Hand und entstehen auch ständig neu, etwa dort, wo bei großen Straßenbauten und sonstigen Anlagen Wegeprovisorien auf privatem Gelände geschaffen werden ${ }^{58}$ ). Und sogar bei den Gewässern, nämlich der großen Zahl von Bächen, Teichen und kleineren Wasserläufen, ist es gar nicht anders einzurichten, als da $\beta$ der dort vorgesehene Gemeingebrauch mit Privateigentum zusammentrifft und da $B$ der Eigentümer schon wegen der Uferbenutzung oder der Entnahme fester Gegenstände aus dem Gewässer sein Recht heischt, so sehr auch das neue Wasserrecht im übrigen die Rolle des Eigentümers ignoriert. Es ist in dieser Hinsicht bezeichnend, daß das Hamburgische Wegegesetz und das Wassergesetz von Baden-Württemberg nur ganz vereinzelte Kategorien von Straßen und Wasserläufen herausgreifen und ihnen nur unter weiteren einengenden Voraussetzungen das Etikett „öffentlichen Eigentums“ anhängen konnten.

Die hier erwähnten Beispiele eines Zusammentreffens von öffentlicher Sachherrschaft und privater Eigentümerposition, möglicherweise einer anderen als der des Herrn der öffentlichen Sache, werden von der vorgetragenen herrschenden Lehre der öffentlichen Sache glatt und elegant bewältigt. Sie ermöglicht es nicht zuletzt, die permanent geschehenden Wiedereingliederungen entwidmeter Sachen des Verwaltungsvermögens in den uneingeschränkten privatrechtlichen Rechtsverkehr ebenso wie den umgekehrten Vorgang juristisch widerspruchslos und automatisch $\mathrm{zu}$ vollziehen ${ }^{59}$ ).

\section{VI.}

An dieser Stelle kann die schon eingangs thesenhaft berührte Frage wieder aufgegriffen werden, welche Gegenstände

57) Darauf weist vor allem Diether $\mathrm{H}$ a a s, DVBl. 1962, $655 \mathrm{hin}$.

58) Weitere aufschlußreiche Beispiele bei Karl W inkler, Bedeutung des Privateigentums bei öffentlichen Sachen, insbesondere beim Zusammentreffen öffentlicher Verkehrswege, in: Beiträge zum Eisenbahnrecht, herausg. von Werner Haustein (1955) S. 39 ff.

59) Dies ist besonders auch von $K \ddot{~} t \mathrm{tg}$ e $n$, Offentliches Sachenrecht S. 447 hervorgehoben worden. 
denn überhaupt öffentliche Sachen sein können. Sie war veranlaßt durch die gelegentlich anzutreffende Behauptung, daß auch die Elektrizität und der Luftverkehrsraum öffentliche Sachen seien. Nach den Erörterungen über den in der herrschenden Lehre ausgeformten Begriff der öffentlichen Sache läßt sich jetzt mit aller Präzision feststellen, daß öffentliche Sachen nur körperliche Gegenstände sind, die Objekt privaten Sacheigentums sein können, konkret: die öffentlichen Wege, die Binnengewässer, soweit ihr Charakter durch den Gemeingebrauch geprägt wird, und der Meeresstrand, also die Sachen im Gemeingebrauch, und die körperlichen Gegenstände des Verwaltungsvermögens einschließlich der res sacrae. Wenn es nämlich den Begriff der öffentlichen Sache ausmacht, daß in ihr privateigentumsfähige Sachen in einen das private Sacheigentum beschränkenden öffentlichen Status erhoben sind, so scheiden andere als körperliche Gegenstände schon begrifflich von der Deklarierung und Behandlung als öffentliche Sachen aus. Das bedeutet nicht, da $\beta$ der Begriff der öffentlichen Sache mit dem der Sache im Sinne des bürgerlichen Rechts identisch ist. Mit Recht ist im Schrifttum bemerkt worden, daß eine einheitliche öffentliche Sache nach bürgerlichem Recht sich in mehrere oder viele Sachen auflösen könne, wie etwa eine Bibliothek oder ein Weg, der über die Grundstücke mehrerer Eigentümer führt; auch sind die Grundsätze des bürgerlichen Rechts über wesentliche Bestandteile und Zubehörungen nicht auf öffentliche Sachen übertragbar $\left.{ }^{00}\right)$. Das ist aber auch nicht entscheidend und ändert jedenfalls nichts daran, daß der Begriff der öffentlichen Sache nur auf körperliche Gegenstände bezogen werden kann.

Negativ bedeutet das, daß die Elektrizität, deren Kraft uns dient, die Luft, die wir atmen oder mit der wir unser Feuer nähren oder unsere Autoreifen füllen, und der hohe Luftraum oder gar der Weltraum, durch die unsere Flugzeuge und Raumschiffe ziehen, mit dem Institut der öffentlichen Sache keinen Zusammenhang haben. Natürlich ist damit nicht geleugnet, daß sich hier höchst wesentliche Gestaltungsfragen des öffentlichen Rechts anbieten, für die als Stichworte nur Energiewirtschaft, Luftreinheit und Luftverkehrsregelung genannt $\mathrm{zu}$ werden brauchen. Aber die öffentliche Sache ist kein Zauberwort, in dessen Spiegel man alle möglichen Fragen der öffentlichen Lebensordnung einfangen kann. Sie hat nur das beschriebene begrenzte Aktionsfeld.

co) For s th off, Lehrb. S. 328; Hans J. W olff, Verwaltungsrecht I S. 307; $\mathrm{Z}$ i p peli us, DOV 1958, 840 . 
VII.

Auch hier gibt es allerdings genug der offenen Fragen, wie abschließend an einem Úberblick über die gegenwärtige Gemeingebrauchsproblematik deutlich $\mathrm{zu}$ machen ist.

1. Ein wirkliches Problem stellt nur der Gemeingebrauch an öffentlichen Wegen dar. Hier hat die mit dem Bundesfernstraßengesetz eingeleitete neue Straßengesetzgebung zunächst insofern eine neue Ära heraufgeführt, als sie sich um eine zeitgerechte Umschreibung des Gemeingebrauchs, auch in der Abgrenzung zum Sondergebrauch und den Sondernutzungsrechten bemüht. Die Bedeutung dieses Vorgangs ist nicht gering. Denn während bislang Inhalt und Grenzen des unentgeltlichen Gemeingebrauchs und gleichzeitig die Tatbestände von Sondergebrauch und Sondernutzungen im wesentlichen in einer diffusen gerichtlichen Präjudizienpraxis ihre Konturen gewannen, tritt an deren Stelle künftig primär die positivrechtliche Norm, und zwar offensichtlich mit dem Anspruch, einige Züge des durch Richterrecht ausgebildeten Gemeingebrauchsregimes kräftig zu verändern.

In diesem Zusammenhang ist von vielen Seiten, vor allem auch von Interessenten, die Besorgnis geäußert worden, die Konzentration der neuen gesetzlichen Gemeingebrauchsdefinitionen auf den fließenden und nächst ihm auf den ruhenden Verkehr ( $\$ 7$ Abs. 1 BFStrG) werde eine Vielzahl von bisher erlaubnis- und entgeltfreien Tatbeständen des Anliegergebrauchs und eines mißverständlich so genannten "gesteigerten Gemeingebrauchs", die aus dem Leben unserer Städte und Dörfer, auch dem Erwerbsleben nicht weggedacht werden könnten, auf die Seite des erlaubnis- und gebührenpflichtigen Sondergebrauchs hinüberdrängen ${ }^{61}$ ). Indessen ist zu bedenken, da $B$ das Bundesfernstraßengesetz und die Landesstraßengesetze ihre Gemeingebrauchsdefinition auf die überland führenden Straßen abstellen mußten, deren Verkehrsfunktion in der Tat nur dann aufrechtzuerhalten ist, wenn sich auf ihnen nicht unkontrolliert noch alle möglichen sonstigen Formen eines angeblichen Gemeingebrauchs ausbreiten. In mancher Hinsicht anders ist allerdings die Lage auf den Straßen der Städte und Dörfer mit den dörflichen Bänken vor der Haustür, den Abstellplätzen für landwirtschaftliches Gerät, den Ein- und Zufahrten, fliegenden Händlern, Balkonen, Aus-

61) Friedrich Sch ack, DVBl. 1961, 899 f.; Kurt Koda l, Der „gesteigerte Gemeingebrauch" in den neuen Straßengesetzen, DÖV 1960, $444 \mathrm{ff}$., der eingehend über die vielfach stark interessenbedingten Einwendungen berichtet und sich mit ihnen auseinandersetzt. 
lagen, Vordächern, Werbeschildern, Dauerparkern usf. Indessen treffen die Landesstraßengesetze hierfür insofern Vorsorge, als sie generell den Gemeinden die abweichende Regelung des Sondergebrauchs an den Ortsstraßen, also auch die Freistellung hierfür geeigneter Sondergebrauchsformen von der Erlaubnis- und Gebührenpflicht, überlassen, während das Hamburgische Wegegesetz ( $\$ 19$ Abs. 7) eine entsprechende Rechtsetzungsdelegation an den Senat erteilt und außerdem (§17) ebenso wie das Berliner Straßengesetz ( $\$ 10$ Abs. 2) einen Vorbehalt zugunsten des Anliegergebrauchs macht. Im übrigen aber ist die Disziplinierung des Gemeingebrauchs zur Sicherung der Verkehrsfunktion der Straßen auch in den Städten und Ortschaften - vor allem gegenüber der Ausuferung der gewerblichen Betätigung im Straßenbetrieb - wirklich und mit gutem Grunde gewollt.

2. Wie schon dargelegt wurde, ist der Sondergebrauch an öffentlichen Wegen seit dem Bundesfernstraßengesetz ganz in das öffentlich-rechtliche Regime der öffentlichen Sache Weg hineingezogen. Dieser Vorgang liegt beispielgebend auf der Linie einer Festigung des öffentlichen Status der öffentlichen Sache; er wurde gebilligt, weil damit der öffentliche Status der öffentlichen Wege richtiger gegenüber der verbleibenden privatrechtlichen Benutzung des Wegegrundes abgegrenzt ist als bisher. Die durch Gebrauchserlaubnis erschlossenen Beispiele eines Sondergebrauchs gehören auch faktisch zur öffentlichen Funktion des Weges, und schon deshalb ist es notwendig, den Öffentlichkeitsstatus des Weges auf ihn zu erstrecken, und zwar ganz. Die Formulierungen, die die Straßengesetze verwenden, um den Bereich des öffentlich-rechtlichen Sondergebrauchs von dem der privatrechtlich zu begründenden Benutzungsrechte abzugrenzen, sind freilich noch unsicher. Am wortreichsten drückt sich in dieser Hinsicht das Straßengesetz von Schleswig-Holstein aus, das (§28) für die Einräumung von Rechten an öffentlichen Straßen dann das bürgerliche Recht für maßgebend erklärt, wenn der Gemeingebrauch nicht beeinträchtigt wird oder die Nutzung der öffentlichen Versorgung dient oder weder das Land noch eine Gebietskörperschaft Träger der Straßenbaulast des genutzten Straßenteiles ist. Ich selbst habe das maßgebende Abgrenzungskriterium in meinen bisherigen Ausführungen schon insofern im Vorbeigehen angedeutet, als ich die "Oberflächensondernutzungen" den Benutzungen "in der Tiefe des Straßenkörpers" gegenübergestellt habe. Die einen gehören wegen ihres regelmäßig gegebenen Zusammenhangs mit der öffentlichen Funktion der Straße zum öffentlich-rechtlichen Stra- 
Benregime, die anderen unterliegen, weil sie die öffentliche Funktion der Straße nicht oder bei der Verlegung der Rohre, Kabel usw. höchstens vorübergehend berühren, in die privatrechtliche Gestaltungssphäre. Freilich ist die Gegenüberstellung etwas grob, weil es gewisse Oberflächennutzungen, nämlich an Obstbäumen und Grasrändern gibt, die ebenfalls in privatrechtlichen Formen vergeben werden. Doch ist das Wesentliche mit ihr bezeichnet. Es wäre nützlich, wenn man die beiden Benutzungsfälle auch terminologisch klar gegeneinander abheben könnte. Das bayerische Straßengesetz spricht in beiden Fällen von "Sondernutzungen" und gliedert sie in solche "nach öffentlichem Recht" und "nach bürgerlichem Recht". Andere der neuen Gesetze beschränken den Terminus "Sondernutzungen" auf die öffentlich-rechtliche Benutzungsform und stellen ihnen die privatrechtlich konstruierten Benutzungen, besonders in der Tiefe des Straßenkörpers etwa als „sonstige Benutzungen" gegenüber. Befriedigend ist das alles nicht. Mir schiene es wünschenswert, wenn etwa eine Verständigung dahin erzielt werden könnte, die eng dem Gemeingebrauch verschwisterte öffentlich-rechtliche Oberflächensondernutzung als "Sondergebrauch" zu benennen, wodurch für die privatrechtliche Benutzungsform der Terminus "Sondernutzungen" frei würde. Indessen sind das Fragen nebengeordneten Ranges.

3. Wichtiger ist, in der öffentlich-rechtlichen Qualifizierung des Sondergebrauchs nicht nur eine fällige Korrektur im Status der öffentlichen Sache Straße, sondern darin zugleich, wie übrigens auch im Reden davon, man könne den Gemeingebrauch entgeltpflichtig machen, und etwa in der Parkuhrenregelung des $\S 16$ Abs. 3 StVO Symptome dafür zu erkennen, daß der Gemeingebrauch an Straßen und auch an schiffbaren Gewässern in deutlicher Umbildung zur Anstaltsbenutzung hin begriffen ist. Denn der Gemeingebrauch ist eine archaische Form der Benutzung öffentlicher Sachen, die nicht viel mehr als die reine Existenz der Sache, die bloße Benutzung ihrer Körperlichkeit und bescheidene Regelungen zur Aufrechterhaltung der Gemeinverträglichkeit der Benutzung voraussetzt und verträgt $\left.{ }^{62}\right)$. Diese schlichte Einfachheit der Gemeinge-

62) Weil der Gemeingebrauch über die Benutzung der unmittelbaren Körperlichkeit einer Sache (Weg, Meeresstrand, Gewässer) nicht hinausgehen kann, ist es übrigens unvollziehbar, den Besuch einer Kirche als Gemeingebrauch aufzufassen. Der Besucher einer Kirche nimmt entweder an einem Gottesdienst teil, oder er begibt sich sonst zur Andacht in das Gotteshaus, oder er sucht die Kirche als Zeugnis der Geschichte und der Kunst auf. Trotz Unentgeltlichkeit und - jedenfalls im allgemeinen - fehlender Individualzulassung weist jede dieser „Benutzungsarten“ über die bloße 
brauchsbedingungen ist zunehmend im Schwinden, und deshalb lösen sich die Konturen des Instituts im ganzen auf.

Eine moderne Autobahn ist mit ihren Zubehörungen, den Parkplätzen, Wasserstellen, Tafelhinweisen und Telefonanschlüssen, den Raststätten, Verlade- und Umschlaganlagen, Tankstellen, Werkstätten, dem Straßendienst und der Straßenwacht ein höchst artifizielles Gebilde, zu dessen Funktionsfähigkeit ein ständiger beträchtlicher Einsatz von persönlichen und sächlichen Mitteln nötig ist. Das bedeutet, daß das Autobahnnetz, worauf $\mathrm{K}$ ö $\mathrm{t} t \mathrm{~g}$ e $\mathrm{n}$ schon 1937 hingewiesen hat ${ }^{63}$ ), eine öffentliche Anstalt ist, wobei es keinen wesentlichen Unterschied macht, ob man das Benutzungsentgelt wie bei den italienischen Autostradas durch Lösen einer Benutzungskarte an der Zufahrt oder durch zweckgerichtete Steuern entrichtet. Im übrigen schließt weder das Fehlen der Entgeltlichkeit noch das einer individuellen Zulassung im Einzelfalle den Anstaltscharakter aus; denn es gibt zahlreiche Anstalten, die der Benutzer einfach von sich aus aufsuchen kann, und ebenso solche, für deren Benutzung ein Entgelt nicht entrichtet zu werden braucht. Unentgeltlichkeit. der Benutzung und Fehlen einer jeweils besonderen Benutzungszulassung sind also nicht untrügliche Kennzeichen für das Vorliegen von Gemeingebrauch, sie können in gleicher Weise bei der Anstaltsbenutzung und bei anderen Lebensvorgängen vorkommen, die weder Gemeingebrauch noch Anstaltsbenutzung sind.

Bei den innerstädtischen Straßen und Plätzen ist die Lage nicht viel anders als bei den Autobahnen oder den sich ihnen im modernen Ausbau angleichenden Bundesstraßen $\left.{ }^{64}\right)$. Für den Fußgängerverkehr reicht hier zwar noch der Gemeingebrauch aus, obwohl auch die Bedienung des Fußgängers mit Automaten, Werbeeinrichtungen und Verkaufskiosken im Straßenraum und mit Droschkenhaltestellen und besonderen Anlagen für die städtischen Massenverkehrseinrichtungen, also mit auf Sondergebrauch beruhenden Veranstaltungen, und die Schleusung des Fußgängerverkehrs über besondere Passagen die

Körperlichkeit der Inanspruchnahme in andere Ordnungen hinaus. Ahnlich Forsth off, Res sacrae, AöR NF 31 (1940) S. 209 ff., 220 f.

6s) Arnold Köttgen, Offentliches Sachenrecht S. 442. Auf den fließenden thergang vom Gemeingebrauch zur Anstaltsbenutzung hat $\mathrm{K} \ddot{\mathrm{ot}} \mathrm{tg}$ en erneut in seiner Schrift "Gemeindliche Daseinsvorsorge und gewerbliche Unternehmerinitiative“ (1961) S. $33 \mathrm{f}$. aufmerksam gemacht.

-4) Bezeichnenderweise liefern auch die Landesstraßengesetze (vgl. etwa Hessen § 2, Niedersachsen § 2) für die Straßen mit Zubehör und Nebenanlagen eine Beschreibung, die mehr die Züge einer Anstalt als die einer Gemeingebrauchssache zeigt. 
Funktion der innerstädtischen Straßen differenzierter werden läßt. Für den Kraftfahrer indessen ist das innerstädtische Straßensystem mit seinen Park- und Halteverboten, seinen durch Strich- und Feldmarkierungen abgegrenzten Benutzungsflächen, seinen gebühren- oder nichtgebührenpflichtigen, bewachten oder unbewachten Parkplätzen und seinem signalgesteuerten Verkehrsfluß eine differenziert eingerichtete Verkehrsanstalt geworden, die er nach den Regeln einer sehr komplizierten Anstaltsordnung benutzt. Daß weiter die Benutzung der Schiffahrtskanäle mit ihren Schleppdiensten und Schleusen Anstaltsbenutzung und nicht Gemeingebrauch ist, kann schon als gesicherte Auffassung gelten ${ }^{65}$ ). Aber auch wer die Verhältnisse auf einer "natürlichen" Schiffahrtsstraße wie dem Rhein betrachtet, wird dort wenig mehr von den bekannten Äußerungsformen des Gemeingebrauchs an Gewässern vorfinden als mit Verkehrszeichen, Tank- und Versorgungsfahrzeugen, Lotsenstationen, Häfen, Ankerplätzen und Fahrrinnenregulierungen die Merkmale einer staatlich vorgehaltenen Verkehrsanstalt verwirklicht sehen, die nahezu nur noch von Verkehrsunternehmern, ebenfalls im Rahmen einer sehr genau festgelegten Ordnung benutzt wird. Weiter bieten das Hamburgische Gesetz über Grün- und Erholungsanlagen vom 18. Oktober 1957 (GVBl. S. 466) und das Berliner Gesetz zum Schutze der öffentlichen Grün- und Erholungsanlagen vom 3. November 1962 (GVBl. S. 1226) schöne Beispiele dafür, wie auch die öffentlichen Grün- und Erholungsanlagen einer groBen Stadt mit ihren Gehwegen, Plätzen, Gehölzen, Spiel- und Sportplätzen, Zelt- und Lagerplätzen nur nach Art einer Anstalt funktionsgerecht verwaltet werden können. Ebenso zeigt die Bremer Verordnung zur Regelung des Gemeingebrauchs am Werdersee vom 13. August 1962 (GBl. S. 190) deutlich das Umschlagen des Gemeingebrauchs in Anstaltsbenutzung.

Das bedeutet in der juristischen Konsequenz, daß man die Benutzung von Schiffahrtskanälen und Autobahnen überhaupt nicht mehr in die unpassend gewordenen Gemeingebrauchsvorstellungen hineinpressen, sondern sie nach Anstaltsrecht behandeln sollte. Bei den innerstädtischen Straßensystemen, den schiffbaren Strömen und bei in größerem Stile gehaltenen Grün- und Erholungsanlagen der Städte ergeben sich Gemengelagen. Ein Teil der Benutzung dieser öffentlichen Sachen, vornehmlich der Fußgängerverkehr und auf schiffbaren Flüssen der gelegentliche Bootsverkehr, wird sich auch weiter als Gemeingebrauch abwickeln lassen. Aber etwa die innerstädtische Straße als Trägerin für den Kraftfahrzeugverkehr

65) Zum Nord-Ostsee-Kanal besonders eindrücklich BGHZ 35, 111. 
juristisch noch als Gemeingebrauchssache zu manipulieren, wird immer mehr irreal. Schon die verwirrende Vielfalt von Kraftfahrzeugbahnen, Fußgänger- und Radfahrwegen, Einbahnstraßen, Straßen mit Verboten für bestimmte Fahrzeugtypen und für den Kraftfahrzeugverkehr überhaupt, mit Parkund Halteverboten noch als Differenzierungen der Widmung einer Gemeingebrauchssache $\mathrm{zu}$ verstehen, erscheint als gequält, und man verwendet für diese spezialisierenden, vielfach wechselnden „Widmungen" bezeichnenderweise auch gar nicht mehr die Widmungsform. Aber auch die besonderen Verkehrseinrichtungen wie die zur gebührenpflichtigen oder freien Benutzung ausgewiesenen Parkräume auf Straßen und Plätzen mit ihren oft im Laufe des Tages wechselnden Benutzungsmöglichkeiten, die Droschkenhaltestände, Haltebuchten, Omnibusbahnhöfe u. ä.m. noch als Sondergebrauch an einer Gemeingebrauchssache zu praktizieren, ist der Sachlage nicht adäquat, zumal auch die Rechtsprechung es bisher offengelassen hat, wer denn eigentlich in diesen Fällen den Sondergebrauch hat, der Kraftfahrzeughalter oder Omnibusunternehmer selbst oder derjenige, der den Stand- oder Halteplatz vergibt ${ }^{66}$ ).

Wiederholt darf daran erinnert werden, daß die Verwendung einer Sache im Gemeingebrauch einfache Verhältnisse voraussetzt, und zwar Einfachheit in der körperlichen Beschaffenheit der öffentlichen Sache selbst und Einfachheit im Gebrauch ihrer unmittelbaren Körperlichkeit, verbunden mit einer erheblichen Variationsbreite der Zweckbeliebigkeit. Gerade deshalb, nur deshalb ${ }^{67}$ ), verträgt auch echter Gemeingebrauch nicht die individuelle Abgabepflichtigkeit der Benutzung. Wird die öffentliche Sache wie in den beschriebenen Fällen zu einem kunstvoll ausgestalteten Apparat der Verkehrsbedienung mit normativ differenzierenden Benutzungsmöglichkeiten und nimmt demgemäß auch die Normalbenutzung, von dorther bestimmt, vielfach gestufte und demgemäß gelenkte Formen an, dann versagt das Regime des Gemeingebrauchs in der gedanklichen Konstruktion wie in der praktischen Handhabung. Das Verwaltungsrecht fängt dann das Ganze als Anstalt und den bisherigen Gemeingebrauch - ohne Substanz-

\footnotetext{
66) Vgl. BGHZ 21, 319 = VwRspr. 9, 24; BGH VwRspr. 13, 413; BVerwGE 4, 342.

67) Dies zu der Auseinandersetzung zwischen Herbert Krüger und E. R. Huber: Krüger, Gegen eine Entstaatlichung der öffentlichen Wege (1954); H u ber, Wegekosten und Kraftverkehr (1954); D e r s e l b e, DƠv 1955, 129 ff.; später nochmals K r ü g e r, Grundfragen einer rechtsstaatlichen Wassergesetzgebung (1957) S. 138 ff.; ferner zu BVerwGE 5, 342 (345 f.), BGHZ 19, 85 (90) und Forsth of $f$, Lehrb. S. 339. Vgl. weiter Ulrich $S \mathrm{cheuner}$ Festschr. f. Gieseke S. 79 f. (Anm. 13).
} 
veränderung im übrigen - als anstaltliche Benutzung einer öffentlichen Sache auf. Bei den Autobahnen und Schiffahrtskanälen ist die Grenze zur Anstalt klar überschritten. Bei innerstädtischen Straßen treffen Gemeingebrauch der Fußgänger und - in verschiedener Hinsicht differenzierte - anstaltliche Benutzung weiterhin zusammen; ähnlich ist es bei den Bundeswasserstraßen, die nicht Kanäle $\left.\operatorname{sind}^{68}\right)$. Bei anderen Wegen und beim Meeresstrand wird der Gemeingebrauch die bestimmende Benutzungsform bleiben, während er bei den nichtschiffbaren Gewässern ohnehin nur einen begrenzten Aktionsradius hat. Einer „Entstaatlichung der öffentlichen We$\mathrm{ge}^{\prime 69}$ ) und Wasserläufe ist damit keineswegs das Wort geredet. Man könnte an dieser Konstruktion eher bemängeln, daß sie neue rechtliche Komplikationen heraufführe. Dem ist entgegenzuhalten, daß sie vielmehr aus der Sackgasse einer hoffnungslosen Uberforderung des Gemeingebrauchsinstituts mit den Nebeninstitutionen des Sondergebrauchs und der Sondernutzung herausführt, und zwar mit Mitteln, die in der Verwaltungsrechtssystematik der Gegenwart vollkommen gewöhnlich sind.

Aber vielleicht könnte der ernstere Einwand auftauchen, der gedankliche Schritt vom Gemeingebrauch zur anstaltlichen Benutzung öffentlicher Sachen könnte die Freiheit menschlichen Gebarens und den rechtlichen Schutz dieser Freiheit beeinträchtigen, weil nämlich im Gemeingebrauch mehr Freiheit beschlossen liege. Darauf wäre zunächst zu erwidern, $\mathrm{da} B$ in einer sachnäheren und sachgerechteren rechtlichen Konstruktion an sich schon ein höheres $\mathrm{Ma} B$ an Effizienz und Rechtssicherheit verbürgt ist. Sodann aber kann uns die Gewißheit beruhigen, daß die anstaltliche Vorhaltung und Benutzung öffentlicher Sachen den Zugang zum Gebrauch, die Art des Gebrauchs und den Rechtsschutz im Gebrauch in keinem Falle weniger großzügig und weniger freiheitlich gewähren als ein denaturierter Gemeingebrauch. Natürlich muß man sie recht verstehen, nämlich von den Zusammenhängen der rechtsstaatlichen Verfassung her begreifen.

68) E. R. H u b e r, Wegekosten und Kraftverkehr S. 55 deutet an, da $B$ er den hier angenommenen Ubergang vom Gemeingebrauch zur anstaltlichen Benutzung nicht für vollziehbar halte, weil zur öffentlichen Anstalt eine besondere Organisationsform, nämlich die organisatorische Verselbständigung der Verwaltung einer öffentlichen Sache gegenüber der allgemeinen Staats- und Gemeindeverwaltung gehöre, wie sie für Eisenbahnen und Post bezeichnend sei. Doch ist die anstaltliche Benutzungsform keineswegs von so hohen Anforderungen an die anstaltliche Organisationsform abhängig.

09) Wie sie Herbert $\mathrm{Kr} \ddot{\mathrm{u} g e r}$ in seinem so betitelten Rechtsgutachten (1954) als bedenklich gekennzeichnet hat. 


\section{Leitsātze des Berichterstatters über: Die Offentliche Sache}

1. Die öffentliche Sache hat einen festen Platz im Begriffssystem des modernen Verwaltungsrechts. Ihre Problematik muß von dorther beurteilt werden. Der Werdegang der Lehre von den öffentlichen Sachen und die geschichtlichen Erscheinungsformen heute als öffentliche Sache begriffener Gegebenheiten haben demgegenüber nur noch historisches Interesse.

2. Die Lehre von der öffentlichen Sache muß, um theoretisch konsequent und praktikabel zu sein, das Verwaltungsvermögen pari passu mit den Sachen im Gemeingebrauch einbeziehen. Ihr eignet ein hohes Maß abstrakter Begrifflichkeit. Deshalb kann sich die Dynamik der Umbildungsvorgänge in der Verwaltungsordnung der Gegenwart an ihr nur im Reflex zeigen.

3. Die öffentliche Sache ist ein Komplementärbegriff zur Sache im Sinne der allgemeinen (privatrechtlichen) Eigentumsordnung. Von öffentlichen Sachen kann deshalb nur dort die Rede sein, wo körperliche Gegenstände im Sinne der allgemeinen Eigentumsordnung gegeben sind und diese in spezifischer Weise in die Verwaltungsordnung hineingenommen werden.

4. Eine Fortentwicklung des Rechts der öffentlichen Sache zeigt sich vor allem in den neuen Straßen- und Wassergesetzen. Sie halten, von einzelnen Ausnahmen abgesehen, an dem einheitlichen Eigentum fest, das im bürgerlichen Recht ausgeformt ist, und verstehen die Eigenschaft als öffentliche Sache als einen dieses (Privat-)Eigentum überwölbenden öffentlich-rechtlichen Status. Hierbei tendiert das neue Straßenrecht dazu, den öffentlich-rechtlichen Status der öffentlichen Sache konsequenter zu verwirklichen als bisher, während das neue Wasserrecht die öffentliche Verantwortung für den nationalen Wasserhaushalt überhaupt unter eine neue Konzeption stellt und von dorther den Gemeingebrauch an den Gewässern als konstitutives Element für die traditionelle Behandlung der Gewässer als öffentliche Sachen relativiert.

5. Theoretische Überlegungen, praktische Rücksichten und rechtsstaatliche Erwägungen sprechen dafür, an der Grund- 
konstruktion der öffentlichen Sache festzuhalten, zu der sich die Verwaltungsrechtslehre der Gegenwart in Wissenschaft, Gesetzgebung und Rechtsprechung bekannt hat. Nach dieser Grundkonstruktion kennzeichnet der Begriff der öffentlichen Sache den öffentlich-rechtlichen Sonderstatus, den körperliche Gegenstände dadurch empfangen, daß sie als Objekte des Verwaltungsvermögens oder des Gemeingebrauchs unmittelbar Zwecken der hoheitlichen Verwaltungsordnung dienstbar gemacht (gewidmet) werden.

Der öffentlich-rechtliche Sonderstatus der öffentlichen Sache begründet für den zuständigen Verwaltungsträger öffentlich-rechtliche Dispositionsmacht über die öffentliche Sache und öffentlich-rechtliche Verantwortung für sie. Er verdrängt das Eigentum und die allgemeinen Eigentümerbefugnisse nur in den Grenzen des Widmungszwecks.

Soweit bisher eine im Verhältnis zu privatrechtlichen Eigentumsvorstellungen unzulängliche Berücksichtigung des öffentlichen Status der öffentlichen Sache Anlaß zur Kritik bot, ist Abhilfe nicht in einer Änderung der Grundkonzeption der Lehre von der öffentlichen Sache zu suchen; es genügt vielmehr, Fehlanwendungen dieser Lehre zurechtzurücken, wie es durch Hineinnahme des Sondergebrauchs an Wegen in die öffentlich-rechtliche Ordnung der Straßen geschehen ist.

6. Das neue Straßenrecht hat dem Gemeingebrauch, dem Sondergebrauch und den Sondernutzungen an öffentlichen Wegen eine neue, klarere und straffere Ordnung gegeben. Es wird aber in zunehmendem Maße deutlich, daß der Gemeingebrauch eine archaische Form der Benutzung öffentlicher Sachen darstellt, die nicht viel mehr als die reine Existenz der Sache, die bloße Benutzung ihrer Körperlichkeit und bescheidene Regelungen zur Aufrechterhaltung der Gemeinverträglichkeit der Benutzung voraussetzt und verträgt. Beschaffenheit und Benutzung der Autobahnen, des innerstädtischen Systems von Straßen und Plätzen, der Kanäle und Stromschiffahrtswege sprengen diesen Rahmen. Die bisher als Gemeingebrauch verstandene Benutzung dieser Sachen hat sich z.T. schon in klare Anstaltsbenutzung umgebildet, z. T. ist sie auf dem Wege dahin. Dabei ergeben sich auch Gemengelagen von Gemeingebrauch und anstaltlicher Benutzung in bezug auf dieselben öffentlichen Sachen. Die anstaltliche Benutzung fängt die mit dem Gemeingebrauchsregime nicht mehr zu bewältigenden Differenzierungen in der Vorhaltung und Benutzung der erwähnten Straßen und Schiffahrtswege juristisch glatt und ohne Substanzveränderung für den Benutzer auf. 


\title{
Die Offentliche Sache
}

2. Mitbericht von Professor Dr. Klaus S tern, Berlin

\author{
1. Teil
}

Institution und Konstruktion

der öffentlichen Sache

A.

Begriff und Sonderstellung der öffentlichen Sache

I.

Die öffentliche Sache ${ }^{\mathbf{1}}$ ) ist ein von der Wissenschaft ausgebildeter Mantelbegriff für einen vorgefundenen, unterschiedlich weit erstreckten Kreis von Gegenständen, die von altersher eine für das Gemeinwesen und die Gesamtheit der Bürger bedeutsame Funktion besitzen und darum im deutschen Rechtskreis eine von den übrigen Sachen abgehobene Rechtsstellung erhalten. Der Lehre von der öffentlichen Sache scheint es jedoch an Stetigkeit und Festigkeit zu fehlen; wohl deshalb, weil auf die öffentliche Sache zuvörderst vom öffentlichen u n d privaten Recht eingewirkt wird ${ }^{2}$ ), zum anderen dem Begriff öffentlich nicht anders als bei verwandten Erscheinungen, wie öffentliche Anstalt, öffentliches Unternehmen, öffentlicher Dienst und öffentliches Amt, ein Sinnbezug zu politisch-soziologischen Komponenten anhaftet, der rechtsnormativ nicht leicht zu verarbeiten ist, und zum dritten, weil Bestand und Ordnung, Recht und Funktion der öffentlichen Sache von staats- und gesellschaftskonstituierenden Prinzipien abhängig sind. Ubereinstimmung herrscht in einem Punkt: Sachen, die

1) Zur Entstehung des Begriffs Moll, G r u c hot 54 (1910), S. 319; E. L o en ing, Verwaltungsrecht, 1884, S. 569; Gg. M e y er Doch ow, Verwaltungsrecht, 3. Aufl., 1893, S. 237 ff.; Otto Mayer, Verwaltungsrecht, 2. Aufl., 1917, Bd. 2, S. $71 \mathrm{ff}$.

2) Die umfangreiche Literatur ist deshalb im Schrifttum beider Rechtskreise zu finden. Vgl. die Zusammenstellungen in den Lehrbüchern des Verwaltungsrechts, bürgerlichen Sachenrechts und des allg. Teils des BGB. Monographisch zuletzt Hans J. W o If $\mathrm{f}$ in Handwörterbuch der Sozialwissenschaften (HdSw.) 38. Lieferung, Art. Offentl. Sachen, S. 36 ff.; S t r i ck s t r o c k, Betrieb 58, 1119ff.; $S$ c h a ck, Verw.Arch. 54, 43 ff.; Salzwedel, DOV 63, 241; F. S i ede r, in: Staatsbürger und Staatsgewalt, Bd. 2, 1963, S. 91 ff.; F. M a ye r und J e s h, JuS 63, 205 ff. 
öffentlichen Zwecken dienen, können, so lehrt man, "unmöglich nur's) dem privaten Recht unterliegen

II.

Rechtshistorisch basiert diese Betrachtung auf der Einteilung des römischen Rechts nach der Fähigkeit res in commercio oder res extra commercium zu $\operatorname{sein}^{4}$ ). Das deutsche Privatrecht vor dem BGB übernahm diese Grundeinteilung ${ }^{5}$ ), allerdings mit veränderter Bedeutung ${ }^{6}$ ), die durch germanische Rechtselemente verursacht wurde. Als extra-kommerzielle und damit öffentliche Sachen wurden diejenigen angesehen, an denen Privatpersonen "aus Gründen des Staatsrechts"7) kein Eigentum - wohl aber andere Rechte - erwerben können.

III.

Ursache der rechtlichen Sonderstellung ${ }^{8}$ ) der öffentlichen Sachen waren in beiden Rechtskreisen die natürliche Beschaffenheit der Objekte, religiöse, militärische, polizeiliche oder staatswirtschaftliche Motive, Erfordernisse des Gemeinwohls ${ }^{\mathbf{9}}$ ),

3) So En neccerus-Nipperdey, Allg. Teil des bürgerl. Rechts, 15. Aufl., 1959, 1. Hbbd., \& 129 I; ähnlich H. P e te r s, Lehrbuch der Verwaltung, 1949, S. 207: "nicht einfach“.

4) Sohm-M it te is - W e $\mathrm{nger}$, Institutionen, Geschichte und System des röm. Privatrechts, 17. Aufl., 1949, S. 253 f.; K a s e r, Das römische Privatrecht, 1955, S. 322; Vegt ing, Domaine public et res extra commercium, 1950, (dazu S c h a c k, MDR 50, 574).

5) Vgl. W e i s k e, Rechtslexikon, 1855, Art. Sache, Bd. 9, S. 464 ff.

6) DaB das römische Recht noch anders fortgebildet werden konnte, zeigt die französische Theorie des domaine public. 1875 vermochte $Z$ a ch a ri ä, Handb. des franz. Civilrechts, 6. Aufl., Bd. 1, S. 435 Fußnote, allerdings noch zu schreiben, daß die Lehre vom domaine public den Redakteuren des Code Napoleon unklar gewesen sei und auch jetzt noch nicht durch die Doktrin festgestellt sei. Uber die Theorie des italienischen Rechts vgl. Za n ob in i, Corso di diritto amministrativo, 8. Aufl., 1958, Bd. 1, S. 163 ff., Bd. 4, S. 3 ff.

7) M a urenbrecher, Lehrbuch des gesamten heutigen gemeinen deut. Privatrechts, 2. Aufl., 1840, Bd. 1, \$175; ähnlich E i c h h or n, Einleitung in das deut. Privatrecht, 4. Aufl., 1836, S. 673: aus Gründen der "Staatsgewalt"; s. auch O. v. G i e r k e, Genossenschaftsrecht, 1881 , Bd. 3, S. 54 f., für öffentl. Wege s. auch L u t h a r d, Bl.f. administrative Praxis, Bd. 20 (1870), S. 326, Anm. 7; v o n K a h r, Bayer. Gemeindeordnung, 1896, Bd. 1, S. 345, Anm. 12.

8) Egon $\mathrm{K}$ a p p l e r, Die Theorien über die rechtliche Sonderstellung der öffentl. Sache in ihren praktischen Auswirkungen, Diss., Kiel, 1955.

9) So schon Mühlen b u ch, Lehrbuch des Pandektenrechts, 13. Aufl., 1840, $\S 213$; S in te n is, Das praktische gemeine Civilrecht, 2. Aufl., 1860, Bd. 1, \$ 40 ff.; G. H o I s t e i n, Die Lehre von der öffentlichrechtlichen Eigentumsbeschränkung, 1921, S. 20. 
die man heute mit Zueignung an einen öffentlichen Zweck umschreibt, der den einheitlichen Rechtsgedanken widerspiegelt, welcher einer Vielheit von Rechtstatsachen zugrunde liegt.

\section{IV.}

Die historische Betrachtung vermittelt noch eine weitere für die moderne Rechtsdogmatik wertvolle Erkenntnis:

1. Im römischen Recht steht entscheidend das Eigentum ${ }^{10}$ ) im Vordergrund, im altdeutschen Recht hingegen ist die Eigentümerstellung nachrangig ${ }^{11}$ ) gegenüber der Zurechnung der Verfügungsmacht an einen Nicht-Privatmann, an einen Herrschaftsträger. Modern gesprochen: Nicht ein Eigentümer, sondern ein öffentlichrechtlicher Sachherr herrscht über die öffentliche Sache. In die deutschrechtliche Auffassung von der öffentlichen Sache fließt sehr frühzeitig, vielleicht sogar ab origine, ein heute öffentlichrechtlich begriffenes Element ein. Vertraut mit der Gefahr retrospektiver Betrachtungsweise ${ }^{\mathbf{1 2}}$ ), behaupte ich nicht, daß im germanischen Recht öffentliches und privates Recht fein säuberlich getrennt wurden ${ }^{13}$ ), wohl

10) Zum Problem des Eigentums am Kirchengut zuletzt $S$. Gr u n d $\mathrm{m}$ a $\mathbf{n} \mathbf{n}$ in: Staatsverfassung und Kirchenordnung, Festg. für Smend, 1962, S. 324, mit Literaturangaben Anm. 52; aus dem älteren Recht B e k k e r, Pandekten, 1886, Bd. 1, S. 332; R ot h, Bayer. Civilrecht, 2. Aufl., 1881, Bd. 1, S. 331 .

11) Auch dem altdeut. Recht war das Eigentum bekannt, zunächst nur an Fahrnis (vgl. H. B r u n n e r, Grundzüge der deut. Rechtsgeschichte, 7. Aufl., 1927, S. 197; v. G e r b e r, System des deut. Privatrechts, 7. Aufl., 1895, S. 127 ff.; S c h r ö d e r - v o n K ü n B b e r g, Lehrbuch der deut. Rechtsgesichte, 6. Aufl., 1922, S. 224 f.; Max M e r t e n, Gutgläubiger Eigentumserwerb und Zeitablauf in ihrer Bedeutung für das rechtliche Schicksal öffentlicher Sachen, Diss., Berlin, 1935, S. 31 f.).

12) vor der $\mathrm{Ehmke}$ und $\mathrm{S} \mathrm{ch}$ euner jüngst wieder gewarnt haben (Staatsverfassung und Kirchenordnung, aaO., S. 23 ff. und S. 252). - Die deutschrechtliche Entwicklung ist bei der Behandlung der öffentl. Sachen bislang vernachlässigt worden - sehr zu Unrecht, wie ich meine -, obschon $K r$ e it $t m$ a y $r$ in seinen Anmerkungen über den Cod. Max. Bav. civ. II. Teil, 1844, S. 56 sagt: „Der sich [von den öffentlichen Sachen] nette und deutliche Begriffe machen will, der muß das Corp. jur. Rom. nicht zum Lehrbuch gebrauchen; denn es siehet sehr verwirrt, finster und mangelhaft darin aus. Das wenigste davon schickt sich auf unseren heutigen Staat."

13) Dazu etwa Eduard Albrecht, Rezension über Maurenbrechers Grundsätze des heutigen deut. Staatsrechts, Göttingische gelehrte Anzeigen, 1837, S. $1489 \mathrm{ff}$., zitiert nach der Sonderausgabe der wissenschaftl. Buchgesellschaft, 1962, S. 5, 19; K e u t g e n, Der deut. Staat des Mittelalters, 1918, S. 13 ff.; O. v. G i e r k e, ZRG 28, 618; H. M it te i s, Lehnrecht und Staatsgewalt, 1958, S. 6 ff. 
aber wurde erkannt, daß substantielle Unterschiede bestehen zwischen dem Eigentumsrecht eines Privatmannes und der Herrschaftsmacht des Königs oder Kaisers bzw. später der Landes- oder Reichshoheit über Sachen ${ }^{14}$ ). Pointiert ausgedrückt: Befugnisse aus dem Eigentum und aus der Souveränität des Staates wurden getrennt ${ }^{15}$ ). Wurzel dieser Differenzierung sind die jura regalia ${ }^{16}$ ), deren germanischrechtliche Abkunft auch dann deutlich blieb, als der germanische König längst Kaiser des römisch-deutschen Reiches wurde und diese Befugnisse in jura imperialia hätte umwandeln können, entsprechend seiner sonstigen Neigung, sich auf römisches Recht zu stützen. Gegen Ausgang des Mittelalters wurden Regalien und Eigentum des Regalieninhabers klar geschieden und, als um die Wende des 16. zum 17. Jahrhundert Arumäus und Limnäus in Jena ihre ersten öffentlichrechtlichen Systeme schrieben, wurden die Regalien sogar aus dem Privatrecht ausgesondert und als Hoheiten, Gerechtsame, Majestäts- oder Regierungsrechte bezeichnet, die der Herrscher für sich in Anspruch zu nehmen berechtigt war, bisweilen freilich den Legitimitätsgrund im dunkeln lassend ${ }^{17}$ ). Wege- und Wasser-

14) Vgl. bes. Gg. Wa it $\mathrm{z}$, Verfassungsgeschichte, 4. Aufl., Neudruck 1953, Bd. II 2, S. 319; Joh. Jac. M o s e r, Von der Landeshoheit in Ansehung der Untertanen, Personen und Vermögen, 1773, 24 Cap., S. $244 \mathrm{ff}$; ders. Von der Landeshoheit in Ansehung Erde und Wassers, 1773, 3. Cap., S. 8 ff.; S. R i e t s ch e I, Markt und Stadt in ihrem rechtl. Verhältnis, 1897, S. 18.

15) Unrichtig $\mathrm{Z}$ a c h a ri ä, aaO., S. 492.

16) Als Regalien bezeichnete man den Inbegriff der dem König als solchem zukommenden besonderen Rechte und Güter zur Erfüllung seiner Gemeinschaftsaufgaben, zum Teil auch als Anerkennung für seine besonderen Leistungen (vgl. Hans Wolrad W a i t z, Entwicklung des Begriffes der Regalien usw., Diss., Frankfurt, 1939, S. 9). Aus der umfangreichen Literatur seien noch genannt: $\mathrm{H} \ddot{\mathrm{u}} \mathrm{b} \mathrm{n} \in \mathrm{r}$, Grundzüge des deutschen Privatrechts, 5. Aufl., 1930, S. 286 ff.: Joh. Jac. M o s e r, Von der Landeshoheit derer S. 9). Aus der umfangreichen Literatur über die Regalien seien noch Teutschen Reiches überhaupt, 1773, 10. Cap., S. 208 ff. (grundlegend); H. T h i e m e, ZRG 62, 1942, S. 57 ff.; F. N e u m a r k, HdWbdStW, 4. Aufl., 1925, Bd. 6, S. $1208 \mathrm{ff}$.; H e u s l e r, Institutionen des Deut. Privatrechts, 1885, Bd. 1, S. 368 ff.; O. v. G i e r k e, aaO., S. $396 \mathrm{ff}$.

17) Vgl. W a it z, Diss., aaO., S. 13, 75 f., 97; H a s e l a u, Die Freiheit der Straße als Rechtsproblem, Schriftenreihe der Arbeitsgemeinschaft Güterfernverkehr im Bundesgebiet, Heft 11, 1960, S. $144 \mathrm{f}$. - Unerörtert kann bleiben, ob die Regalien die Gesamtheit der Hoheitsrechte erschöpfen (dazu M o s e r, aaO., S. 8, 218, 295; W a i t z, Diss., aaO., S. 58; Herbert K r ü g e r, Grundfragen einer rechtsstaatlichen Wassergesetzgebung, Rechtsgutachten, (o. J. 1956), S. 162, 166 mit Nachw.), ferner die Zweiteilung in höhere und niedere Regalien und das originäre oder derivative Recht der Landesherrn auf Regalien (dazu $P$ ütter, Institutiones juris publici germanici, 1770, Lib. VII, §325 f.). 
regal als die wichtigsten Regalien der öffentlichen Sachen sind jedenfalls seit dem 18. Jahrhundert fest in der Hand der Landesherren. Die landesherrliche Gerechtsame wird in deutschen Landen entscheidender Ansatzpunkt, "Ordnung" und Gebrauchsregelung für die der Regalität unterliegenden Sachen zu verfügen ${ }^{18}$, wie des preuß. ALR (Teil I Titel $8 \S 98$, Teil II Titel $14 \S \S 21,24$, Titel $15 \S 38$ ff.), der Cod. Max. Bav. Civ. (Teil II Cap. 1 §) sowie das Bayer. Generalmandat vom 3.1. 1735 beweisen $^{19}$ ).

2. Die industrielle Revolution, Wirtschafts- und Wettbewerbsfreiheit ließen noch vor der Mitte des 19. Jahrhunderts das zentrale Ordnungselement der Regalien zugunsten des römischrechtlichen Privateigentums in den Hintergrund treten, das zunächst nur langsam Eingang in das Wege- und Wasserrecht fand. Das preuß. Privatflußgesetz von 1843 und die Wege-VO von Schleswig-Holstein von $\left.1842(\S \S 6,13,17)^{20}\right)$ deuten die Wandlung an, die im Bayer. Wasserbenützungsgesetz von 1852 und mehr noch im BayerWG von 1907 sowie im Reichsgesetz über die Rechtsverhältnisse der zum dienstlichen Gebrauche einer Reichsverwaltung bestimmten Gegenstände vom 25.5.1873 - RGBI. S. 113 - evident wurde ${ }^{21}$ ).

3. Die öffentliche Sache wurde Zwittergebilde privaten und öffentlichen Rechts. Ihre Kreislaufkrankheit begann. An öffentlichen Sachen bestand Eigentum und öffentliche Verwaltung ${ }^{22}$ ), sog. modifiziertes Privateigentum ${ }^{23}$ ). „Das Wegeregal verliert sich stillschweigend in Wegepolizei und Privateigentum“24). Man konstruierte die öffentlichen Sachen „ianus-

18) So überzeugend M o s e r, aaO., 9. Cap., S. 160 ff., S e c k e n d o r ff $f$, Teutscher Fürstenstaat, 5. Aufl., 1687, S. 352; s. auch H a sel a $u$, aaO., S. 144: Forsth of $f$, Rechtsfragen der leistenden Verwaltung. res publica 1, 1959, S. 38; E. K a u f m a n n, Gesammelte Schriften 1960, Bd.1, S. 115.

19) $\mathrm{S}$ i evers. DVBl. 60, 461, Anm. 21, zitiert einen alten Gewährsmann: „Was für die Römer die öffentlichen, im Gemeingebrauch stehenden Sachen waren, das rechneten die Deutschen zu den Regalien"; $\mathbf{s}$ ferner Ey man $\mathbf{n}-\mathrm{Sch}$ u be r t, Komm. $\mathrm{z}$. Bay. WG, 1928, Bd. 2, S 472 ff.; R e u B, Die bayer. Wassergesetze, 2. Aufl., 1896, S. 3, 13 f.; H ol t $z-K$ reu tz-S ch le g e 1 b e r g e r, Komm. z. preuß. WG. 3./4. Aufl., 1955, Bd. 1, S. 1; Herbert $\mathrm{K}$ r üger Grindfragen, S. 165; $\mathrm{H}$ a s e l a u, aaO., S 144 .

20) Germershausen-Sevdel-Marschall, Wegerecht und Wegeverwaltung in der BRD. 5. Aufl., 1961, Bd. 2. S. 1786.

21) Das "gemeine Eigentum" des Staates wurde abgelöst.

22) Für Wege vgl. Preuß. Gesetz vom 8.7.1875 (GS S. 497), für Wasserstraßen, Art. 97, Weim. Verf.

23) VgI. Hans J. W o l f f, HdSw., S. 37.

4) Herbert Kr üg e r, Grundfragen, S. 168. 
köpfig“25): Dem Staat erwuchs eine „hoheitlich-fiskalische Doppelrolle $\left.{ }^{u 28}\right)$. Nach der vorherrschenden Dogmatik des Verwaltungsrechts stehen die öffentlichen Sachen im Herrschaftsbereich des Privatrechts, der jedoch durch den öffentlichen $\mathrm{Zweck}$, dem die Sache ${ }^{27}$ ) dient, beschränkt ist ${ }^{28}$ ). Anders ausgedrückt: Das öffentliche Recht überlagert das private Recht und kupiert die Eigentümerrechte partiell. Die Ausbildung einer rein öffentlichrechtlichen Konstruktion analog dem domaine public des französischen Rechts scheiterte ${ }^{29}$, nicht zuletzt aus Gründen gerichtlicher Unzuständigkeit für öffentlichrechtliche Fragen ${ }^{30}$ ). Immerhin hat $\mathrm{K} \ddot{\text { ö }} \mathrm{t}$ g e n bereits 1937 die Frage der Berechtigung und Notwendigkeit der „zweischichtigen" Konstruktion der öffentlichen Sache gestellt").

\section{V.}

Dem Versuch Otto Mayers, die öffentliche Sache als eigenständiges Institut des Verwaltungsrechts auf der Grundlage einer Addierung und Amalgamierung von Eigentum und öffentliche Gewalt aufzubauen, blieb der Erfolg versagt ${ }^{32}$ ). Ich

25) H a t s c h ek - K u rtzig, Verwaltungsrecht, 7./8. Aufl., 1931, S. 475, bezüglich der Rechtsträger.

26) Herbert Kr ü g e r, Grundfragen, S. 126.

${ }^{27}$ ) Ubergehen kann ich die hiernach getroffene Einteilung der Sachen je nach dem Verwendungszweck unter Zuhilfenahme finanzwissenschaftlicher Elemente: vgl. etwa Hans J. W o lff, HdSw., S. 39; ders. Verwaltungsrecht I, 4. Aufl., 1961, S. 306; O b e r mayer in: $M$ ang-Maunz-Mayer-Obermayer, Verwaltungsrecht in Bayern 1962, S. $168 \mathrm{ff}$.; Art. 174, Entw. einer Verwaltungsrechtsordnung für Württemberg.

Das italienische Recht kennt die praktikable Einteilung in demanio publico (necessario bzw. accidentale), der fuori commercio ist, und in beni patrimonali (so klar vecchio Cod. civ. Art. 426 fif.; $\mathrm{Z}$ a n ob i n i, aaO., Bd. 4, S. 5 ff., Bd. 1, S. 165 f.).

28) Vgl. Hans J. W o l $f$, HdSw., S. 37; ders. VerwR I; S. 309; F or s th of $f$, Verwaltungsrecht I, 8. Aufl., 1961, S. 329 f.; H. P e ters, Lehrbuch der Verwaltung, S. 207; v. Turegg-Kraus, Verwaltungsrecht, 4. Aufl., 1962, S. 176 ff.; K öt tg e n, Gemeindliche Daseinsvorsorge und gewerbliche Unternehmerinitiative, Göttinger rechtswissenschaftliche Studien, Bd. 34, 1961, S. 24; W o l f f $R$ a i s e r, Sachenrecht, 10. Aufl., 1957, S. 182 f.; aus der Rspr. zuletzt BGHZ 36, 218; allgemein noch D. H a a s, DVBl. 60, 303 und DVBl. 62, 653; S c h a c k, Verw.Arch. 54, 43 ff.

${ }^{20}$ ) Klar E. K a u f m a n n, aaO., Bd. 1, S. 115 ff.

30) Dazu L e r c h e, DVBl. 55, 283 ff.

31) In F r a n k, Deut. WerwR, 1937, S. 447.

32) Vgl. Verwaltungsrecht, 2. Aufl., Bd. 2, S. 71 ff.; ders. AöR 21, 499 ff.; zustimmende wie kritische Außerungen, die es zahlreich gibt, zu zitieren, scheint mir nur von historischem Wert (gute Zu- 
halte die Lehre vom „öffentlichen Eigentum “33) trotz des hamburgischen Wegegesetzes vom 4.4.1961 und trotz befürwortender Äußerungen etwa von For sth of ${ }^{34}$ ), Grund$\mathrm{man} \mathrm{n}^{35}$ ), $\mathrm{H} \mathrm{a} \mathrm{a} \mathrm{s}{ }^{36}, \mathrm{~K} \ddot{u} I z^{37}$ ), $\mathrm{S} \mathrm{ch} \mathrm{a} \mathrm{c}{ }^{38}$ ) und $\mathrm{Z}$ eid le $\mathrm{r}^{38}$ ) einer Restauration nicht für würdig ${ }^{40}$ ). Sie ist in ihrer Grundkonzeption verfehlt angelegt, weil ihre Konstruktionsmittel öffentliche Gewalt und Eigentum der Funktion und Idee der öffentlichen Sache als einer leistungsverwaltungsrechtlichen Institution nicht gerecht werden (dazu unten 2. Teil A und B). Auch ist für die moderne Problematik der öffentlichen Sache nicht entscheidend die Eigentumslage ${ }^{11}$ ), sondern die Rechtsmacht, erstens eine Sache in Verwaltung zu nehmen und kraft Verwaltungsrechts bereitzuhalten, genauer: sie öffentlichrechtlich zu institutionalisieren, und zweitens zu bestimmen, nach welcher Ordnung und in welchen Rechtsformen sie von der Offentlichkeit genutzt werden darf. Diesen Schritt über den Rubikon ging Otto Ma y e $\mathrm{r}$ eben nur sehr bedingt.

sammenstellungen finden sich bei $\mathbf{M}$ a unz, Hauptprobleme des öffentlichen Sachenrechts, 1933, S. 126 ff.; Gerhard M a h l e r, Die Gemeindewege als öffentliche Sachen, Leipziger Diss., 1934, S. 10 ff.); s. noch E. Ka u f m a n $n$, aaO., Bd. 1, S. $116 \mathrm{ffi}$; I p s e n, VeröffVDStRL 10, 111; C l a s e n, DOUV 59, 285 ff.; OVG Koblenz, DVBl. 62, 110; unklar in Bezug auf Art. 14 GG von $M$ a $\mathrm{ngoldt}-\mathrm{Kle}$ in, Komm. zum GG, Anm. III 1 a und BVerwG, DVBl. 62, 178. Otto $M$ a yers Lehre vermochte manche Ungereimtheiten des öffentlichen Sachenrechts nicht $\mathrm{zu}$ lösen, auch enthielt sie selbst einige Rätsel (vgl. etwa die Theorie der Widmung, aaO., S. 109).

$\mathrm{DaB}$ sie älter ist als Otto $\mathrm{M}$ a y e $r$, beweist $\S 1$, Art. 2 Gesetz bezüglich der Staatsgüter vom 22.11./12. 1790 (Germers ha us enSeyde]-Marsch a 11, aaO., Bd. 2, S. 1580); ferner Roland U l s e n h e i m er, Die Wasserläufe als öffentl. Sachen, Diss., München, 1937, S. 14).

33) Der Begriff ist nicht einfach der französischen Rechtswissenschaft entnommen (vgl. Otto $\mathrm{M}$ a y e $\mathrm{r}$, Verwaltungsrecht, 2. Aufl., Bd. 1, S. IX und S. 117). Nicht jeder Autor, der ihn akzeptiert, verstand darunter das gleiche (zutreffend Mahler, aaO. S. 26). Das „öffentliche Eigentum “ in $\$ \S 4,5$ bad-württ. WG von 1960 ist nicht gleichbedeutend mit dem Begriff Otto $M$ a y er $\mathbf{s}$ (ebenso Hans J. W o l f $\mathrm{f}, \mathrm{HdSw}$., S. 36; S i e ver s, DVBl. 62, 317, Anm. 32).

34) VerwR S. 329, Anm. 3.

85) Staatsverfassung und Kirchenordnung, aaO., S. 325.

s6) DVBl. 62, 653 ff.

37) Eigentum und Verwaltungskompetenzen an den Bundeswasserstraßen, Recht der Wasserwirtschaft, Heft 9, 1961, S. $37 \mathrm{ff}$.

39) DVBl. 61, 897.

39) AöR 86, 394, Anm. 90.

10) Ebenso L e r c h e, DVBl. 55, 286.

11) Richtig gesehen bei $M$ a unz, aaO., S. 91; Kormann$L$ is $t$, Einführung in die Praxis des Deutschen Verwaltungsrechts, 2. Aufi., 1930, S. 175; Kö t $\mathrm{tg}$ e $\mathrm{n}$ in F r a n k, Deut. VerwR, S. 438. 


\section{VI.}

Die Konstruktion der öffentlichen Sache als „Rechtsverhältnis" durch $\mathrm{Maunz}{ }^{42}$ ) bietet ebenfalls nur Ansätze für eine konstruktive Lösung, so namentlich für die Nutzungsformen.

\section{VII.}

Für verfehlt erachte ich es, die öffentliche Sache als öffentliche Anstalt zu begreifen ${ }^{43}$ ). Ein darauf erstreckter Anstaltsbegriff würde nahezu jede Verwaltungstätigkeit erfassen ${ }^{44}$ ) und eine Annäherung an das französische System der service public bedeuten. Der Anstaltsbegriff findet sinnvoll nur dort Verwendung, wo von einem Hauptträger der Verwaltung abspaltbare Verwaltungs- (gelegentlich auch Wirtschafts-)funktionen von einer mindestens partiell verselbständigten und damit Teil-Rechtssubjektivität besitzenden ${ }^{45}$ ) Verwaltungseinheit ${ }^{\mathbf{4 6}}$ ) wahrgenommen werden ${ }^{\mathbf{4}}$ ). Mit Recht betont Hans J. W olf $f$ in seinem soeben erschienen 2. Band seines Verwaltungsrechts das Kriterium rechtlicher Subjektivierung als Begriffsmerkmal

42) AaO., S. 71 f.; zustimmend z. B. M a h 1 er, aaO., S. 32 ff.

43) Vgl. z. B. O. M a y e r, Verwaltungsrecht, 2. Aufl., Bd. 2, S. 171; Gerhard Meinzolt, Der Gemeingebrauch an öffentl. Sachen; Diss., München, 1950, S. $52 \mathrm{ff}$., gelegentlich das pr. OVG z. B. 105, 179 für öffentl. Wege; E. R. H u be r, DOV 55, 130.

44) So richtig bereits E. K a ufmann, aaO., Bd. 1, S. 120; s. auch $\mathrm{K}$ ö t $\mathrm{tg}$ e n, VeröffVDStRL 6, 110.

45) Ich vermeide mit Bedacht den Begriff Rechtsfähigkeit, weil das öffentliche Recht bereits zahlreiche Gebilde geschaffen hat, denen diese umfassende Rechtssubjektivität nicht mehr zukommt (Einzelheiten bei B a ch of, AöR 83, 208 ff.; S t e r n, AöR 84, $280 \mathrm{ff}$.; Hans J. W o l f f, Organschaft und Juristische Person, 2 Bde. 1933/34; Werner W e b e r, Körperschaften, Anstalten und Stiftungen des öffentl. Rechts, 2. Aufl, 1943, S. 91; K ö t t g e n, Die rechtsfähige Verwaltungseinheit, 1939, S. 8 ff.; F u B, DOV 56, 566 f.; F a b r i c i u s, Relativität der Rechtsfähigkeit, 1963).

46) Vgl. Kö t t g e n, VeröffVDStRL 6, 125; ders., Die rechtsfähige Verwaltungseinheit, 1939; der Begriff ist inzwischen vom Gesetzgeber übernommen, z. B. $\$ 2$, Abs. 1, Berl. Bezirksverwaltungsgesetz v. 30.1. 1958 - GVBl. S. 126 -.

47) Ubereinstimmend Herbert $\mathrm{K}$ r üg e r, Gegen eine Entstaatlichung der öffentl. Wege, Rechtsgutachten in: Schriftenreihe der Arbeitsgemeinschaft Güterfernverkehr im Bundesgebiet, Heft 1, 1954, S. 24; F or s th of f , AöR 31, 221; ders. VerwR, S. 433 ff.; H. Schneider, NJW62, 705; T a rtar in-Tarnheyden, VeröffVDStRL 6, 156 (Diskussionsbeitrag); M e rkl, Allg. Verwaltungsrecht, 1927, S. $306 \mathrm{f}$.; K öt t g e n, Gemeindliche Daseinsvorsorge, S. 33; ders., Verwaltungseinheit, S. 30, Anm. 1 a; Werner We be r, Körperschaften usw., S. $12 \mathrm{f}$., $90 \mathrm{f} . ;$ zu weitgehend schon K or ma n n, Art. Offentliche Anstalt in: WbStuVR, ’. Aufl., 1914, Bd.3, S. 1 ff.; allgemein bedeutsam für die Unterschzidung von Rechtssubjekt und Rechtsobjekt $\mathrm{Naw}$ i a s ky, Allg. Rechtslehre, 2. Aufl., 1948, S. 185 f. 
der Anstalt ${ }^{48}$ ). Daran wird es aber bei Wegen und Gewässern als wesentlichen öffentlichen Sachen im Regelfall fehlen; sie bleiben Objekte, so daß ich der von W. W e b e r angenommenen Umbildung des Gemeingebrauchs in anstaltliche Nutzung schon aus diesem Grunde nicht beizustimmen vermag. Auch hinsichtlich der primären Nutzungsformen bestehen hinreichende Unterschiede $z$ wischen beiden Institutionen: einerseits zulassungs- und gebührenfreier Gemeingebrauch, andererseits zulassungs- und abgabepflichtiger Sondergebrauch weitgehend nicht der potentiellen Allgemeinheit, sondern eines spezifischen Interessentenkreises ${ }^{49}$ ). Das schließt nicht aus, daß eine Anstalt als Rechtssubjekt öffentliche Sachen als Rechtsobjekte darbietet ${ }^{50}$ ).

B.

Grundgedanken einer öffentlichrechtlichen Theorie der öffentlichen Sache

I.

Der öffentlichen Sache als Institution fehlt im Gegensatz zum öffentlichen Dienst die verfassungsrechtliche Verankerung ${ }^{51}$ ). Gebietet Art. 33 Abs.4 GG eine grundsätzliche Kongruenz zwischen öffentlichrechtlicher Agende und auf öffentlichrechtlicher Rechtsgrundlage Agierenden ${ }^{52}$ ), so besteht keine

48) S. 256; wie hier auch $\mathrm{H}$ a a s, DVBl. 62, 654; F. B a u r, BB 63,485 .

49) Darauf legen Erich Becker, HdSw, Art. Anstalten des öffentlichen Rechts, Bd. 1, S. 208 und $H$ et t l a g e, Staatslexikon, 6. Aufl., 1957, Art. Anstalt, Bd. 1, S. 351 das Schwergewicht.

50) Zutreffend E.R. H u ber, DOV 55, 130; Hans J. W o If $f$, VerwR I, S. 307; K ö t t g e n, Verwaltungseinheit, S. 77: „Vereinzelt hat man um eine solche öffentliche Sache gleichsam eine besondere rechtsfähige Verwaltungseinheit herumgebaut. Organisationsrecht und öffentliches Sachenrecht sind hier eine eigentümliche Verbindung eingegangen"; beispielhaft das Unternehmen Reichsautobahn (vgl. \&1, Reichsautobahngesetz vom 27.6. 1933, RGBl. 1933, II, S. 509).

51) Für den öffentlichen Dienst U l e, Offentlicher Dienst, Handb. der GrundR IV/2, 1962, S. 537 ff., mit dem Hinweis: „Das Wort Dienst muB deshalb im institution ellen Sinn verstanden werden; es bezeichnet eine Einrichtung, die zur Leistung von Diensten bestimmt ist. Eine solche Einrichtung kann sich aus $\mathrm{s}$ a chlichen (Hervorhebung durch mich) und persönlichen Bestandteilen zusammensetzen...“. Für das öffentliche Amt, Köttgen, in: Staatsverfassung und Kirchenordnung, S. $119 \mathrm{ff}$.

52) Vgl, v on M a n g o l d - K l e i n, Komm. z. GG, 1960, Anm. IV zu Art. 33; H a m a n n, Komm. z. GG, 2. Aufl., Anm. B 4 zu Art. 33; Köttgen, aaO., S. $131 \mathrm{f}$.; W. Thieme, Der öffentliche Dienst in der Verfassungsordnung des Grundgesetzes, 1961, S: 31, $55 \mathrm{ff}$.; Ule, aaO., S. 559. 
Vorschrift, die eine Befriedigung von sächlichen Gemeinwohlerfordernissen mit ausschließlich öffentlichrechtlich institutionalisiertem Gut befiehlt. Auch der Gesetzgeber hat trotz seiner Abundanz bei Teilregelungen, besonders im Wege- und Wasserrecht, die Grundfragen des öffentlichen Sachenrechts ${ }^{\mathbf{5 3}}$ ) stiefmütterlich und ohne stabilisierende Konzeption behandelt. Die Ungereimtheiten, die Leitsatz 7 aufzählt, sind die Folge.

II.

Die Wissenschaft ist mithin bei der Begriffsbildung der öffentlichen Sache auf sich allein gestellt. Ich meine, der $\mathbf{h} . \mathbf{M}$. nicht folgen zu können, wenn sie den Begriff der öffentlichen Sache ausschließlich aus ihrem öffentlichen $Z_{\text {weck }}{ }^{54}$ ) und als Bestandteil des technischen, variierbaren ${ }^{55}$ ) Verwaltungsrechts ${ }^{56}$ ) zu erklären versucht. Begriffe, wie öffentliche Sache, öffentliche Anstalt, öffentliches Amt und öffentlicher Dienst sind nicht , reine Zweckbegriffe, die mit einem ganz beliebigen Inhalt gefüllt werden können, sondern institutionelle Wesensoder Dingbegriffe“57), „ideenbezogene Institutionen“, wenngleich geschichtlich anpassungsfähig ${ }^{68}$ ), deren normative Ausprägung auf einem einheitlichen und klaren Ordnungsprinzip, auf einer funktions-, sach- und formgerechten ${ }^{59}$ ) Wertung beruhen muß, die, wie ich noch darlegen möchte, im "besonderen Integrationswert der öffentlichen Rechtsform "60) liegt. Diese Erkenntnis könnte $z u$ folgenden Überlegungen führen:

$\left.{ }^{53}\right)$ Schwierige Kompetenzfragen über dieses Gebiet wie überhaupt über das allgemeine Verwaltungsrecht sind sicher mitursächlich gewesen; s. dazu auch Bulling e r, Mineralölfernleitungen, res publica 8, 1962, S. 51 ff.; H a m a n n, DVBl. 61, 394 ff.; BVerwG, DVB1. 63, 815.

54) Vgl. statt vieler F or sth of $f$, VerwR, S. 146.

65) Hierzu v. Köhler, Verw.Arch. 50, S. 221. - „Ein Verwaltungsrecht des demokratischen Rechtsstaates muß erst noch geschrieben werden“ (Z e i d le r, Empfiehlt es sich, die bestehenden Grundsätze über Auskünfte und Zusagen in der öffentl. Verwaltung beizubehalten?, Gutachten für den 44. DJT, 1962, Bd. 1, 2. Teil, S. 10, Anm. 15).

56) Vgl. Köttgen, in: Staatsverfassung und Kirchenordnung, S. 120, Anm. 3; S m e n d, Verfassung und Verfassungsrecht, Staatsrechtliche Abhandlungen, 1955, S. 263.

67) L e i b holz, Strukturprobleme der modernen Demokratie, 1958, S. 268, 274; s. auch E. K a u f m a n n, aaO., Bd. 3, S. 266 ff., der juristische Relations- und Dingbegriffe unterscheidet; ders., VeröffVDStRL 3, 20 (Diskussionsbeitrag); L e r c h e, DVB1. 61, 694.

58) Vgl. E. K a u f m a n n, aaO., Bd. 3, S. 376. - Dahinter steht das Postulat des Verwaltungsrechts als ,konkretisiertem Verfassungsrecht" (W e r n e r, DVBl. 59, 527 ff.).

59) L e i b h o Iz, aaO., S. 267, spricht von einer "sachhingegebenen" Wertung; hierzu auch L e p s i e n, Prinzipien der Leistungsverwaltung, Diss., Münster, 1961, S. 88, Anm. 2.

B0) Forsth off, VerwR, S. 385. 
1. Sachen sind Stücke der den Menschen umgebenden beherrschbaren ${ }^{61}$ ) Natur oder von Menschen künstlich geschaffene Gegenstände, die für sich allein bestehen und im Verkehrsleben besonders bezeichnet und bewertet werden, also als selbständige Rechtsobjekte anerkannt $\operatorname{sind}^{62}$ ). Mit dieser am körperlichen Substrat haftenden Erläuterung ist jedoch nur der unwesentliche Teil der öffentlichen Sache erkannt, der sich von der privaten Sache nicht wesenhaft unterscheidet ${ }^{63}$ ). Hintangesetzt bleibt die Dignität, die Wertung dieser körperlichen res durch die Rechtsordnung und ihre Beziehung zu den Rechtssubjekten ${ }^{64}$ ), durch die die öffentliche Sache ihre entscheidende Rechtsqualität erhält, nicht anders als Kunstwerk, Literaturerzeugnis, Patent und Gebrauchsmuster ihr hervorstechendes Gepräge nicht aus ihrer körperlichen Sinnhaftigkeit empfangen. Unerklärbar bliebe ansonsten auch die Eingliederung in das Integratiossystem der öffentlichen Verwaltung und die besondere Pflichtenstellung ${ }^{65}$ ), die die öffentliche Verwaltung in bezug auf die öffentliche Sache besitzt, für die

61) Darum sollte man den freien Luftraum und das offene Meer nicht mehr unter die Kategorie der Sachen rechnen, da die Beherrschbarkeit mit jedermann zugänglichen Mitteln fehlt, (so Sohm-Mit teis, Wenger, Institutionen, S. 254 f.; Ennecc e r u s-N i p perd e y, aaO., \$121, II, 5, 130, IV, rechnen sie nicht zu den privaten, wohl aber zu den öffentlichen Sachen). §1, Abs. 1, LuftVG i. d. F. v. 10.1. 1959 (BGBl. I, S. 9) erklärt lakonisch: Die Benutzung des Luftraumes ist frei (dazu $\mathrm{Krebs}$, Verkehrsrecht und Verkehrswirtschaft, 1960, S. 165 ff.). Zu völkerrechtlichen Fragen des Luftraumes $F$ a s a n und $G$ ros $s$, Osterr. JZ 62, 1 ff.

62) im AnschluB an Enneccerus-Nipperdey, aaO, $\S 121$ II.

B3) $\mathrm{DaB}$ der Sachbegriff des öffentlichen Sachenrechts weiter gezogen ist (F o r s t h of $f$, VerwR, S. 328; W o l f $f$, VerwR I, S. 307; Dieter H a a s, DVBl. 62, 654; a. A., Z i p peli u s, DOV 58, 840). ist zweitrangig und durch das positive Recht des BGB ( $\$ 90 \mathrm{ff}$.) bedingt. - Gegen eine Ubernahme des Begriffs Sachenrecht in das öffentliche Recht wendet sich $S$ panner in seinem Gutachten für den 43. Deut. Juristentag, Bd. 1, 2. Teil, Heft A, S. 22; s. auch Eckert, DVBl. 62, 11, Anm. 3; N a B, Verwaltungsreform durch Erneuerung der Verwaltungswissenschaft 1950, S. 6, 9, 29; G. J e I 1 i n e k, Allg. Staatslehre, 3. Aufl., 7. Neudruck, 1960, S. $399 \mathrm{f}$.

64) S. hierzu M a u n z, aaO., S. 72 ff.; $M$ a h l e r, aaO., S. 32 f., 35; s. ferner den Hinweis F o r s th of $\mathrm{f}$ s, VerwR, S. 324 auf den ,funktionellen Zusammenhang, der sich an dieses Substrat anschlieBt"; ders. auch für die res sacrae AöR 31, 210.

$\left.{ }^{65}\right)$ Diese hebt M a unz, aaO., S. 209 ff. nachdrücklich hervor; s. auch G. Hol s te in, Offentl-rechtl. Eigentumsbeschränkung, S. 96; S c h e l c her, Fischers Zschr. 48, 388. - F or s th of $f$ stellt in seiner Untersuchung über die res sacrae als Grundgedanken der rechtlichen Sonderstellung der öffentlichen Sache heraus, daß diese „guter staatlicher Ordnung“ entspreche (AöR 31, 233); H a a s, DVBl. 62, 6533 weist auf das Merkmal des besonderen öffentlichrechtlichen Schutzes" hin. 
es bei privaten Sachen keine hinreichende Entsprechung gibt. Entscheidende Bedeutung für die Begriffsbestimmung muß also das Adjektiv "öffentlich" gewinnen ${ }^{66}$ ). Die Kennzeichnung eines Gegenstandes oder einer Angelegenheit als "öffentlich“ ist vorab eine Wertung ${ }^{07}$ ). Einigkeit besteht heute auch darüber, daß öffentlich nicht gleich staatlich ist ${ }^{68}$ ). Die öffentliche Sache wurde nie als Staats-Sache empfunden, sondern immer als Sache des "politischen Gemeinwesens", um eine jüngst von $\mathrm{Eh} \mathrm{mke} \mathrm{wiederbelebte} \mathrm{Formulierung} \mathrm{zu} \mathrm{übernehmen}{ }^{69}$ ). Die öffentliche Sache steht nicht nur in, sondern auch namens der Öffentlichkeit.

2. Die Eigenschaft des Offentlichen bezeichnet nach $\mathrm{S} m$ e n $\mathrm{d}$ die „Zugehörigkeit zu dem Lebens-, Sinn- und Wertbereich des Volkes als Gemeinwesen"; das bedingt, wie S m e n d fortfährt, auch eine „normative Zuordnung..." ${ }^{\text {70 }}$ ). Diese normative Zuordnung erscheint mir für die öffentliche Sache wesentlich und nur durch das öffentliche Recht zu vermitteln, entsprechend der Fremdnützigkeit der öffentlichen Sache (dazu unten 2. Teil A, C) ${ }^{71}$ ). „Im Begriff der [öffentlichen Sache] liegt die Vorstellung von einer öffentlichrechtlichen Sachherrschaft" ${ }^{42}$ ). Bislang ist die öffentliche Sache jedoch nur als Umschreibung von etwas Tatsächlichem begriffen worden, das eine bestimmte Funktion, ein bestimmtes Telos erfüllt. Eine institutionell-normative Absicherung fehlte. Diese ist aber für

66) Die Vielschichtigkeit und Vielfältigkeit des Offentlichkeitsbegriffs im allgemeinen kann hier nicht aufgerollt werden; zum vorliegenden Aspekt noch $M$ üller, Straßenverkehrsrecht, 21. Aufl., 1959, S. 137; R e g e ls b e r g e r, Pandekten 1893, Bd. 1, S. 415; F ors th of $f$, Die öffentliche Körperschaft im Bundesstaat, 1931, S. 11 ff., Herbert K r ü g e r, Handb. d. GrundR Bd. 3, Teil 1, S. 300; ders. VeröffVDStRL 15, $116 \mathrm{f}$.

67) G e r b e r, VeröffVDStRL 6, 154 (Diskussionsbeitrag); vgl. auch, $Q$ u a r its c h, DVBl. 62, 589, der vom Offentlichen als einem „integrierenden Merkmal“ spricht (mit Nachw. ebda. Anm. 23).

6) Vgl. F o r s th of f, Offentliche Körperschaft, S. 18; K ö t tg e n, in: Staatsverfassung und Kirchenordnung, S. 121, $146 \mathrm{f}$.; ders. Verwaltungseinheit, S. 18.

69) Bes. in Staatsverfassung und Kirchenordnung, S. 23 ff.; früher und gerade in Bezug auf öffentliche Sachen F or $s$ th of $f$, AöR 31, 210; neuerdings $\mathrm{H}$. $\mathrm{H}$ u b e r, Zschr. des Bernischen Juristenvereins 1962 , S. $171 \mathrm{f}$.

70) Berichte und Forschungen aus dem öffentlichen Recht, Gedächtnisschrift für W. J ell in ek, S. 12.

71) soweit ersichtlich im Ansatz zuerst von Tezner, AöR 9 (1894), 376 ff. erkannt. - K ö t t g e n (VeröffVDStRI, 6, 111) hat seiner Zeit für die öffentliche Anstalt die Gleichung „die öffentliche Anstalt ist identisch mit der öffentlich-rechtlichen Verwaltungseinheit“ abgelehnt. - Zur Stärkung der normativen Seite auch Le r che, DVBl. 61, 691.

72) $\mathrm{S}$ i ever s, DVBl. 62, 81. 
das Verwaltungsrecht entscheidend, da dafür im Gegensatz zu Strafrecht und Straßenverkehrsrecht nicht tatsächliche Beziehungen, sondern nur rechtliche Kriterien ${ }^{73}$ ) maßgeblich sein dürfen, die über Sachherrschaft, Sachordnung und Sachverantwortlichkeit entscheiden; denn im Bereich der staatlichen Organisation herrscht der Rechtssatz, der die Staatsfunktionen nur innerhalb des Rechts gültig agieren läßt. Es ist ein Rechtsakt, der die öffentliche Sache kreiert, nicht natürliche Verhältnisse ${ }^{74}$ ). Von einer verwaltungsrechtlich relevanten öffentlichen Sache sollte daher nur dann gesprochen werden, wenn es sich um Sachen handelt, die durch einen Rechtsakt des öffentlichen Rechts einen besonderen institutionellen Status erhalten, der ebenso wie die Rechtsbeziehungen zu den Benutzern durch Rechtssätze des öffentlichen Rechts geregelt ist. Das Kriterium der öffentlichen Sache erblicke ich nicht in der zweckgebundenen Nutzung, sondern in der substantiellen Ordnung durch Normen des öffentlichen Rechts und in der dadurch begründeten integrierenden Einbeziehung in das Gefüge der öffentlichen Verwaltung. - Die Parallelität zur juristischen Person des öffentlichen Rechts ist nicht zufällig. Beide Institutionen sind aus der privatrechtlichen Ordnung herausgelöst und in den öffentlichrechtlichen, vorwiegend verwaltungsrechtJichen Organismus eingefügt ${ }^{75}$ ).

3. Offentliche Sache ist nur die öffentlichrechtliche institutionalisierte Sache. Sie entsteht durch einen noch näher zu erläuternden Organisationsakt, der üblicherweise ${ }^{76}$ ) zwei Hauptkategorien von Sachen erzeugt:

a) Sachen, deren Funktion auf den internen Gebrauch durch staatliche (und dem Staat ein- oder angegliederte öffentlichrechtliche Verbände) oder kirchliche Organe zugeschnitten ist und die höchstens akzidentiell einer externen Benutzung unterliegen; Hauptbeispiele: Inventar und Arbeitsmittel der Verwaltung, Militärgut;

73) D. h. die Stellungnahme der Rechtsordnung zu Objekten, Verwaltungsobjekten im Verwaltungsrecht oder Steuerobjekten im Steuerrecht (aufschluBreich hierzu $\mathrm{N}$ a w i a s k y, Allg. Rechtslehre, S. 203 ff.); s. auch $\mathrm{M}$ e in $\mathrm{z}$ o $1 \mathrm{t}$, aaO., S. 46; G. H o $1 \mathrm{~s}$ t e i n, Offentl.rechtl. Eigentumsbeschränkung, S. 92; F or s th of $f$, Die öffentliche Körperschaft, S. 27.

74) Vgl. Z i p p e li u s, DÖ 58, 841 mit Nachw. d. Gegenstimmen.

75) Vgl. Tula S i m o n s, Der Aufbau der Kohlenwirtschaft, 1931, S. 32; F o r s t h of f, AöR 31, 221 f., s. auch BVerfGE 12, $244 \mathrm{ff}$.

76) E. R. H u ber, DOV 55, 130. - Jedoch darf nicht verkannt werden, daß, wie F o r s t h of f mit Recht sagt (AöR 31, 220), „das sog. öffentliche Sachenrecht disparate Rechtserscheinungen umfaßt und jener durchgängigen Systematik ermangelt, die das bürgerliche Sachenrecht auszeichnet"; ebenso Köttgen in Frank, Deut. VerwR, S. $433 f$. 
b) Sachen, deren Funktion essentiell auf externe Nutzung in spezifisch öffentlichrechtlichen Nutzungsformen zugeschnitten ist; Hauptbeispiele: Wege und Plätze, Gewässer, Flughäfen $\left.{ }^{77}\right),{ }^{78}$ ), Häfen ${ }^{78}$ ).

4. Sachen der Gruppe b) sind nicht „gegenständlich in den Verwaltungsapparat eingefügt ${ }^{* 80}$ ), also nicht verwaltende Objekte, sondern verwaltete Objekt.e ${ }^{81}$ ); ihr interner Verwaltungswert tritt gegenüber dem externen Nutzungswert in den Hintergrund. Umgekehrt liegt es bei den Sachen der Gruppe a), bei denen die Nutzung, z. B. des Rathauses, „zwangsläufige Folgeerscheinung ${ }^{\mathbf{4 8 2}}$ ) der Tätigkeit der Staatsorgane ist, mit denen die Bürger Kontakt aufnehmen müssen. Uberdeckungen zwischen beiden Gruppen sind nicht zu vermeiden; entscheidend für die Typisierung ist der statusformende Organisationsakt ${ }^{83}$ ).

5. Aus der Kategorie der öffentlichrechtlich institutionalisierten Sachen fallen mithin die nur tatsächlich oder kraft Privatrechtsakt der Offentlichkeit zur Verfügung gestellten

77) Ewalt S ch e n k, Der Flughafen, 1931, bes. S. $41 \mathrm{ff}$.

78) Am W a I d erkennt G. R i n ck, MDR 61, 984, keinen „verwaltungsrechtlichen" Gemeingebrauch an, selbst dann nicht, wenn er Eigentum der öffentlichen Hand ist. Es fehle an einem Widmungswillen. Er erkennt nur einen „gewohnheitsrechtlich begründeten, zivilrechtlichen Gemeingebrauch" an. Diese Konstruktion ist nur denkbar angesichts der Zwitterstellung der öffentlichen Sache. Die Normen, die $\mathbf{R}$ i $\mathbf{n} \mathbf{k}$ für seinen zivilrechtl. Gemeingebrauch anführt (Art. 141, Abs. 3, Satz 1 BayVerf., Feld- und Forstgesetze) sind doch wohl öffentlich-rechtlicher Art. Entscheidend dürfte m. E. sein, ob der Organisationsakt (oft noch auf Gewohnheitsrecht beruhend) den Wald in den öffentlich-rechtlichen Status einer extern nutzbaren Sache überführt. Das ist für die einzelnen Wälder durchaus unterschiedlich zu beurteilen. S. auch Klaus M eyer, DVBl.60, 269 ff.; Figge, RdL 60, 115; v. Rauscher auf WeegS c h m i d t, BayvBl 57, $372 \mathrm{f}$.

79) Hansjürgen Nölle, Die bremischen Häfen, Diss., Hamburg, 1959.

80) Obermayer in: $\mathrm{M}$ ang-Maunz-M a yer-Ober$\mathrm{m}$ a y e $\mathrm{r}, \mathrm{S} .171 ; \mathrm{R}$ u c k, Schweizerisches Verwaltungsrecht, 3. Aufl. o. J., Bd. 1, S. 140; K ö t t g e n in Frank, Deut. VerwR, S. 439.

82) O b e r m a y e r, aaO., S. 169 ; $R$ u c k, aaO., S. 145.

Daseinsvorsorge, S. 33 in Abgrenzung zur Anstalt.

Vgl. ähnliche Bemerkungen bei $K$ ö $t \mathrm{tg}$ e $n$.

83) Aus ihm sind Art und Rechtsnatur so verschiedener Erscheinungen, wie der neuen Landeskarte der Schweiz, die als Unterlage zur Herstellung anderer Karten aufgrund staatlicher Bewilligung benützt werden darf (freundlicher Hinweis von Hans $H u b e r$ ), oder des Xthers (dazu Herbert $\mathrm{K}$ r ü g e r, Der Rundfunk im Verfassungsgefüge und der Verwaltungsordnung in Bund und Länder, 1960 , S. 17) zu erklären. 
Gegenstände ${ }^{84}$ ) und das konkurrenzwirtschaftlich ${ }^{85}$ ) oder in den Rechtsformen des Privatrechts monopolistisch ${ }^{86}$ ) genutzte Vermögen des Staates heraus, da ihnen in der Regel der öffentlichrechtliche Organisationsakt fehlt, den Aufsichtsbefugnisse ${ }^{87}$ ), haushaltsrechtliche Normen ${ }^{88}$ ) oder Privilegierungen in der Zwangsvollstreckung ${ }^{89}$ ) nicht $\mathrm{zu}$ ersetzen vermögen. Sie sind damit noch nicht dem Verwaltungssystem inkorporiert.

\section{III.}

Im Rahmen dieser Begriffsbildung kommt der Unterscheidung, Finanzvermögen, Verwaltungsvermögen, Betriebsvermögen und Sachen im Gemeingebrauch ${ }^{80}$ ) kein für das öffentliche Sachenrecht heuristischer Wert $\mathrm{zu}^{01}$ ). Etwas anderes

84) Die Adressierung an die Offentlichkeit durch den Eigentümer (besonders deutlich bei W. J ell i n e k, Verwaltungsrecht, S. 509; s. auch $J$ a $h \mathrm{n}$ und $\mathrm{K}$ e $\mathrm{n} \mathrm{t} \mathrm{n}$ er, DOV 62, 292), z. B. bei einem Privatweg, ist ein wesensmäßig anderer Akt, da er ebensowenig die Unterstellung unter besondere Nutzungsformen des öffentlichen Rechts bewirkt wie die Begründung öffentlich-rechtlicher Sachherrschaft bei einem Träger öffentlicher Verwaltung. Der offene Privatweg erhält nicht einen vom öffentlichen Recht verliehenen Status.

85) Ich halte diesen Begriff für klarer als erwerbs- bzw. ertragswirtschaftlich oder fiskalisch genutzt.

86) B a c h of , Freiheit des Berufs, Handb. d. GrR III/1, S. 200 ff.; H a m a $n \mathrm{n}$, Dt. Wirtschaftsverfassungsrecht, 1958, S. 180 f.; E. R. H u ber, WirtschaftsVerwR I, S. 482 ff.; R i n g s, NJW 57, 657; Th i e m e, JZ 61, 280 ff.; S c h ick, DOV 62, 931.

87) Die staatliche Verwahrung nach $\$ 5$, Abs. 1, Satz 1, AtomG als besonderer Schutz vor den Gefahren der Kernbrennstoffe begründet daher keine öffentliche Sache (wohl richtig $M$ a t ter n$\mathrm{R}$ a i s ch, Komm. z. AtomG, 1961, Band Nr. 1 und 2 zu $\S 5$; F is cherh of, Deut. Atomgesetz und Strahlenschutzrecht, 1961, Anm. I zu $\$ 5$ AtomG; B or s t, DVBl. 60, 160). Es fehlt am transformierenden Organisationsakt; die Sache wird nicht öffentlich.

Hingegen dürften die Sachen, die nach dem Bundesleistungsgesetz angefordert sind, als öffentliche Sachen zu qualifizieren sein, wenn sie in das Verwaltungsgefüge eingegliedert sind.

88) Vgl. $\S \S 46$ ff. RHO. - Zu erwähnen sind auch die Verdingungsordnungen. Uber staatliche und kommunale Vertretungen in den Aufsichtsräten s. I p s e n, JZ 55, $597 \mathrm{ff}$.

89) Z. B. $\$ \S 882$ a ZPO; 129 Rhpf. GemO; 131 SchlesH GemO.

0) Vgl. die Einteilungen bei Hans J. W o l f f, VerwR I, S. 305 ff. u. HdSw S. 36 ff.; F o r s th of $f$, VerwR, S. 326; O b e r m a y e r, aaO., S. 167 ff.; W. J e 11 i n e k, VerwR, S. 506 f.; H. P e t e r s, aaO., S. 207; F le i n er, Institutionen, S. $351 \mathrm{ff}$; H e r r n i t t, Grundlehren des Verwaltungsrechts, 1921, S. 377.

91) So wohl auch Köttgen, Gemeindliche Daseinsvorsorge, S. 34; M e inzolt, aaO., S. 24; $\mathrm{H}$ a a s, DVBI. 62, 653; früher schon A. A r ndt, Staatsrecht des deut. Reiches, S. 436; zur Trennung von Staats- und Finanzvermögen, $L$ a b a n d, Staatsrecht, 5. Aufl., 1914, Bd. 4, S. 345, 352; ders. Annalen des Dt. Reiches 1873, S. 414; 
mag für die Lehre vom Staats ve rm ö g e n gelten, die hier ebenso wie das auf anderen Ordnungsgesichtspunkten beruhende Verkehrsrecht ${ }^{92}$ ) außer Betracht bleibt.

IV.

Da abgrenzendes Kriterium allein der durch Organisationsakt geschaffene öffentlichrechtliche Status der Sache ist, kann Sachträger auch ein Beliehener oder Indienstgenommener ${ }^{93}$ ) sein.

V.

Ausschlaggebende Bedeutung in meinem System besitzt der Organisationsakt, der die Sache in den öffentlichrechtlichen Status überführt. Die h. M. kennt nur die „Widmung", die die Sache einem öffentlichen $\mathrm{Zw} \mathrm{e} \mathrm{ck}$ dienstbar macht $t^{94}$ ). Dadurch wird die Sache zwar ihrem Telos nach gebunden, aber ihr Status bleibt gleich: privatrechtlich mit aufgepfropften öffentlichrechtlichen Schranken ${ }^{95}$ ); unverändert bleibt auch die Folge jenes Dualismus: Eine Fülle von Unebenheiten und Zweifeln, die diesen Akt, seine Qualifizierung, seine Voraus-

L. v. S te i n, Finanzwissenschaft, 5. Aufl., 1885, Bd. 1, S. 463, 105; $\mathrm{J}$ è z e, Das Verwaltungsrecht der franz. Republik, 1913, S. 237.

92) Richtig Evers, NJW 62, 1033; OLG Bremen, NJW 62, 1582; OVG Münster, MDR 63, 79; OLG Köln, NJW 62, 2073 (nur Leitsatz).

93) R u c k, aaO., Bd. 1, S. 141. - Zu den genannten Rechtsflguren I p s e $n$ in: Festschrift für $E$. K a u f $m$ a $n$ n, 1950, S. 141 ff.; E. R. $\mathrm{H}$ u b e r, Wirtschaftsverwaltungsrecht, 2. Aufl., 1953, Bd. 1, S. 533 f.; Hans J. W o 1 f f, VerwR II, S. 304 ff.; S t e r n, AöR 84, 156; K1. V o ge l, Offentliche Wirtschaftseinheiten in privater Hand, Abh. aus dem Seminar für öffentl. Recht, Hamburg 1959, S. 46 ff.; Wolfgang $S \mathbf{c h w}$ eikert, Die beliehenen öffentlichen Unternehmen, Diss. Tübingen, 1959; Jürgen Terrah e, Die Beleihung als Rechtsinstitut der Staatsorganisation, Diss. Münster, 1961.

94) Vgl. Hans J. W o l $1 \mathrm{f}$, VerwR I, S. 310; ders. HdSw, S. 37; F or sth of $f$, VerwR, S. 329; S chall e n berg, Die Widmung, 1955; OVG Münster, OVGE 16, 112; BadWürtt. VGH, VerwRspr. 13, Nr. 28; BGH, DÖV 62, 906; DƠV 63, 707 f.; BayVBl. 63, 356. - Für die Entstehung der res sacrae spricht Forsth of f (AöR 31, 210) allerdings von einem "publizistischen Akt" bzw. von "publizistischer Anerkennung“; s. auch Klaus Vog e 1, aaO., S. 213, 240.

$\left.{ }^{95}\right)$ Weitergehend erwähnt F or s th of $f$, AöR 31, $224 \mathrm{f}$., allerdings eine tberlegung, nach der sich die Widmung auch darauf erstrecken könnte, „den Bestand und die ordnungsgemäße Verwendung der öffentlichen Sache durch mit ihr entstehende positive Pflichtigkeiten der Beteiligten sicherzustellen", lehnt aber selbst tiese „positiv-gestaltende“ Wirkung der Widmung ab. 
setzungen und Wirkungen belasten. Die Widmung ist nicht $t^{80}$ ) als ein Organisationsakt begriffen, der die Sache in die öffentlichrechtliche Ordnung überführt, ihr also einen anderen Status verleih ${ }^{97}$ ), den sog. ",institutionell öffentlichen Status ${ }^{\text {(98)), }}$ jenem Status gleich, der bei der Kreierung einer juristischen Person des öffentlichen Rechts durch den Akt der Organisationsgewalt entsteht ${ }^{\text {98)}}$.

1. Die Organisationsgewalt ist bislang nahezu ausschließlich auf die Erzeugung von Rechtssubjekten oder deren Organe (Behörden, Ämter, Gerichte, Streitkräfte, Verfassungsorgane) bezogen worden ${ }^{100}$, aber ihre Gestaltungswirkung, ihre „Ordnungsgewalt "101), insbesondere ihre Kraft zur Umstrukturierung einer privatrechtlichen Institution in eine öfentlichrechtlich ${ }^{102}$ ), kann sich auch auf Rechtsobjekte erstrecken, solange Rechtssätze nicht entgegenstehen ${ }^{103}$ ). Die Organisationsgewalt besitzt mitnichten nur eine Erscheinungsform ${ }^{104}$ ). Anerkennt

96) Sonst wäre es nie möglich auf das Eigentum, um die Sache zu schützen (vgl. zuletzt BGHZ 33, 230), oder auf eine privatrechtliche Verkehrssicherungspflicht (grundsätzlich BGHZ 9, 380) zu rekurrieren.

$\left.{ }^{97}\right)$ Auch nicht bei $\mathrm{M}$ a u $\mathrm{n}$, der sie als "Mantelrechtsgeschäft" begreift (aaO., S. $219 \mathrm{ff}$ ), oder Klaus $\mathrm{Vogel}$, aaO., S. 213; E. R. $\mathrm{H} \mathrm{u}$ b e r, DOV 55, 130, spricht von einem "generellen Verleihungsakt"; Z i p p eli u s, DƠV 58, 843, 846, von einer "Doppelfunktion".

98) For $s$ th of $f$, VerwR, S. $384 \mathrm{f}$.

89) Für diese ist die juristische Andersartigkeit gegenüber den juristischen Personen des Privatrechts längst anerkannt (vgl. etwa Werner W e b e r, Die Körperschaften usw., S. $10 \mathrm{ff.}$; K ö t t ge n, Verwaltungseinheit, S. 13 ff., jeweils mit weiteren Nachweisen), und zwar auch von privatrechtlicher Seite En n e cerus-Nipperd e y, aaO., $\$ 104$; s. auch F or s th of $f$, Die öffentl. Körperschaft, S. 37, 41.

100) Vgl. insbes. die Zusammenstellung bei Ermacora, VeröffVDStRL 16, $205 \mathrm{ff}$.

101) BayVerfGHE n. F. 4, 165; s. auch BGHZ 9, 387.

102) Vgl. For s th off, VerwR, S. 380.

103) Das hat haftungsrechtlich die Konsequenz der Geltung des $\$ 839$ BGB mit Art. 34 GG. Daß ein Organisationsakt diese Wirkung auslösen kann, bejahe ich mit BGH 9,387 gegen Hans J. W o $11 f$, VerwR I, S. 320 und H. S chneider, NJW 62, 709, Anm. 28. Richtig \& 5 Hamb.-Wege-Gesetz.

104) Zur Organisationsgewalt allgemein $\mathrm{Köttgen}$ und $\mathrm{Er} \mathbf{m}$ ac or a, VeröffVDStRL 16, $154 \mathrm{ff}$;; F o r s t h of $\mathrm{f}$, VerwR, S. $375 \mathrm{ff}$; S p a n n e r, DOV 57, 640 ff.; $\mathrm{H}$ a m a n $n$, NJW 56, 1 ff.; Hans J. Wolff, VerwR II, S. 94 ff.; $R$ a s ch-P a tzig, Verwaltungsorganisation und Verwaltungsverfahren, in: M. v. Brauch i t s ch-Ule, Verwaltungsgesetze des Bundes und der Länder, Bd. 1, 1. Halbb., 1962, S. $11 \mathrm{f}$. jeweils mit Nachweisen des älteren Schrifttums; zu Einzelfragen aus der Rspr. etwa BayVerfGH, BayVBl. 62, $181 \mathrm{ff}$. und E 13, II, $53 \mathrm{ff}$.; BVerwG, DVBl. 62, $371 \mathrm{ff}$. mit Anm. von $\mathrm{H}$ e in ze; BVerwG, JZ62, $62 \mathrm{ff}$. mit Anm. v. Ober ma yer und Bespr. v. M e $\mathrm{g}$ e $\mathrm{r}$, Verw.Arch. 53, $183 \mathrm{f}$. 
man in ihr auch die Macht, die einem "Sozialgebilde" den „institutionell öffentlichen Status“, den „, besonderen Integrationswert der öffentlichen Rechtsform "105) mit spezifisch öffentlichrechtlicher Ordnung, verleiht, so ist es unabweisbar, daß sich diese Rechtsbefugnis nicht nur personalbezogen ${ }^{106}$ ), sondern auch gegenständlich ${ }^{107}$ ), objektbezogen ${ }^{108}$ ) auswirken kann. Die Parallele zum besonderen Gewaltverhältnis ${ }^{109}$ ) wird evident; nur geht es nicht um den Status von Rechtssubjekten, sondern von Rechtsobjekten, Sachen, Einrichtungen, auch Unternehmen ${ }^{110}$ ), für die gleichermaßen eine besondere Rechtsstellung sichtbar werden soll. Der Statusbegriff könnte sich mithin als taugliche Klammer erweisen, so heterogene Erscheinungen wie öffentliche Anstalt, öffentlicher Dienst, öffentliche Sache zusammenzuordnen und als in sich geschlossene öffentlichrechtliche Institute mit eigenem Ordnungswert zu begreifen. Der Organisationsakt als Kreationsakt öffentlicher Sachen bietet ein formales und damit leicht erkennbares Abgrenzungskriterium, das das stets wandelbare und in psychologischen Vorstellungen verhaftete Zweckmoment eliminiert ${ }^{111}$,

105) F o r s th o f $f$, VerwR, S. 385. - K ö t $t$ g e n, VeröffVDStRL Nr. 16, 160 spricht von den "Wechselwirkungen zwischen status und institutio"; s. auch G. E r I e r, Grundprobleme des internationalen Wirtschaftsrechts, 1956, S. 135; H. D o m b o is, Recht und Institution, 1956.

106) Von den privatrechtlichen Statusakten abgesehen, ist eine vielfache Verwendung des Begriffs Status als Inbegriff einer Rechtsstellung des Bürgers (Hans J. W olf $f$, VerwR I, S. 152 ff.), des Ministers (Köt $\mathrm{g}$ e $n$ in: Berichte und Forschungen aus dem öffentlichen Recht, Gedächtnisschrift für W. J ell i n e k, 1955, S. $195 \mathrm{ff}$.), der Bundesverfassungsrichter ( $\mathrm{L}$ e i b h o l z, JOR 6, 114 ff.), festzustellen. - S a s s e, DOV 62, 323 rechnet Gemeingebrauch und Straßenverkehr in das „,allgemeine Statusverhältnis und nicht zu dem anstaltlich gewährten Sondernutzen"; s. auch die Statusakte bei $\mathrm{Obermayer}$, VA und innerdienstl. Rechtsakt, 1956, S. 113.

107) "Verdinglicht“ (Lerche, Ubermaß und Verfassungsrecht, 1961, S. 222).

108) F o r s th of 1 , AöR 31, 253, spricht von einem „öffentlichrechtlichen Status der res sacrae"; s. auch von $\mathrm{Ka} \mathrm{h} \mathrm{r}$, Bayer. Gemeindeordnung, 1896, Bd. 1, S. 398.

109) Vgl. Herbert K r ü g er, VeröffVDStRL 15, 110; M a u nz, aaO., S. 238.

110) Klaus V o g e 1, aaO., S. $227 \mathrm{ff}$.

111) $\mathrm{K}$ ö $t$ tg e $n$ hatte seinerzeit Bedenken, einen Anstaltsbegriff zu prägen, der seine Hauptstütze im Zweckmoment findet (VeröffVDStRL 6, 115). - S. allgemein $\mathrm{K}$ or $\mathrm{m}$ a $\mathrm{n} \mathrm{n}$, PreußVerwBl. Bd. 34, S. 393; für Körperschaften des öffentlichen Rechts Werner W e b e r, Körperschaften usw., S. 81, 84; F or s th of $f$, Die öffentliche Körperschaft, S. 12 bezeichnet den verwandten Begriff des öffentlichen Interesses als reines "Motivationsprinzip". 
2. Die Frage der Gesetzesabhängigkeit der Organisationsgewalt ist für das öffentliche Sachenrecht weitgehend entschärft. Wege und Gewässer besitzen fast durchweg einen gesetzlich geordneten Status. Für die öffentlichrechtliche Institutionalisierung des Verwaltungsapparats gibt der in der Verfassung liegende Verwaltungsauftrag ${ }^{12}$ ), die Mission der Verwaltung, der Exekutive die Kompetenz, die für die Behördentätigkeit notwendigen "Arbeitsaggregate" und Betriebsmittel öffentlichrechtlich zu organisieren Offen bleibt, wem die Verfügungsmacht zusteht, die übrigen Sachen, besonders anstaltlich zu nutzende Sachen, in das öffentlichrechtliche Organisationsmodell zu überführen, z. B. die Vielzahl der Unternehmen der Daseinsvorsorge, wie Friedhöfe ${ }^{113}$ ), Müllabfuhr, Bahn ${ }^{114}$ ), Post ${ }^{115}$ ) öffentliche Waagen ${ }^{116}$ ) usw. ${ }^{117}$ ). Die Uberschneidung von offentlichem Anstalts- und Sachenrecht ist hier augenfällig. Den gestaltenden Faktor, den Institution und Organisation der Anstalt entfalten, halte ich gegenüber der Ordnungseinheit öffentliche Sache für dominant, weil bei diesen Einrichtungen das sächliche Substrat zwar eine wichtige Rolle spielt, aber daneben ein bedeutsamer Verwaltungsapparat existiert, der das Ganze zu einer abgeschlossenen Einheit eigener Prägung zusammenfaßt und ihm eine der Art des Unternehmens angepaßte eigengeartete Rechtsform und Nutzungsordnung verleiht, denen die Strukturen des öffentlichen Sachenrechts weichen. Offentliche Anstalten, die öffentliche Sachen bereithalten, erweisen sich letzteren gegenüber als Organisationsform einer höheren Ebene. Die öffentliche Organisation hat sich indes bei derartigen Unternehmen nicht in vollem Gewicht durchgesetzt, obwohl $\mathrm{K}$ öttgen schon 1929 die privatrechtliche Nutzungsordnung der öffentlichen Anstalt als "Schönheitsfehler" bezeichnet hat ${ }^{118}$ ). Praktikabili-

112) Vgl. M a l l m a n n, VeröffVDStRL 19, 186; $\mathrm{Z}$ e i d l e r, Gutachten, S. 53; H. P eter s, Festschrift für H. H u ber, 1961, S. 206 ff.; $\mathrm{H}$ a u e i s e n, DVBl. 62, 881 unter Berufung auf $\mathrm{E}$. K a u $\mathrm{f}-$ m a n n, VeröffVDStRL 9, 8; VG Frankfurt, RzW 62, 573.

113) BayVGH, BayVBl. 60, 56; BGH, DOV 62, 545; E y e r m a n nFröhler, Komm. z. VwGO, Rdnr. 54, §40; Berl. FriedhofG v. 12. 7. 1956 (GVBl. S. 918); G a e d k e, Handb. d. Friedhofs- u. Bestattungsrechte, 1954, S. $8 \mathrm{ff}$.

114) Werner $H$ a u s t e i $n$, Die Eisenbahnen im deut. öffent. Recht, 1960 , bes. S. 74 ff.; Bad-Württ. VGH, Verw.Rspr. 8, 447; BGH, BB 60, 42; B a u r, JZ 63, 44.

115) BGHZ 16, 111; 20, 102; BVerwGE 10, 275 ff.; OLG Köln, JR 62, 24; Hess. VGH, VerwRspr. 11, 1034; Bad-Württ VGH, ESVGH 6, 152; $S$ te in $m$ e t $z$ und $K$ ä $m$ m e re r, APF 1958, S. $1 \mathrm{ff}$.

116) M ang el s, BayBgm. 62, 58.

117) Weitere Beispiele bei Hans J. W o $1 f f$, VerwR II, S. 256.

118) VeröffVDStRL 6, 123; ders auch in Fra n k, Deut. VerwR, S. $441 \mathrm{f}$. 
tätserwägungen und Utberlieferung waren offenbar stärker als die Idee des Formenfehlgebrauch ${ }^{119}$ ).

3. Der Organisationsakt, der den institutionell öffentlichen Status einer Sache begründet, kann, wie andere Organisationsakte, Verfassungsrechtssatz, Gesetz einschließlich des Gewohnheitsrechts, Rechtsverordnung oder Satzung sein oder auf deren Grundlage als Einzelakt ergehen. Auch im letzteren Falle erschöpft er sich in seinen Rechtsfolgen nicht im internen Verwaltungsbereich, und zwar selbst dann nicht, wenn Eigentümer und öffentlichrechtlicher Sachherr identisch sind; denn die Begründung des institutionell öffentlichen Status richtet sich stets auch an die Allgemeinheit ${ }^{\mathbf{1 2 0}}$ ), weil gegenüber jedermann "eine allgemein wirkende Rechtslage" hergestellt wird ${ }^{121}$ ). Er besitzt mithin stets auch ein normatives Element ${ }^{122}$ ), das ihn von der Anfechtungsklage ausnimmt. Die Qualität als Verwaltungsakt muß allerdings gegenüber dem Eigentümer angenommen werden, sofern dieser ein anderes Rechtssubjekt ist als der organisierende Sachherr ${ }^{\mathbf{1 2 3}}$ ).

\section{VI.}

Nach der hier entwickelten Konstruktion erweist sich die öffentliche Sache nicht als privatrechtlich mit öffentlichrecht-

119) H. S c h n ei der, NJW 62, 706, Anm.9, trat jüngst wieder für ein Festhalten an privatrechtlichen Nutzungsordnungen ein, wo sie überkommenen und bewährten Vorstellungen entsprechen. - Uber die Freiheit der Wahlmöglichkeit des Anstaltsträgers vgl. BGHZ 34, 206 f.; BayVerfGH 9, II, $114 \mathrm{ff.}$

120) F orsth of $f$, VerwR, S. 334 nimmt bereits für die Widmung, deren wesentlicher Gehalt, "nämlich die Unterstellung der Sache unter das öffentliche Recht“, an, daß sie „für jedermann gilt".

121) F or s t h of $f$, aaO., S. 385. - Der Organisationsakt verkörpert auch jene der Allgemeinheit gegenüber kundzugebende Erklärung, die der BGH für die Annahme einer öffentlich-rechtlichen Nutzungsordnung verlangt ( $\mathrm{E} 9,387 ; 20,59 ; 27,281 ; 34,209 \mathrm{f}$.).

122) A. A. F o r s t h of $\mathrm{f}$, aaO., S. $385 \mathrm{f}$; "konstitutiver Rechtsakt, ohne normativen Charakter", differenzierend BayVGH, BayVBl. 56,121 und DVBl. 60, 401; wie im Text wohl auch Werner Weber, Körperschaften usw., S. 29; O bermayer in: $\mathbf{M}$ a $\mathbf{n} \mathbf{g}$ $\mathrm{M}$ a u nz-M y e $\mathrm{r}-\mathrm{O}$ be $\mathrm{rm}$ a y e $\mathrm{r}, \mathrm{S}$. 166 .

123) Eine solche Doppelnatur mag mißlich erscheinen; sie ist aber mitunter, und zwar nicht nur bei Organisationsakten, unvermeidlich; vgl. die Qualifizierung von Umgemeindungen gegenüber Gemeinde bzw. Bürger (dazu $S \mathrm{ch} \mathrm{a} \mathrm{ck,} \mathrm{DOV} \mathrm{58,} 273 \mathrm{ff}$; O O e r m a y e r, BayVBl. 58, $69 \mathrm{ff}$.; $\mathrm{s} \mathrm{c} \mathrm{h} \mathrm{w} \mathrm{e} \mathrm{i} \mathrm{g} \mathrm{e} \mathrm{r,} \mathrm{BayVBl.} \mathrm{56,} 72 \mathrm{ff}$.); ferner die staatlichen Mitwirkungsakte bei Rechtsetzungsakten von Selbstverwaltungsorganisationen (dazu Obermayer, in: $M$ a n $\mathbf{g}-\mathbf{M}$ a unz-M a e r - O berm a yer, $S .273$ ff. mit Nachweisen, ferner M e $n g$ ex, Verw.Arch. 52, 410 ff.; E y e r m a n nFröhle r, Komm. z. VwGO, Rdnr. 38 zu § 42). 
lichen Schranken versehen, letztlich "halböffentliches" Institut, sondern als eine Einrichtung, die durch einen öffentlichrechtlichen Akt geschaffen und darum auch ausschlieBlich öffentlichrechtlich geordnet ist. Ihre publizistische Qualität beruht ebensowenig auf einer Modifizierung des Eigentums römischrechtlicher Provenienz, wie auf einem öffentlichrechtlichen Eigentum Otto $\mathrm{M}$ a y e $\mathrm{r}$ scher Prägung, sondern auf der fortentwickelten deutschrechtlichen Regalität ${ }^{124}$ ). Das Eigentum ist seiner dynamischen Funktion der Verfügungs- und privatnützigen Verwendungsfreiheit ${ }^{125}$ ) entkleidet ${ }^{126}$ ). Es besitzt nur noch die statistische Position, die Sache nicht zur res nullius werden zu lassen ${ }^{127}$ ). Die entscheidenden Akte im Ge-

124) Klar und folgerichtig erweist sich die Verfassungsrechtslage für das Kirchengut, das Art. 14 und Art. 140 GG mit Art. 138 Abs. 2 Weim.Verf schützt. Beide Vorschriften haben jedoch verschiedene Schutzfunktionen: einerseits die privatrechtliche Nutzungsbefugnis, andererseits die im rechtlich verselbständigten Kirchengut zum Ausdruck kommende, historisch aus anderen Wurzeln entspringende öffentliche Funktion dieser Sachen (vgl. H a m a n n, Komm. z. GG, 2. Aufl., Anm. 12 zu Art. 140 mit Nachw.; ferner Forst h of $f$, AOR 31, 212; M. W o l f $f$, Festgabe f. Kahl, 1923, S. 3 ff.).

125) Das private Gesellschaftsrecht kann hier insofern als Parallele herangezogen werden, als auch dort Eigentum und wirtschaftliche Gestaltungsmacht - Managment - auseinanderfallen können. Auch das Steuerrecht beharrt nicht mehr starr auf dem Eigentumsbegriff, sondern erkennt auf Grund der ihm immanenten - sicher nicht durchweg $\mathrm{zu}$ billigenden - Eigenprägung auch eine eigentumsähnliche wirtschaftliche Sachherrschaft an.

126) Nicht so weitgehend $K$ öttgen, Gemeindliche Daseinsvorsorge, S. 33; richtig $\mathrm{M}$ a hler, aaO., S. 37; S i evers, DVBl. 60, 460: „Das Primäre ist... an den Wasserstraßen... der öffentlichrechtliche Status der Wasserstraße als öffentliche Sache. Fiskalisches Eigentum ist Folge, nicht Voraussetzung der Eigenschaft als Wasserstraße". Sehr weitgehend $\mathrm{Cl}$ a s e $\mathrm{n}, \mathrm{DOV} 59,284$. Tartarin-Tarnheyden hat seine Untersuchung über das Staatsvermögen ebenfalls nicht auf das Eigentum, sondern auf das Erfaßtsein der Sachgüter durch „die hoheitliche Verfügungsgewalt des Staates" abgestellt. Im weiteren Sinne bezieht er auch die

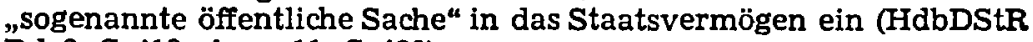
Bd. 2, S. 419, Anm. 11, S. 420).

127) Im Ergebnis zutreffend v. T u reg $\mathrm{g}-\mathrm{K}$ r a u s, Verwaltungsrecht, S. 180, Anm. 3; K ö t t g e n, Gemeindliche Daseinsvorsorge, S. 29; ders. in Fra nk, Deut. VerwR, S. 436, 446 („Auffangorganisation der Privatrechtsordnung "); gegen eine Eigentumslosigkeit öffentlicher Sachen schon $\mathrm{R}$ oth, Bayer. Civilrecht, Bd.1, S. 332, Anm. 15; zuletzt Klaus $R$ e in hardt, Berechtigung und Bedeutung des Eigentums an Wasserläufen nach deut. Wasserrecht, Diss., Bonn, 1960; Siegbert T o b e r, Der Rechtsstatus der Jade, Diss., Göttingen, 1961, S. 95 ff. Aus dem positiven Recht vgl. Art. 89 f., 134 f. GG, Gesetz über das Reichsvermögen (BGBl. I 1961, S. 597) und die ebda. \$15 erwähnten weiteren Gesetze. - Durch die Freistellung von der Buchungspflichtigkeit (\$ $3 \mathrm{Nr} .2$ a GBO) und von Grund- und Grunderwerbssteuer ( $\$ 4$ GrStG-dazu BFH, NJW 62, 
schehen der öffentlichen Sache, wie Nutzung ${ }^{128}$ ) und Unterhaltung, sowie die Entziehung des institutionell öffentlichen Status erfolgen ohne substantielle Mitwirkungsrechte des Eigentümers ${ }^{129}$ ). Darin liegt mitnichten eine Enteignung auf kaltem Wege; denn der öffentlichrechtliche Status kann nur begründet werden, wenn der organisierende Sachherr selbst Eigentümer ist oder wenn zwar ein anderer Eigentümer ist, dieser aber dem Organisationsakt zustimmt ${ }^{\mathbf{1 3 0}}$ ). Bis zur öffentlichrechtlichen Institutionalisierung hat also das Eigentum seine volle verfassungsrechtlich gewährleistete Abwehrfunktion; darnach hat die öffentlichrechtliche Sachherrschaft seine capitis deminutio vorgenommen, die mit der Aufhebung des öffentlichrechtlichen Status wieder rückgängig gemacht wird $^{\mathbf{1 3 1}}$ ).

\section{VII.}

Durch die Eliminierung privatrechtlicher Rechtspositionen aus der Institution der öffentlichen Sache ist eine konstruktive Lösung der Ungereimtheiten und Unvollkommenheiten des öffentlichen Sachenrechts angebahnt ${ }^{132}$ ):

$1415-, 4$ Nr. 4 ff. GrErwStG) ist das Eigentum auch für solche außerhalb des öffentlichen Sachenrechts liegende Tatbestände kein notwendiger Anknüpfungspunkt.

128) Die stets als privatrechtlich angesehenen Verträge über Obstund Grasnutzung (vgl. F le i n e r, Institutionen, S. 359; G e r mersh a u sen-seydel, Wegerecht und Wegeverwaltung in Preußen, 4. Aufl., Neudruck 1955, Bd. 1, S. 109) können als belanglos außer Betracht bleiben (ebenso $K$ öttgen, Gemeindliche Daseinsvorsorge, S. 27). - Für Eigentumsübertragung und dingliche Belastung, die praktisch so selten sind, gilt gleiches. Sie berühren auch den institutionell öffentlichen Status nicht (ebenso $\mathrm{H}$ a a s, DVB1. 62, 655).

129) A. A. noch zuletzt BGHZ 36, 1 ff. - Eine Auseinandersetzung über den Charakter des Eigentums an einer öffentlichen Sache ist daher entbehrlich (vgl. etwa die Erwägungen zum Verwaltungsoder öffentlichen Wirtschaftseigentum bei $\mathbf{E}$. $R$. $\mathrm{Hu}$ ber, Wirtschaftsverwaltungsrecht, Bd. 1, S. $64 \mathrm{f}$., und Gottfried $\mathrm{L}$ a n $\mathrm{g}$ er, Recht und Staat, Heft 239/240, 1961; ferner v. K ö h le r, DVBl. 58, 191). Uber das Volkseigentum der SBZ $\mathrm{K}$ r a m e $\mathrm{r}$, Verw.Arch. 52, $325 \mathrm{ff}$.

130) Richtig z.B. Si eder-Z e itler, Komm. z. BayStrWG, Rand Nr. 1, 5 ff. zu Art. 11; 5 ff. zu Art. 13 und Note 1 zu Art. 22, S. 177 ; Köttg e n, Gemeindliche Daseinsvorsorge, S. 31, 33; ders. in F r a n k, Deut. VerwR, S. 448.

131) Hier besteht im Ergebnis Einklang mit der h. M. Vgl. etwa BGHZ 9, 373 ff.; BGH, DVBl. 62, 178; BayObLG, Dt. Wohn-Wirtsch. 62, 23; Köt tg e n in: Frank, Deut. VerwR, S. 446; zur "Entwidmung " auch OVG RhId.-Pfalz, AS 8, $241 \mathrm{ff}$.

132) Allgemein zur Einwirkung des Privatrechts auf das offentliche Recht und über die Bedenklichkeit dieses Zustands jetzt Gi a c o met $t$, Allg. Lehren des rechtsstaatlichen Verwaltungs- 
1. Der Schutz der öffentlichen Sache erfolgt nicht mehr mit den Mitteln des Eigentumsrechts ${ }^{133}$ ), sondern auf der Grundlage der öffentlichrechtlichen Sachherrschaft durch die Befugnis, jeden auszuschließen, der rechtswidrig die Funktion der öffentlichen Sache stört. Man mag hier von einer „Polizei“ der öffentlichen Sache sprechen ${ }^{\mathbf{1 3 4}}$ ).

rechts, 1960, S. $112 \mathrm{ff}$. - Das italienische Recht sagt schlicht: beni pubblici sono amministrati (Art. 1, Gesetz v. 18.11.1923 [n. 2440]), während die beni patrimonali "oggetto di rapporti giuridici privati“ sind, allerdings mit gewissen öffentlichrechtlichen Beschränkungen (vgl. $\mathrm{Z}$ a n o b i n i, aaO., Bd. 4, S. 5 ff.; $\mathrm{Ca} \mathrm{m} \mathrm{meo,} \mathrm{Corso}$ di diritto amministrativo, 1960, S. 477).

${ }^{133}$ ) So noch BGHZ 33, 230, mit Anm. von Ne d d e n, DVBl. 61, 249; das Urteil zeigt deutlich, welche Schwächen diese Schutzmittel aufweisen.

134) Polizei ist hier als eine Summe von Befugnissen zum Schutz der öffentlichen Sache vor Gefahren und Störungen für deren Substanz und Funktion verstanden. Von dieser Sachpolizei abgespaltet ist die Verkehrspolizei, deren Befugnisse auf die Ordnung des Verkehrs gerichtet sind (zu diesen polizeilichen Aspekten vgl. Evers, NJW 62, 1034, mit weiteren Angaben, und B e t t e r m a n n, Deut. Autorecht, 1962, Sonderdruck, S. 8; N e d d e n, DOV 59, 844; B r o h I, DVBl. 62, 392). - Eine ältere Auffassung konstruiert, ähnlich der Anstaltspolizei (darüber F or s th of $f$, VerwR, S. 398; Karl S c h ö p f, Offentliche Anstalt und Polizei, Diss., Erlangen, 1958; OVG Berlin, AS 4, 183, und 1, 254) eine Polizei der öffentlichen Sache, deren Rechtsgeltung und Befugnisse allein auf der "Eigenart" der öffentlichen Sache oder auf der öffentlichrechtlichen Sachherrschaft beruhen (vgl. M a u n z, aaO., S. 286; O. M a y e r, Verwaltungsrecht, 2. Aufl., Bd. 2 S. $124 \mathrm{ff}$.; F l e i n e r, Institutionen, S. 330; T h om a, Der Polizeibefehl im badischen Recht, 1906, S. 373; Me r te n, aaO., S. 51; pr. OVG 105, $179 \mathrm{f}$; $\S \S 55 \mathrm{ff}$., $65 \mathrm{ff}$. preuß. Zuständigkeitsgesetz v. 1. 8. $1883-$ GS, S. $237-$ ). Eine derartige Zwangsgewalt gegen Dritte muß nach rechtsstaatlichen Grundsätzen jedoch auf eindeutiger gesetzlicher Grundlage beruhen (Forsth of $f$, aaO., S. 384, 398; $M$ a unz, aaO., S. 287).

Indes wird man zwei Seiten der Sachpolizei unterscheiden müssen: einmal gegen den Benützer im Rahmen eines besonderen Rechtsverhältnisses, zum anderen gegen „untitulierte“ Benützung. Im ersten Fall dürfte es sich zwar nicht um Polizei handeln, sondern um die Geltendmachung von Befugnissen aus einem Rechtsverhältnis (z. B. Widerruf der Sondernutzungserlaubnis bei Uberschreiten der zugelassenen Nutzung; Schadensersatzansprüche wegen Verletzung öffentlichrechtlicher Pflichten [dazu Hans J. W o l f f, VerwR I, S. 209 ff., 215 ff.; $K$ ö t $\mathrm{tgen}$ in F r a $\mathrm{k}$, Deut. VerwR, S. 443]). Solange es hingegen im zweiten Fall an entsprechenden als Annex zur Sachordnung gesetzlich zu schaffenden (vgl. Herbert K r ü g e r, Der Rundfunk usw., S. 65 ff.) Eingriffsbefugnissen (vgl. früher $\$ 21$ preuß. WG, jetzt $\$ 67$, Satz 2 BerlWG; gegen die Generalklausel des $\S 4$, Satz 2 HambWegegesetz möchte ich rechtsstaatliche Bedenken anmelden; generalklauselartig auch Art. 823, Abs. 2, ital. Cod. civ. von 1942) fehlt, muB auf das allgemeine Polizeirecht rekurriert werden (vgl. auch BGHZ 33, 230; Köttgen, aaO., S. 436, 443). 
2. Benutzungsrechte erteilt allein der öffentlichrechtliche Sachherr ${ }^{135}$ ).

3. Erhaltung, Unterhaltung ${ }^{136}$ ) und Verkehrssicherung sind im öffentlichen Recht verwurzelt ${ }^{137}$ ).

4. $\$ 40$, Abs. 1 VwGO begründet für Streitigkeiten die $\mathrm{Zu}-$ ständigkeit der Verwaltungsgerichte ${ }^{\mathbf{1 3 8}}$ ).

5. Probleme der Lenkung der Nr:tzungskapazität brauchen nicht mit sachinadäquaten fiskalischen Mitteln gelöst zu wer$\operatorname{den}^{130}$ ).

C.

Das positive Wasser- und Wegerecht

des Bundes und der Länder

I.

Die Abweichung meiner Konstruktion von der h. M. wäre leichter in Kauf zu nehmen als der Widerspruch zum positiven

135) Die Einschaltung des Eigentümers bei der Vergabe von Sondernutzungen ist ja bekanntlich ein großer Streitpunkt in der bisherigen Doktrin; vgl. etwa $O$. $M$ a y e $r$, Verwaltungsrecht, 2. Aufl., Bd. 2, S. 158; E. R. H u b e r, Wirtschaftsverwaltungsrecht, Bd. 2, S. 597; S t e r n, AöR 84, 158 ff. mit weiteren Nachweisen; zuletzt BGH, DVBl. 62, 178. Erhebliche Schwierigkeiten in der Praxis sind die Folge solcher Stilwidrigkeiten. Der Eigentümer besitzt gegen das Allgemeinwohl (z. B. bei der Energieversorgung) nahezu ein Vetorecht.

136) Vgl. dazu Bay Kompetenzkonfliktsgerichtshof, Bay VBl. 58, 54; Ket te r e r, Die Streupflicht, 2. Aufl., 1957.

137) Für letztere a. A. die Rspr. des BGH (zuletzt BGH, MDR 62, 549; NJW 62, 1051; DVBl. 62, 866 mit Anm. von M a r s c h a 11) seit BGH 9, 373 ff.; s. früher pr. OVG 18, 415. Wie im Text $\S 5$ HambWegeG und das Schrifttum (vgl. etwa $H$. S c h n e ider, NJW 62, 707; Ever s, JuS 61, 125 ff.; $S$ t e r n, AöR 84, 164 ff. jeweils mit weiteren Nachweisen; zuletzt Friedrich-Adolf $J$ a h n, Rechtsanspruch bei Verletzung der Verkehrssicherungspflicht auf öffentl. Straßen, Diss. Münster 1961; Fr e u n d, NJW 62, 614; T h i e r f e ld e r, DOV 62, 256.

138) Für Gewässer vgl. S i e ver s, DVBl. 62, $193 \mathrm{ff}$; BVerwG, DVB1. 61, 248; OVG Münster, OVGE 15, $294 \mathrm{ff.;}$ E y erm a n nFröhler, Komm. z. VwGO, Rdnr 15 zu $\S 40 ; \mathrm{H}$ a a s, DVBl.62, $656 \mathrm{f}$.

139) Vgl. dazu I p s e $n$, Das Verbot des Massengütertransports im Straßenverkehr, Rechtsgutachten zum Regierungsentwurf eines Straßenentlastungsgesetzes, 1954; H. P e te r s, Die Verfassungsmäßigkeit des Verbots der Beförderung von Massengütern im Fernverkehr auf der Straße, Rechtsgutachten, 1954; S ch e u ne r, Die Abmessungen der Lastkraftfahrzeuge und die Verkehrspolitik, Rechtsgutachten in: Der Güterverkehr 1956, S. 205 ff.; H. S c h n e i de $r$, Zur Neufassung von Abmessungen und Gewichten im StraBenverkehr, Rechtsgutachten, 1956; ferner Klaus $\mathrm{H}$ a s ela u, aaO. 
Recht, besonders hinsichtlich des Schutzes der öffentlichen Sache und der Vergabe von Sondernutzungen im Wegerecht. Ich glaubte jedoch, mein Thema falsch zu verstehen, wenn ich nur eine Analyse der widersprüchlich und uneinheitlich konzipierten bestehenden Gesetze und eine Repristination des undurchsichtigen Dogmas der verfehlten Verschränkung privaten und öffentlichen Rechts geboten hätte. Die Gesetze des öffentlichen Sachenrechts sind infolge ihrer Konstruktionsfehler zu einem Problem der Rechtsprechung geworden. Der Gesetzgeber wird darum guttun, sich den Grundfragen des allgemeinen öffentlichen Sachenrechts zu stellen; das Hamburgische Wegegesetz ist bereits der Testfall ${ }^{140}$ ).

\section{II.*)}

Nachstehend seien folgende wesentliche Abweichungen des positiven Rechts hervorgehoben:

1. Wegerecht ${ }^{\mathbf{1 4 1}}$ ):

a) Die Widmung ist nicht als Organisationsakt verstanden - ausgenommen wohl in den Rechtsfolgen das HambWegeG - , der die Sache öffentlichrechtlich institutionalisiert, sondern als „Verfügung", die die allgemeine Nutzung, insbesondere den Gemeingebrauch eröffnet (vgl. §§ 2, 7 BFernstrG; Art. 6, 14 BayStrWG - GVBl. 1958, S. 147 -; $\S \S 1,3,8$ BerlStrG — GVBl. 1957, S. 743 -; 1, Abs. 1 BremStrO - GVBl. 1960, S. 51 -; 2, Abs. 1, 4, Abs. 1,

140) S. auch D. H a a s, DVBl. 60, 304; 62, 653; S c h a c k, DVBl. 61, 897 ff.; v. K ö h l e r, Verw.Arch. 50, 222 f. - Dagegen meint K r ö m e r, DVBl. 62, $423 \mathrm{f}$. (Buchbesprechung): „Die in geduldiger Arbeit entwickelte herrschende Theorie der öffentlichen Sache hat nicht nur Lebensfähigkeit bewiesen, sondern ist die einzige, die zwanglos und einleuchtend die einschlägigen Erscheinungen erklären kann."

*) Aus Gründen der Zeitersparnis wurde dieser Abschnitt nicht vorgetragen.

141) Neben der schon erwähnten Literatur noch: $B$ a $u$ m e is te $r$, Zur Geschichte und Problematik des deutschen Straßen- und Wegerechts, 1957; F rits ch-Golz, Straßengesetz des Landes Nordrhein-Westf., 1962; J. W. G ot t s c h a lk, Handb. des niedersächs. Wegerechts, 1961; Ludwig Schwar z müller, Die verfassungsrechtlichen Grundlagen des Wegerechts, Diss. München 1961; Spanner. Grenzen zwischen öffentlichem und bürgerlichem Recht im Wegerecht, 1958; Wessel de Weldige-Cremer, Die Benutzung öffentl. Verkehrswege nach der neuen Wegegesetzgebung, insbes. dem Entwurf eines Straßengesetzes des Landes Nordrhein-Westf., Diss. Münster 1960; Z i m n i o k, Komm. z. BayrStrWG, 1961; B o ch a 11 i, DVBl. 59, 612; C a 11 s e $n$, GewArch. 60, 177; F I o e r k e, MDR 61, 993; G r o e b e, DOV 58, 832 und BayVBl. 59, 181; R a th, Staats- und Kommunalverw. 60, 154. 
14 HessStrG - GVBI. I 1962, S. 437 -; 6, NiedersStrG GVBl. 1962, S. 251 -; 2, Abs. 1, 6, Abs. 1, 14 Nordrh-WLStrG - GVBl. 1961, S. 305 —; 2, Abs. 1, 6, Abs. 1, 20 SchlHStrWG - GVBl. 1962, S. 237 - ${ }^{142}$ ).

b) Das Eigentum besitzt - abgesehen vom HambWegeG, $\S \S 4$, 19 - nicht die nur statische Bedeutung, sondern ist auch nach der Widmung zumindest mitentscheidendes Element ${ }^{143}$ ), und zwar in folgenden Punkten:

aa) Ausschließliche Mitwirkung bei der Erteilung von Sondernutzungen, die den Gemeingebrauch nicht oder nur kurz für Zwecke der öffentlichen Versorgung beeinträchtigen (§ 8, Abs. 10 BFernstrG; Art. 13, Abs. 1, 18, 22 BayStrWG; $\S \S 20$, Abs. 1 HessStrG; 23, Abs. 1 NiedersStrG; 23, Abs. 1 Nordrh-WLStrG; 28, Abs. 1 SchlHStrWG);

bb) Notwendige Mitwirkung bei der Erteilung jedweder Sondernutzung nach $\S \S 8$, Abs. 1, 10, Abs. 1, 11 BerlStraßG; 2, Abs. 2, Satz 2 BremStrO.

cc) Der Schutz der öffentlichen Sache gegen Beeinträchtigung durch Dritte erfolgt auf Grund der $\$ \S 903$ ff.,

142) Die gegen meine wegerechtlichen Ausführungen AöR 84, 158 gerichteten Angriffe von $K$ öttgen, Gemeindliche Daseinsvorsorge, S. 26 beruhen auf der rechts - p o l i t i s c h e n Erwägung, den Einfluß des öffentlich-rechtlichen Sachherrn möglichst weit auszudehnen. Das begrüße ich durchaus. Ich sah mich allerdings damals, $1958 / 59$, nicht in der Lage, dies de lege lata aus der Widmung als dem entscheidend die öffentliche Sache rechtskonstitutiv erfassenden Akt begründen zu können. Die jetzt gegebene Konstruktion vermeidet es, dem Eigentümer einen zu starken Einfluß einzuräumen und glaubt, den Vorteil in Anspruch nehmen zu können, dogmatisch sauberer zu begründen als aus der "Zweckbestimmung “

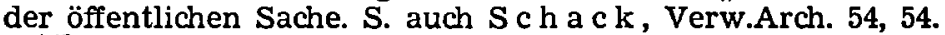

143) Vgl. G e rm e r s h a u s e n-S ey d e I, Bd. 1, S. 90 ff.; S i e d e $r-Z$ e it l e $r$, Komm. z. BayStrWG, Rand-Nr. 38 ff. zu Art. 6, 3 ff. zu Art. 18; Köttgen, Gemeindl. Daseinsvorsorge, S. 31; S te r n, AöR 84, 158 ff.; pr. OVG 50, 284; BVerwG v. 24. 8. 1956, I B 94. 56. Bekanntlich gibt es auch bei den Vertretern der h. M. eine starke Tendenz, die diese Eigentumsposition, jedenfalls soweit sie bei Hoheitsträgern liegt, durch öffentlich-rechtliche Grundsätze (Grundrechte, Verhältnismäßigkeitsprinzip, venire contra factum proprium, Vorhandensein von Motiven öffentlicher Verwaltung; vgl. S i e d e r- Z e itl e r, aaO., Rand-Nr. 43 zu Art. 6 ; K öt tgen, aaO., S. 26 ff.; S c h i c k, DOV 62, 935) beschränken will, aber hierbei handelt es sich doch immer um Erwägungen, die nicht dem Gesetz entnommen sind, sondern von außen, gewissermaßen aus dem Wesen der öffentlichen Sache als Verwaltungsinstitution, herangetragen werden. Sie charakterisieren trefflich die gesetzlichen Strukturfehler, sind aber nur Korrektur an Symptomen der Krankheit. - Uber die Rechtslage für die Versorgungswirtschaft nach den neuen Gesetzen, S c h a c k, Verw.Arch. 54, $57 \mathrm{ff}$. 
1004 BGB. Die Wegegesetze regeln diese Rechtsfolge zwar von § 6, Abs. 1 B FernstrG, Art. 13 Abs. 1 BayStrWG sowie $\S \S 13$, Abs. 1 NiedersStrG und $\S 13$, Abs. 1 Schl-HStrWG abgesehen, nicht ausdrücklich, aber sie ist notwendige Konsequenz der Eigentumsfähigkeit der öffentlichen Wege (vgl. $\S \S 10 \mathrm{ff}$. Nordrh-WLStrG, 8 Abs. 1 BerlStraßG).

dd) Verliehene Sondernutzungen unterliegen als „verwaltungsrechtliche Besitzstände" oder "intransitive" subjektive öffentliche Rechte dem zivilrechtlichen Schutz ${ }^{144}$ ).

2. Wasserrecht ${ }^{145}$ ):

a) Die größeren Gewässer stehen auf Grund gesetzlicher Regelung allgemeiner Nutzung frei, ohne daß jedoch eine durchgängige, wohl aber stärkere ${ }^{146}$ ) öffentlichrechtliche Institutionalisierung vorliegt, $(\S \S 2,23 \mathrm{f}$. WHG, 5 WStrRG ${ }^{147}$ ), 2, Abs. 3, 26, 36 Bad-WürttWG - GBl. 1960, S. 17 -; Art. 4 ff., 23 ff. BayWG - GVBl. 1962, S. 143 -; $\$ \$ 25$ ff. BerlWG - GVBI. 1960, S. 133 -; 61 ff. BrWG GVBl. 1962, S. 59 -; 9 ff. HambWG - GVBl. 1960, S. 335 -; 27 ff. HessWG - GVBl. 1960, S. 69 -; $55 \mathrm{ff}$. NiedersWG GVB1. 1960, S. $105-; 6,31$ ff., Nordrh-WestfLWG - GVBl. 1962, S. 235 -; 26 ff. Rhld-PfWG - GVBl. 1960, S. 153 -; 24 ff. SaarlWG - Amtsbl. 1960, S. 511 -; 17 ff. Schl-HolstWG - GVBl. 1960, S. 39 -).

b) Konsequenz der ausschließlich öffentlichrechtlichen Konstruktion der Erteilung von Sondernutzungen ( $\$ 2 \mathrm{ff}$. WHG, 4 ff. WStrRG) wäre es, die Eigentumslage aus dem Wasserrecht zu eliminieren, wie es Art. 664, Abs. 2 Schw ZGB tut. Eine Eigentumslosigkeit der Gewässer anzunehmen, wäre nach früherem ${ }^{148}$ ) und auch nach jetzigem Rech ${ }^{149}$ ) falsch, ob-

144) Vgl. Hans J. W o l ff, VerwR I, S. 224, 226, 230; OLG Köln, NJW 62, 302 .

145) Neben der schon erwähnten Literatur noch: Berg d o ld t, PreuBisches Wasserrecht, 1957; Gi e s e k - A b t, Schrifttum und Rspr. des Wasserrechts, Recht der Wasserwirtschaft, Heft 8, 1960;

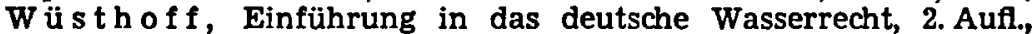
1957; Komm. z. WHG von $G$ ä B l e r, 1958; K o l b , 1958; W i t z e I, 1962, sowie die Kommentare zu den neueren Landeswassergesetzen: ferner G i e s e k e, DƠV 57, 735; 58, 324; BB 60, 1152; in Festschrift für L e hmann, 1956, Bd. 1, S. 308 ff.; G r i m m e, JR 60, 201; Köhler, BB 60, 601; Kübler, DOV 61, 936; Linkel mann, DOV 60, 521 .

140) Die Einwirkung der Regalien war im Wasserrecht offenbar stärker als im Wegerecht; so auch $\mathrm{K}$ öt $\mathrm{tg}$ e $\mathbf{n}$, Gemeindliche Daseinsvorsorge, S. 19, 29: „[Im Wasserrecht] wird die publizistische Note akzentuiert, [im Wegerecht] bemüht man sich sorgfältig um Konservierung privatrechtlicher Elemente ${ }^{\text {“. }}$ 
wohl WHG und WStrRG Eigentumsrechte nicht erwähnen. Art. 89, $90 \mathrm{GG}$, das Bundeswasserstraßengesetz vom 21. Mai 1951 (BGBl. I, S. 352) und die Landeswassergesetze verankern ein privatrechtliches ${ }^{150}$ ) Eigentum an den Gewässern, das auch dynamische, wenngleich weniger starke, Funktionen verleiht, wie:

aa) den Eigentümergebrauch ( $\S 24$ WHG, 28 Bad-WürttWG, Art. 24 BayWG, §§ 26 BerlWG, 64 BrWG, 13 HambWG, 28 HessWG, 58 NdsWG, 33 Nordrh-WestflWG, 28 Rhld-PfWG, 27 SaarlWG, 21 Schl-HolstWG).

bb) Während nach früherem Recht für die Erteilung von Sondernutzungen die Zustimmung des Gewässereigentümers jedenfalls nach preußischem und bayerischem Recht erforderlich war ${ }^{151}$ ), ist sie nach den neuen landesrechtlichen Regelungen ( $\S \S 11$ f. Bad-WürttWG, Art. 4, Abs. 2 BayWG, §§ 13 BerlWG, 5, 62 BrWG, 8 HambWG, 14 HessWG, 5 NdsWG, 12 Nordrh-WestfLWG, 12 Rhld-PfWG, 10 SaarlWG, 9 Schl-HolstWG) zweifelhaft geworden.

cc) Der Schutz der Gewässer gegenüber Dritten kann ebenfalls auf Grund eigentumsrechtlicher Befugnisse erfolgen ${ }^{152}$ ), obwohl die neuen Wassergesetze sachpolizeiliche Ermächtigungen enthalten ( $\S 52,75,82 \mathrm{Bad}-$ WürttWG, Art. $68 \mathrm{ff}$. BayWG, $67 \mathrm{ff}$. BerlWG, 41, $120 \mathrm{ff}$. BrWG, 64 ff. HambWG, 50, 74 ff. HessWG, 50, $120 \mathrm{ff}$. NdsWG, 79 ff. Nordrh-WestfLWG, 85 ff., 102 Rhld-PfWG, 76 ff. SaarlWG, 69 ff. Schl-HolstWG).

147) Dessen Nichtigkeit nunmehr das BVerfG feststellte (DOV 62, 863).

148) Vgl. Sievers, DVBl.61, 142; Riederer-Sieder, Komm. z. BayWG, Rand-Nr.11, 18 zu Art. 1. Anm. zu Art. 2; für das Grundwasser $K$ öt $t$ g e $n$, Gemeindl. Daseinsvorsorge, S. $14 \mathrm{ff}$; $\mathrm{G}$ i e s e k e, Eigentum und Grundwasser, Veröff. d. Arbeitsgem. 1. Forschung d. Landes Nordrh.-Westf., 1959.

149) Si e ver s, DVBl. 62, 77, 86; Herbert Kr üger, Grundfragen, S. $125 \mathrm{ff}$; F r i e s e ke, Recht der Bundeswasserstraßen, 1962, S. 61 ff. mit Nachw.; B o e h m e, Bad.-Württ. VBl. 60, 97 ff.; Bundestag, 2. Wahlperiode, Drucksache 2072, S. 20; deutlich $\$ \$ 58$ Abs. 1 BrWG; 6 Nordrh.-WestfLWG.

150) A. A. S i e ver S, DVBl. 62, 78: öffentliches Eigentum; ferner $\mathrm{K}$ ü I z , in: Staatsbürger und Staatsgewalt, Bd. 2, S. $293 \mathrm{ff}$.

151) Vgl. S i e vers, DVBl. 62, 84, Anm. 49; Ri ed e r e r - S i e d e r, aaO., Rand-Nr. 32 ff. zu Art. 1, 7 ff. zu Art. 2, 5 zu Art. 42; $\mathrm{S}$ i e d e r, ZschrfWasserR 1962, S. 57 (Urteilsanm.); BGHZ 30, 382; teilweise abw. K öttg e n, Gemeindliche Daseinsvorsorge, S. 15 f;; bejahend auch für das neue Recht $G$ i es eke, ZschrfWasserR 1962 , S. 47.

152) Vgl. Sievers, DVBl. 59, 649; H o l tz-K r e u tz-S c h leg e l b e rg e r, Komm. z. preuß. WG, Bd. 2, S. 6 f.; A b t, DOV 60, 819; Thierfelder, DOV 60, 58, 824. 
dd) Verliehene Nutzungsrechte werden als eigentumsähnliche Positionen geschützt (z. B. §§ 15 BerlWG, 12 BrWG, 12 NdsWG, 14 Rhld-PfWG, 12 Schl-HolstWG ${ }^{153}$ ).

\section{Teil}

Funktion und Nutzung der öffentlichen $\mathrm{S}$ a che

A.

Die Einwirkung des Sozialstaatsprinzips auf die öffentliche Sache

I.

Die Funktion der öffentlichen Sache ist heute verfassungsrechtlich jedenfalls durch die Sozialstaatlichkeit ${ }^{154}$ ) determiniert, was nicht heißt Patrimonialstaatlichkeit vergangener oder Kommerzialstaatlichkeit moderner Prägung. Die sozialstaatliche Verfassung erwähnt außer in Kompetenzvorschriften keine einzelnen sozialen Institutionen, will aber sicher bestehende verfassungsrechtlich absichern. Dazu gehört auch die öffentliche Sache als Einrichtung für und zum Nutzen der Allgemeinheit, die dem Staat auf Grund der Vorstellung einer ihm zukommenden obersten Steuerungs-, Verteilungs- und Darreichungsaufgabe, eines leistungsfähigen „ensemble des service public ${ }^{\text {(155)}}$ ), zugewachsen ist. Die öffentliche Sache ist damit einbezogen in das Sinngefüge der Leistungsverwaltung ${ }^{\mathbf{1 6 8}}$ ) - ein Begriff, der trotz seiner Mehrdeutigkeit hier abbreviativ für die Darbietung als zentrale Funktion der öffentlichen Sache verwendet sei.

153) Früher $\$ 81$ preußWG (dazu Sievers, DVBl. 59, 645); s. jedoch auch $\$ \$ 11$ WHG, 19 WStrRG.

154) Hierzu zuletzt E. R. H u ber in: Oldenburgische Verwaltungsakademie, Heft 1 (1962).

155) Léon $\mathrm{D} u \mathrm{gu}$ it, zitiert bei $\mathrm{S}$ ch e uner in: Staatsverfassung und Kirchenordnung, S. 237 f.; daselbst S. 225 ff. allgemein zu diesem Problemkreis; ferner Ernst $\mathrm{K}$ e r n, Festschrift für Carl Schmitt, S. 80 ff. mit den dort Zitierten; S ter $n-S$ ch a t te nf r o h, Il concetto di "Lavori pubblici“ nel diritto tedesco, Rassegna dei lavori pubblici 1961, Nr. 6 mit Nachw.

156) So deutlich bei F le in e r, Institutionen, $S$. 351 ff,; F or s t h of $\mathrm{f}$, VerwR, S. $320 \mathrm{ff}$.; zuletzt Wolfgang L e p s i e n, Prinzipien der Leistungsverwaltung, Diss., Münster, 1961. - Hinter der Leistungsverwaltung steht ideologisch die "soziale Idee“ (vgl. L. von S te i n, Finanzwissenschaft, 5. Aufl., Bd. 1, S. 109, 154). 
II.

Ungeachtet aller Wandlungen der "sozialen Struktur“ gilt die öffentliche Sache stets als ein "historisch bezeugtes Naturale“15i) der Gemeinwesen, ohne freilich zum "Sozialmodell“168) des BGB zu passen. Die liberale Staats- und Eigentumsideologie zog sie anders als die staatseigene Wirtschaftsbetätigung nicht in Zweifel. Das Zurück zum klassischen Verwaltungsstaat $^{159}$ ), den ein moderner Wohlfahrts- und Wirtschaftsstaat ${ }^{160}$ ) verdrängt hat, ist nie im Sinne einer „Entstaatlichung “161), einer Privatisierung, der öffentlichen Sachen verstanden worden $^{102}$ ). Im Gegenteil, das Selbstverständnis der öffentlichen Sache in der Hand des kraft Verfassungsgebots rechtsgebunden, gleichmäßig und unter Ausschluß des Marktmechanismus verteilenden und lenkenden Gemeinwesens ist eher vom Wunsch einer Ausdehnung begleitet. Angesichts der legitimen staatlichen Beherrschungs- und Ordnungsmacht ist eine sonst nicht allzu häufig zu bemerkende Symbiose und Synthese gesellschaftlicher wie staatlicher Kräfte feststellbar. Individualund Gemeinwille stehen in einem Kräfteparallelogramm, dessen Resultante die öffentliche Sache als anerkannte staatliche Aufgabe ist. Staatliche Aktivität durch den Leistungsträger Verwaltung ${ }^{163}$ ) ist hier rechtshistorisch seit Hammurabi nachweisbar $\left.{ }^{164}\right)$. Produktion und Darreichung öffentlicher Sachen

167) Köttge n in: Staatsverfassung und Kirchenordnung, S. 144.

158) W i e a c k e r, Schriftenreihe der Juristischen Studiengesellschaft Karlsruhe, Heft 3, 1953; ders. in: 100 Jahre Deutsches Rechtsleben, Festschrift Deutscher Juristentag, 1960, Bd. 2 , S. 3 ff.

159) Vgl. H. Peters, Der Kampf um den Verwaltungsstaat, Festschrift für L a f o r e t, 1952, S. $21 \mathrm{ff}$.; U le, Uber das Verhältnis von Verwaltungsstaat und Rechtsstaat, Speyerer Beiträge, 1957, S. 127 ff.; Werner W e b e r, Das Richtertum in der deutschen Verfassungsordnung, Festschrift für $\mathrm{N}$ i e d e rm e y e r, 1953, S. 267; Le i b hol z, Universitas 59, $459 \mathrm{ff}$; $S$ ter $\mathrm{n}$, JZ 60, 525; BVerfGE $7,397 \mathrm{f}$.

180) E. R. H u ber, Das Deutsche Reich als Wirtschaftsstaat, 1931.

161) Den Versuch des wissenschaftlichen Beirats beim Bundesverkehrsministerium, die öffentlichen Straßen in wirtschaftliche Anlagen umzuwandeln, hat Herbert $\mathrm{Kr} \ddot{\mathrm{u}} \mathrm{g}$ er überzeugend als rechtlich unzulässig qualifiziert (Entstaatlichung, aaO., passim).

162) Gefahren bestehen deshalb nicht, weil sich der Staat nicht im Wettbewerb mit Funktionen der Gesellschaft befindet (vgl. F o r s t $h$ of $f$, Rechtsfragen der leistenden Verwaltung, res publica, 1959, S. 19).

163) Vgl. etwa Forsth off, VerwR, S. 323; ders. Rechtsfragen der leistenden Verwaltung, S. $11 \mathrm{f}$, 20; Herbert $\mathrm{K}$ r ü g e r, Der Rundfunk usw., S. 21; Erich B e c k e r, VeröffVDStRL 14, 98, 109 f.; E. K a u fman n, aaO., Bd. 1, S. $75 \mathrm{ff}$.; K e I s e n, Hauptprobleme der Staatsrechtslehre, 1923, S. 493; K ö t t g e n, DVBl. 57, 441 ff.; L os ch eld e r, DVBl. 57, 820; M eng e r, DVBl. 60, $297 \mathrm{ff}$.

164) Moll, Gruchots Beiträge 54 (1910), S. $320 \mathrm{ff}$. 
ist gewissermaßen geborene, nicht gekorene Leistungsverwaltung, vielleicht sogar die Urform staatlicher Daseinsvorsorge, jedenfalls klassische, nicht erst hinzugekommene, durchaus akzidentielle. Trägerschaft und Kompetenz der öffent lichen Verwaltung über die öffentliche Sache sind sohin unbezweifelt ${ }^{185}$ ), wenngleich eine Identität von "gemeinschaftsbezogener Staatstätigkeit“166) und publizistischer Qualität nicht durchweg besteht ${ }^{187}$ ).

B.

Die Notwendigkeit öffentlich-rechtlicher Nutzungsformen

Die Funktion der öffentlichen Sache besteht im Dasein und Dargebotensein zur Befriedigung von Allgemein-, Individualund Staatsbedürfnissen ${ }^{\mathbf{1 6 8}}$ ); sie steht im wahrsten Sinne des Wortes im "öffentlichen Dienst“. Diesem Ziel entsprechen die Nutzungsformen Gemein-169) und Sondergebrauch der Bürger $^{170}$ ) sowie Exklusivgebrauch der Staatsorgane. Diese überkommenen Nutzungsformen dürften jedoch angesichts der ständigen Zunahme der Verwaltungsleistungen nicht mehr den realen Bedürfnissen entsprechen. Die Ausbildung besonderer verwaltungsrechtlicher Nutzungsverhältnisse in Analogie zu privatrech tlichen Typen wird unausbleiblich $\operatorname{sein}^{\mathbf{1 7 1}}$ ). Folge einer

165) Vgl. F or s th of $f$, VerwR, S. 323; ders. AöR 31, 223; Kött gen, Gemeindliche Daseinsvorsorge, S. 24, Anm. 3; ders. in F r a n k, Deut. VerwR, S. 439; v. K a h r, Bayer. Gemeindeordnung, Bd. 1. S. 345 f.; Dennewitz, Die Systeme des VerwR, 1948, S. 147 f.

166) R u p p, JuS 61, 60 .

167) Grundsätzlich $M$ a 1 l $m$ a $n n$ und $Z$ e i d l e r, VeröffVDStRL 19, 165 ff.; K ö t $t$ g e n, VeröffVDStRL 6, 124 und Anm. 32; ders. für die öffentliche Anstalt, VeröffVDStRL 6,107, 128, 141; nicht so weitgehend offenbar L. R i c h t e r, ebda. S. 102; für politische Parteien zuletzt Luthman n, DVBl.62, 166; Lenz und S a s s JZ62, 235; allgemein noch $B G H Z, 4,266$ ff. und dazu Herbert $K r$ ü g e r, Grundfragen usw., S. 130, Anm. 231.

${ }^{168}$ ) Außer Betracht bleiben können jene öffentlichen Sachen, die keinen nutzbaren, sondern nur ideellen Wert besitzen, wie Standbilder, Denkmäler usw.

168) Wilhelm Jos. H e y e r s, Zum Problem des Gemeingebrauchs, Diss., Freiburg 1959; Philipp $\mathrm{N}$ a u, Der Gemeingebrauch an öffentlichen Wegen, Diss., Mainz, 1957; Klaus D i e t e $\mathrm{r}-\mathrm{K}$ r a u s e, Der Gemeingebrauch an öffentlichen Straßen im neuen Verwaltungsrecht, Diss., Köln,. 1961; E is en hart-R othe, BB 59, 1192 ff.; K o d a l, DÖv 60, 444 ff.; E. R. H u b e r, DOV 55, 129 ff.; F r i e s e c k e, DVBl. 60, 711; Salzwedel, ZfWasserR 1962, $73 \mathrm{ff}$.

170) Helmut $\mathrm{V}$ a it 1 , Sondernutzungen im Wege- und Wasserrecht, Diss., München, 1959; J a h , NJW 61, 2196; Z e i t le r, DVBl. 60, 90.

171) Vgl. H. S c hneid er, NJW 62, 707, im AnschluB an Hans J. W o l f $f$, VerwR I, S. 231 f. Das Fernsprechverhältnis und gewisse 
öffentlich-rechtlichen Institutionalisierung hat eine öffentlichrechtliche Ordnung auch der Nutzungsformen zu sein ${ }^{172}$ ). Solche Kongruenz verlangt das Gebot juristischer Stilremheit und die Adäquanz von Sachstruktur und Sachfunktion. Eine vom Eigentum abgeleitete, früher auch aus prozessualen Rücksichten vertretene Nutzungsordnung könnte zu einer kommerzialisierten Auswahl der Nutzungsberechtigten führen, bzw. eine maximale Schonung statt einer optimalen Nutzung der Sache intendieren ${ }^{173}$ ), Der statusformende Organisationsakt regelt nicht nur die Verwendungsart der öffentlichen Sache, sondern prägt auch den allgemeinen Inhalt der möglichen Nutzungsrechtsverhältnisse ${ }^{174}$ ). Gemeingebrauch ist hierbei jene Nutzung, deren Inhalt durch den Organisationsakt bereits generell festgelegt ist, und Sondergebrauch jene Nutzung, deren Inhalt noch durch einen individualisierenden Rechtsakt $\mathrm{zwischen}$ Benützer und Sachherr konkretisiert wird ${ }^{175}$ ). Gemeingebrauch ist also untitulierte, Sondergebrauch titulierte Nutzung. Während der Sondergebrauch eines speziellen Zulassungsakts bedarf, braucht ihn der Gemeingebrauch nicht. Anders ausgedrückt: Jede eines besonderen Zulassungsakts bedürftige Nutzung ist kein Gemeingebrauch $m$ ehr $^{\mathbf{1 7 6}}$ ). Der Zulassungsakt ist in der Regel Verwaltungsakt, selten öffentlich-rechtlicher Ver$\operatorname{trag}^{177}$ ).

Postnutzungsverhältnisse können hier Vorbild sein (BVerwGE 10, 277). - Selten ist die Begründung eines gesetzlichen Sondernutzungsverhältnisses wie nach $\$ 1$ TelWG (dazu BGHZ 36, $217 \mathrm{ff}$.).

172) S. bereits $L$ uth ardt, Bl.f. adm. Praxis 20, 337: „Die Benutzung von öffentlichen Sachen ist nicht Ausübung von Privatrechten, sondern Ausübung einer von der Staatsgewalt eingeräumten Befugnis"; L a u e, Verw.Arch., Bd. 34, S. 352; Herbert K r ü g e r, Grundfragen usw., S. 136 ff.; $\mathrm{H}$ a a s, DVBl. $62,653 \mathrm{ff}$.

${ }^{173)}$ Grundrechtsbindungen vermögen nur repressiv korrigierend zu wirken; vgl. hierzu auch BGHZ, 36, 91 ff. mit meiner Anmerkung, JZ 62, $181 \mathrm{ff}$.

$\left.{ }_{174}\right)$ Zutreffend $M$ a u nz, aaO., S. 279, freilich von einem anderen Ausgangspunkt her; wie hier wohl Evers, NJW 62, 1034: "Der Gemeingebrauch an der Straße ist daher heute ein Oberbegriff für ein Bündel von Nutzungen, deren Inhalt und Umfang sich aus dem Gesetz und dem normativ vorentworfenen Verwaltungsakt ergibt".

175) Vgl. M a unz, aaO., S. 280.

176) Auch ein Kontrahierungszwang ändert daran nichts (richtig F or s th of $f$, VerwR, S. 339; M a u n z, aaO., S. 282); im Ergebnis mag ein solcher Gewährungszwang, der den Benutzer nicht auswählt, dem Gemeingebrauch gleichkommen.

177) Z. B. § 19, Abs. 6 HambWegG; ferner BGH 33, 230; OVG Saarlouis, JZ 61, 673; B u 11 ing e r, Vertrag und Verwaltungsakt, res publica 9, 1962, S. 55, mit weiterer Rspr.; s. auch I m b ode n, Der verwaltungsrechtliche Vertrag, 1958, S. 86, 175 f.; B a r o cka, Verw.Arch. 51, $1 \mathrm{ff}$. 
C.

Auswirkungen einer öffentlich-rechtlichen Nutzungsordnung

I.

Die nutzbare öffentliche Sache ist ein „Mehrzweckinstitut ${ }^{\text {“178) }}$, das vielfältigen Interessen und Interessenten dient, deren Selektion und Differenzierung unabweisbar ist, um die Gemeinwohlfunktion der öffentlichen Sache nicht zu denaturieren. Eine Reduzierung gemeingebräuchlicher Nutzung ist die $z$ wangsläufige Folge $^{179}$ ), die in Kauf genommen werden muß, solange die moderne Gesellschaft Sondernutzungen heftig begehrt (öffentliche Versorgungs- und Verkehrseinrichtungen, billige Schiffs- und Massengütertransporte auf der Straße, industrielle Wasserbenutzung, gewerbliche StraBennutzung usw.). Trotz Art. 3 GG kann hier nicht nach dem Prinzip des cuique idem, sondern nur nach dem des suum cuique verfahren werden, sofern das Gesetz nichts anderes befiehlt ${ }^{180}$ ). Im Rahmen des Gemeingebrauchs verlangt Art. 3 GG

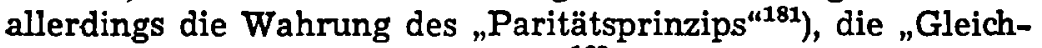
heit vor der öffentlichen Wohltat“"182).

II.

Die öffentliche Sache bietet keinen wirtschaftsinterventionistischen Ansatzpunkt; denn Wirtschaftsinvention ist final gesteuerte - korrigierende, unterstützende oder planende -

178) Köttg e n, Gemeindliche Daseinsvorsorge, S. $28 \mathrm{ff}$.

179) Vgl. E. R. Huber, DOV 55, 131 ff. Insofern gebe ich W. We ber durchaus recht, ohne jedoch seine Folgerung einer forcierten Umwandlung in anstaltliche Nutzung zu teilen. Der Umstrukturierung sind $\mathrm{m}$. E. jedoch Grenzen gezogen (richtig Herbert $\mathrm{K}$ r ü g e r, Entstaatlichung, S. 22): so dürften zwar keine Bedenken gegen die Parkometerbenutzung bestehen (Ko d a l, NJW 62, 480, mit verkehrs-, nicht wegerechtlicher Begründung), wohl aber gegen das Verbot der sog. „Laternengarage“ (ebenso E v e r s , NJW 62, 1033 ff.; S chultz, MDR 61, 471; BGH, NJW 62, 1023; OLG Köln, NJW 62, 2073; OLG Bremen, NJW 62, 1582; z. T. abw. OVG Hamburg, BBBl. 61, 134). Das Utbermaßverbot dürfte gegen eine übermäßige Antastung gemeingebräuchlicher Nutzungsrechte schützen. Der aus dem Wesen der öffentlichen Sache entnommene Verwendungszweck (oben 2. Teil A und B) steht nicht uneingeschränkter souveräner Verfügung des Verwaltungsträgers offen.

180) Vgl. Erich B e cker, VeröffDStRL 14, $112 \mathrm{f}$. - Eine Vorzugsstellung der öffentlichen Versorgung ist daher nicht verfassungswidrig. Hier bestehen "sachliche" Differenzierungsmotive.

181) F or s th of $f$, VerwR, S. 364 .

182) Herbert Krüg e r, Grundfragen usw., S. 146. 
Ingerenz in die Wirtschaft ${ }^{183}$ ), während die Funktion der öffentlichen Sache sich im Gewähren erschöpft ${ }^{184}$ ).

\section{III.}

Die öffentliche Sache bedeutet auch keine Chance auf unternehmerischen Gewinn; denn sie dient ,in der vollen Breite ihrer Bestimmung dem individuellen Nutzen der Bürgerschaft und ist daher weder ein ökonomisches Potential noch ein Betriebsmittel der Verwaltung "185). Die Ableitung aus der akommerziellen Herrschaftsmacht, nicht aus dem Wirtschaftsmacht verleihenden Eigentum unterstreicht diese Deutung ${ }^{\mathbf{1 8 6}}$ ). Die Darbietung öffentlicher Sachen ist keine selbstnützige, sondern gemeinnützige Staatstätigkeit, frei von unternehmerischer marktwirtschaftlicher Transaktion ${ }^{\mathbf{1 8 7}}$ ). Der Grundsatz der "Eigenwirtschaftlichkeit" der öffentlichen Sachen würde diese aus ihrer dienenden Funktion herauslösen und sie in eine werbende überführen. $\mathrm{Da}$ die öffentliche Sache der Allgemeinheit dient, hat ihre Finanzierung durch das allgemeine staatliche Einnahmemittel der Steuer zu erfolgen und nicht durch das vielleicht für die Anstalt zweckdienliche Finanzierungsmittel der Gebühr ${ }^{\mathbf{1 8 8}}$ ). Der Gemeingebrauch ist gebührenfrei ${ }^{189}$ ),

183) Vgl. S t e r n, JZ 60, 520 und DOV 61, 325 ff. mit Nachweisen.

184) Da sie nicht zu marktmäßig zu ermittelnden Preisen gekauft werden muß, mag sie als „kostensenkend" begriffen werden (so Herbert $\mathrm{K}$ r ü g e r, Grundfragen usw., S. 157).

185) K ö t t g e n, Gemeindliche Daseinsvorsorge, S. 34.

186) Die Nichtaufnahme eines sog. Wasserzinses in das WHG (vgl. dazu Herbert $\mathrm{K}$ r ü ger, Grundfragen usw., S. $141 \mathrm{ff.}$.) und von Wegegeldern in die neuen Straßen- und Wegegesetze (über deren Schicksal Herbert Kr ü g e r, aaO., S. 165 f.) beweisen die gleichgerichtete Auffassung der gesetzgebenden Organe.

${ }^{187}$ ) Vgl. hierzu Herbert $\mathrm{K} r$ ü ge $\mathbf{r}$, Grundfragen usw., S. 157; K ö t t g e n, VeröffVDStRL 6, 117 ff.; G. J e 11 i n e k, Allgemeine Staatslehre, S. 623; L a b a n d, Staatsrecht des Deutschen Reiches, 5. Aufl., 1914, Bd. 4, S. 345; a. A. offenbar S a m p e r, BayVBl. 56, 41.

188) Ebenso Herbert Kr üg e r, Entstaatlichung, S. 22; ders. Grundfragen usw., S. $174 \mathrm{ff}$; ferner im einzelnen hierzu $S$ te $\mathrm{r}$, Rechtsgutachten zu Art. 8 Bayer. Kostengesetz (noch unveröffentlicht).

189) Doch mehren sich die Stimmen, die eine Benutzungsgebühr zulassen: vgl. F or sth of $f$, VerwR, S. 339; Hans J. W o lff, VerwR I, S. 332; E. R. H u b e r, DOV 55, 135 f.; a. A. Herbert Kr ü g e r, Grundfragen usw., S. 151; BVerwGE 4, $342 \mathrm{ff}$; B e t t e r -

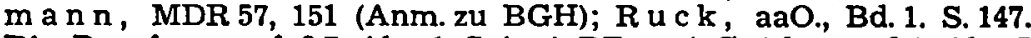
Die Berufung auf $\S 7$ Abs. 1 Satz 4 BFernstrG (ebenso $\$ 8$ Abs. 5 BerlStraßG) scheint diese These unwiderlegbar zu machen. Immerhin kann aus dieser Bestimmung und mit Hinweis auf Art. 185 Entw.VerwaltungsRO für Württemberg gefolgert werden, da $B$ erst die ausdrückliche Gestattung durch den Gesetzgeber den Gemein- 
während die Entgeltlichkeit der Sondernutzung keinem Zweifel begegnet ${ }^{190}$ ), und zwar durch Erhebung einer Verwaltungsgebühr nach den landesrechtlichen Kostengesetzen, deren causa jedoch nicht der Inanspruchnahme der Sache, sondern der Verwaltung liegt - sie scheiden mithin aus dem Thema aus ${ }^{191}$ ) -, und durch Erhebung einer nach dem wirtschaftlichen Vorteil bemessenen Sondernutzungsgebühr ${ }^{102}$ ). Bedenken gegen solche rentabilitätsorientierte Synallagmatik sind jedenfalls dann nicht leichter Hand beiseitezuschieben, wenn man den Staat des GG als Steuerstaat begreift, dessen Einnahmequellen vom verfassungsrechtlichen Vollständigkeits- und Non-Affektationsprinzip des Haushalts und vom parlamentarischen Einnahmebewilligungsprinzip geordnet sind (Art.110 GG und besonders Art. 75, Abs. 1 Berl.Verf.) ${ }^{183}$ ). Es sähe einer „öffentlichrechtlichen Vorteilsausgleichung "104) ähnlich, die Kosten des Gemeingebrauchs über die Sondernutzungsgebühren zu finanzieren und dadurch die Idee der öffentlichen Sache, breitester Nutzung zu dienen, und die Finanzgesetzgebung zu überspielen. Was Köttgen 1929 für die öffentliche Anstalt darlegte, gilt mutatis mutandis auch für die öffentliche Sache: „Im Gegensatz zu der Privatwirtschaft, im Gegensatz zu der Verwaltung des Patrimonialstaats beherrscht die moderne Verwaltung das Prinzip der völligen Lösung von Leistung und Gegenleistung. Jede planmäßige Verbindung der Verwaltungsarbeit mit dem Streben nach entsprechenden Einnahmen steht im

gebrauch unter Abgabepflicht stellt (so richtig Herbert $\mathrm{K}$ r ü ger, Entstaatlichung, S. 21 f., der gleichzeitig auf die Abschaffung der Chaussee- und Brückengelder, Mauten etc. hinweist).

190) Vgl. Hans J. W o lf f, VerwR I, S. 329.

191) Uber Probleme der Verwaltungsgebühr vgl. das oben Anm. 188 erwähnte Rechtsgutachten; $E$ h le und $O$ berläu ter, DÖV 62, 45 ff.; T h i e m e y e r, DOV 62, 893; B a c h of, JZ 63, 58; BVerwGE 13, $214 \mathrm{ff}$, und DÖV 62, 225; OVG Münster, DVBl. 62, 726.

192) $\$ 8$ Abs. 3 BFernstrG, Art. 18 Abs. 3 BayStrWG; $\S 10$ Abs. 5 BerlStrG; 2 i. V. m. 45 BremStrO; 19 Abs. 3 HambWegeG; 16 Abs. 3 HessStrG; 21 Abs. 1 NiedersStrG; 18 Abs. 2 NordrhWestfLStrG.

Herbert K r üg e r, Grundfragen usw., S. 165, hält die „Gebühr“ für einen "Straßenzins"; M a r c hall, Komm. z. BFernstrG, 1954, S. 143, für eine Konzessionsabgabe.

193) Die Unbegrenztheit des Gebührenmaßstabs (z. B. \$§9 Abs. 2 BerlStraßG; 26 Abs. 1 Schl-HStrWG; 18 Abs. 2 Satz 3 NordrhWestfLStrG) läßt überdies rechtsstaatliche Zweifel, denen $\$ \S 18$ Abs. 3 HessStrG und 19 Abs. 3 HambWegeG Rechnung tragen, aufkommen (dazu Stern, Rechtsgutachten [Anm. 188]; bedenklich auch BayVGH 13, 110 [Gebührenänderungsvorbehalt zulässig], 14, 35 [rückwirkende Gebührenerhebung]). - Uber die Formel: Nur ein reicher Staat könne Rechtsstaat sein vgl. T a r t a r i n - T a r n h e y d e n, HdbDStR Bd. 2,.S. 418; K ö t tg e n, VeröffVDStRL 6, 77. S. auch BadWürtt. VGH, KommStZ 62, 76.

194) Herbert Kr ü g e r, Grundfragen, S. 152. 
Widerspruch $\mathrm{zu}$ diesen steuerstaatlichen Prinzipien “195). Sondernutzungsgebühren dürfen daher nicht als kostendeckende oder gar marktwirtschaftliche ${ }^{196}$ ) Entgelte erhoben werden, sondern nur in Höhe einer sinnvollen Kapazitätslenkung knapper Güter zu optimaler Nutzung $\left.{ }^{197}\right)^{198}$ ).

\section{IV.}

Die Vergabe von Wohltaten ist bekanntlich eine gute Möglichkeit, Herrschaft zu begründen ${ }^{\mathbf{1 0}}$ ). Die Realität der Gleichung Leistungsfunktionen sind auch Herrschaftsfunktionen vermag gerade die Darbietung öffentlicher Sachen zu bezeugen, für die weitgehend Monopole bestehen. Der Staat kann nicht nur durch Befehl, sondern auch durch Bereitstellen entpersönlichen ${ }^{200}$ ) und die Rechtsposition des Bürgers in entsubjektivierende Abhängigkeitsverhältnisse zurückverwandeln. Die Sicherung der Freiheit im Staat der Daseinsvorsorge ist weder grotesk noch eine contradictio in adjecto. Im öffentlichen Sachenrecht heißt es, den verhängnisvoll „absolutistischen Zug“201) aus Otto Mayers verwaltungsrechtlichem Repertoire zu korrigieren, beruhend auf der von Gerber-Labandschen Verkennung der Grundrechte und individuellen Berechtigungen $^{202}$ ), vor allem die Konstruktion der Polizeierlaubnis als Wiederherstellung der natürlichen Freiheit ${ }^{203}$ ). Hiegegen sei

195) VeröffVDStRL 6, 121.

196) Dazu auch B ulli inger, Die Mineralölfernleitungen, S. 17.

197) Z. B. Parkplatz- oder Parkometergebühren (dazu BVerwGE 4, $342 \mathrm{ff}$; $\mathrm{H}$. P e ters in: Berichte und Forschungen aus dem öffentlichen Recht, S. 583 ff.; R o th, NJW 61, 2192; K od a 1, NJW 62, 480). - Ubber Konzessionsabgaben $S$ t e r n, AöR 84, 301 ff. mit Nachw.

198) Privatrechtliche Entgelte aus Eigentum oder Gebrauchsüberlassung scheiden nach meiner Konstruktion ohnehin aus (strukturwidrig deshalb $\S 10$ Abs. 5 BerlStraßenG, richtig hingegen $\$ 13$ BerlWasserG); wie hier auch Hans J. W o l $f$, VerwR I, S. 329 f.; a. A. die Rspr. des $\mathrm{BGH}(19,85$ ff.; 22,$398 ; 28,34)$; unentschieden $\mathrm{E}$ v e r s, NJW 62, 1037.

199) Vgl. B a c h of, VeröffVDStRL 12, 58, 77; F or s th of f, Rechtsfragen der leistenden Verwaltung, S. 41 f.; B u ll inger, Vertrag und Verwaltungsakt, S. 47; Rupp, DVB1.58, $113 \mathrm{ff}$; S t e r n, JZ 60, 518 ff.

200) P. Tillich, zitiert bei L e p s e n, aaO., S. 120; H. Freyer, Festgabe für Carl $S \mathrm{ch}$ m itt, $S .63 \mathrm{ff}$.

201) Tri e pel, Staatsrecht und Politik, 1927, S. 35; G. Erler, Grundfragen des internationalen Wirtschaftsrechts, spricht S. 185 vom "Erbteil des Polizeistaates".

202) "H a s e l a u, aaO., S. $69 \mathrm{ff}$.; L e is n e r, Grundrechte und Privatrecht, 1960, S. 38 ff.; S che u ner in: Staatsverfassung und Kirchenordnung, S. 228.

${ }^{203}$ ) Bereits T h o m a ist dieser grobschlächtigen Konstruktion mit den Worten entgegengetreten: „Was nicht rechtlich verboten 
folgende These gestellt: Sub specie der materialen Sozialstaatlichkeit geht es um den allgemeinen und gerechten, sub specie der grundrechtserfüllten Rechtsstaatlichkeit um den im subjektiven öffentlichen Recht verfestigten und gesicherten Anteil an den dargebotenen öffentlichen Sachen.

V.

Das führt zu nachstehenden Folgerungen:

1. Es besteht ein subjektives öffentliches Recht auf Gemeingebrauch „als spezielle Konkretisierung des allgemeinen Rechts auf Teilhabe an den Staatsleistungen "204) im Rahmen der durch den Organisationsakt als gemeinverträglich ${ }^{205}$ ) ausgewiesenen Nutzung ${ }^{208}$ ). Eine nicht von Gegenrechten gedeckte Entziehung und Beeinträchtigung ist verwaltungsgerichtlich (Art. 2, Abs. 1 $\mathrm{GG}^{207}$ ), $\S \S 40,42 \mathrm{VwGO}$ ) und zivilgerichtlich ( $839 \mathrm{BGB}$, Art. 34 GG; $\$ 823$ BGB) geschützt ${ }^{208}$ ).

ist, ist rechtlich erlaubt, ist nicht etwa eine Maxime des Liberalismus, sondern eine denknotwendige Ableitung aus der Existenz einer staatlichen Rechtsordnung" (HdbDStR Bd.2, S.619; s. auch ders. VerwArch 32, 24 f.); ferner $P$ i l o t y - S e y d e l, Bayer. Staatsrecht, 2. Aufl., 1913, Bd. 1, S. 173.

204) F or $s$ th of $f$, VerwR, S. 341; heute vorherrschende Meinung: vgl. H a s e l a u, aaO., S. 20; I p s e n, Rechtsgutachten, aaO., S. 39; E. R. H u b e r, DÖV 55, 129 ff.; Hans J. W o If $f$, VerwR I, S. 323, 326 ("positiven verwaltungsrechtlichen Status"); S c h n u r, DVB1. 62, 5 (mit Nachw.); Kl. Vogel, Offentl. Wirtschaftseinheiten, S. 254 Anm. 88.

205) Zur Gemeinverträglichkeit E r m a c or a, Die Verunreinigung der Gewässer als innerstaatliches und internationales Rechtsproblem, Verhandlungen des 1. österr. Juristentags 1962, Bd. II 3. Teil, S. 21; S cheuner, Festschrift für Gi es eke, 1958, S. 73 ff.; S a l z wede 1, Der Personenverkehr 1960, Heft 5. - Die Unterscheidung vom Gemeingebrauch und Anliegergebrauch (gesteigerter Gemeingebrauch) halte ich für entbehrlich, da grundsätzlich nicht das Recht, sondern nur das wirtschaftliche Interesse des Anliegers am Bestand des Gemeingebrauchs größer ist (so richtig F l e i n e r, Institutionen, S. 377); das positive Recht kann freilich den besonderen Gemeingebrauch des Anliegers mit zusätzlichen Rechtsgarantien versehen (so z. B. \& 16 Nordrh.-WestfLStrG, Art. 17 BayWG); ferner Horst Schneider, NJW 63, 276; OVG Lüneburg, DVBl. $63,223$.

206) Dieses Ergebnis kann schon aus $\$ \S 1$ StVZO, 7 Abs. 1 BFernstrG, 23 Abs. 1 WHG, 5 WStRG und den landesrechtlichen Wasserund Wegegesetzen abgeleitet werden, so daß eine Begründung aus den Grundrechten oder internationalem Recht (so $\mathrm{H}$ a s ela $u$, aaO., S. $17 \mathrm{ff}$.) nicht erforderlich ist.

207) Richtig Dü r ig in M a u nz-Dür i g, Komm. z. GG, RandNr. 36 zu Art. 19 Abs. 4: Art. 2 Abs. 1 gewährt das subjektive öffentliche Recht auf Freiheit von allen gesetzlich nicht gerechtfertigten Belastungen und Vorenthaltungen; OVG Rhld-Pfalz, DOV 62, 69; 
2. Nach der $h . M$. besteht kein materielles subjektives öffentliches Recht auf eine Sondernutzungserlaubnis, allenfalls ein formelles (auf ermessensfehlerfreie Entscheidung), wobei das Ermessen nicht auf speziell wege- oder wasserrechtliche Erwägungen beschränkt ist ${ }^{209}$ ). Auch die Selbstbindung der $\mathrm{Be}-$ hörde an eine ständige Ermessenspraxis über Art. 3, Abs. 1 $\mathrm{GG}^{210}$ ) verhilft nur selten zu einem Rechtsanspruch. Diese Auffassung gründet sich auf das Otto Mayer'sche Verbot mit Erlaubnisvorbehalt, nach dem alle den Gemeingebrauch überschreitenden Nutzungen "an sich" verboten seien und erst ausnahmsweise durch die staatliche Erlaubnis die "Wiederherstellung der natürlichen Freiheit" verfügt werde. Herbert Krüger betont mit Recht die dadurch ausgelöste Pervertierung des Leistungscharakters der öffentlichen Sache $^{\mathbf{2 1 1}}$ ). Jedes Verbot stellt per se eine Grundrechtsbeeinträchtigung dar. Bedarf nach der Rspr. des $\mathrm{BVerfG}^{\mathbf{2 1 2}}$ ) ein Verbot der Rechtfertigung und nicht die Tätigkeit des Bürgers, sofern sie nicht in sich verbietungswürdig ist, und hält man alle staatlichen Reglemen-

OVG Münster, MDR 63, 79; DVBl. 61, 890; HessVGH ESVGH 9, 144; OVG Lüneburg, DOV 54, 90; wohl auch Bad-Württ. VGH, AöR 86, 100; VG Koblenz, DOV 63, 353; s. auch Fle in e r, Institutionen, S. 376; zumindestens mißverständlich $\$ \S 14$ Satz 2 HessStrG; 14 Abs. 2 NiedersStG; 14 Abs. 1 Satz 2 Nordrh.WestfLStrG; 20 Abs. 4 SchlHolStrWG.

208) Ein verfassungsrechtlicher Schutz über Art. 14 dürfte nur in den besonders gelagerten Ausnahmefällen denkbar sein, in denen eine öffentlich-rechtliche Position als Eigentumsrecht $\mathrm{zu}$ bewerten ist (vgl. BVerfG 4, $240 \mathrm{f}$;; 11, 64 ff.; NJW 63, 29; BayVerfGH, BayVBl. 63, 51; BSozG, JZ 58, $20 \mathrm{ff}$. mit Anm. von D ür i g; ders., Der Staat und die vermögenswerten Berechtigungen seiner Bürger, Festschrift für A pelt, 1958, S. $13 \mathrm{ff}$., $47 \mathrm{f}$; s. auch E. R. H u ber, DOV 55, 129; K r ö n e r, DRiz 60, 422 ff.). Eher erfolgversprechend könnte ein Hinweis auf den Schutz des eingerichteten und ausgeübten Gewerbebetriebes sein.

${ }^{209}$ ) Vgl. Hans J. W o l $f$, VerwR I, S. 328; F or s th of $f$, VerwR, S. 345; M a r sch a l 1, aaO., S. 142; Herbert $\mathrm{K}$ r üge r, Grundfragen, S. 17, 25, 64; $\S$ 2, Abs. 2, Satz 2 BremStraßeno; 19, Abs. 1, Satz 3 HambWegeG; gegen die h.M. mit Recht OVG Lüneburg, VerwRspr. 12, 28 zu \$9 BFernstrG mit Anm. von F r i a u $f$, JuS 62, 422 ff.; weitgehend auch S ch i ck, DOV 62, 936; Schulke, BayVBI. 61, 206.

210) Zuletzt BayVerfGH, DƠV 62, 381; BVerwG, DVBI. 59, 745; DVBI. 62, 452, 680 .

211) „Es ist der selbstverständliche Sinn solcher nutzbringender Tätigkeit des Staates, den Bürgern im weitestmöglichen Umfang zugutezukommen. Es wirkt daher zum mindesten paradox, wenn ... das Gebrauchmachen von staatlichen Gewährungen grundsätzlich verboten wird" (Grundfragen, S. 30; ähnlich DOV 58, 674).

212) Vgl. E. 6, 32 ff.; 7, 397 ff.; E. v. 21. 3. 1961 - 1 BvL $3158-$ zitiert bei $\mathrm{Ech}$ te r höl te r, BB 61, 1017. Für die Gewerbefreiheit G. U b e r, Freiheit des Berufs, 1952; für die Verkehrswirtschaft. H a s ela uaO. 
tierungsakte an das Prinzip der Erforderlichkeit und Verhältnismäßigkeit ${ }^{213}$ ) gebunden, die verlangen, die verbotene Zone nicht maximal auszudehnen, sondern erst am unerläßlich notwendigen Punkt beginnen zu lassen, so erweist sich die überkommene, für den Bürger am ungünstigsten wirkende Konstruktion als unangemessen und sachinadäquat. Eine Neuordnung kann als Umkehrung der alten Schablone weder in der generellen Erlaubnis mit Verbotsvorbehalt noch in der Gewährung lediglich mit Auslesevorbehalt liegen; denn die Knappheit des öffentlichen Guts, auf dessen Nutzung ein quantitativ allzu umfangreiches und qualitativ überaus vielfältiges Begehr besteht, und die dadurch bedingte Selektion lassen eine Abschaffung der Erlaubnispflicht nicht zu ${ }^{214}$ ). Die Erlaubnis ist jedoch in ihrem Zweck zu verändern: Sie darf nicht mehr freiheitsgewährend, sondern muß freiheitsbestätigend wirken. Ihre Funktion ist Kontrolle aus Gemeinwohlgründen zum Zwecke optimaler Nutzung eines staatlich dargebotenen Guts, nicht „Lähmungs“-, sondern „Lenkungsfunktion“215). Sie wancelt sich ähnlich der Bauerlaubnis zur öffentlichrechtlichen Unbedenklichkeitserklärung ${ }^{\mathbf{2 1 6}}$ ), d. h.: Gewährung unter rechtlich gebundenem Erlaubnisvorbehalt. Folge dieser Umstruktuierung ist der Rechtsanspruch auf die Erteilung einer Sondernutzung, sofern keine ges etzlichen Hinderungsgründe bestehen ${ }^{217}$ ). Das positive Recht steht gegenüber solchen rechtsstaatlichen Erwägungen freilich noch zurück. Eine normativ nicht gebundene Erlaubnis würde ich für eine grundsätzlich unzulässige Blankovollmacht an die Exekutive halten, die allenfalls dann noch verfassungsrechtlich $z u$ halten ist, wenn man aus Sinn und Zweck des ganzen Gesetzes Voraussetzungen für ihre Erteilung oder Versagung entnehmen kann. Die Einräumung von Handlungsermessen ist nur zulässig, wenn anders nicht eine sinnvolle Koordinierung der zahlreichen und verschiede-

213) Allgemein L e r ch e, Ubermaß und Verfassungsrecht, 1961; B a ch of, JZ 62, 753; speziell für die öffentliche Sache Herbert K r ü g e r, DOV 58, 673 ff.

214) $\mathrm{Zu}$ weitgehend, daher W. G e i g e r, Grundgesetzliche Schranken für eine Kartellgesetzgebung, 1955, S. 15; Herbert K r ü g e r, DÖV 56, 555; bedenklich auch BVerfGE 2, 279, wo verfeinerte Konstruktionsmittel nicht in Erwägung gezogen werden.

215) G. Erler, aaO., S. 186; ähnlich Fri a u f, JuS 62, 423 mit Nachw.

216) Vgl. Verfasser, bereits AöR 84, $148 \mathrm{ff}$. und JZ 62, 298 sowie die dort Erwähnten; Has elau, aaO., S. 100 f.; E R. Huber, Wirtschaftsverwaltungsrecht, Bd. 1, S. 71.

217) Im Ergebnis übereinstimmend Herbert $K \mathrm{r}$ üg e r, Grundfragen, S. 59 ff., 70; $S$ tri ckstrock in: Festschrift für A pelt, 1958, S. 235; F r i a u f, JuS 62, 423 f.; nicht so weitgehend B u 11 in ger, Mineralölfernleitungen, S. 41 f.; D rews - W a cke, Allg. Polizeirecht, 7. Aufl., 1961, S. 304 ff. 
nen Benutzungszwecken dienenden Ansprüche zu erreichen ist, wenn also die sachrichtige Entscheidung wegen ständig wechselnder Situationen nicht gerecht und angemessen auf der Stufe des Gesetzes, sondern erst durch Auswahlbefugnisse der Exekutive entschieden werden $\mathbf{k a n n}^{\mathbf{2 1 8}}$ ).

3. Die h. M. lehrt die grundsätzlich "freie“ Widerruflichkeit der Sondernutzungserlaubnis sowie die uneingeschränkte $\mathrm{Zu}$ lässigkeit eines Widerrufsvorbehalts und sonstiger Nebenbestimmungen ${ }^{219}$ ). Neuere Gesetze des Wegerechts folgen weitgehend dieser These ${ }^{220}$ ), während das positive Wasserrecht eine nur begrenzt widerrufliche Rechtsverleihung ${ }^{221}$ ) kennt. Gewohnheitsrechtlich hat sich allerdings auch im Wegerecht eine Nutzungs rechts verleihung durchgesetzt ${ }^{222}$ ). Die Fragwürdigkeit solcher Differenzierung unter den Sondernutzungen habe ich an anderer Stelle dargelegt ${ }^{223}$ ).

4. Die Rechtsstellung des Erlaubnisnehmers ist durch die Widerruflichkeit „prekär(“224). Erhebliche finanzielle Investitionen ruhen auf rechtlich schwachem Fundament. Andererseits verlangt das Gemeinwohl nicht selten eine Beseitigung bestehender Sondernutzungen. Derartige Interessenkollisionen möchte ich nach dem Grundgedanken der Widerrufslehre des allgemeinen Verwaltungsrechts lösen ${ }^{225}$ ); denn auch beim Wi-

218) Hierzu auch B e t t e r m a n n, Der Staat, 1962, S. 79 ff.; ders. AöR 86, 137, Anm. 13: Eine Erlaubnis, die ausschließlich im behördlichen Ermessen liegt, ist verfassungswidrig; ebenso $F r i$ a $u f$, JuS 62, 425 (mit Hinweis auf die Rspr.); s. ferner Herbert $\mathrm{K} r \ddot{u}-$ g e r, Grundfragen, S. 47; S c h e u n e r, VeröffVDStRL 11, 17; J e s c h, JZ 61, 624 ff.; $\mathrm{H}$ a s e l a u, aaO., S. 104 und die Schweizer Lehre (Nachweise bei $\mathrm{Ehmke}$, Ermessen und unbestimmter Rechtsbegriff im Verwaltungsrecht, 1960, Recht und Staat, Heft 230/231, S. 51).

219) Vgl. F or s th of $f$, VerwR, S. 345; Hans J. W o $1 f f$, VerwR I, S. 328; v. T u r e g g - K r a u s, aaO., S. 190; einschränkend BayVGH, BayVBl. 61, 281.

220) Vgl. \& 8, Abs. 2 BFernStrG; Art. 18, Abs. 2 BayStrWG; \$§ 10, Abs. 4 BerlStrG; 2, Abs. 3 BremStrO; 19, Abs. 2 HamWG; 16, Absatz 2 HessStrG; 18, Abs. 1 NiedersStrG; 18, Abs. 2 Nordrhein-WestLStG; 21, Abs. 1 SchlHolsStrG.

221) $\S \S 8$, Abs. 1 WHG; 15 BerlWG; 11 BremWG; 11 NiedersWG; 16. Abs. 1 Nordrh-WestfWG; 19 RhldPfWG; 12 SaarlWG; 12 SchlHolstWG.

222) Vgl. Hans J. W o l f $f$, aaO., S. $329 \mathrm{ff}$; F o r s th of $f$, aaO., S. 344, 346; S c h a c k, Verw.Arch. 54, $43 \mathrm{ff}$.

223) JZ 62, 298; ebenso wohl auch strickstrock, Zschr. f. WasserR 1962, S. $50 \mathrm{f}$. und $S \mathrm{ch}$ a c k, Verw.Arch. 54, $43 \mathrm{ff}$.

224) Herbert $K$ r ü g e r, Grundfragen, S. 77.

225) Vgl. die Literaturangabe bei $S$ tern, JZ 62, 299; ferner B a c h of, JZ 62, 749; N e u m a n n, NJW 62, 1085; Z e i d l e r, Gutachten, aaO., S. 68 ff., der allerdings die Gegenposition bezieht, mit der sich auseinanderzusetzen jedoch hier nicht der Ort ist; aus der Rspr. zuletzt BVerwGE 13, $253 \mathrm{ff}$. 
derruf von Sondernutzungen divergieren Interessen des Individual- und Allgemeinwohls. Beide sind zu bewerten und abzuwägen: Fordern unabdingbare Gemeinwohlerfordernisse, die spezifisch wege- oder wasserrechtlicher Natur sein müssen ${ }^{226}$ ), eine Beseitigung der Sondernutzung, so hat das Individualinteresse zurückzutreten.

Am Schlusse meines Berichts bin ich mir seiner Verlustliste bewußt: der Rechtsvergleichung ${ }^{227}$ ), der Probleme des Kirchenguts ${ }^{228}$ ), der Rechtsstellung der Sachen im Völkerrecht ${ }^{229}$ ) und anderer Fragen. Dafür und für manches, das im Stadium des Versuches - tauglich oder untauglich - steckengeblieben ist, sei mir die Nachsicht der meliora potentes gewährt.

226) So zutreffend Herbert $\mathrm{Kr}$ üg e r, Grundfragen, S. 78, $112 \mathrm{ff}$; $\mathrm{H}$ a s e l a u, aaO., S. $107 \mathrm{f}$.

227) S. im einzelnen: für Osterreich Antoniolli, Allg. Verwaltungsrecht, 1954, S. 247 ff.; A d a m o v i c h, Handbuch des österr. Verwaltungsrechts, 5. Aufl., 1953, Bd. 2, S. $89 \mathrm{ff}$; Herrnrit t, Grundlehren, S. 382; $\mathrm{M}$ a u nz, aaO., S. 122; $S$ i e ver s, Verw.Arch. 51, 191; für die Schweiz $R$ u ck, aaO., S. 139 ff.; $S$ i e ver s, Verw.Arch. 51, 190; für Dänemark Vinding Krus e, Das Eigentumsrecht 1931, Bd. 1, S. 239 f.; für Frankreich und Italien bereits oben; ferner allg. Hans J. W o $1 \mathrm{f} f$, HdSw., S. $36 \mathrm{f}$. - Ob die Rechtsvergleichung bej so sehr in nationalen und historischen Wurzeln verhaftenden Institutionen weiterhilft, scheint mir fraglich (vgl. etwa die Bedenken von L or e $\mathrm{nz}, \mathrm{JZ} 62,270$; andererseits L i v e $\mathrm{r}$, ZSchwR 80 [1960], S. 229).

228) Außer den schon Erwähnten noch etwa $M$ e u r e r, Der Begriff und Eigentümer der heiligen Sachen, Bd. 1, 1885; Joh. H e kkel, Kirchengut und Staatsgewalt, Festgabe für $S \mathrm{~m}$ e n d, 1952, S. 103 ff. bes. 123, 131, 137 ff.; G. H o l s t e i n, Verw.Arch. 35 (1930), $105 \mathrm{ff}$, E. R. Huber, Die Garantie der kirchlichen Vermögensrechte in der Weim. Verf., 1927.

220) Dazu etwa B e r ber, Völkerrecht, 1960, Bd. 1, S. 322; D a h m, Völkerrecht, 1958, Bd. 1, S. 666; v. d. H e y d t e, Völkerrecht, 1958, Bd. 1, S. 234; H a t s c h e k, Völkerrecht 1926, S. 203; U ll m a n n, Völkerrecht, 1908; S. 324; H e f f t e r, Europ. Völkerrecht, 1888, \$ 73; ferner American Journal of Intern. Law, Bd. 54 (1960), S. 349; K r a u s - S c h e u n e r, Rechtsfragen der Rheinschifffahrt, 2 Rechtsgutachten, 1956. 


\title{
Leitsātze des Mitberichterstatters über: Die Offentliche Sache
}

\author{
1. Teil \\ Institution und Konstruktion \\ der öffentlichen Sache
}

A.

Begriff und Sonderstellung der öffentlichen Sache

1. Die öffentliche Sache als ein von der Wissenschaft ausgebildeter Mantelbegriff ist weder in der Gegenwart, noch war sie in der Vergangenheit ein scharf konturiertes Gebilde.

2. Ursachen hierfür sind:

a) die komplexe Einwirkung des öffentlichen bzw. privaten Rechts,

b) der normativ schwer zu erfassende Gehalt des Begriffs öffentlich,

c) die von Gesellschafts- und Staatsauffassung abhängige Funktion und Ordnung der öffentlichen Sache.

3. Die rechtliche Sonderstellung der öffentlichen Sachen wird mit der natürlichen Beschaffenheit der Objekte, religiösen, militärischen, politischen, staatswirtschaftlichen Motiven, kurz: Anforderungen des Gemeinwohls, begründet.

4. Rechtshistorisch beeinflussen zwei verschiedene Bildungsgesichtspunkte die Dogmatik der öffentlichen Sache: das römisch-rechtliche Eigentum und die germanisch-rechtliche Regalität.

5. Die herkömmliche Theorie konstruiert darum die öffentliche Sache als Mischgebilde öffentlichen und privaten Rechts: die öffentliche Sache gilt als eigentumsfähig und damit einer privatrechtlichen Ordnung zugänglich, die jedoch durch öffentliche $Z$ wecke beschränkt ist.

6. Die französische Lehre des domaine public (Otto Mayer) oder der Versuch, die öffentliche Sache als "Rechtsverhältnis" (Maunz) zu begreifen, können nur in Teilaspekten als dogmatisch förderlich erkannt werden. 
7. Ein für den Gesetzgeber brauchbares und rechtstheoretisch klares Dogma der öffentlichen Sache ist notwendig, um zahlreiche Ungereimtheiten auszuräumen, wie z. B.:

a) die Konstruktion der Verkehrssicherungspflicht nach $\S 823$ BGB,

b) die doppelten gerichtlichen Zuständigkeiten je nach Einkleidung des Streits,

c) die Mitwirkung des Eigentümers bei der Vergabe von Sondernutzungen,

d) das Fehlen einer „Polizei" der öffentlichen Sache,

e) die Probleme sinnvoller Nutzung der öffentlichen Sache.

B.

Grundgedanken einer öffentlich-rechtlichen Theorie der öffentlichen Sache

8. a) Ausgangspunkt einer Konstruktion nach dem Leitbild des sozialen Rechtsstaats muß eine durchgängige öffentlich-rechtliche Ordnung der öffentlichen Sache sein.

b) Rechtsvergleichende gesetzliche Hinweise können Art. $822 \mathrm{ff}$. des italienischen Codice Civile von 1942 bieten.

9. Als verwaltungsrechtlich relevant sind nur diejenigen Sachen Gegenstand des Themas, die aus dem Gesamtbestand der Sachen durch einen besonderen Rechtsakt (= Organisationsakt) in das öffentliche Recht transformiert, d. h. spezifisch normativ zugeordnet sind und einen besonderen institutionellen Status besitzen.

10. Im Regelfall handelt es sich hierbei um zwei Kategorien von Sachen:

a) Sachen, deren Funktion auf den internen Gebrauch durch staatliche (und dem Staat ein-bzw. angegliederte öffentlich-rechtliche Verbände) oder kirchliche Organe zugeschnitten ist und die höchstens akzidentiell einer externen Nutzung unterliegen;

b) Sachen, deren Funktion essentiell auf externe Nutzung in spezifisch öffentlich-rechtlichen Nutzungsformen zugeschnitten ist.

11. Der Organisationsakt, der die solchermaßen bestimmte öffentliche Sache kreiert, ist nicht identisch mit der Widmung, sondern Rechtsakt eigener Prägung, der einem Rechtsobjekt den „institutionell öffentlichen Status" (Forsthoff) verleiht. 
12. Seine Rechtsgrundlagen sind Verfassung, Gewohnheitsrecht, Gesetz, Rechtsverordnung, Satzung und der "allgemeine Verwaltungsauftrag".

13. Seine rechtsformale Gestalt kann neben den unter 12. genannten Typen auch ein Individualakt sein, der aber nicht frei von normativen Elementen ist, da die Begründung des institutionell öffentlichen Status einer Sache sich auch an die Allgemeinheit wendet.

C.

Der Stand des positiven Rechts

14. Das geltende Recht, besonders das Wege- und Wasserrecht, steht mit dieser unter $B$ genannten Konzeption nur zum Teil in Einklang. Abweichend wird

a) die Widmung nicht als Organisationsakt begriffen, ausgenommen wohl das Hamburgische Wegegesetz, besitzt

b) das Eigentumsrecht für Nutzung und Schutz der Sache noch eine nachhaltige Bedeutung, ist also nicht allein auf die statische Position reduziert, die öffentliche Sache nicht zur res nullius werden zu lassen.

15. Sachordnung, Sachnutzung und Sachverantwortlichkeit sind de lege lata noch nicht kongruent geregelt; Unvollkommenheiten (Leitsatz 7) in Gesetz und Praxis sind die Folge der uneinheitlichen Konzeption.

\section{Teil}

Funktion und Nutzungder öffentlichen Sache

A.

Die sozialstaatliche Verankerung der öffentlichen Sache

16. Die öffentliche Sache ist ihrer Funktion nach einzubeziehen in das Sinngefüge der modernen Leistungsverwaltung, die vom Verfassungsprinzip des rechtlichen Sozialstaats durchzogen ist.

17. Ihrer Idee nach dient die öffentliche Sache der Erfüllung von Allgemein-, Individual- und Staatsbedürfnissen, denen spezifische Nutzungsformen entsprechen (vgl. Leitsatz 22).

18. Die Darreichung öffentlicher Sachen ist seit langem durch alle Gemeinwesen geübt. Hierin scheint vielleicht sogar die 
Urform staatlicher Daseinsvorsorge zu liegen, sicher aber "geborene" Leistungsverwaltung.

19. Die Darbietung öffentlicher Sachen ist anders als die Staatswirtschaft ideologisch und soziologisch nicht in Zweifel gezogen und darum kein Diskussionsgegenstand einer „Privatisierung".

20. Aus ihrem staatlichen Selbstverständnis wird eher die Forderung nach einer Vermehrung abgeleitet.

B.

Die Notwendigkeit einer öffentlich-rechtlichen Nutzungsordnung

21. Das Gebot juristischer Stilreinheit verpflichtet zu einer Kongruenz von öffentlich-rechtlicher Organisationsform und öffentlich-rechtlicher Nutzungsform, d.h. die ausschließlich öffentlich-rechtliche Institutionalisierung intendiert eine ausschließlich öffentlich-rechtliche Nutzungsordnung und ausschließlich öffentlich-rechtliche Nutzungsformen.

22. (All)Gemein- oder/und Sondergebrauch der Bürger, sowie Exklusivgebrauch der Staatsorgane als herkömmliche Nutzungsformen nutzbarer öffentlicher Sachen sind daher soweit noch nicht geschehen - privat-rechtlicher Einwirkungen zu entkleiden.

23. Diese Nutzungsformen können ergänzt werden durch besondere verwaltungsrechtliche Leistungsverhältnisse.

24. Gemeingebrauch ist jene Nutzung, deren Inhalt durch den öffentlich-rechtlichen Organisationsakt bereits generell festgelegt ist; Sondergebrauch (auch in Form anstaltlicher Nutzung) ist jene Nutzung, deren Inhalt noch durch einen individualisierenden Rechtsakt zwischen Benützer und Sachherr konkretisiert wird.

25. Beide Nutzungsformen sind unentbehrlich, da die öffentliche Sache als ein „Mehrzweckinstitut" (Köttgen) allen, aber auch speziell zuzulassenden Interessenten dient.

C.

Auswirkung einer öffentlich-rechtlichen Nutzungsordnung

26. Die öffentliche Sache darf auf Grund ihrer Gemeinwohlfunktion weder einen wirtschaftsinterventionistischen Ansatzpunkt bieten, noch als ein ökonomisches Potential der Verwaltung begriffen werden. 
27. Eine Vergabe nach marktwirtschaftlichen Gesichtspunkten verbieten die Prinzipien steuerstaatlicher Einnahmeerzielung.

28. Es sind daher Bedenken gegen die gesetzlich teilweise vorgesehene Synallagmatik bei der Bemessung von Sondernutzungsgebühren zu erheben.

29. Das Konstruktionsmittel des „Verbots mit Erlaubnisvorbehalt" (Otto Mayer) bei der Darreichung öffentlicher Sachen wird deren Funktion nicht mehr gerecht.

30. Leistungsfunktionen dürfen sich nicht als Herrschaftsfunktionen auswirken.

31. Sub specie der materiellen Sozialstaatlichkeit geht es um den allgemeinen und gerechten, sub specie der grundrechtserfïllten Rechtsstaatlichkeit um den im subjektiven öffentlichen Recht verfestigten und gesicherten Anteil an der Darbietung öffentlicher Sachen. Daraus wird folgen:

a) Ein schon von der vorherrschenden Meinung angenommenes subjektives öffentliches Recht auf Gemeingebrauch im Rahmen der durch den Organisationsakt als gemeinverträglich ausgewiesenen Nutzung auch in der Gesetzgebung durchzusetzen.

b) Die weitgehend angenommene Ablehnung eines subjektiven Rechts auf Sondernutzungsbewilligungen, sowie deren "freie" Widerruflichkeit einer kritischen Uberprüfung zu unterziehen und auf eine Verstärkung berechtigter Nutzungsansprüche des Bürgers hinzuwirken. 


\section{Die Offentliche Sache}

\section{Aussprache und Schlußworte}

Scupin (Diskussionsleiter): Ich habe schon einige Wortmeldungen und frage Sie, ob Sie es für zweckmäßig halten, Schwerpunkte zu bilden. Mir scheint das bei der heutigen Materie im Gegensatz zur gestrigen etwas schwierig. Ich habe überlegt, ob man die Einordnung der öffentlichen Sache in die Leistungsverwaltung erst dann diskutieren soll, nachdem die neuen Aspekte der öffentlichen Sache diskutiert worden sind. Aber ich glaube, daß gewisse Veränderungen der Kriterien der öffentlichen Sache mit jener Folgerung sehr zusammenhängen. Daher würde man heute durch Bildung besonderer Schwerpunkte nicht viel gewinnen.

Merk: Gegen die Auffassung, daß aus dem geltenden Recht ein einheitlicher Begriff der öffentlichen Sache abzuleiten sei, möchte ich Bedenken erheben. Die Rechtsbegriffe sind bekanntlich Zweckbegriffe. Es können sich daher nach den Gesetzen für die verschiedenen Rechtsbereiche verschiedene Rechtsbegriffe ergeben. Bezeichnet man als öffentliche Sachen im weitesten Sinne den Inbegriff der einem öffentlichen Verwaltungsträger gehörenden Gegenstände, so kann man weiterhin zwischen einem Begriff der öffentlichen Sache im weiteren und einem Begriff im engeren Sinne unterscheiden. Jenen Begriff gewinnt man indem man aus dem angegebenen Inbegriff das Finanzvermögen ausscheidet und das Verwaltungsvermögen als öffentliche Sachen bezeichnet. Diese Unterscheidung hat vor allem finanzrechtliche Bedeutung. So ist z. B. Grundbesitz des Bundes, der Länder, Gemeinden und Gemeindevérbände, der für einen öffentlichen Dienst oder Gebrauch benutzt wird, von der Grundsteuer befreit. Dagegen sind unter öffentlichen Sachen im engeren oder verwaltungsrechtlichen Sinne im Anschluß an Otto Mayer, der das Verdienst hat, diesen Begriff herausgearbeitet zu haben, zu verstehen nur die Sachen aus dem Bereiche des Verwaltungsvermögens, die einem öffentilichen Vervsaltungszweck unmittelbar dienen, gleichviel ob sie - was nicht wesentlich ist - im Gemeingebrauch stehen oder nicht; so z. B. öffentliche Wege, Wasserstraßen, Friedhöfe, Festungen. Danach lehne ich die Auffassung ab, öffentliche Sachen einfach dem Verwaltungsvermögen gleich zu stellen, wie das heute morgen geschehen ist, 
wobei dann noch die Sachen im Gemeingebrauch hinzugerechnet werden, ohne da 3 doch das gemeinsame Band ersichtlich gemacht worden wäre. Verwaltungsgebäude, wie Schul-, Post-, Eisenbahngebäude, dienen zweifellos einem öffentlichen Zweck, aber doch nicht unmittelbar, wie z. B. Festungen dem Verteidigungszweck: hier verkörpert oder prägt sich die Verwaltungsaufgabe unmittelbar in dem Gegenstand aus. Bei Verwaltungsgebäuden ist dies nicht der Fall. So kann z. B. die Post ja auch für ihre Verwaltungszwecke ein Gebäude mieten; das Verwaltungsgebäude ist sozusagen nur das Gehäuse, in dem die Verwaltung tätig wird. Das ist weiter auch z. B. von Bedeutung für die Unterhaltungspflicht. Wenn ein Verwaltungsgebäude sich in polizeiwidrigem Zustand befindet, so kann die Polizei zweifellos eingreifen; desgleichen mit Bezug auf die Pflicht zur Unterhaltung und Reinigung des daran angrenzenden Gehwegs usf. Die Post usf. steht hier der Verwaltung gegenüber nicht anders als ein gewöhnlicher Untertan. Das ist bei öffentlichen Sachen im verwaltungsrechtlichen Sinne nicht der Fall. Bei einer Festung z. B. kann die allgemeine Polizei so nicht eingreifen. So bin ich - auch im Gegensatz zum französischen Recht - der Auffassung, daß das Verwaltungsvermögen nicht einfach als öffentliche Sache im verwaltungsrechtlichen Sinn nach deutschem Recht bezeichnet werden kann. Daher nehme ich auch durchaus an, wie es in der Rechtsprechung bejaht worden ist, daß z. B. jemand aus einem Gerichtsgebäude aufgrund des Eigentums ausgewiesen werden kann, wenn er sich ungebührlich benimmt.

Was die Abgrenzung des Begriffs der öffentlichen Sachen anbetrifft, so mag manches zweifelhaft erscheinen, worauf hier nicht näher einzugehen ist. Ich sehe aber im Gegensatz zu Herrn Weber nicht ein, daß es sich hierbei unbedingt um körperliche Sachen i.S. des bürgerlichen Rechts handeln muß, daß sozusagen das Privateigentum Voraussetzung für die öffentlichrechtliche Sachherrschaft ist. Ich bleibe im übrigen bei der Unterscheidung zwischen Privateigentum und öffentlich-rechtlicher Sachherrschaft im Gegensatz zu Otto Mayer und der neuen Regelung des Wegerechts in Hamburg. Jedenfalls gehen unsere Gesetze sonst durchweg davon aus, wie z. B. auch das Bundesfernstraßen-Gesetz und auch das neue bad.-württ. Wassergesetz von 1960. Auch der Luftraum über dem Staatsgebiet ist $\mathrm{m}$. E. als öffentliche Sache anzusehen. Das Luftverkehrsgesetz trifft hier eine Regelung, wonach seine Benutzung grundsätzlich frei ist usf. Der Luftraum über dem Staatsgebiet gehört eben mit zum Staatsgebiet. Es ist nicht einzusehen, warum er nicht im Hinblick auf den Luftverkehr und seine Regelung 
als öffentliche Sache angesehen werden könne; anders ist es allerdings bei đer offenen See, da sie keiner Gebietshoheit unterliegt. Es deckt sich eben der Begriff der öffentlichen Sache nicht einfach mit dem Sachbegriff des bürgerlichen Rechts. Auf der anderen Seite will Herr Weber selbst darüber hinausgehen, indem er z. B. eine öffentliche Bücherei mit ihren sämtlichen Bücherbeständen als e in e öffentliche Sache, d. h. als eine Gesamtsache, ansieht; für mich jedoch ist das ein Inbegriff öffentlicher Sachen.

Weiter ist mir nicht verständlich, warum die Hamburger Regelung i.S. einer öffentlich-rechtlichen Haftung aufgrund der Straßenunterhaltungspflicht unter Ablehnung einer bürgerlichrechtlichen Verkehrssicherungspflicht im Widerspruch zu Art. 34 GG stehen soll. Der Bundesgerichtshof hat selbst ausgeführt, es bestehe die Möglichkeit, neben der - früher allein von ihm angenommenen - bürgerlich-rechtlichen Straßenverkehrssicherungspflicht noch aufgrund der öffentlich-rechtlichen Unterhaltungspflicht eine Haftung eintreten zu lassen; er verlangt allerdings eine Erklärung des betr. Verwaltungsträgers, daß dies so sein soll. M. E. hat diese Wahlerklärung, welches Recht Anwendung finden soll, das bürgerliche oder das öffentliche, keine Grundlage im Gesetz. Ich bin hier immer auf dem Standpunkt gestanden, daß die Verkehrssicherungspflicht beim Fehlen besonderer gesetzlicher Vorschriften ein Bestandteil der öffentlich-rechtlichen Unterhaltungspflicht überhaupt ist; ich lehne die Auffassung $a b, d a B$ bei öffentlichen Wegen eine besondere bürgerlich-rechtliche Verkehrssicherungspflicht i. S. der Übernahme einer Gefährdungshaftung durch die Eröffnung des Weges bestehe, bei deren Verletzung $\S 823$ BGB eingreife. Die Verkehrssicherungspflicht bei privaten Wagen ist etwas ganz anderes als die Unterhaltungspflicht öffentlich-rechtlicher Verwaltungsträger bei öffentlichen Wegen und die Abspaltung einer besonderen bürgerlich-rechtlichen Verkehrssicherungspflicht davon nicht einleuchtend. Hier kommt §839 BGB in Verbindung mit Art. 34 GG in Betracht. Wenn danach bei Fahrlässigkeit nur aushilfsweise eine Haftung eingreift, so müssen wir uns mit dem geltenden Recht abfinden.

In Kürze noch etwas zu einigen weiteren Punkten. Es ist schon bisher der Standpunkt vertreten worden, daß es sich bei den öffentlichen Sachen, wie insbesondere bei den öffentlichen Straßen, z. T. um Reste öffentlicher Anstalten handele. Wenn ein Verkehrsschutzmann z. B. ein Gebot erläßt, sich in bestimmter Richtung zu bewegen, so ist das keine Verwaltungsverfügung im gewöhnlichen Sinne, sondern eine Weisung - etwa gleichartig einer solchen, die einem Besucher einer öffentlichen 
Gemäldesammlung erteilt wird -, deren Befolgung auch strafrechtlich gesichert ist. Aber die polizeiliche Regelung des Gemeingebrauchs, die z. B. in Straßen- und Wassergesetzen vorbehalten ist, ist nicht einfach rechtlich als Ordnung einer öffentlichen Anstalt aufzufassen, da eine Zulassung, wie bei der Benutzung einer solchen hier nicht in Frage kommt, andererseits bei einer öffentlichen Anstalt wegen des Erfordernisses der Zulassung, auch mit Bezug auf die Benutzung öffentlicher Sachen, wie z. B. bei Kanälen, ein Gemeingebrauch nicht in Frage kommt.

Der Auffassung von Herrn Stern, daß im römischen Recht das Eigentum die Grundlage der öffentlichen Sachen gebildet habe, vermag ich in dieser Form nicht zuzustimmen; die dem öffentlichen Gebrauch dienenden Sachen, wie z. B. öffentliche dauernd fließende - Gewässer, galten als Gegenstände außerhalb des Rechtsverkehrs, die in niemandes Privat e ig e $\mathbf{n -}$ $\mathrm{t} u \mathrm{~m}$ standen. Im deutschen Recht ist die Allmende der Ausgangspunkt für die öffentlichen Wege und Gewässer gewesen; erst in der späteren Entwicklung, nachdem sich schon in der Fränkischen Zeit das Volkseigentum in Königseigentum verwandelt hatte, kam dann der Begriff der Königsstraßen oder Reichsstraßen i. S. eines königlichen Regals auf, wie z. B. in der bekannten constitutio de regalibus Kaiser Friedrichs I. von 1158. $\mathrm{Daß}$ weiter die öffentlichen Sachen eine Urform der „Daseinsvorsorge" sein sollen, ist $m$. E. eine verfehlte Auffassung, die heutige Einrichtungen und Anschauungen auf frühere Zeiten und ihrem Ursprung nach anders geordnete Gegenstände überträgt. Es handelt sich $\mathrm{m}$. E. vielmehr bei den öffentlichen Sachen dem Ursprung nach um Reste von anfänglich ungeschiedener Gemeinherrschaft und Gemeineigentum. Sie dienten außer für gewisse unmittelbare öffentliche Zwecke, wie z. B. Heeresstraßen, Verkehrsstraßen, auch dazu, die schroffe Abgrenzung der privaten Willensmacht der Einzelnen mit Bezug auf das Eigentum nach dessen Ausbildung zu ergänzen und abzumildern unter dem Gesichtspunkt allgemeiner öffentlicher Belange. Weiter ist es nicht richtig, daß Otto Mayer den Begriff „Verbot mit Erlaubnisvorbehalt" auf die Sondernutzungen bei öffentlichen Sachen angewendet habe; er hat vielmehr diesen Begriff nur für die Polizeierlaubnis verwendet. Aber von der Polizeierlaubnis ist im Gegensatz zu Fleiner die Gebrauchserlaubnis wohl zu unterscheiden. Bei ihr wird nicht, wie bei jener, die natürliche Handlungsfreiheit des Einzelnen wiederhergestellt, deren Ausübung zunächst in vorbeugender Weise rechtsatzmäßig allgemein unter dem Vorbehalt der Erlaubniserteilung im Einzelfalle, wenn keine öffentlich-rechtlichen Beden- 
ken gegen ein entsprechendes Gesuch bestehen, verboten ist; vielmehr erhält der Einzelne hier mit Bezug auf eine - ihm fremde - öffentliche Sache eine Befugnis, etwas zu tun, was ihm nicht schon an sich rechtlich zusteht. Auch die Behauptung, daß ein subjektives öffentliches Recht auf den Gemeingebrauch und auf Sondernutzungen bestehe, trifft beim Fehlen besonderer Vorschriften, wie in Gemeindeordnungen, m. E. nicht zu. Endlich verneine ich, daß ein "Gebot der Stilreinheit" verpflichte, alle Nutzungen der öffentlichen Sachen öfentlich-rechtlich aufzuziehen; dafür besteht $\mathrm{m}$. E. kein zwingendes Bedürfnis. Soweit die öffentlich-rechtliche Zweckbestimmung nicht berührt wird, bleibt grundsätzlich noch Raum für bürgerlichrechtliche Nutzungen und Verfügungen.

Ipsen: Ich habe kürzlich einen zweiten Wohnsitz in Niedersachsen begründet und aus diesem $A n l a ß$ gehofft, mich nicht in so spezifischer Weise meiner hamburgischen Herkunft erinnern zu müssen. Aber nachdem Herr Weber geradezu genüßlich hier ausgebreitet hat, wie die zuständigen Mitglieder der Hamburger Rechtswissenschaftlichen Fakultät beim hamburgischen Wegegesetz Pate gestanden hẩtten, kann ich nicht umhin, mich zu diesem Punkte und zu zwei weiteren zu äußern.

In einer Beratung des Wegerechtsausschusses des hamburgischen Parlaments, der Bürgerschaft, sind einige Fakultätsmitglieder um ihre Meinung gebeten worden. Ich darf das hier zunächst klarstellen, um die Verantwortlichkeit zu klären. Von den hier Anwesenden waren das Herr Schack und meine Wenigkeit, außerdem von unseren Zivilisten Herr Schultze-von Lasaulx und Herr Stoll, der kurz in Hamburg wirkte. Herr Schack hat sich zu dem Vorhaben des hamburgischen Gesetzgebers (sofern er nicht die Absicht hat, das selbst hier zum Ausdruck zu bringen, darf ich es hier schon einfließen lassen) sehr skeptisch geäußert und sich ganz auf der konservativen Linie bewegt, die das Referat von Herrn Weber kennzeichnet. Ein anderer Fachvertreter hat in den Verhandlungen, die gedruckt sind, folgendes gesagt: „Wenn die Begründung des Senatsentwurfs zu diesem Wegegesetz aussagt, Hamburg habe jetzt alle Veranlassung, in seinem Wegegesetz sehr moderne, systematisch einwandfreie Wege zu beschreiten und hier nun einmal ein Muster eines Landeswegegesetzes zu schaffen, das klar das öffentliche Eigentum ausweise, dann zeugt das von gesetzgeberischem Avantgardismus, der sicher alle Achtung verdient und den Verfassern des Gesetzes das Prädikat klarer Systematik zuerkennt. Aber die Gesetzgebung hat ja doch nicht die Aufgabe, wenn ich es recht sehe, wissenschaftliche Kategorien zu formieren und in schlüssiger Abfolge zur Darstel- 
lung zu bringen, sondern, den faktischen Bedürfnissen und den rechtspolitischen Zielen entsprechend, die man verfolgt, eine praktikable Lösung zu finden." Das habe i $\mathrm{ch}$ damals gesagt, woraus Sie schließen mögen, daß die Unterstützung zuständiger Fakultätsmitglieder bei der Aktivierung des öffentlichen Eigentums in Hamburg zumindest eine nuancierte gewesen ist.

Nun, was die praktikablen Lösungen angeht, zur Sache: Gewiß, das hamburgische Wegegesetz hat sich zum öffentlichen Eigentum bekannt. Ob das dogmatisch zutreffend und richtig ist und welche Auswirkungen diese Lösung haben wird, das soll die Zukunft erweisen. Ich frage mich zunächst folgendes: Bestanden Kompetenzbedenken gegen eine solche Lösung? Ich bin der Auffassung: Nein. Ich glaube, die Bedenken, die von Herrn Weber in dieser Richtung geäußert worden sind, waren überwindbar; das gilt insbesondere auch in Bezug auf die Verkehrssicherungspflicht. Auch insofern sind bei diesen Vorerwägungen keine Bedenken gesehen worden, und ich glaube auch nicht, daß sie gehegt werden müssen. Ich will mir aus Zeitgründen ersparen, das im einzelnen auszuführen. Herr Schultze-von Lasaulx hat diese Dinge in den gedruckten Ausschußberichten ausführlich zu Papier gebracht.

Die zweite Frage hat Herr Stern in seinem Leitsatz 21 dahin formuliert, ob es nicht Gebote juristischer Stilreinheit gebe, für ein solches Institut sachadäquate Regelungen zu finden. Dazu würde ich meinen, daß eine Regelung wie die des hamburgischen Wegegesetzes diesen Geboten entsprechen kann, sofern sie dabei den Dingen nicht in irgendeiner Weise Gewalt antut oder irgendwelchen Prinzipien widerstreitet, die zu berücksichtigen wären. Diese Gefährdung bestimmter Prinzipien sieht Herr Weber unter anderem aus gewissen rechtsstaatlichen Gesichtspunkten. Wenn ich ihn recht verstand, hatte er Bedenken, von der Charakterisierung des öffentlichen Eigentums zu sprechen in Bezug auf die Vorfrage der Herstellung der Verfügungsgewalt der öffentlichen Hand über diese Objekte. Dem ist, glaube ich, der Gesetzgeber gerecht geworden. Ich will hier auf die Texte verweisen: $\S 4$ Abs. 2 und $\S 6$ Abs. 1 HambWegeG stellen sehr eindeutig klar, daß in dieser Beziehung rechtsstaatlich sicher alles in Ordnung sein müsse. Ich sehe Bedenken auch nicht in der Richtung, da $\beta$ durch dieses Institut die Herrschaft der Zivilrechtsordnung aus ihren Restbeständen verdrängt wird, wenn - das ist natürlich die Voraussetzung, war die Klippe für den Gesetzgeber - diese Lücke, die durch die Verdrängung der Zivilrechtsordnung entsteht, durch adäquate öffentlich-rechtliche Sachnormen wieder ausgefüllt werden kann, wozu aber das Gesetz, glaube ich, hinreichende Re- 
gelungen bietet. Ich frage mich weiter: was spricht gegen eine solche Lösung, selbst wenn man sie als etwas Intensiveres charakerisiert, als Herr Weber es getan hat, der sie eine bloße "Etikettierung“ öffentliches Eigentum nannte, die sachlich nichts entscheidend Abweichendes oder Neues bringe. Den groBen Vorzug dieser Lösung sehe ich in ihrer Formenklarheit, in der Adäquanz der zuständigen Normen für das Institut der öffentlichen Sache, in einer Utberwindung - jedenfalls teilweise - des Dualismus der Rechtswege in Rechtsschutzfragen, insgesamt also auch in gewissen Rationalisierungseffekten des Gesetzgebers, die hier erzielt werden könnten. Entscheidende Einwendungen - wenn ich es einmal so pronociert formulieren darf -, warum denn ein Landesgesetzgeber, von der Kompetenzfrage abgesehen, nicht eine solche Lösung praktizieren solle oder dürfe, wie sie hier gefunden worden ist, glaube ich, nicht gehört zu haben. Ich wäre dankbar, wenn dazu noch entscheidende Argumente gesagt würden. Vor allen Dingen habe ich sie nicht gehört aus dem Munde von Herrn Stern, der sich zu der Frage: Institut des öffentlichen Eigentums oder nicht, negativ geäußert hat, ohne mir allerdings entgegenzuhalten, warum ein Gesetzgeber, wenn er für die betreffende Materie zuständig ist, nicht diesen Weg sollte gehen können.

Dürig: Herr Ipsen. Darf ich unterbrechen? Sie haben doch aber den Eigentumsbegriff geändert, der doch eigentlich vom BGB her feststeht?

Ipsen: Nein, wir haben ihn nicht verändert, sondern wir haben einen Eigentumsbegriff für öffentliche Sachen verwendet, für den mit Notwendigkeit und durch irgendeinen Kodifikationsvorbehalt des Bürgerlichen Rechts ein Eigentumsbegriff noch nicht präokkupiert und fixiert war. Der hamburgische Gesetzgeber hat sich auf den Standpunkt gestellt, daß ein Raum zur Fixierung öffentlichen Eigentums noch verfügbar war. Ob Sie dieses Institut nun zufällig auch gerade Eigentum nennen, so wie das BGB es Eigentum nennt, oder ob Sie es als Herrschaft - oder was weiß ich, wie sonst - bezeichnen, das ist dabei unerheblich. Sollte das aber als nicht unerheblich betrachtet werden, sind wir uns wenigstens einig, worin wir uneinig sind. Das betrachte ich als einen wesentlichen Fortschritt dieser Aussprache.

Darf ich ein Letztes sagen? Es ist von beiden Referenten, glaube ich, zutreffend darauf abgestellt worden, daß die öffentlichen Sachen als körperlich zu begreifen sind und ihr Begriff nicht unter Absehen von der Körperlichkeit in irgendeiner Weise ausgeweitet werden dürfte in verschiedene Richtungen, wobei mir eine am Herzen liegt. Sie ist heute morgen nur in einem 
Punkte angeklungen, nämlich in Bezug auf das, was wir öffentliche Unternehmen oder Unternehmen der öffentlichen Hand oder sonstige Sach- und Betriebsgemeinschaften mit öffentlicher Beteiligung und Einflußnahme nennen. Das ganze Thema unser Kollege Zeidler hat die Dinge ja in Köln (VVDStRL Heft 19) erörtert, die Frage der Mehrheitsbeteiligung, der Minderheitsbeteiligung, der Einflußnahme und dergleichen mehr -, diesen ganzen Fragenkomplex der Zuordnung zu den öffentlichen Unternehmen sollten wir, wie heute morgen, glaube ich, zutreffend geschehen ist, aus unserem Diskussionsbereich ausgeklammert lassen und uns damit in diesem Punkte wohltuend unterscheiden von den Franzosen, die in diesem Gemengelage untergehen und überhaupt keinen Uberblick und keine Scheidung mehr besitzen in den verschiedenen Institutionen des "service public". Ich möchte dabei aber nicht unterlassen, darauf hinzuweisen, daß dieses Thema der Kölner Tagung für uns thematisch noch nicht zu Ende sein sollte: Das sollten wir einmal wieder aufnehmen, aber aus diesem engeren Bereich jetzt ausklammern, weshalb - noch ein letztes hamburgisches Wort es mir dogmatisch auch nicht gefällt, daß mein Doktorand Klaus Vogel in seiner Arbeit über die öffentlichen Wirtschaftseinheiten in privater Hand den Vorgang der Indienstnahme solcher Betriebsunternehmungen mit dem verfänglichen Ausdruck „Widmung“ des öffentlichen Sachenrechts versehen hat, womit er gerade das in Verbindung brachte, was nach meiner Meinung sauber getrennt bleiben sollte.

Fuß: Ich gedenke nicht die hamburgische Lösung, insbesondere das Institut des öffentlichen Eigentums, zu verteidigen, sondern ich bin da ganz und gar der Meinung der beiden Herren Referenten. Ich glaube nicht, daß wir das Rechtsinstitut des öffentlichen Eigentums überhaupt benötigen, weil wir nämlich alle einschlägigen Probleme auch auf đie bisherige Weise lösen können, nämlich mit einem privatrechtlichen Eigentum, das öffentlich - rechtlich überlagert ist.

Erlauben Sie, daß ich einige Aspekte herausgreife und kurz behandele. Das erste ist die Benutzungsordnung, herkömmlich mit den Begriffen Gemeingebrauch und Sondernutzung bestimmt. Selbstverständlich muß diese Benutzungsordnung jedenfalls teilweise öffentlich - rechtlich ausgestaltet werden. Dabei ist es aber gut, daß zumindest auch die $\mathrm{Mög}$ li $\mathrm{chk}$ e it einer privatrechtlichen Nutzung weiter bestehen bleibt. Allerdings haben die Protagonisten des öffentlichen Eigentums richtig herausgestellt, daß die Widmung bisher nicht deutlich genug $\mathbf{z u}$ erkennen ist. Man weiß häufig nicht, ob eine Sache eine öffentliche Sache ist. Deshalb halte ich die Vorschläge für nützlich, 
entweder die Widmung in einem Grundbuch einzutragen - das wird häufig nicht möglich sein, weil die betreffenden Liegenschaften und Gegenstände nicht in ein Grundbuch hereingehören - oder vielleicht ein besonderes Buch dafür einzurichten. Ich glaube auch, daß dieser Aspekt dafür spricht, daß die Benutzungsordnung in den Vordergrund gestellt werden sollte und vielleicht einmal eine ähnliche Selbständigkeit erlangt wie das öffentliche Dienstrecht.

Der zweite Punkt ist die Frage der Beschränkung der Nachbarschaftsrechte. Auch hier meine ich, daß wir ohne weiteres auf eine totale öffentlich-rechtliche Lösung verzichten können, weil nämlich in $\S 906$ BGB n. F. und in $\S 26$ Gewerbeordnung schon gewisse Ansätze im geltenden Recht bereitstehen, die wir nur zu verwerten brauchen.

Drittens die Frage der Verantwortung für den Zustand der öffentlichen Sache, also in erster Linie die Verkehrssicherungspflicht. Es ist immer wieder darauf hingewiesen worden, daß es mißlich sei, daß der BGH hier zivilrechtlich konstruiert. Aber was ist denn die Alternative? Doch nur die Amtshaftung, und die Amtshaftung - $\$ 839 \mathrm{BGB}-$ ist ja, ursprünglich jedenfalls, auch ein zivilrechtliches Institut. Der Unterschied ist also gar nicht sehr groß. Und Herr Weber hat $m$. E. richtig darauf hingewiesen, daß eine Amtshaftung gar nicht im Interesse des Staatsbürgers steht.

Viertens nenne ich die Rechtswegfrage: Es ist für die global öffentlich - rechtliche Lösung vorgebracht worden - Herr Ipsen hat eben noch davon gesprochen - daß diese eine saubere Rechtsweglösung mit sich bringen würde. Nun, es ist selbst in diesem Falle technisch nicht möglich, die Rechtswegfrage endgültig zu bereinigen, ohne daß eine zivilgerichtliche Restkompetenz übrig bleibt. Diese Situation findet sich im übrigen auch anderswo. Für Amtshaftung und Enteignung ist der Rechtsweg $\mathrm{zu}$ den ordentlichen Gerichten eröffnet, und es besteht die Verwaltungsgerichtsbarkeit parailel dazu. Solange das Problem als solches noch nicht gelöst ist, also dieser Dualismus von ordentlichem Rechtsweg und Verwaltungsrechtsweg, solange sollte man nicht versuchen, auf dem Nebengeleis des öffentlichen Sachenrechts eine Teilbereinigung herbeizuführen.

Ein Institut des öffentlichen Eigentums ist also nicht notwendig, es wäre sogar nicht unbedenklich. Aus zwei Gründen: Es ist, glaube ich, nicht ohne besonderen Grund, daß Herr Weber als besonderer Kenner des französischen Verwaltungsrechts davon abgeraten hat, auch in Deutschland ein "domaine public" einzuführen. Und Herr Stern hat mit Recht, als er auf Otto Mayer 
zu sprechen kam, einen verhängnisvollen absolutistischen Zug in dessen Lehre hervorgehoben.

Weiterhin meine ich, daß der Begriff des öffentlichen Eigentums nur verwirrt. Denn es ist ja gerade das Verdienst des modernen Staates, daß er das dominium von den Hoheitsbefugnissen klar getrennt hat. Ich würde daher den Begriff "hoheitliche Sachherrschaft" als widersprüchlich ansehen. Eigentum ist eben privatrechtliche Sachherrschaft, mögen auch Hoheitsbefugnisse damit verknüpft sein.

Noch eine kurze Stellungnahme zu der Frage, ob der Gemeingebrauch in die Anstaltsnutzung zu überführen ist - der letzte Leitsatz von Herrn Weber. Ich glaube, mich dieser Meinung nicht anschließen zu können. Erstens meine ich, daß das Anstaltsrecht noch nicht genügend dogmatisch durchdrungen ist, um eine geeignete Basis abzugeben dafür, da $B$ der Gemeingebrauch durch Anstaltsnutzung ersetzt wird, insbesondere, wenn man berücksichtigt, daB ja nur an das Institut der unselbständigen Anstalten gedacht werden kann. Mir scheint dieses Institut noch besonders vage zu sein. Ferner: Wie steht es mit der Frage des Rechtsanspruchs auf Benutzung? Beim Gemeingebrauch ist dessen Existenz heute völlig herrschende Meinung. Soll auch ein Rechtsanspruch auf Anstaltsbenutzung bejaht werden? Wenn ja, stellt sich die Frage: Wie ist es mit den anderen herkömmlichen Anstalten? Läßt sich da auch durchgängig ein Rechtsanspruch auf Benutzung begründen?

Weber: Ca dépend; von der Art der Anstalt hängt das ab.

Fuß: Mit dieser Entgegnung spielen Sie m. E. auf die Frage der Gleichbehandlung an; und dann läuft letzlich wieder alles auf die Anwendung des Gleichheitssatzes hinaus, der ja ohnehin in weitem Maße überstrapaziert wird. Ein letztes, was Herr Stern $\mathrm{m}$. E. sehr richtig angedeutet hat: Anstaltsnutzung ist gegenüber dem Gemeingebrauch - ich glaube, Sie haben gesagt — „eine Organisationsform höherer Ordnung“. Ich würde sagen, das ist eine intensivere Verwaltung, ein Mehr an Verwaltung, und in unserer heutigen Welt, die ohne dies so sehr verwaltet ist, sollte man dem mit Bedenken begegnen. Ich glaube, daß der einfache Staatsbürger es auch kaum verstehen würde, daß seine öffentlichen Plätze, Grünanlagen, Wege usw. als Anstalten bezeichnet werden.

Krüger: Der Gegenstand und die Theorie der öffentlichen Sache sind Themen, die sich in den letzten Jahrzehnten in ihren Pro und Contra immer mehr verhärtet haben. Wir sind daher unseren beiden Referenten vor allem auch deswegen zu aufrichtigem Dank verpflichtet, weil sie diese Verhärtung weit- 
gehend aufgelöst haben, und wenn auch Herr Weber sich hier - ich weiß nicht aus welchem Grunde - als konservativ gesonnen vorgestellt hat, so hat er sich doch mit dem, was er über den Gemeingebrauch gesagt hat, vielleicht nicht geradezu als Revolutionär erwiesen, aber zum mindesten als Vertreter eines beweglichen Konservativismus gezeigt. Ich will versuchen, in dieser Linie noch etwas fortzufahren.

Es handelt sich ais erstes um die Frage, welche Kategorie wir zu wählen haben, um die öffentlichen Sachen und zwar in Utbereinstimmung mit Herrn Ipsen einschließlich Versorgungsund Staatsunternehmen, ihrem öffentlichrechtlichen Träger zuzuordnen. Wenn hier die Meinung vertreten worden ist, daß „Eigentum“, jedenfalls „Privateigentum" nicht die hierfür geeignete Kategorie ist, dann kann man dem nur zustimmen, und zwar gerade auch für das Staatsunternehmen. Ich empfinde es als eine ganz besondere Paradoxie, daß wir zwar für die Zuordnung der persönlichen Verwaltungsmittel statt des allgemeinen Arbeitsrechts uns eines besonderen Beamtenrechts bedienen, daß man aber auf die Notwendigkeit der gleichen Lösung für die sächlichen Verwaltungsmittel offensichtlich nicht gestoßen ist. $\mathrm{DaB}$ mit der Kritik hieran nicht etwa Begrifflichkeit um ihrer selbst willen am Werke ist, daß vielmehr das Fehlen einer adäquaten Kategorie zu den wichtigsten Folgen führen kann, zeigt das Urteil des Bundesverfassungsgerichts im Streit um die Privatisierung des . Volkswagenswerkes ${ }^{1}$ ). Das proton pseudos liegt hier bereits im ersten Satz, der das VW-Werk zu den zahlreichen „erwerbswirtschaftlichen" Unternehmen des Bundes rechnet -..., wie mit allem Respekt ausgesprochen werden darf. Es mutet wie ein Satyrspiel an, wenn wenige Wochen später dieselbe Regierung, die das Unternehmen „privatisiert" hatte, dem Leiter des Werkes heftige Vorwürfe machte, weil er sich wie der Leiter eines Privatunternehmens statt als Träger staatlicher Konjunktur- und Preispolitik verstanden und verhalten hatte. Hatte hier die Kategorie „Privateigentum“ zu einer Verkennung der volkswirtschaftlichen Funktion eines solchen Staatsunternehmens - nicht Gewinnerzielung, sondern Konjunkturpflege - geführt, so konnte das Gericht aus der gleichen Kategorie ohne weiteres zu dem verfehlten Schluß gelangen, daß ein „Erwerbsunternehmen" auch veräußerlich sein müsse. Der Gedanke, es könne sich um eine res extra commercium oder wenigstens um Verwaltungsvermögen handeln, ist offensichtlich niemand gekommen. Wenn dieser Vorfall nicht darüber belehrt, wie dringend notwendig es ist, auf die Kategorie „Privateigentum" für die Zuordnung der öffentlichen Sachen einschließlich der Staats-

1) Urteil vom 17. Mai 1961 in: BVerf G E 13 S. 354 ff. 
unternehmen zu ihrem staatlichen oder kommunalen Träger zu verzichten und sie durch eine adäquate Kategorie zu ersetzen, dann ist allerdings nicht zu sehen, wann jemals hier der Durchstoß zur adäquaten Qualifikation erwartet werden kann.

Beinahe noch wichtiger ist es aber, sich über die Funktion zu verständigen, die man der öffentlichen Sache im Zusammenhang mit der industriellen Entwicklung zuzuschreiben hat. Ich bin völlig mit dem einverstanden, was Herr W e b e r über die Sinn- und Funktionswandlung des Gemeingebrauchs gesagt hat. Wenn noch das Preußische Wassergesetz als Beispiele für Gemeingebrauch nennt Wasserentnahme für den Hausgebrauch, Viehschwemmen, Kahnfahren, Eisschlagen, dann spiegelt es vorindustrielle Zustände wieder. Demgegenüber sind die öffentlichen Sachen heute vor allen Dingen - und insofern hat Herr Stern ganz recht, wenn er sie in den großen Bereich der gewährenden Verwaltung einordnet -, zu sehen als staatliche Darbietung ebenso essentieller wie knapper Produktionsfaktoren. Ich habe früher zwar selbst dagegen polemisiert, daß man den Gemeingebrauch im Wasserhaushaltsgesetz in den zweiten Rang versetzt hat, habe mich aber inzwischen davon überzeugt, daß die industrielle Nutzung, die heute weniger denn je mit "Gemeingebrauch" zu erfassen ist, so sehr in den Vordergrund getreten ist, daß dem auch in der Systematik des Gesetzes Rechnung getragen werden muß -, so bedauerlich das vom Standpunkt der Freiheit aus erscheinen mag.

Ich möchte sogar noch einen Schritt weiter gehen: Der Funktionswandel der öffentlichen Sachen erschöpft sich nicht darin, daß sie aus Hilfen für die Hauswirtschaft zu Produktionsfaktoren für die Betriebe geworden sind, sondern daß sie darüber hinaus immer mehr in eine Rolle in der Wirtschaftspolitik, insbesondere in der Konjunkturpflege hineinwachsen. Hierfür werden die Mittel der "Beeinflussung von innen heraus" immer wichtiger - , eine Veränderung, der allerdings nicht Rechnung getragen wird, wenn man mit Herrn Stern hier immer noch von "Intervention" spricht. Die öffentlichen Sachen sind typische Mittel solcher Beeinflussung von innen heraus, jedenfalls wenn man sie richtig versteht und entsprechend einsetzt. Nehmen wir z. B. an, es sei richtig, daß - wie amerikanische Nationalökonomen lehren - die westlichen Völker zuviel ihres Nationalproduktes für kurzlebige Wirtschaftsgüter, insbesondere Verkehrsmittel verwenden. Wäre es unter solchen Umständen nicht richtig, wenn man den Straßenbau jedenfalls nicht mehr forcieren würde?

Man sieht auch an der Funktionswandlung der öffentlichen Sache, wie wenig die Kategorie "Privateigentum" geeignet ist, das Verhältnis zwischen Herrn und Sache und vor allem den 
Sinn dieser Herrschaft richtig zu bezeichnen. Utber diese Diskrepanzen kommt man nicht dadurch hinweg, daß man das Privateigentum mit einer, durch die Widmung umschriebenen öffentlichrechtlichen Hypothek belastet. Die Herrschaft über die öffentlichen Sachen muß von vornherein und innerlich als eine ausschließlich öffentlichrechtliche und ebenso ausschließlich öffentlichen Funktionen bestimmte verstanden werden.

Scupin: Ihrer Äußerung, mit der Sie, Herr Krüger, den Gemeingebrauch in die zweite Linie gerückt haben, möchte ich zustimmen. Wenn Sie aber sagen, daß man die öffentlichen Sachen nur dem industriellen Gebrauch zuordnen sollte, so möchte ich demgegenüber doch an die weiteren Bereiche erinnern, die durchaus erhaltenswert sind und in denen der Gemeingebrauch - Gott sei Dank - mit einer gewissen überlieferten "Gemütlichkeit" eine Rolle spielt. Verzeihen Sie, daß ich das so emotional ausdrücke; das hat aber einen ernsthaften Hintergrund. Denn das, was vorhin zum Naturschutz angeregt wurde, hat insofern seine sehr ernsthafte Bedeutung, als es eben nicht nur auf die technische Reinhaltung der Luft und des Wassers ankommt. Die Sache hat vielmehr auch eine psychische Seite, genauer: eine sozialpsychische! Der Mensch der Industriegesellschaft muß den Gemeingebrauch an Luft und Wasser mit Entspannung ausüben können. Insofern möchte ich also die Akzentuierung lieber so, wie Sie es zuerst sagten, primär auf den industriellen Gebrauch, sekundär auf den überlieferten Gemeingebrauch gesetzt sehen.

Stern: Herr Krüger, ich möchte nur einen Punkt richtigstellen. Wenn ich sagte, die öffentliche Sache dürfe keinen wirtschaftsinterventionistischen Ansatzpunkt bieten, so meinte ich damit folgendes: Die Sache soll nicht, wenn sie einmal entstanden ist, wirtschaftssteuernd eingesetzt werden; denn bei den öffentlichen Sachen steht nach meiner Auffassung die Funktion, grundsätzlich der Gesamtheit der Bürger zu dienen, im Vordergrund. Sie als ökonomisch-fiskalisch verwertbares Potential zu begreifen, wird ihrem Zweck, gewährt zu werden, nicht gerecht. Ich bin jedoch Ihrer Meinung, wenn Sie sagen, man solle beschränkend auf die Produktion öffentlicher Sachen einwirken, wenn die Gefahr eines sich überhitzenden Booms vorhanden ist, der eingedämmt werden soll. Das ist eine Frage der Herstellung der öffentlichen Sache, bei der eine Selektion durchaus möglich ist, nicht ihrer Gewährung, bei der nach sozialstaatlichen Grundsätzen verfahren werden muß.

Bettermann: Ich glaube, daß die Ausräumung der vom $B G H$ fortgesetzten "traditionellen" Rechtsprechung, wonach die Ver- 
kehrssicherungspflicht eine privatrechtliche Pflicht ist, nicht die Rechtsfigur des öffentlichen Eigentums notwendig macht, sondern hierzu ist nur die Erkenntnis notwendig, daß die Pflicht der öffentlichen Hand, die öffentlichen Sachen, die sie dem öffentlichen Verkehr gewidmet hat, in ordnungsmäßigem und verkehrssicherem Zustand zu halten, eine Amtspflicht, eine öffentlich-rechtliche Pflicht ist. M. E. handelt es sich bei dieser Rechtsprechung nur um ein Festhalten aus Tradition. In Wirklichkeit ist dies eine Zuständigkeit der ordentlichen Gerichte kraft Tradition.

Herrn Fuß muß ich entschieden widersprechen, wenn er generell sagte, daß damit rechtspolitisch nichts gewonnen wäre, weil die Amtshaftung schlechter sei als die bürgerlich-rechtliche Haftung nach $\S 823$ BGB. Sie denken vermutlich an die Subsidiarität. Ich bestreite aber, daß der $\S 839$ Abs. 1 S. 2 BGB für die Staatshaftung gilt; denn diese Subsidiarität ist um des leistungsschwachen Beamten willen geschaffen worden und entfällt in dem Augenblick, wo an die Stelle des leistungsschwachen Beamten der leistungsstarke Staat tritt. Ich habe das wiederholt ausgeführt.

Weber: Aber solange an der Rechtsprechung zu $\S 839$ festgehalten wird, ergibt sich diese Wirkung; dann muß man eben das Schadensersatzrecht als ganzes neu ordnen.

Bettermann: Viel wesentlicher noch ist der andere Punkt, in dem die Staatshaftung schärfer ist als die bürgerlich-rechtliche Haftung, nämlich bei der Frage der Exkulpation für Erfüllungsgehilfen. Bei bürgerlich-rechtlicher Haftung im Gegensatz zur Amtshaftung schafft $\S 831$ BGB eine Haftungsbefreiung. Bei der Amtshaftung wird aber für den letzten Erfüllungsgehilfen so gehaftet wie für einen Organwalter.

Bachof: Wegen der Rechtsprechung zum „Organisationsmangel", der mehr oder minder fingiert wird, kann aber im praktischen Ergebnis eine Haftungsbefreiung über § 3831 BGB nicht mehr eintreten.

Bettermann: Damit allerdings gibt die Rechtsprechung im Grunde die Schwäche ihrer Position zu.

Bachof: Sie deckt also eine Schwäche mit einer anderen zu, sie kompensiert die Folgewirkung einer Schwäche mit den Konsequenzen einer anderen dogmatischen Schwäche.

Bettermann: Eben. Für die Rechtswege würde sich ja, solange Art. 34 S. 3 GG besteht, nichts ändern. Ich meine nur, da $B$ nicht gerade die Öffentlichrechtler berufen sein müßten, 
hier eine dieser traditionellen Zuständigkeiten des Zivilrechts und der Zivilgerichte aufrecht $\mathrm{zu}$ erhalten.

Was die Versicherungen angeht, Herr Weber, auf die Sie angespielt haben, über die Subsidiaritätsklausel ( $\S 839$ Abs. 1 S. 2 BGB), wonach man sich anrechnen lassen muß, daß man versichert ist, möchte ich einwenden, daß dieser Gesichtspunkt auch bei $\$ 823$ auftritt; denn die öffentliche Hand hat sich ja gegen ihre Haftpflichtschäden auch - sei es direkt, sei es im Wege der Selbsthilfe durch den Gesamtverband der Gemeinden - versichert.

Weber: Immerhin, die Verantwortung bleibt bei der öffentlichen Hand, und es fällt auf sie selbst zurück, wenn sie dort Leistungen $z u$ erbringen hat.

Bettermann: Aber letzlich trägt diese Verantwortung doch die Allgemeinheit, ob Sie nun die Staatshaftung nehmen oder ob Sie die Haftung aus $\S 823$ begründen.

Weber: Aber es spielt eine große Rolle, wie hoch diese Gemeindeunfallversicherungsverbände aus Schäden in Anspruch genommen werden.

Dürig: Auch der Gemeindeunfallversicherungsverband wird aber doch von den Gemeinden gespeist, Herr Weber. Es zahlt doch stets letztlich die öffentliche Hand.

Weber: Das will ich ja auch gerade.

Bettermann: Wesentlicher scheint mir die Frage des „Öffentlichen Eigentums" zu sein. Ich möchte nicht dafür plädieren, nun für alle öffentlichen Sachen die Rechtsfigur des öffentlichen Eigentums zu kreieren. Aber ich meine, daß dogmatisch gegen öffentliches Eigentum keine Bedenken bestehen und gegen ein solches Rechtsinstitut, wie es Hamburg - wenn ich es recht verstanden habe - geschaffen hat. Es ist ja bezeichnend, daß Herr Stern einerseits die Rechtsfigur des öffentlichen Eigentums abgelehnt, andererseits aber wiederholt den Terminus „öffentlich-rechtliche Sachherrschaft" gebraucht hat. Eigentum ist doch eine Form der Sachherrschaft. Und warum soll es nicht öffentlich-rechtliche Sachherrschaft geben, wie es privatrechtliche Sachherrschaft gibt? Es ist doch kein Widerspruch, Herr Fuß, wenn die Hoheitsgewalt von der früheren Privatgewalt über Dinge und auch über Personen getrennt worden ist. Das hindert doch nicht, daß es eine öffentliche Gewalt nicht nur gegenüber Menschen gibt. Die Herrschaftsgewalt des Staates ist nicht nur eine Gewalt über seine Untertanen, sondern ist auch eine Gewalt über die Sachen, die diese haben und die sich in dem Staatsgebiet befinden. Wir 
haben eine Fülle von sachenrechtlichen Beziehungen des Staates. Sie haben den Begriff der öffentlichen Last erwähnt. Wir haben doch eine unendliche, überhaupt nicht zu übersehende Fülle von öffentlichen Lasten jeglicher Art, die in der Zwangsversteigerung in dem Katalog der zu übernehmenden Rechte aufgeführt werden. Da haben wir doch öffentlich-rechtliche Sachherrschaftsverhältnisse, die neben den Sachenrechten des bürgerlichen Gesetzbuches stehen. Wenn immer gesagt wird, daß der Kreis der dinglichen Rechte ein geschlossener sei, dann trifft das allenfalls - und auch das nicht einmal vollständig - für die privaten Rechte zu, daneben steht aber doch die Fülle sachenrechtlicher Beziehungen des Staates oder sonstiger Träger öffentlicher Gewalt. Beschränkte dingliche Rechte an Sachen des öffentlichen Rechtes gibt es also. Nur das umfassendste Sachenrecht, das Eigentum, das soll es nur im Privatrecht geben? Ich bin der Meinung, daß das Eigentum ein Begriff nicht des Privatrechtes ist, sondern der allgemeinen Rechtslehre und Rechtstheorie und als solcher ein Oberbegriff. Wie wir heute wissen, daß es eine öffentlich-rechtliche Bereicherung gibt, wie wir ein öffentliches Schadensersatz- und Entschädigungsrecht, eine öffentlich-rechtliche Verwahrung, einen öffentlich-rechtlichen Dienst haben, so ist nicht einzusehen, warum es nicht ein öffentlich-rechtliches Eigentum geben soll. Eigentum kommt vor im Privatrecht und es kommt vor im öffentlichen Recht.

Klein: Ist das Eigentum an den Bundeswasserstraßen im Sinne des Art. 89 GG rein privatrechtlich? Doch wohl kaum!

Bettermann: Die Frage ist m. E. nur, für welche öffentlichen Sachen man diese Rechtsfigur in Anspruch nehmen soll. Es kommt sicher nicht in Frage, daß alles das, was wir unter öffentlichen Sachen verstehen - nach Herrn Krüger offenbar auch das Geld der Bundesbank, wenn ich ihn recht verstanden habe - dieser Rechtsfigur zugerechnet wird.

Krüger: Darf ich gleich etwas einwerfen? Man kann die Kategorie „Privateigentum" sowohl für die Innehabung wie die Beherrschung einer Sache durch den Staat nicht verwenden, weil Eigentum immer impliziert Freiheit der Funktionsund Motivationswahl durch den Eigentümer, dem Staat aber eine solche Wahlfreiheit gerade nicht zugestanden ist: Staatliche Herrschaft ist nicht ein Blankett, das nach eigener Wahl mit Funktionen und Motivationen ausgefüllt wird, hier ist vielmehr die Herrschaft mit Funktion und Motivation identisch. Die Bundesbank z. B. kann mit ihrem Gelde nicht primär machen was sie will -, es meinetwegen wie ein Privateigen- 
tümer in den Ofen stecken oder verwetten. Sie kann vielmehr mit diesem Gelde von vornherein nur das, was sie soll und darf: In ihrer Innehabung und Beherrschung des Geldes steckt von vornherein nicht mehr drin, so daß es des Gedankens einer nachträglichen Bestimmung oder Beschränkung gar nicht bedarf. Die Identifikation von Herrschaft einerseits, Funktion und Motivation andererseits ist es, die ein kommerzielles Mißverständnis dieser Herrschaft ausschließt.

Bettermann: Darf ich gleich richtigstellen, da $\beta$ ich nicht den Begriff des Privat eigentums für das öffentliche Recht in Anspruch nehmen will, sondern nur den Begriff des Eigentums und unterscheiden will zwischen privatem Eigentum und öffentlichem Eigentum. Was das Verfügen über das Eigentum angeht, so wissen wir doch alle, daß das, was im $\S 903$ BGB steht, nur einen ganz kleinen Aspekt der Rechtsordnung wiedergibt, daß doch keineswegs der Eigentümer mit seiner Sache nach Belieben verfahren kann, nicht einmal mit dem Schoßhund, wenn er nicht mit dem Tierschutzgesetz in Konflikt geraten will. Je wichtiger das Eigentum ist und je größer seine gesellschaftliche und öffentliche Funktion wird, umsomehr nehmen ja die Bindungen des privaten Eigentums zu. Da haben wir ja eine reiche Skala von Bindungen, die so weit gehen, daB von §903 BGB überhaupt nichts mehr übrigbleibt! Die Bundesbankgesetzgebung kann doch geändert werden und wird geändert. Die Verfügungsmacht, die die Bundesbank über das Bargeld hat, kann wechseln und wechselt auch. Gerade das Verhältnis von Bundesbank zur Regierung ist äußerst problematisch. Worauf ich bei alledem nur hinaus will, ist, daß ich jedenfalls dogmatisch gegen den Begriff des öffentlichen Eigentums keine Bedenken sehen kann. Die Frage ist nur die nach der Nützlichkeit des Begriffs - und die zweite Frage ist: Für welche öffentlichen Sachen soll diese Rechtsfigur verwendet werden und für welche nicht?

Ein letztes Wort zur öffentlichen Anstalt. So wenig ich Herrn Weber im Endergebnis folgen kann, so möchte ich doch meinen, daß das mindestens ein fruchtbarer Gedanke ist, den Sie hier in die Debatte geworfen haben: ob und inwieweit insbesondere der Straßenverkehr und seine Einrichtungen zu einer Anstalt geworden sind und nach öffentlichen Anstaltsrecht behandelt werden sollen. Das hängt wahrscheinlich davon ab, welche Definition man der Anstalt gibt. Gefühlsmäßig habe ich den Eindruck, daß der Straßenverkehr die Schwelle der „Veranstaltung" noch nicht überschreitet und noch nicht jene organisatorische Verdichtung erreicht hat, die wir für den Begriff der Anstalt brauchen. Aber das kann sich ändern, und das mag 
auch bei den verschiedenen Arten öffentlicher Sachen verschieden liegen. Vor allem möchte ich davor warnen, die Ordnung unseres öffentlichen Straßenverkehrs und seine Einrichtungen $\mathrm{nur}$ anstaltlich zu sehen. Die Folge ist nämlich die, daß diese Ordnung, wie sie insbesondere in der Straßenverkehrsordnung und der Straßenverkehrszulassungsordnung enthalten ist, nur noch als Anstaltsordnung begriffen wird. Primär ist sie aber eine Polizeiverordnung. Und es wird in den entscheidenden gesetzlichen Bestimmungen sorgfältig unterschieden, welche Funktionen die Regelungen unseres Straßenverkehrsrechtes einschließlich des Zulassungsrechtes haben. Ich zitiere hier, weil ich keinen Gesetzestext habe, aus der Entscheidung des Bundesverfassungsgerichtes zu $\S 21$ StVG $^{2}$ ). Es wird unterschieden zwischen Normen, die die öffentliche Sicherheit und Ordnung des Verkehrs betreffen, und Normen zur Verhütung einer über das Verkehrsübliche hinausgehenden $\mathrm{Ab}$ nutzung der Straßen - das wäre wohl die Überschreitung des Gemeingebrauches --, und drittens Normen zur Verhütung von Belästigungen, was auch mit dem Gemeingebrauch zusammenhängt. Hier wird also sorgfältig unterschieden zwischen dem Normenkomplex polizeilicher Natur und dem Normenkomplex, der den Gemeingebrauch und die Gemeinverträglichkeit betrifft. Ich glaube, daß dazwischen unterschieden werden muß, wenngleich ich zugebe, daß hier die Grenzen fließend sind und es eine Reihe von Normen gibt, die sowohl der Sicherheit und Leichtigkeit des Verkehrs dienen als auch der Gemeinverträglichkeit.

Weber: Ist das denn ein Unterschied: Sicherheit und Leichtigkeit des Verkehrs und Gemeinverträglichkeit?

Bettermann: Die Sicherheit, keinen Unfall zu erleiden, ist sicher etwas anderes, als die Möglichkeit, am Straßenverkehr teilzunehmen, etwa einen Parkplatz zu finden. Ich gebe aber $z u$, daß da Grenzübergänge sind. Trotzdem ist die Unterscheidung wichtig, auch für die Frage der Pönalisierung. Und die Einrichtungen, die das Substrat dieser öffentlichen Anstalt „Straße" bilden, dienen dann eben teils dazu, daß jeder am Verkehr teilnehmen kann, daß also die Gemeinverträglichkeit des Gemeingebrauchs sichergestellt wird; ein Teil dieser Veranstaltungen dient aber dazu, die Sicherheit des Verkehrs zu gewährleisten. Ich meine, daß wir das Straßenverkehrsrecht nicht durch das Anstaltsrecht verdrängen lassen dürfen, so wichtig auch der Gesichtspunkt der Anstalt ist.

9) Beschl. v. 25. 7. 1962, 2 BvL 4/62, NJW 1962, 1563 (Anm. d. Red.). 
Scupin: Dies ist der einzige Punkt, bei dem ich heute Bedenken hatte, als nämlich Herr Weber den Úbergang von dem Gemeingebrauch in die anstaltliche Regelung fand. Gegenüber dem Gemeingebrauch haben wir auch Möglichkeiten der polizeilichen Regelung. Im anstaltlichen Bereich haben wir sie nicht mehr; dann gibt es Kompetenzüberschneidungen und Schwierigkeiten. Von daher tritt in der Tat ein Problem in Erscheinung, auf das man sein Augenmerk sehr scharf richten sollte.

Bullinger: Herr Professor Bettermann hat ausgeführt, es sei dogmatisch nicht ausgeschlossen, ein öffentliches Eigentum zu begründen. Man kann natürlich, ich gebe das zu, einen öffentlich-rechtlichen Kauf, eine öffentlich-rechtliche Miete, einen öffentlich-rechtlichen Beförderungsvertrag schaffen, wie es die Franzosen ja getan haben. Ich zweifle nur daran, daß es dem deutschen Recht nach seiner ganzen Entwicklung entspricht. Ich habe ja schon einige Druckerschwärze gegen den öffentlichrechtlichen Vertrag verspritzt - eine parallele Problematik und will mich nicht wiederholen. Nur soviel grundsätzlich: Es ist doch wohl so, daß wir sehr vorsichtig sein sollten mit der, wenn ich so sagen darf — Gefräßigkeit des öffentlichen Rechts, mit dem Bestreben, einfach alles Beliebige in das öffentliche Recht hinüberzuziehen. Vorher müßte man in jedem Einzelfall demonstrieren, da $\beta$ das Privatrecht unangemessen ist und daher besondere, öffentlich-rechtliche Regeln angewendet werden müssen. Wenn das nicht der Fall ist, wozu dann das Wort "öffentliches" Recht? Es wird dann doch ein bloßes Etikett. Speziell bei der öffentlichen Sache geht es wohl darum - ich glaube, Herr Professor Krüger, das ist Ihr besonderes Anliegen - , daß nicht der Träger einer öffentlichen Sache, wenn er zugleich Eigentümer ist, dieses Eigentum sozusagen privatnützig mißbraucht. Aber ich bin nicht der Ansicht, daß man deshalb das öffentliche Eigentum benötigt - man kann etwa mit dem Gedanken des Rechtsmißbrauches allen Auswüchsen entgegentreten.

Nun zu einer anderen Sache. Herr Stern, Sie haben den Begriff des "Organisationsaktes" neben die Widmung gestellt, was bisher in der Diskussion nicht aufgegriffen worden ist. Dagegen habe ich einige Bedenken.

Stern: Organisationsakt $s \mathrm{t}$ a $\mathrm{t} t$ der Widmung.

Bullinger: Dann habe ich Sie falsch verstanden, und wir sind vielleicht nicht so weit auseinander. Mir war nur eines nicht ganz klar: Sie sagten erst, Sie wollten durch den "Organisationsakt" die öffentliche Sache vollständig in eine öffentlichrechtliche Ordnung überführen, wollten damit aber doch wohl nicht das Privatrecht völlig ausschließen, sondern im wesent- 
lichen im bisherigen Umfang bestehen lassen. Aber ich weiß nicht, ob man unter diesen Umständen das neue Wort des "Organisationsaktes" einführen sollte, das - soweit ich weiß aus der Rechtsprechung des Bundesgerichtshofs zur Verkehrssicherungspflicht kommt und dort die Verwaltungsmaßnahme kennzeichnen soll, die eine öffentliche Sache nach außen hin im Verhältnis zu den Benutzern dem öffentlichen Recht unterstellt. Ich halte den Ausdruck "Organisationsakt" daher für mißverständlich und nicht sehr glücklich und glaube, man sollte bei der „Widmung“ bleiben.

Bachof: Darf ich dazu eine Zwischenfrage stellen? Herr Stern, wenn ich Ihren Leitsatz 11 noch einmal lese: „Der Organisationsakt, der die solchermaßen bestimmte öffentliche Sache kreiert, ist nicht identisch mit der Widmung, sondern Rechtsakt eigener Prägung, der einem Rechtsobjekt den institutionell öffentlichen Status verleiht". Ich hatte das auch wie Herr Bullinger dahin verstanden, daß hier Organisationsakt und Widmung $u$. U. neben- bzw. nacheinander vorgenommen werden sollten. Wie ist es denn z. B. bei der Straße, wo ist hier der Akt, der die Straße zur öffentlichen Sache kreiert? Ersetzt er die Widmung oder ist eine Widmung zum öffentlichen Gebrauch gar nicht mehr notwendig, oder wie ist das vorstellbar? Wollen Sie hier die Widmung beseitigen und durch den Organisationsakt ersetzen? Ich hatte Sie zunächst so verstanden, da $B$ beides nebeneinander steht - Herr Bullinger offenbar auch. Jetzt bringen Sie eine Korrektur an. Aus Ihrem Leitsatz wird das nicht ersichtlich. Ich wäre Ihnen dankbar, wenn Sie das in Ihrer Antwort noch etwas erläutern würden.

Scupin: Obgleich ich als Leiter der Debatte wenig eingreifen sollte, möchte ich doch einen sachlichen Gesichtspunkt, ein einziges Wort, nicht unter den Tisch fallen lassen. Könnten Sie vielleicht auch dahingehend eine Präzision treffen, ob Sie die Indienststellung der öffentlichen Sachen auch ausschalten wollen. Wir kennen ja die Indienststellung als Vorstufe, dann kommt Widmung oder manchmal gibt es auch nur Indienststellung. Wie steht Ihr ja etwas unbestimmt gefaßter „Organisationsakt" zu diesen beiden Vorgängen?

Bullinger: Darf ich vielleicht noch ganz kurz einen dritten Punkt anschneiden? Herr Professor Weber, Sie haben beinahe überzeugend gezeigt, daß die Sachen im Gemeingebrauch mehr zur Anstalt überwandern, mindestens bei Autobahnen und ähnlichen Einrichtungen. Ich will die tatsächliche Entwicklung gern zugeben, glaube aber, daß es noch verfrüht ist, diese Einrichtungen sozusagen in die Anstalt abzuschieben. Es gibt 
nämlich einen Straftatbestand der Aussetzung in hilfloser Lage. Ich darf daran erinnern, daß Herr Professor Krüger vor kurzem die Anstalten hinsichtlich des „besonderen Gewaltverhältnisses" als vorrechtsstaatlichen Urwald bezeichnet hat. Dürfen wir also die Autobahnen und ähnliche Einrichtungen sozusagen in den Urwald aussetzen? Ich habe dagegen stärkste Bedenken.

Thieme: Es will mir nach diesen vielen Beiträgen zur Frage des öffentlichen Eigentums mehr oder weniger als ein Scheinproblem erscheinen, wie man die Sachkomplexe, die sich in einem Zustand der Bindung durch das öffentliche Recht befinden, kategorisiert. Unser Eigentumsbegriff als solcher hat ja doch zwei Pole, einen Pol in $\S 903$ BGB — der Eigentümer kann tun und lassen, was er will - und einen im Art. 14 Abs. 2 GG - der Eigentümer ist gebunden. Dieser Eigentumsbegriff in beiden Vorschriften ist lediglich eine Hülse, die durch positives Recht so oder so ausgefüllt wird. Die Vorstellung, wir hätten im Zivilrecht einen einheitlichen Eigentumsbegriff, ist doch - wenn ich recht sehe - auch von den Zivilrechtlern weitgehend aufgegeben. Es ist eine dogmatische Figur, an die sich alles Mögliche anknüpft. Herr Weber hat etwas sehr Treffendes gesagt, das weitgehend überhört worden ist. $\mathrm{Er}$ hat nicht gesagt, das Eigentum bei den öffentlichen Sachen is t bürgerlich-rechtliches Eigentum, sondern: es $\mathrm{h}$ a $\mathrm{t}$ in der positiven Ordnung des bürgerlichen Rechtes se in e Verankerung g ef unden. Herr Bettermann hat ja bereits darauf hingewiesen, daß das öffentliche Recht eine Fülle von anderen Rechtsinstituten kennt, die auch im BGB geregelt sind. Daß etwas im BGB steht, entscheidet ja noch lange nicht, ob es sich um einen bürgerlich-rechtlichen oder einen öffentlich-rechtlichen Gegenstand handelt (siehe $\S 839$ BGB, das Namensrecht usw.).

Mit Herrn Stern stimme ich darin nicht überein, daß wir, wenn wir von der öffentlichen Sache sprechen, das Wort "öffentlich" untersuchen müssen. Sondern: "Öffentliche Sache" will doch wohl "öffentlich-r e ch tl i che " Sache heißen; das Wort „rechtlich" verschwindet darin etwa genau so, wie bei den öffentlichen Körperschaften das "rechtlich" in einem Teil der Literatur verschwindet. Das ist nur eine vereinfachende Redeweise. Es kommt darauf an, ob wir das öffentliche Eigentum unter der Kategorie des öffentlichen Rechtes oder des Privatrechtes traktieren. Nun wissen wir aber nicht recht, wieweit eigentlich das öffentliche Recht geht und wo das Privatrecht anfängt, und keine der derzeit gelehrten Theorien kann diese Frage wirklich ohne Rest lösen. Es ist doch so, daß der Begriff des öffentlichen Rechtes im Gegensatz zum Privatrecht eine historische Kategorie ist, eine Kategorie, die sich verän- 
dert. In diesem Wandlungsprozeß steht auch die öffentliche Sache. Es ist daher eine müßige Frage, ob wir sagen, wir sind historisch schon einen Schritt weiter, wobei ich dahingestellt sein lassen will, was das "weiter" bedeutet: zum öffentlichen Recht oder zum Privatrecht. Es kommt doch nur darauf an, wie das einfache Gesetz, das zwischen den Polen des Art. 14 GG und des $\S 903$ BGB das Eigentum konkretisiert, die Einzelfrage löst. Die Frage: öffentlich- oder privatrechtlich? Das mag der Gesetzgeber kennzeichnen oder in den Lehrbüchern stehen. Für die Sache ist es völlig gleichgültig.

Ich möchte noch zu einem zweiten Punkt sprechen. Eine Frage an Herrn Weber: Die tatsächliche Entwicklung in unserem Straßenrecht und in unserem Wasserrecht sehe ich genau so wie Sie, daß nämlich Züge der Anstalt immer stärker werden.

Weber: Nicht im Wasserrecht; im Wasserrecht ist es etwas anderes.

Thieme: Im Wasserstraßenrecht doch wohl! - Aber ich sehe nicht recht, was eigentlich damit gewonnen ist, wenn wir diese mehr verwaltungssoziologische Beobachtung nunmehr ins Rechtliche transponieren. Darüber hätte ich gern eine Information, die vielleicht im Schlußwort gegeben werden könnte. Wenn wir die Begriffe "Gemeingebrauch" einerseits und „anstaltliche Nutzung" andererseits haben, können wir das, wie mir scheint, in einer doppelten Weise verstehen. Entweder haben wir Typenbegriffe vor uns: Aus der Fülle tatsächlicher Erscheinungen, die rechtlich $\mathrm{zu}$ qualifizieren sind, bieten sich gewisse Festpunkte an: Kom m t so et w a s t ypischerwe is e vor, was wir dann Gemeingebrauch nennen, oder typischerweise etwas, was wir als Anstalt bezeichnen. Später schafft dann der Gesetzgeber oder die tatsächliche Entwicklung neue Möglichkeiten, die irgendwo auf der Grenze zwischen beiden Rechtsinstituten liegen und wir stehen dann vor der Notwendigkeit, es so oder anders zuzuordnen. Nun will es mir scheinen, daß die Dinge in unserem modernen Wasserstraßenrecht und Wegerecht anders liegen, weil der Begriff des Gemeingebrauchs aus dem allgemeinen Teil unserer Lehrbücher in diesen beiden Rechtsgebieten in den letzten Jahren in erheblichem Maße in das positive Recht eingeflossen ist und dort vielleicht einen Inhaltswandel durchgemacht hat. Wenn nämlich das Bundesfernstraßengesetz und die Landesstraßengesetze etwas als $\mathrm{Ge}$ meing e b $\mathrm{rauch}$ bezeichnen, so können wir natürlich trotzdem sagen: das ist anstaltlicher Gebrauch. Das halte ich nicht für die richtige Lösung. Wir müssen dann eben feststellen, daß sich hier am Begriff des Gemeingebrauch etwas 
verändert hat. Wir können dagegen remonstrieren aber der Gesetzgeber hat nun einmal rechtliche Fakten geschaffen.

Dürig: Gestatten Sie mir bitte nur drei kurze Bemerkungen in derselben Reihenfolge wie Herr Bettermann. Erstens: Herr Weber, ich verstehe nicht recht Ihre Toleranz gegenüber der Rechtsprechung des Bundesgerichtshofs zur Verkehrssicherungspflicht, die er ja immer noch privatrechtlich einordnet. Natürlich ist der Ausgangspunkt nicht mehr das Eigentum, und auch der Passivlegitimierte wird nicht mehr nach dem Eigentum bestimmt. Etwa wenn auf Bundesstraßen etwas passiert, wird allein nach der Verwaltungsmacht verurteilt; der Passivlegitimierte ist also das Land. Es ist eigentlich nicht recht verständlich, daß man, wenn man die Passivlegitimation nicht mehr aus dem Eigentum herleitet, nicht auch die actio, die Anspruchsgrundlage, vom Eigentum abhebt und ganz aus dem Imperium, aus der Amtspflicht, ableitet. Aber das Bedenkliche bei der jetzigen Rechtsprechung und der dunkle Punkt ist in der Tat der § 831 mit seiner leichten Exkulpationsmöglichkeit. Bedenklich ist es m. E. auch, wenn beim BGH manchmal auch $\S 836$ zitiert wird. Wir waren uns ja bisher eigentlich darüber einig, daß sowohl die Verkehrssicherungspflicht, wenn wir sie dem $\S 823$ BGB zuordnen, als auch die Amtshaftung - Art. 34 GG i. V. m. § 839 BGB - eben doch Verschuldenshaftung sind.

Weber: Gefährdungshaftung!

Dürig: Das ist mir neu. Wieso denn?

Bachof: So leicht ist die Exkulpation nach $\S 831$ BGB nicht mehr. Sie ist praktisch durch die Rechtsprechung fast ausgeschlossen. Die Haftung wegen Verletzung der Verkehrssicherungspflicht gem. $\S \S 823,831$ BGB ist eine durch Gerichtsgebrauch geschaffene Gefährdungshaftung.

Dürig: Herr Fuß, Sie haben Herrn Weber insofern mißverstanden als er nicht gesagt hat, daß über $\S 839$ BGB der Bürger schlechter stünde, sondern er meint nur, daß hier die Verweisungsmöglichkeit gem. $\S 839$ Abs. $1 \mathrm{~S}$. 2 bestünde und daB die eigentlich Getroffenen die Versicherungen sind, vor allen Dingen auch die Sozialversicherung. Ich verstehe das offengestanden immer noch nicht; denn dieser Gemeindeunfallversicherungsverband lebt doch von Geldern der Gemeinden.

Weber: Verzeihung, es gibt doch bei $\S 839$ BGB praktisch gar keinen Anspruch gegen die Gemeinde oder gegen den Staat, sondern die Sozialversicherung, Krankenkasse, Rentenversicherung, Unfallversicherung oder sonstige Versicherung 
zahlt und kann nicht Regreß nehmen. Der Schaden wird also letzten Endes vom Versicherungsträger gedeckt.

Dürig: Ein zweites: Wir haben in Baden-Württemberg in dem neuen Wassergesetz auch den Begriff des öffentlichen Eigentums. Ich glaube, für Freiburg zu sprechen und auch für Heidelberg - für Tübingen jedenfalls weiß ich nichts Gegenteiliges -, wenn ich sage, daß wir nicht gefragt worden sind. Die Materialien sind unergiebig. Ich glaube, Herr FuB, Sie haben recht, das stammt vom Tisch eines Ministerialrats, der bei uns freilich der Sache nach Entsprechendes im $\S 7$ des alten Württembergischen Wassergesetzes vorfand. Aber der Ausdruck "öffentliches Eigentum" ist jedenfalls neu. Nun weiß ich nicht, ob das so einfach geht, Herr Ipsen. Wenn Sie sich den Vorbehalt im Einführungsgesetz des BGB anschauen, was danach das Land auf dem Gebiet des Wasserrechts tun kann, da ist etwa von Flößerei usw. die Rede. Aber hier wird doch - ich wiederhole noch einmal - ein neuer Eigentumsbegriff kreiert, und, Herr Bettermann, ich muß Ihnen widersprechen, es gibt zwar öffentlich-rechtliche dingliche Lasten, aber ein öffentlich-rechtliches dingliches Vollrecht kennen wir in unserer Rechtsordnung - Herr Bullinger, da haben Sie m. E. recht - bisher nicht. Zwischen der Gebietshoheit und dem Privateigentum haben wir z. Z. kein Rechtsinstitut, wie Obereigentum, Treuhandeigentum usw. Mit dem "öffentlichen Eigentum" wird eine neue Kategorie eingeführt, und ich frage mich doch, ob das ein einzelnes Land gegenüber einem kodifizierten, vorgefundenen Privatrechtssystem mit einem Eigentumsbegriff i. S. des Privatrechts tun kann. Ich hätte dagegen keine Bedenken, Herr Weber, gegen die hamburgische Regelung des Schadensersatzrechts. Das Bundesrecht stellt § 823 BGB zur Verfügung und die Amtshaftung als Alternative. Wenn nun Hamburg, gewissermaßen statt des BGH, sagt: „Wir nehmen d i e s e actio“, ist das $\mathrm{m}$. E. unschädlich. Und zum dritten: der Verlagerung vom Gemeingebrauch zur Anstaltsnutzung. Herr Weber, das war eine vorzügliche Leistung. Sie haben sich eine Stunde lang konservativ gegeben und uns dann in 5 Minuten einen aufregenden und sensationellen Gedanken hingeworfen. Sie haben nichts anderes getan, als diese große traditionelle Trias: Gemeingebrauch $=$ Zulassungsfreiheit $=$ Unentgeltlichkeit umzubiegen in: Anstaltsnutzung, Zulassungsnötigkeit und Gebührenmöglichkeit zumindest. Ich habe aufgeatmet, als dann Herr Stern die Laternengaragen nannte. Kommen wir hier nicht vom Lebenssachverhalt her weiter? Natürlich sind viele Stunden lang am Tage die öffentlichen Straßen ohnegleichen in Anspruch und in Dienst genommen, aber nachts kann ich 
doch meinen Wagen hinstellen. Sind wir nicht hier am Nerv der ganzen Geschichte? Der Gemeingebrauch ist etwas sehr Personelles, sehr Natürliches und Menschliches. Jetzt machen wir daraus etwas Materielles, wir versachlichen es. Wir sind so dankbar, daß wir jetzt die Universität als Körperschaft und nicht mehr als Anstalt auffassen, und nun wollen wir solche natürlichen Betätigungen, wie gehen, laufen, reiten usw. verdinglichen, indem wir nun den Gemeingebrauch zu einer Anstaltsnutzung machen!? Das ist m. E. das große Problem: Wir verdinglichen, versachlichen, entpersönlichen jetzt natürliches menschliches Verhalten.

Köttgen: Herr Bettermann hat vorhin unter Bezugnahme auf eine Reihe anderer Institute, z.B. auf die Verwahrung, die sowohl im öffentlichen wie im Zivilrecht heimisch sind, die offenbar rein konstruktiv gemeinte Frage aufgeworfen, ob man nicht "Eigentum" sowohl in dem einen wie in dem anderen Bereich haben könne. Ich kann in diesem Punkte unserem verehrten Herrn Präsidenten nur zustimmen, der doch wohl ungefähr folgendes meinte: Für das private Eigentum sei die zentrale Figur immer noch der Berechtigte. Ich würde meinen, daß es im öffentlichen Sachenrecht zwar wohl Rechte des Publikums gibt, daß aber, soweit die Verwaltung selbst in Betracht kommt, dieses publizistische Eigentum für sie Ausübung einer Kompetenz ist, die Übernahme einer öffentlichen Verantwortung. Deshalb erscheint es mir problematisch, auch nur die Vokabel Eigentum, bei der nach einem fundierten Sprachgebrauch eine individualistische Komponente mitschwingt, auch in dem anders strukturierten Bereich des Verwaltungsrechts anzusiedeln. Ich darf allein folgende Frage andeuten: Wie sieht es eigentlich bei den Gegenständen, die sich im „öffentlichen Eigentum" befinden, mit jenen Vorschriften - ja auch zum wesentlichen des öffentlicher Rechtes - aus, die sich mit der Sozialpflichtigkeit des Eigentümers befassen? Sie sind ja doch in erster Linie das "Ventil" - vgl. Art. 14 Abs. 2 GG - gegenüber der privaten Sachherrschaft, ohne etwa den $\S 903$ BGB hier speziell anführen zu wollen. Wieweit paßt das eigentlich? Es gibt neuerdings Stimmen, wonach die öffentliche Verwaltung nicht mehr unter die Baupolizei falle. Eben dieses wurde offenbar unter bestimmten Ressortgesichtspunkten, von Herren der Bundeswehrverwaltung behauptet. Wir wollen das nicht vertiefen, bloß dahinter steht offenbar auch unser Problem. Ich würde allerdings meinen, daß Herr Krüger das Kind mit dem Bade ausgeschüttet hat. Wenn die Bundesbank ihr Geld unsachgemäß verwendet, dann ist das zwar intern eine Zweckentfremdung, dann setzt sie sich zwar mit ihrem "Amte" in Widerspruch, aber, was die 
Außenwirkung angeht - und da zeigt sich nun der Unterschied zu den de jure publizistisch gewidmeten öffentlichen Sachen -, muß das wohl hingenommen werden. Das ist ja doch gerade das Charakteristikum der öffentlichen Sachen, daß hier bis $\mathrm{zu}$ einem gewissen Grade das Privatrecht und die Herrschaftsrechte des Eigentümers außer Kurs gesetzt, während bei "freien" Vermögenswerten der öffentlichen Hand Zweckentfremdungen juristisch irrelevant sind. Ich würde meinen, daß man deshalb bei der juristischen Deutung öffentlicher Unternehmen - Herr Krüger hat das auch angedeutet - vorsichtig sein muß, weil für diese gerade charakteristisch ist, daß nicht nur ihre Produkte, soweit sie produzieren, sondern zumeist auch das Produktionsvermögen aus in der Sache selbst liegenden Gründen im freien Verkehr bleiben muß. Die Bundesbahn kann zwar ihre Schienen nicht ohne weiteres frei veräußern, sie muß sie gegebenenfalls entwidmen. Es gibt aber große Komplexe des Bundesbahnvermögens, die nicht unter der Herrschaft des öffentlichen Sachenrechtes stehen, und auch praktisch nicht in dieser Weise dem Verkehr entzogen werden können. In der sowjetischen Zone hat diese Problematik der Zweckbindung bei den VEBs eine ziemliche Rolle gespielt.

Wenn ich noch eine letzte Bemerkung machen darf, so habe ich mich eigentlich gewundert, daß die bei Herm Stern allerdings anklingende Frage hier nicht diskutiert wurde, inwieweit das Privateigentum an öffentlichen Sachen im Sinne eines fiskalischen Potentials praktiziert werden kann. Tatsache ist, daß insbesondere die Gemeinden ihr Wegeeigentum als ein lediglich im Sinne des Art. 14 GG sozialpflichtiges Privatrecht dort als ein administratives Mittel heranziehen, wo ihnen das Verwaltungsrecht keine Handhabe bietet. Wenn dies gemeinhin nicht beanstandet wird, so lediglich deswegen, weil wir die Zweckbindung des öffentlichen Eigentums zu traditionalistisch auffassen. Ich bin demgegenüber der Überzeugung, da $B$ es der heutigen realen Situation - wie immer der Bundes- oder Landesgesetzgeber sich dazu stellt - nicht mehr gerecht wird, wenn man die Wege nur als Verkehrseinrichtungen ansieht. Wer einmal im Kriege nach einer Bombennacht gesehen hat, was ein moderner Weg an Leitungen usw. in sich birgt, wer also weiß, welche vielfältige Funktion der Weg heute hat Herr Stern hat meine Formulierung vom "Mehrzweckinstitut" zitiert -, der wird sich die Frage vorlegen müssen, ob wir nicht die Zweckbindung der öffentlichen Wege, um nur von diesen zu sprechen, zu Unrecht auf den Gemeingebrauch beschränken. Ich meine, man sollte sich das sehr genau überlegen. Denn wenn die Zweckbindung des öffentlichen Weges nur den Ge- 
meingebrauch betrifft - nach dem Bundesfernstraßengesetz muß man die Dinge in der Tat ungefähr so sehen - dann bedeutet das, daß alles andere ein „Überhang" ist, der als solcher dem Fiskus, wenn ich diese öminöse Figur hier noch einmal zitieren darf, zur Verfügung steht. Im übrigen, wer an die Praxis denkt, weiß daß es dieser vorerst egal ist, wie skeptisch man in unseren Kreisen ganz allgemein über den Fiskus denkt. Ganz im Gegenteil, dieses dem Praktiker höchst willkommene Potential wird gerade heute mit dem besten Erfolg in den Dienst der Verwaltung gestellt.

Kaiser: Von dem was Herr Krüger unter dem Stichwort "öffentliches Eigentum" Revue passieren ließ, hatte manches gewiß den Reiz des Neuen. Außer den Bedenken, die Herr Köttgen soeben ausgesprochen hat, möchte ich mir erlauben, noch ein paar Gesichtspunkte beizutragen. Wenn etwa öffentliche und private Unternehmen auf ein und demselben Markt miteinander konkurrieren, dann stößt eine Sonderbehandlung von öffentlichen Unternehmen an enge Grenzen. Auf dem Kohlenmarkt könnte die staatliche Hibernia gewiß etwa dazu benutzt werden, um ein Kohleverkaufskartell aufzubrechen, aber im übrigen muß die staatliche Hibernia ähnlich behandelt werden wie die Krupp-Zechen. Das folgt jedenfalls aus dem Vertrag über die Europäische Gemeinschaft für Kohle und Stahl.

Ich habe im übrigen Bedenken dagegen, daß öffentliche Sachen ohne weiteres zur Wirtschaftssteuerung eingesetzt werden könnten. Aus Gründen, die ich im einzelnen hier nicht ausführen kann, ist seit langem, vor allem aber seit Keynes, in erster Linie das Geld dafür benutzt worden. Das Geld ist nun einmal ein besonderer Stoff und kann in der Konjunktursteuerung nicht beispielsweise durch Wasser, wie Herr Krüger meinte, ersetzt werden; es würde rechtlich und tatsächlich auf Schwierigkeiten stoßen. Das liegt zum Teil daran, daß die Wirtschaft ein Globalphänomen ist und es zu deren Steuerung eines Globalmittels bedarf, das so nuanciert und so schnell wirksam eingesetzt werden kann wie das Geld.

Darf ich außerdem noch eine Frage an Herrn Stern richten? Sie haben, Herr Stern, die öffentlichen Sachen prinzipiell dem öffentlichen Gemeinwesen statt dem Staat zugeordnet und sich dazu auf Smend berufen. Nun frage ich mich: Worin liegt der Erkenntniswert dieser Distinktion? Wollen Sie sagen, daß bei den öffentlichen Sachen der Sachherr nicht der Staat ist, sondern etwas anderes, daß die öffentlich-rechtliche Ordnung der öffentlichen Sachen, von der Sie in den Leitsätzen sprechen, durch einen anderen als den Staat geschaffen wird? Was bedeutet es 
dogmatisch und praktisch, wenn hier ein - wie ich meine so wenig prägnanter Begriff wie „politisches Gemeinwesen“ als ein Rechtsbegriff eingeführt wird?

Uber: Es ist gesagt worden, daß die beiden Referate diametral entgegengesetzt seien. Ich glaube aber, daß wir das nicht sagen können, sondern feststellen müssen, daß beide Referate im Ergebnis im wesentlichen übereinstimmen. Beide versuchen mit anderen Mitteln das gleiche Ziel zu erreichen, nämlich die öffentliche Sache - oder besser gesagt: bestimmte Sachen $\mathrm{zu}$ "veröffentlichrechtlichen“. Das tut Herr Weber in der Weise, $\mathrm{da} ß$ er den Begriff der anstaltlich genutzten Sache stärker einsetzt, während Herr Stern eine revolutionäre Lösung anbietet. Beides hat im wesentlichen das gleiche Ergebnis der „Veröffentlichrechtlichung" der Sachen, die vom Staat unmittelbar zu öffentlichen Zwecken der Verwaltung eingesetzt werden. Die Lösung von Herrn Stern liegt mir näher und ist mir sympatischer, allerdings nur im Ergebnis, nicht aber im Wege. Hinsichtlich des Weges, den Herr Stern aufgezeigt hat, möchte ich gewisse Bedenken anmelden, nämlich dagegen, daß er die Widmung und die Indienststellung über Bord wirft und sagt: „Die ,Veröffentlichrechtlichung' erreiche ich dadurch, daß ich eine öffentlich-rechtliche Sachordnung herstelle für die bestimmten Sachen, von denen hier die Rede ist. Das soll durch einen ,Organisationsakt' geschehen". Wenn nach der Rechtfertigung gefragt wird, wie Herr Stern dazu kommt, wird als Antwort dem Referat, wenn ich recht verstanden habe, zu entnehmen sein, das ergebe sich im wesentlichen aus der Sozialstaatlichkeit. Wenn als Fundierung seiner Aussage, eine staatliche Norm genüge, um die öffentlich-rechtliche Sach ordnung herzustellen, oder sei sogar notwendig, um die gemeinten Sachen $\mathrm{zu}$,veröffentlichrechtlichen", angegeben wird, daß dieser höhere Rechtssatz begründet sei in der Sozialstaatlichkeit i. V. m. der Daseinsvorsorge und mit Aufgaben der Leistungsverwaltung, dann sind schon in dieser Hinsicht Bedenken anzumelden, die jetzt hier nicht näher ausgeführt werden sollen und zu werden brauchen. Wenn aber nun der nächste Schritt, nämlich die Herstellung der öffentlich-rechtlichen Sachnutzung, einfach damit begründet wird, daß aus Gründen der Stilreinheit ebenfalls öffentlich-rechtlich verfahren werden müsse, weil die erste Stufe, die Herstellung der öffentlich-rechtlichen Sachordnung, öffentlich-rechtlich erfolge, dann scheint mir das doppelt bedenklich zu sein. Ich glaube, daß die Begründung und die Darlegung, warum diese bestimmten Sachen, von denen hier die Rede ist, öffentlich-rechtlich behandelt werden sollen, noch einer gründlicheren Fundierung bedarf. Ich sehe in diesem Thema und der 
heutigen Behandlung des Themas den zweiten Versuch in dieser Vereinigung innerhalb von zwei Jahren, ein weiteres Teilproblem aus dem Dilemma herauszuführen, in dem wir uns hinsichtlich der Abgrenzung zwischen öffentlichem und privatem Recht befinden. Herr Thieme hat es ganz kurz schon angedeutet. Aber ich wundere mich, daß dieses Hauptproblem hier nicht näher angesprochen und vertieft worden ist. Denn dieses ist der Grund, warum wir uns überhaupt über die öffentlichen Sachen unterhalten und warum sie so streitig sind. Herr Stern hat eine totale, revolutionäre Lösung angeboten. Ich glaube aber, daß sie nicht ganz befriedigt, und ich frage, ob nicht der Gedanke, den Herr Krüger genannt hat, und der, wenn ich ihn recht verstanden habe, vielleicht umschrieben werden könnte mit „absoluter öffentlicher Zweckadäquanz staatlichen Handelns" - m. a. W., daß alles staatliche Handeln zunächst öffentlich und in der weiteren Konsequenz auch öffentlich-rechtlich sein muß -, eher einen Ansatzpunkt bietet, um zu einer grundsätzlichen Beantwortung der Einzelfragen zu gelangen.

Salzwedel: Als ersten Punkt möchte ich nur hervorheben, daß meiner Ansicht nach das aufregendste Ereignis im Bereich der öffentlichen Sachen eigentlich nicht die Einführung des öffentlichen Eigentums in Hamburg und Baden-Württemberg war, sondern daß das Eigentum an Gewässern in manchen Ländern scheinbar so ziemlich mit Stumpf und Stiel ausgerottet worden ist. Wenn man beispielsweise $\S 12$ des nordrhein-westfälischen Wassergesetzes ansieht, dann steht darin schlicht und einfach, $\mathrm{da}$ der Eigentümer verpflichtet ist, sämtliche Gewässerbenutzungen mit wenigen Ausnahmen zu dulden - eigentlich nur noch mit der in Betracht kommenden Ausnahme, daß die Entnahme fester Stoffe aus dem Gewässerbett schon in das Eigentum eingreifen soll. Alle anderen Benutzungen hat der Gewässereigentümer entschädigungslos und unentgeltlich hinzunehmen. Dies ist unter den Wasserrechtlern freilich nicht ganz unbestritten, weil es in den meisten Wassergesetzen heißt: der Gewässereigentümer muß die Gewässerbenutzung "als solche“ dulden. Nun weiß man nicht, heißt das: nur die Benutzung des Wassers oder: auch die Benutzung des Gewässerbettes. Aber was sich bisher als herrschende Lehre andeutet, geht dahin, daß heute auch die Ausnutzung - oder wenn man boshaft ist die Ausbeutung des Gewässer b e t t e s ohne Rücksicht auf den Willen des Eigentümers vor sich gehen kann. Wenn das so sein sollte, dann wäre zu fragen, ob wir in diesem Punkte nicht schon längst über das öffentliche Eigentum, über das wir uns heute so lange gestritten haben, hinaus, nämlich auf dem Wege einer kalten Sozialisierung der Wasserläufe und der stehenden Ge- 
wässer etwa zu einem Gemeineigentum im Sinne des Art. 15 GrundG. gekommen sind. Das, was wir im Wegerecht als Inhalt des Wegeeigentums verstehen, ist die Privatnützigkeit, die sich noch darin äußert, daß der Wegeeigentümer für die Benutzung im Falle der Inanspruchnahme der Wegesubstanz zumindest ein Entgelt verlangen kann. Nichts dergleichen im Wasserrecht, wo sich, wie gesagt, die Geltendmachung des privaten Eigentums auf den Fall der Entnahme fester Stoffe aus dem Gewässerbett beschränkt. Wenn man die Privatnützigkeit als den Kern des Privateigentums begreift (ich glaube, Herr Weber hat das besonders hervorgehoben), dann ist das Gewässereigentum, vorausgesetzt da $\beta$ man die nahezu vollständige Ausschaltung des Eigentümers akzeptieren wollte, kein Eigentum mehr in dem Sinne, in dem wir bisher von Eigentum gesprochen haben. Gewässereigentum bedeutet dann weder Sachherrschaft noch Privatnützigkeit - die Neuregelung des Gewässereigentums ist eine Enteignung der Gewässer. Die Eigentumsentziehung wäre entschädigungslos und mithin nichtig. Man muß deshalb wohl versuchen, zu einer verfassungskonformen, das kann hier nur heißen: einer einschränkenden Auslegung der Vorschriften über die Duldungspflicht des Gewässereigentümers zu kommen. Aber wie dem auch sei, das ist m. E. der Punkt, an dem die klassische Konstruktion der öffentlichen Sache - als öffentlich-rechtliche Dienstbarkeit auf privatem Eigentum -, die Herr Weber hier vertreten hat und die ich ebenfalls nach wie vor für richtig halte, ins Wanken geraten ist, nämlich von der privatrechtlichen Basis her.

Meine zweite Frage richtet sich an Herrn Stern. Sie haben gemeint, daß eine privatnützige, eine fiskalische Ausnutzung der öffentlichen Sache überhaupt ausgeschlossen sein soll - in welchem Bereich, ist noch nicht ganz klar, darauf wollten Sie noch eingehen. Sie wollen aber auch eine hoheitliche Ausnutzung der öffentlichen Sache mittels Erhebung von Sondernutzungsgebühren ausschließen, wenn dies in der Weise geschähe, daß synallagmatisch, Zug um Zug und Leistung gegen Gegenleistung, wirklich ein wirtschaftliches Äquivalent verlangt würde. Ich wei $\beta$ nicht, ob man das unter irgendwelchen verfassungsrechtlichen Aspekten oder unter dem Gesichtspunkt einer Gebundenheit auch der Leistungsverwaltung und einer hilflosen Angewiesenheit des Staatsbürgers auf Teilhabe an der öffentlichen Sache rechtfertigen kann. Denken Sie nur an das Wasserrecht. Es ist doch eigentlich nicht $\mathrm{zu}$ verstehen, warum ein Industrieunternehmer eine Bewilligung bekommen soll, 30 Jahre lang in der Stunde 50001 verschmutztes Wasser in den Rhein einzuleiten, ohne daß dafür eine echte Gegenleistung verlangt 
wird. Ich halte es für durchaus richtig, daß man in diesen Fällen eine echte wirtschaftliche Gegenleistung verlangt. Sonst kommen Sie nämlich gerade nicht zu dem, was Sie anstreben, nämlich zu einer sozialgerechten Lösung. Sozial gerechtfertigt ist sie doch nur, wenn dem unerhörten Privileg, das dem einzelnen hier vor allen anderen Bürgern gewährt wird, auch tatsächlich ein Äquivalent in Gestalt einer echten wirtschaftlichen Gegenleistung gegenübergestellt wird.

Drath: Ich weiß nicht, ob ich Herrn Weber richtig verstanden habe; ich bin nicht sicher, daß er zu den öffentlichen Sachen außer den Betrieben, die unmittelbar - etwa in kommunaler Regie - geführt werden, auch die rechnen würde, die in Form einer $\mathrm{GmbH}$ oder $\mathrm{AG}$ betrieben werden, aber doch genauso behandelt zu werden verdienen, wie die, die im unmitttelbaren Eigentum der Gemeinden stehen. Seine Bezugnahme auf Sachen und nicht auf Rechte schien mir in diesem Punkte problematisch.

Nun will ich nicht auf das Volkswagenurteil als solches eingehen; das ist nicht meine Sache, gehört auch nicht hierher. Ich möchte aber daran anknüpfen: In diesem Punkte zeigt sich nämlich gerade am Volkswagenwerk eine Problematik. Das Werk ließ nach meiner Auffassung nicht recht erkennen, daß es in besonderer Weise einer öffentlichen Aufgabe diente. Ich bin nicht sicher, da $B$ die Entscheidung im Ergebnis so ausgefallen wäre, wie sie ausgefallen ist, wenn eine öffentliche Aufgabe des Volkswagenwerkes sichtbar geworden wäre. $\mathrm{Da} \beta$ man auf die ursprüngliche Aufgabenstellung nicht zurückgreifen konnte, ist wohl klar; denn die war überholt. Der Ausdruck "Finanzvermögen" im Urteil deutet darauf hin, daß dem Gericht eine neue Aufgabenstellung öffentlicher Art nicht sichtbar war, daß man - Sie mögen damit einverstanden sein oder nicht vielleicht vom Volkswagenwerk im Ergebnis eher sagen konnte, es war der Typus eines Betriebes „an und für sich“, eines Betriebes, der sich selbst aufbaute, ausbaute, pflegte. $\mathrm{Daß}$ das hinter dieser Formulierung steht und da $\beta$ dies in einem anderen - in dieser Hinsicht nicht so liegenden - Fall zu einer anderen Entscheidung führen könnte, möchte ich doch kurz erwähnen um der Mißverständnisse willen, die da entstehen könnten, aber auch, um zu zeigen, daß unsere allgemeine Diskussion hier noch der Präzisierung bedarf. Irgendwo muß eine öffentliche Aufgabe bei den öffentlichen Sachen sichtbar sein und die Problematik des Volkswagenfalles lag gerade darin, daß dies nicht der Fall war.

Hans Schneider: Ich möchte Herm Krüger nicht allein lassen mit seinen Bedenken, die er gegen die These von Herrn Stern vorgebracht hat, daß man das Potential der öffentlichen Sachen 
nicht auch für Zwecke, die außerhalb der normalen Sachnutzung liegen, einsetzen könnte. Herr Kaiser hat zwar gesagt: „Dafür ist das Geld da". Aber bekanntlich kann man mit Geld nicht alles machen. Auch der Staat kann nicht alles mit Geld machen. Ich möchte deswegen ausdrücklich - welche wirtschaftspolitischen Gründe auch immer eine Rolle spielen mögen - jedenfalls von Verfassungs wegen die Möglichkeit offen gehalten wissen, daB die Nutzungsordnung auch im Sinne einer Beeinflussung des nationalökonomischen Ablaufes gestaltet werden kann. Nicht nur die Schaffung, sondern auch die Nutzung öffentlicher Sachen muß auch unter diesem Gesichtspunkt gesehen werden.

Was Herr Weber gesagt hat über die Entwicklung von Gemeingebrauch an öffentlichen Sachen zur Anstaltsnutzung, scheint mir sehr einleuchtend. Nur das Beispiel gerade des innerstädtischen Wegesystems würde ich nicht für so glücklich halten, weil es da ja so ist, daß der Veranstalter oder Anstaltsherr nicht das maßgebliche Wort über die Nutzungsart zu bestimmen hat. Weil hier die Straßenverkehrsordnung, also ein Verordnungsgeber oder Gesetzgeber, der gar nicht Veranstalter ist, die Benutzungsarten weitgehend vorfixiert, verbleibt dem eigentlichen Anstaltsherrn, der Gemeinde, wenig Gestaltungsfreiheit.

Weber: Die technischen Mittel werden zwar vorfixiert, aber ihre Anwendung, die Aufstellung der Schilder usw. liegt in der Hand der Gemeinde.

Drath: Die bloße Aufstellung der Schilder, aber nicht einmal - wie das Bremer Urteil, das von Herrn Stern zitiert worden ist, zeigt - die Möglichkeit, den Gemeingebrauch wegen der Laternengaragen einzuengen. Die Möglichkeiten, die dem Anstaltsherrn für die Benutzungsordnung bleiben, sind begrenzt.

Stern (Schlußwort): Als ich vom Vorstand unserer Vereinigung zu Beginn dieses Jahres den Vorschlag erhielt, zum Thema öffentliche Sache zu sprechen, da überlegte ich mir ebenso wie die gestrigen Referenten, was den Vorstand bewogen habe, zu dieser Materie ein Referat halten zu lassen. Sicher lag es nicht in meiner Absicht, "revolutionär" wirken zu wollen, aber auch nicht einem Konservatismus anzuhängen, zu dem gerade die Beschäftigung mit diesem Rechtsgebiet verlocken mag. Ich wollte jedenfalls aus der Kirchhofsruhe überlieferter Formeln erwecken, die sich bei einem noch nicht konsolidierten Rechtsgebiet so gerne einstellen, solange der Gesetzgeber nicht in vollem Umfang klärend eingegriffen hat. Ich glaubte mein Thema auf zwei Wegen angehen zu sollen, einmal, indem ich die öffentliche Sache vor allen Dingen unter einem leistungsverwaltungsrechtlichen Aspekt betrachtet habe. Hier - und 
hier allein, Herr Uber - habe ich das Prinzip der Sozialstaatlichkeit eingeführt, um Funktion und Nutzung der öffentlichen Sache deutlich zu machen und um klarzustellen, daß die öffentliche Sache ein Institut ist, das für alle Bürger vorhanden ist und mit optimaler Nutzung durch alle Bürger sowie durch spezielle Interessenten genützt werden soll. Zum anderen lag mir daran, angesichts der Tatsache, daß im Gebiet des öffentlichen Sachenrechts so vielfältige Erscheinungen und komplexe Gegenstände behandelt werden, die sowohl vom öffentlichen als auch vom privaten Recht her Impulse empfangen, die notwendige Klarheit zu schaffen, die das Institut der öfentlichen Sache aus einer gewissen begrifflichen Unsicherheit und Verflüchtigung herausführt. Dieses Problem versuchte ich auf dem Wege über die Organisationsgewalt zu lösen, indem ich den Begriff des Organisationsaktes einführte mit dem Ziel, in ihm einen zweifelsfreien Ansatzpunkt zu besitzen, der die öffentliche Sache umgrenzt und von verwandten Phänomenen abhebt. Bekanntlich ist man bisher so vorgegangen, daß man sagt: Durch die Widmung wird die Sache öffentlichen Zwecken dienstbar gemacht und damit zur öffentlichen Sache. Streitig war hierbei, ob unter diese öffentlichen Zwecke neben dem Gemeingebrauch auch jedwede Sondernutzung fällt. Herr Weber tritt für eine Beschränkung auf die Oberflächensondernutzung ein; die Sondernutzung unter der Straße hingegen sieht er als ein rein vom Privatrecht her zu lösendes Problem an. Ich habe hier den Organisationsakt eingeführt, weil ich glaubte, damit ein verläßliches, formal erfaßbares Mittel zu finden, um klarzulegen, daß wir die öffentliche Sache nicht ständig als Zwittergebilde, als Kollisionsbegriff, verstehen dürfen, sondern sie in eine einheitliche Ordnung überführen müssen. Daß ich die öffentlich-rechtliche Ordnung gewählt habe, scheint mir in der Natur der Sache zu liegen. Wenn hier Zweifel bestehen, wo ich die Rechtfertigung hernehme, diesen Organisationsakt mit so weitgehender Wirkung auszugestalten, insbesondere mit der Kraft, eine Sache in ein anderes Rechtsgebiet zu transformieren, so glaube ich doch sagen zu müssen, daß die Organisationsgewalt, die wohl mit dem Staat ipso iure gegeben ist, jedenfalls soweit Verfassungsrechtssätze und pasitive gesetzliche Regelung nicht entgegenstehen, den Sachherrn, der entweder Eigentümer ist - Eigentümer, sei es, daß ihm von vornherein dieses Gut gehört oder sei es, daß er sich das Eigentum durch einen Enteignungsakt verschafft hat - berechtigt, dieser Sache einen öffentlich-rechtlichen Status und eine öffentlich-rechtliche Nutzungsordnung zu geben, und zwar entweder, wie es bei den Straßen, Wegen und Gewässern geschehen ist, durch einen gesetzgeberischen 
Akt oder, wie es bei den Gemeinden weitgehend geschieht, durch eine Satzung oder auch durch einen auf eine einzelne Sache bezogenen konkreten Organisationsakt, der seine Rechtsgrundlage in Verfassung, Gesetz oder im "allgemeinen Verwaltungsauftrag“ finden kann. Dadurch entsteht der „institutionell öffentliche Status" einer Sache. In diesem Zusammenhang glaubte ich, vom „politischen Gemeinwesen" sprechen zu sollen, indem als Sachträger nicht nur der Staat, sondern auch Gemeinden und sonstige juristische Personen des öffentlichen Rechts fungieren.

Im System eines solchen die Offentlichrechtlichkeit der Sache begründenden Statusaktes hat das Eigentum lediglich eine statische Rechtsposition, d. h. die Funktion, die Sache nicht zur res nullius werden zu lassen. Das Eigentum ist, wenn wir es vom Privatrecht her sehen, allerdings die Beherrschungsmacht Herr Bettermann hat das sehr klar gesagt -, die berechtigt, nach eigenem Ermessen zu disponieren. Diese Rechtsmacht ist aber gerade bei der öffentlichen Sache nicht gegeben. Die öffentliche Sache ist fremdnützig, dienend. Das Privateigentum ist staats- und drittgerichtet, damit eigennützig. Die öffentliche Sache hat ihre Funktion in der Gewährung an die Bürger. Hinter den öffentlichen Sachen steht der Gewährszwang, so wie einstmals Nipperdey mit dem Kontrahierungszwang gewissen Unternehmen, Theatern usw., die Monopolstellungen innehaben, begegnen wollte, um dem Bürger einen durchsetzbaren Anspruch auf Benutzung zu verschaffen.

Ich habe auch klar herauszustellen versucht, da $\beta$ zwischen öffentlicher Anstalt und öffentlicher Sache meiner Meinung nach ein erheblicher Unterschied besteht. Wir sollten festhalten: Öfentliche Sachen und öffentliche Anstalten dürfen nicht als Allerweltsbegriffe aufgefaßt werden, in die man alles hineinpreßt, was man ins Verwaltungsrecht einordnen will und unter anderen Rechtskategorien nicht unterbringen kann. Das war mein starkes Bedenken gegen den öffentlichen Zweck als alleiniges Angrenzungskriterium. Diese Vorstellung hat mich weiter bewogen, eben diesen Organisationsakt, der die Sache öffentlichrechtlich verfaßt, öffentlich-rechtlich institutionalisiert, als deutliches Abgrenzungskriterium herauszuheben. Das Institut der öffentlichen Anstalt sehe ich nur ungern erweitert; seine Begriffsmerkmale würden sich zu unscharfen Konturen verwischen.

Zum Problem des öffentlichen Eigentums, das ja hier sehr vielfältig angesprochen wurde, nur folgendes: Die Formel vom öffentlichen Eigentum hat sicher etwas Bestechendes, und Herr Bettermann hat mit Recht hervorgehoben, da $B$ der Eigentums- 
begriff aus der allgemeinen Rechtslehre stammt. Ich bin ihm sehr dankbar, daß er mich wieder darauf aufmerksam gemacht hat, nachdem ich selbst in einem Aufsatz über den öffentlichrechtlichen Vertrag 1957 von dieser These ausging. Vielleicht bin ich ohne Not von diesem alten Gedanken abgerückt. Aber ich meine, einem öffentlichen Eigentum deshalb wiedersprechen zu sollen, weil wir mit dem Begriff „öffentlich“ doch recht sparsam umgehen sollten. Ich habe zwar die Parallele zum öffentlichen Amt, zum öffentlichen Dienst, zum öffentlichen Unternehmen gezogen, aber die Etikettierung „öffentlich“ immer mit Vorsicht gewählt. Für die öffentliche Sache scheint mir kennzeichnend, daß für sie eine öffentlich-rechtliche Sachherrschaft besteht. Gerade diese besonders ausgestaltete Sachherrschaft möchte ich als Kriterium dafür erblicken, daß man einen Unterschied zur privatrechtlichen Eigentumsherrschaft ziehen sollte. Jene Sachherrschaft ist aus der Souveränität, aus der inneren Souveränität des Staates heraus entstanden. Darum brachte ich zur Begründung einen historischen Ansatzpunkt, indem ich das Eigentum des römischen Rechts den jura regalia des deutschen Rechts gegenüberstellte. Das allein, Herr Merk, wollte ich mit meinen historischen Einleitungen darlegen, nicht mehr; natürlich hätten wir noch sehr viel weiter zurückgehen und sehr viel tiefer eindringen können.

Wenn ferner die Frage der Entgeltlichkeit oder Unentgeltlichkeit der Sachnutzung im Sinne einer Synallagmatik von Herrn Salzwedel angesprochen worden ist, so möchte ich richtigstellen: Ich habe nicht behauptet, es solle jedwede Entgeltlichkeit einer Sondernutzung ausgeschlossen werden. Ich habe nur gesagt, die marktwirtschaftliche, die kaufmännisch orientierte, Entgeltlichkeit solle bei öffentlichen Sachen nicht praktiziert werden. Die Zeit ist zu knapp, einige drastische Fälle aufzuzählen, die mir aus der Praxis bekannt geworden sind und die mich bewogen haben, hier dem Rechtsschutz des Bürgers und dem Anspruch auf eine nicht mit allzu großen finanziellen Einbußen behaftete Erteilung der Sondernutzung das Wort reden zu sollen.

Ein Moment, Herr Krüger, möchte ich noch ergänzend zu einigen wohl auch von Ihnen erwähnten und von mir bereits gestreiften Uberlegungen vortragen: Es ist uns im privaten Gesellschaftsrecht geläufig, daß eine Trennung zwischen Eigentumsbefugnissen und - wollen wir es einmal kurz formulieren - management vorhanden ist. Es gibt den Manager, der das große Unternehmen beherrscht, aber theoretisch keine Aktie dieser Gesellschaft zu besitzen braucht, um seine Herrschaft auszuüben. Die Eigentumsbefugnisse sind auch hier reduziert 
zu Gunsten einer dynamischen Funktion eines anderen Herrn über die Sache.

Meine Notizen von der Diskussion enthalten noch mehrere Probleme. Ich bedaure, in Anbetracht der knappen Zeit und mit Rücksicht auf das Schlußwort von Herrn Weber nicht zu allen Diskussionsbeiträgen Stellung nehmen zu können. Ich bitte, darin keine Zurücksetzung ihrer Wichtigkeit für mich oder gar ihrer allgemeinen Beachtlichkeit zu erblicken. Ganz im Gegenteil, jede Äußerung, sei sie Zustimmung, Anregung oder Ablehnung, wird mich zu weiterem Nachdenken über diesen Fragenkreis veranlassen. Nur eines noch: Ich weiß nicht, ob ich in der Diskussion zu gut weggekommen bin oder nicht. Das scheint mir auch unwesentlich zu sein angesichts der Aufgabe, im Dienste der Wahrheit zu stehen. Mit Recht hat Herr Krüger gestern gesagt, wir sollten uns keine Zensuren erteilen. Für meine Person bekenne ich freimütig, für jede Kritik dankbar zu sein und sie anzuerkennen, wo immer ich geirrt habe.

Weber (Schlußwort): Meine Herren! In der Abgrenzung zwischen öffentlichem und privatem Recht haben sich in den letzten Jahren oder sogar schon Jahrzehnten gewisse Verzerrungen ergeben. Wir haben uns vielfach über zivilistische Verzeichnungen öffentlich-rechtlicher Probleme etwa durch die Judikatur der Zivilgerichte geärgert. Das hat eine Gegenbewegung hervorgerufen. Nach der Reorganisation der Verwaltungsgerichtsbarkeit auf der Grundlage der Generalklausel hat sodann erneut ein lebhafter Streit über die Abgrenzung der beiderseitigen Zuständigkeitsbereiche eingesetzt. Dieses und anderes hat dazu geführt, daß manche Fragen aus dem Komplex der Zuordnung zivilrechtlicher und öffentlich-recintlicher Betrachtungsweisen verzerrt worden sind. Das müssen wir gelegentlich wieder entzerren, damit wir uns nicht mit Scheinproblemen herumschlagen, vor allem mit dem Scheinproblem, als ob der zivilrechtliche und der öffentlich-rechtliche Teil unserer Rechtsordnung total verschiedene Dinge wären, die nicht aufeinander passen könnten.

Das gilt insbesondere - ich nehme zunächst einige kleinere Punkte aus der Diskussion vorweg - für die Frage der Verkehrssicherungspflicht. Es ist um diese Frage in der letzten Zeit etwas ruhiger geworden. Vor 5 oder 6 Jahren war darüber ein geradezu weltanschaulich bewegter. Kampf im Gange. Man sagte, es sei doch unerhört, daB hier Probleme des öffentlichen Rechts zivilrechtlich aufgefaßt würden usf., und man sah die Frage ganz dogmatisch an, ohne sie von den Folgen und den größeren Zusammenhängen her zu betrachten. Der Bundesgerichtshof hat in dieser Frage eine Schwenkung vorgenommen 
und hat gesagt, er wolle die Verkehrssicherungspflicht gar nicht zivilrechtlich konstruieren; er erkenne an, $\mathrm{da} B$ hier eine öffentliche Verantwortung bestehe, daß bei der Wegeunterhaltungspflicht Betätigung der Hoheitsgewalt über die öffentliche Sache vorliege. $\mathrm{Er}$ leite die Verkehrssicherungspflicht ebensowenig aus dem zivilrechtlichen Eigentum ab wie aus einem öffentlichen Eigentum, sondern aus einem Tatbestand auf anderer Ebene, nämlich dem des In-Verkehr-Bringens, des Schaffens einer Gefahrenlage. Dabei könne er, der BGH, dahingestellt sein lassen, ob sich dieser Vorgang im Gebiet des öffentlichen oder des Privatrechts vollziehe. - Aber die Diskussion über diesen Punkt wird immer noch so geführt, als ob der Bundesgerichtshof darauf bestände, es handele sich hier um eine Auswirkung der privatrechtlichen Eigentümerbefugnisse. Wenn man die Frage der Verkehrssicherungspflicht unvoreingenommen betrachtet, dann muß man sich doch vergegenwärtigen, was im Ergebnis dabei herauskommt; dann muß man die Unstimmigkeiten, die unserem Schadensersatzrecht nach der Judikatur der Zivilgerichte anhaften und deretwegen eine Reform des Schadensersatzrechts gefordert wird, mit in Betracht ziehen. Man kann aber nicht bei der Erörterung dieses Problems auf gewissen dogmatischen Prämissen um ihrer selbst willen bestehen, wenn von ihnen aus im Zusammenhang mit den herrschenden Grundsätzen des Schadensersatzrechts eine befriedigende Lösung nicht erreicht wird. Nur insofern interessiert mich die Frage der Verkehrssicherungspflicht in diesem Zusammenhang, und jedenfalls setzt sich die neuere Judikatur des Bundesgerichtshofs, wie ich wiederholt betonen möchte, mit dem Begriff und dem Wesen der öffentlichen Sache nicht mehr in Widerspruch. Für unser Thema dürfte diese Feststellung genügen.

Der zweite Punkt betrifft die fiskalische Ausnutzbarkeit des Privateigentums an Wegen, die Herr Köttgen stark in den Vordergrund gerückt hat. Ich habe mir diese Seite der Sache gründlich überlegt, und zwar mit dem Ergebnis, daß die Gefahr einer (mißbräuchlichen) fiskalischen Ausnützung der Verfügung über den Wegekörper bei öffentlich-rechtlicher Nutzungsverleihung - wie in Hamburg - um keinen Grad geringer ist, als wenn dafür die Form des bürgerlich-rechtlichen Vertrages verwendet wird. Ich habe anderseits folgendes erwogen: Es gibt in Straßen nicht nur Kabel für Telefon und Elektrizität und Rohrleitungen für Gas, Brauch- und Abwasser, also nicht nur Einrichtungen der öffentlichen Dienste, sondern auch, besonders in den Industriegebieten, zahlreiche Leitungen, die von Wirtschaftsunternehmungen im Zuge der 
Straßen und quer durch das ganze Straßennetz unterhalten werden. Weiter gibt es zahlreiche Fälle, in denen Straßen aufgelassen und verlegt und neue Straßen über schon bestehenden Leitungen angelegt werden. Wenn ich nun die Benutzung des Straßengrundes öffentlich-rechtlich konstruiere, dann bedeutet jenes Hin und Her der tatsächlichen Lagen und der Widmungsverhältnisse einen permanenten Wechsel und ein unübersichtliches Nebeneinander öffentlich-rechtlicher und privatrechtlicher Benutzungsverhältnisse, wodurch außerordentliche praktische Schwierigkeiten und viel Rechtsunsicherheit heraufgeführt werden. Da aber auch die privatrechtliche Vergabe von Konzessionen im Straßengrund unter die von Herrn Krüger so stark betonte öffentliche Verantwortung zu stellen ist und sicher der Wegeherr immer dessen eingedenk sein muß, daß die Straßen als „Mehrzweckinstitut" von Hause aus auch für die Aufnahme von Leitungen da sind und hierin nicht nur einen fiskalisch ausnützbaren Nebenzweck erfüllen, ist es für die Sicherung der öffentlichen Ordnungsaufgaben und zur Vermeidung des Formenmißbrauchs gleichgültig, ob die Benutzung des Straßenkörpers in der Tiefe privatrechtlich oder öffentlichrechtlich konstruiert wird.

Das öffentliche Eigentum hamburgischer und baden-württembergischer Prägung halte ich für eine unglückliche Sache. Was die Kompetenz des Hamburger Gesetzgebers angeht, so würde ich Herrn Ipsen antworten, daß der Gesetzgeber Hamburgs für die Verwenđung des Etiketts „öffentliches Eigentum“ die Zuständigkeit in diesem Falle aus seiner Kompetenz für das Wegerecht mochte herleiten können. Aber wohlgemerkt handelt es sich nur um ein Etikett und nicht um öffentliches Eigentum der Substanz nach. Für Verwaltungsvermögen und eine Reihe anderer öffentlicher Sachen könnte der Landesgesetzgeber mangels Regelungskompetenz nicht einmal das Etikett "öffentliches Eigentum" verwenden. Solche Regelungen können schon wegen ihres durch die Kompetenzbegrenzung bedingten punktuellen Charakters zu nichts führen. Die Umetikettierung allein, und noch dazu auf einige öffentliche Sachen beschränkt, bringt keinen Nutzen. Sie kann auf der anderen Seite für das Eigentumsregime und auch für das System der öffentlichen Sachen erhebliche Unordnung stiften. Sie verlockt dazu, wie auch der einschlägige neue Aufsatz von Diether Haas zeigt, ganz neue Probleme zu erfinden, die sich in Wahrheit von der Sache her nicht stellen. Der Stein wird ins Wasser geworfen und zieht nun seine Kreise. Man hält sich für verpflichtet, aus dem „öffentlichen Eigentum" nun auch systematisch und dogmatisch etwas zu machen, gelangt aber zu nichts anderem als zu unnöti- 
gen Konstruktionen, die nur die Geschlossenheit der überlieferten Eigentumsordnung gefährden.

Herr Draht fragte mich, was ich denn von kommunalen Unternehmungen in Gestalt der GmbH und der AG hielte. Ich habe dieses Problem bewußt vermieden, weil ich streng nur von Verwaltungsvermögen sprechen und mich einer Wiederaufnahme der Diskussion von vor zwei Jahren enthalten wollte; denn das wäre uferlos geworden. Ich würde, nunmehr befragt, folgendes dazu sagen: Wenn ein kommunales Versorgungsunternehmen in der Rechtsgestalt der $\mathrm{GmbH}$ oder AG betrieben wird, kann ich mit der Kategorie der öffentlichen Sache nichts ausrichten. Man befindet sich hier wohl - etwa im Krügerschen Sinne - im Bereich öffentlicher Verantwortung; aber der öffentlichen Sache begegnet man nur im Bereich des förmlich und streng zu nehmenden Verwaltungsrechts; sonst höbe man den Begriff der öffentlichen Sache auf. Die Probleme öffentlicher Unternehmungen in privatrechtlicher Rechtsgestalt lassen sich nicht vom Recht der öffentlichen Sache her lösen.

Nun zum Ganzen, meine Herren: Ich habe mich eines gewissen Konservatismus befleißigt, allerdings doch, wie ich meine, nur in den Teilen meines Referates, in denen ich um eine klare Begriffsbildung bemüht war. Gerade wenn man sich auf das Feld der Entdeckungen begibt und das Wagnis auf sich nimmt, über den gegenwärtigen Stand der Einsicht in die Lage der Verwaltungsordnung und des Verwaltungsrechts hinauszugelangen, muB man meiner Ansicht nach von vollkommen einwandfreien und klaren Begriffen ausgehen; so auch bei der öffentlichen Sache. Ich war dabei von dem Bestreben geleitet, den Begriff der öffentlichen Sache nicht, wie es übrigens auch in dieser Diskussion immer wieder angeklungen ist, vom Gemeingebrauch her einengen zu lassen. Hier wäre einzuschalten, daß nur noch der Gemeingebrauch an Wegen und am Meeresstrand ein echter Gemeingebrauch ist, während der "Gemeingebrauch" an Gewässern, wie ich in Utbereinstimmung mit Herrn Salzwedel feststellen möchte, in ein ganz neuartiges System der öffentlichrechtlichen Verfügung über den Wasserhaushalt eingebettet worden ist und dadurch seinen Charakter verändert hat. Deshalb ist auch davor zu warnen, weiter im Stile älterer Lehrbücher vom wasserrechtlichen Gemeingebrauch als Modell her zu argumentieren. - Ich habe mich also bemüht, einen Begriff der öffentlichen Sache zugrunde zu legen, der alle in gefestigter Tradition als öffentliche Sachen anerkannten körperlichen Gegenstände deckt: die Sachen im Gemeingebrauch, das Verwaltungsvermögen einschließlich desjenigen der Kirchen und die res sacrae. Dann mußte ich allerdings ganz bestimmte $\mathrm{Ab}-$ 
grenzungen vornehmen. Von diesen streiche ich auch nach der soeben geführten Diskussion nichts ab. Ich warne erneut davor, über wasserrechtliche Probleme weiterhin vom Recht der öffentlichen Sache her zu diskutieren, ohne zuvor die neue Systematik des Wasserrechts gründlich zu prüfen. Denn das neue Wasserrechtssystem und der Begriff der öffentlichen Sache sind im Grunde genommen inkommensurabel geworden. Nicht so, als ob das Wasserrechtssystem aus der öffentlichen Ordnung entlassen worden wäre; im Gegenteil ist der ganze Wasserhaushalt in die öffentliche Ordnung hineingenommen worden, aber der Begriff der öffentlichen Sache hat hier keine zentrale Bedeutung mehr.

In der heutigen Diskussion hat sich gezeigt, was sich vielfach auch im Schrifttum niederschlägt, daß sich mit dem Gemeingebrauch weithin noch Vorstellungen verbinden, die stark vom Weltanschaulichen her angereichert sind. Ich glaube, daß wir uns dessen entäußern müssen. Ich rede nun nicht etwa - um das Herrn Kollegen Stern zu erwidern - einer Reduzierung der Gemeingebrauchsformen das Wort. Wo Gemeingebrauch noch möglich ist, wo er eine aktuelle und aktualisierbare Form der Benutzung öffentlicher Sachen ist, da soll er bleiben. Aber ich meine, Gemeingebrauch sei kein Problem weltanschaulicher Prinzipien oder etwa eine Forderung, die wir aus den Grundbedingungen unseres menschlichen Daseins heraus aufstellen. Gemeingebrauch ist nichts weiter als eine Form der Benutzung öffentlicher Sachen, die Einfachheit und unmittelbare Körperlichkeit der Benutzung als Merkmale hat und mit einem Minimum an Regelungen auskommt. Jede andere Form der Benutzung läßt sich mit dem Gemeingebrauchsinstitut nicht mehr bewältigen. Wo man trotzdem an diesem Institut festhält und versucht, von der Gegenwartslage her gebotene differenzierende Nutzungs-, Regelungs- und Verwaltungsformen hineinzupressen, kommt man schließlich zu einem monströsen Gebilde, bei dem ohnehin nichts mehr von der Werthaftigkeit des Gemeingebrauchs vorhanden ist, von der einige der Diskussionsredner noch auszugehen schienen.

Ich will nicht etwa, wie hier gesagt worden ist, den Gemeingebrauch in eine anstaltliche Benutzung öffentlicher Sachen überführen, sage vielmehr: er überführt sich selbst dorthin. In der Entwicklung, in der wir stehen, ergeben sich Lagen, die wir weder nach der Seite der Vorhaltung der öffentlichen Sache, noch hinsichtlich ihrer Benutzung und Funktionsregulierung mit dem archaischen Instrumentarium des Gemeingebrauchsinstituts mehr meistern können, die aber deswegen nicht ins Leere fallen, sondern die wir geordnet auffangen und für die 
wir eine Ordnung bereithalten müssen. Was bisher Gemeingebrauch war, nimmt an vielen Stellen - bald mehr, bald weniger - von selbst die Züge anstaltlicher Benutzung an. Niemand wird verlangen, man solle diese Entwicklung beschleunigen. Wo der Gemeingebrauch genügt, wo das Leben seine einfachen und übersehbaren Züge behält, wollen wir sie beileibe nicht zerstören. Aber wir wollen auch nicht eine Fassade aufrechterhalten vor einer Wirklichkeit, die mit dem Gemeingebrauch nichts mehr zu tun hat.

Es tauchten dazu einige Bedenken auf, die verständlich sind. Herr Bullinger sagte z. B., ob wir denn wirklich den Urwald, als den uns Herbert Krüger in Mainz die anstaltliche Ordnung vorgestellt hat, gegen den Gemeingebrauch eintauschen sollten. Nun hat Herr Krüger mit diesem Bilde damals nicht uneingeschränkte Zustimmung gefunden, und ich persönlich darf sagen, daB ich mich in jenem angeblichen Urwald ganz gut zurechtfinde. Jedenfalls kann wohl keine Rede davon sein, daß die anstaltliche Ordnung Probleme auftürmte, mit denen wir nicht fertig werden könnten. Es ist aber auch das Wort von der Verdinglichung und Entpersönlichung gefallen, und zwar von Herrn Dürig, und Herr Fuß hat hinzugefügt, es bestünde Gefahr, daß hier zuviel an Verwaltung entstände. Wenn diese Bedenken begründet wären, würde ich sie in vollem Umfange teilen. Aber ich will $\mathrm{ja}$ an den Fakten nichts ändern und nicht etwa dahin steuern, daß mehr reguliert werde als bisher. Ich will nicht, daß der einzelne im Gebrauch der öffentlichen Sachen beschränkt, kontrolliert und reguliert wird, sondern eine möglichst freizügige Benutzung der öffentlichen Sachen erhalten wissen. Es geht gerade darum, durch die adäquatere rechtliche Darstellungsform ein möglichst hohes $\mathrm{Ma}$ ( von Leichtigkeit und, wenn man so will, von Menschlichkeit im daseinsnotwendigen Umgang mit den öffentlichen Sachen zu bewahren. So stellen sich mir die Dinge dar, und ich habe es gewagt, vor Ihnen diese Perspektiven zu entwickeln in der Hoffnung, Sie würden mit mir in weiterem Nachdenken darin eine vernünftige und sinnvolle Lösung der Probleme unseres Beratungsgegenstandes erkennen. 